\title{
Erster Beratungsgegenstand: \\ Grundsätze der Finanzverfassung des vereinten Deutschlands
}

1. Bericht von Prof. Dr. Peter Selmer, Hamburg

\section{Inhalt}

A. Einleitung

B. Der Grundsatz der Herstellung „einheitlicher Lebensverhältnisse im Bundesgebiet" .................

I. Die Herstellung „einheitlicher Lebensverhältnisse im Bundesgebiet" - ungeschriebenes Rechtsgut der föderativen Finanzverfassung? . ................

II. Die Finanzverantwortung für die Angleichung der Lebensverhältnisse im Bundesgebiet . ............

III. Insbesondere: Zur Finanzverantwortung für die einigungsbedingten „Einmalaufgaben“ in den neuen Bundesländern ..................... 31

IV. Verfassungsrechtspolitischer Ausblick . . . . . . . . 39

C. Der Grundsatz einer bundesstaatsgerechten Finanzausstattung der Länder . . . . . . . . . . . . . . . 42

I. Vorbemerkung ................. 42

II. Insbesondere: Der Länderfinanzausgleich . . . . . . 43

1. Grundsätzliche Aufgaben- und Bedarfsbezogenheit des Finanzausgleichs . . . . . . . . . . . 43

2. Finanzkraft und Finanzbedarf im horizontalen Finanzausgleich .................... 44

3. Die Verfeinerungsbedürftigkeit der Einwohnerzahl als Bezugspunkt................. 48

4. Der „angemessene“ Ausgleich der Finanzkraft .... . 49

5. Zur Funktion der Bundesergänzungszuweisungen im Länderfinanzausgleich . ............. 53

III. Verfassungsrechtspolitischer Ausblick ......... 58

D. Schlußbemerkung: Finanzverfassung und Länderneugliede-

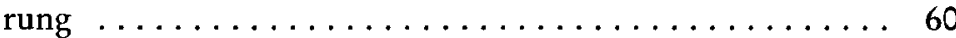




\section{A. Einleitung}

Ließ sich 1955 der Bericht über die „Finanzverfassung im Rahmen der Staatsverfassung" noch unter die einleitende Feststellung bringen: „Unsere heutige Finanzverfassung genießt keinen guten Ruf, obwohl die Finanzen nicht in schlechter Verfassung sind" ${ }^{\text {" }}$, so muß man zur Zeit wohl sagen: „Unsere heutige Finanzverfassung genießt keinen guten Ruf; auch sind die Finanzen in schlechter Verfassung “. Letzteres liegt auf der Hand bei einem Schuldenstand, der uns in Kürze zur Gewöhnung an die Billion als Rechnungseinheit für die Staatsschulden zwingen wird ${ }^{2}$. Ersteres bestätigt nur die alte Einsicht ${ }^{3}$, daß es keine a priori vollkommene Finanzverfassung gibt, sondern nur eine solche in Anbetracht der sie umgebenden gesellschaftlichen und bundesstaatlichen Wirklichkeit sachgerechte. So wird zunehmend die

1 Hettlage, Die Finanzverfassung im Rahmen der Staatsverfassung, VVDStRL 14 (1956), S.2.

$2 \mathrm{Zu}$ Entwicklung und Stand der Staatsverschuldung vgl. instruktiv die Antwort der Bundesregierung auf eine (mit abgedruckte) Kleine Anfrage aus dem Bundestag in BT-Drucks. 12/2191, S. 1 ff., mit einer Übersicht S. 10 über den Schuldenstand der öffentlichen Haushalte für die Jahre 1990-1992; dort werden für 1992 ein Schuldenstand von $1273 \mathrm{Mrd}$. DM und Zinsausgaben von $102 \mathrm{Mrd}$. DM ausgewiesen. H. Siebert, Mitglied des Sachverständigenrats zur Begutachtung der gesamtwirtschaftlichen Entwicklung, erwartet (s. den Beitrag „Drei Fallen für die Wirtschaftspolitik", FAZ v. 29. 8.1992, S. 13) unter Einbeziehung der DDR-Altschulden (Treuhandanstalt, Kreditabwicklungsfonds, staatliche Wohnungswirtschaft) für 1994 einen staatlichen Schuldenstand von 1,8 Billionen DM. Zur im Finanzplan des Bundes 1992 bis 1996 (BT-Drucks. 12/3100, S. 3 f., 37) angekündigten Gegensteuerung vgl. etwa die Feststellung des Bundesfinanzministers (BMF-Finanznachrichten $85 / 92$ v. 10.9.1992, S.3). Zur Einschätzung der Staatsverschuldung (insb. auch unter dem Gesichtspunkt der Finanzierung des Einigungsprozesses) s. vor allem Sachverständigenrat, Jahresgutachten 1990/91 zur Begutachtung der gesamtwirtschaftlichen Entwicklung, BT-Drucks.11/8472, Tz. 350 ff.; Jahresgutachten 1991/92, BT-Drucks. 12/1618, Tz. $197 \mathrm{ff} ., 199 \mathrm{ff}$., 335 f.; Schlesinger/Weber/Ziebarth, Gesamtstaatliche Finanzpolitik in der Bewährung - Schuldenpolitische Aspekte der deutschen Einheit -, 1991; Wille, Die Belastung der öffentlichen Haushalte durch die deutsche Wiedervereinigung, Volkswirtschaftliche Korrespondenz der Adolf-Weber-Stiftung Nr. 9/1992; aus finanzverfassungsrechtlicher Sicht (mit Reformüberlegungen) zuletzt Wieland, Einen und Teilen, DVBl. 1992, 1181 ( $1190 \mathrm{ff}$.), mit Recht krit. vor allem zur zunehmenden Kreditfinanzierung der zahlreichen Nebenhaushalte und ihrer verfassungsrechtlichen Einordnung unter dem Aspekt des Art. 115 I S. 2 GG; zur „Berücksichtigung der Nebenhaushalte“ s. jetzt auch (betr. Art. 109 II GG) den Hinweis von BVerfG, DVB1. 1992, 965 (978).

${ }^{3}$ Vgl. etwa Hettlage (Fn. 1), S.7; Fischer-Menshausen, Finanzausgleich II: Grundzüge des Finanzausgleichsrechts, in: Handwörterbuch der Wirtschaftswissenschaften, Bd.2, Lieferung 24, 1980, S. 636 (638f.). 
geltende Finanzverfassung kritisch auf ihre Tragfähigkeit für die heute an sie zu stellenden Anforderungen abgeklopft ${ }^{4}$. Bund und Länder

${ }^{4}$ Vgl. aus jüngerer Zeit (vor Beginn des Einigungsprozesses) etwa Donner, Aktuelle Probleme des Finanzausgleichs im sozialen Bundesstaat, ZRP 1985, 327; Kabrs u.a., in: Bundesrat (Hrsg.), Haben sich die geltenden Finanzausgleichssysteme nach Art. 106 und $107 \mathrm{GG}$ bewährt und sind sie in der Lage, die föderale Struktur - insbesondere die Selbständigkeit der Länder - zu gewährleisten?, Kolloquium v. 10.6.1985, Bundesrat, Pressespiegel 5/85 v. 18.9.1985; Renzsch, Neuordnung des bundesstaatlichen Finanzausgleichs - Finanzverfassung und Föderalismus, Probleme und Perspektiven -, Gegenwartskunde 1986, 499; Voss, Der Verfassungsauftrag Finanzausgleich nach Art. 107 II GG, BayVBI. 1986, 326; Heilmann, Krise des Finanzföderalismus in der Bundesrepublik Deutschland?, Diskussionsbeiträge aus dem Institut für Finanzwissenschaft der Universität Kiel, Nr. 17, 1987; Peffekoven, Zur Neuordnung des Länderfinanzausgleichs, Finanzarchiv n. F. 45 (1987), 181; Bartsch/Probst, Ansätze zur Reform des Länderfinanzausgleichs, Wirtschaftsdienst 1988, 533; Renzsch, Die Neuordnung des Länderfinanzausgleichs, Gegenwartskunde 1988, 78; Böttcher, Wir brauchen eine neue Finanzverfassung, ZRP 1989, 340; Scharpf, Der Bundesrat und die Kooperation auf der "dritten Ebene“, in: Bundesrat (Hrsg.), Vierzig Jahres Bundesrat, 1989, 121 (147ff.); Wendt, Finanzhoheit und Finanzausgleich, in: Isensee/Kirchbof (Hrsg.), HStR, Bd.IV, 1990, $\$ 104$ Rdn. 102 ff.; Taube, Ein Vorschlag zur Reform des Länderfinanzausgleichs, Wirtschaftsdienst 1990, 372; Kitterer (Hrsg.), Sozialhilfe und Finanzausgleich, 1990, passim; (seit Beginn des Einigungsprozesses) Peffekoven, Deutsche Einheit und Finanzausgleich, Staatswissenschaften und Staatspraxis, 1990, 485; ders., Finanzausgleich im vereinten Deutschland, Wirtschaftsdienst 1990, 346; Littmann, Über einige Untiefen der Finanzverfassung, Staatswissenschaften und Staatspraxis 1991, 31 (dazu der Bericht von $R$. Wagener, DVBl. 1991, 152); Benz, Perspektiven des Föderalismus in Deutschland, DÖV 1991, 586 (590 ff.); H.P. Schneider, Die bundesstaatliche Ordnung im vereinigten Deutschland, NJW 1991, 2448; Kisker, Die Bundesländer im Spannungsfeld zwischen deutsch-deutscher Vereinigung und europäischer Integration, in: J.J. Hesse/ Renzsch (Hrsg.), Föderalstaatliche Entwicklung in Europa, 1991, S. 117 (136 ff.); Franke, Zur Einbeziehung der neuen Bundesländer in den Finanzausgleich, StuW 1991, 311 (319ff.); ders., Zur Neuordnung der Finanzverfassung im vereinten Deutschland, VerwArch. 82 (1991), 526; Kilian, Das System des Länderfinanzausgleichs und die Finanzierung der neuen Bundesländer, JZ 1991, 425; Korioth, Die Finanzausstattung der neuen Bundesländer, DVBl. 1991, 1048; Milbradt, Finanzausstattung der neuen Bundesländer und gesamtstaatlicher Finanzausgleich im Dienste der Einheit, Staatswissenschaft und Staatspraxis 1991, 304; Klatt, Deutsche Einheit und föderales System, ZBR 1992, 225 (226ff.); Heun, Strukturprobleme des Finanzausgleichs, Der Staat 1992, 205; Wieland (Fn. 2), passim; Schemmel/ Borell, Verfassungsgrenzen für Steuerstaat und Staatshaushalt - Ein Beitrag zur Reform der Finanzverfassung -, Heft 75 der Schriften des Karl-Bräuer-Instituts des Bundes der Steuerzahler, 1992. Einen ungemein instruktiven Überblick über die Entwicklung der Finanzverfassungsdiskussion gibt Renzsch, Finanzverfassung und Finanzausgleich - Die Auseinandersetzungen um ihre politische Gestaltung 
haben - auch, aber keineswegs nur unter dem Eindruck der deutschen Einigung - sich diese Einschätzung zu eigen gemacht und in Art.31 $\$ 2$ II des Gesetzes zum Staatsvertrag vom 18.5.1990 bestimmt, mit Wirkung ab 1.1.1995 die Finanzbeziehungen zwischen Bund und Ländern neu zu regeln ${ }^{6}$.

Ausgangspunkt ist, daß die nach der ursprünglichen Konzeption des Grundgesetzes ausgeprägte Trennung der Aufgaben zwischen Bund und Ländern sowie horizontal zwischen den Ländern („Trennsystem ${ }^{\text {(7) }}$ ) in Erscheinungsformen der Unitarisierung ${ }^{8}$ und Selbstkoordinierung", der Kooperation und Politikverflechtung („kooperativer Föderalismus "10) im Laufe der Jahre zunehmend an prägender Kraft verloren hat. Korrespondiert diesem Substanzverlust an föderativer

in der Bundesrepublik Deutschland zwischen Währungsreform und deutscher Vereinigung (1948-1990), 1991, insb. S. $209 \mathrm{ff}$. (Reform von 1969) und S.261 ff. (Diskussion und Gestaltung des Finanzausgleichs von 1970 bis 1990).

5 Vgl. Gesetz v. 25.6.1990 (BGBl. II S. 518). Das Vertragsgesetz mit Begründung (s. BT-Drucks. 11/7350, S. $25 \mathrm{ff}$.) ist abgedruckt etwa bei Stern/SchmidtBleibtreu, Staatsvertrag zur Währungs-, Wirtschafts- und Sozialunion, Verträge und Rechtsakte zur Deutschen Einheit, Bd. 1, 1990, S. 239 ff.

6 Zur Begründung s. bei Stern/Schmidt-Bleibtreu (Fn. 5), S. 311.

7 Vgl. H. Hofmann, Die Entwicklung des Grundgesetzes nach 1949, in: Isensee/ Kirchbof (Hrsg.), HStR, Bd.I, 1987, \$7 Rdn. 62.

${ }^{8}$ Vgl. dazu K. Hesse, Der unitarische Bundesstaat, 1962; ders., Grundzüge des Verfassungsrechts der Bundesrepublik Deutschland, 18. Aufl. (1991), S. 92 (Rdn. 221); Kimminich, Der Bundesstaat, in: Isensee/Kircbhof, HStR, Bd. I, 1987, $\$ 26$ Rdn. $49 \mathrm{ff}$.

9 Vgl. dazu H.Schneider, Verträge zwischen Gliedstaaten im Bundesstaat, VVDStRL 19 (1961), S. 1 (18 und passim); Kommission für die Finanzreform, Gutachten über die Finanzreform in der Bundesrepublik Deutschland, 2. Aufl. (1966) - künftig: Troeger-Gutachten -, Tz.36ff.; aus jüngerer Zeit vgl. insb. Stern, Staatsrecht I, 2. Aufl. (1984), S. 756 ff.; Pietzcker, Zusammenarbeit der Gliedstaaten im Bundesstaat, in: Starck (Hrsg.), Zusammenarbeit der Gliedstaaten im Bundesstaat, 1988, S. $17 \mathrm{ff}$; Ossenbübl, Föderalismus und Regionalismus in Europa, Landesbericht Deutschland, in: ders. (Hrsg.), Föderalismus und Regionalismus in Europa, 1990, S. 140 ff.; Maunz, Staatlichkeit und Verfassungshoheit der Länder, in: Isensee/Kirchhof, HStR, Bd. IV, 1990, \$ 94 Rdn. 10 f.

10 Aus der Überfülle der Stimmen zur Erscheinung und Bewertung des kooperativen Föderalismus einschließlich des übergreifenden Phänomens der sog. Politikverflechtung vgl. Troeger-Gutachten (Fn. 9), Tz. 73 ff.; Kisker, Kooperation im Bundesstaat, 1971; Scharpf/Reissert/Schnabel, Politikverflechtung: Theorie und Empirie des kooperativen Föderalismus in der Bundesrepublik, 1976; J.J. Hesse (Hrsg.), Politikverflechtung im föderativen Staat, Studien zum Planungs- und Finanzierungsverbund zwischen Bund, Ländern und Gemeinden, 1978; aus jüngerer Zeit vgl. etwa Stern (Fn. 9), S.664; Lerche, in: Maunz/Dürig/Herzog/Scholz, Grundgesetz, 1983, Art. 83 Rdn. 92 ff.; Graf Vitzthum, Die Bedeutung gliedstaatli- 
Pluralität, der jedenfalls seit 1969 vor allem den Finanzbereich erfaßt hat ${ }^{11}$, auch ein gewachsener Einfluß auf den Gesamtstaat („Beteiligungsföderalismus ${ }^{\text {"12 }}$ ), so wird die insgesamt zu registrierende föderative Unterbilan ${ }^{13}$ doch seit langem von den Ländern mit wachsendem und nur durch fiskalische Eigeninteressen gezügeltem Unbehagen betrachtet ${ }^{14}$. Es hat durch die Befürchtung, die ihnen noch verbliebenen Kompetenzen könnten vermittels Art. 24 I GG nunmehr europarechtlich ausgedünnt werden, eine zusätzliche Dimension gewonnen $^{15}$. Alle bisherigen Reformversuche, die der schleichenden Aushöhlung der Länderstaatlichkeit entgegenzuwirken trachteten, sind im Sande verlaufen oder in Ansätzen steckengeblieben.

Das gilt $^{16}$ vor allem für das Konzept der Enquête-Kommission

chen Verfassungsrechts in der Gegenwart, VVDStRL 46 (1988), S. $39 \mathrm{ff}$; Rudolf, Kooperation im Bundesstaat, in: Isensee/Kirchbof, HStR, Bd.IV, 1990, $\mathbb{1 0 5}$, passim.

11 Zum unitarischen Grundzug der Finanzreform 1969 vgl. für viele Friauf, Das Verhältnis von Bund und Ländern im Bereich der Finanzverfassung, in: Kewenig (Hrsg.), Deutsch-Amerikanisches Verfassungsrechtssymposium 1976, 1978, S. 177 (184); H. Hofmann (Fn. 7), \$7 Rdn. $67 \mathrm{f}$.

12 Vgl. dazu etwa Kisker, Ideologische und theoretische Grundlagen der bundesstaatlichen Ordnung in der Bundesrepublik Deutschland - Zur Rechtfertigung des Föderalismus -, in: v. Münch (Red.), Probleme des Föderalismus, 1985, S. $23 \mathrm{ff}$; Klatt, Das föderative System der Bundesrepublik als Rahmen für das Verhältnis von Land und Bund, in: ders. (Hrsg.), Baden-Württemberg und der Bund, 1989, S. 19 (33 ff.); Scharpf (Fn. 4), S. 127 ff.; Ossenbühl (Fn. 9), S. 154 ff.

13 Vgl. zusammenfassend Kimminich (Fn. 8), $\$ 26$ Rdn. 56 ff.; H.P. Schneider (Fn. 4), S. 2453.

${ }_{14}$ Vgl. dazu die Überblicke bei Frowein, Gemeinschaftsaufgaben im Bundesstaat, VVDStRL 31 (1973), 13 (19ff.); v. Münch, Gemeinschaftsaufgaben im Bundesstaat, VVDStRL 31 (1973), S.51 (54 ff.); H.Hofmann (Fn.7), $\$ 7$ Rdn. 65; Kimminich (Fn. 8), \$26 Rdn. 57 f.; Renzsch (Fn. 4), S. 282 ff.

${ }_{15} \mathrm{Vgl}$., jew. m. weit. Nachw., für viele Ossenbühbl (Fn. 9), S. $146 \mathrm{ff}$.; Isensee, Der Föderalismus und der Verfassungsstaat der Gegenwart, AöR 115 (1990), 248 (257f.); Sachs, Deutscher Föderalismus und europäische Integration, in: Hirscher (Hrsg.), Die Zukunft des kooperativen Föderalismus, 1991, 183 (186ff.); Badura, Die Verfassungsfrage im wiedervereinigten Deutschland, in: Bitburger Gespräche, Jahrbuch 1991/2, 1991, S. 27 (36 ff.); Starck, Stärkere Bundesländer für Europa, FAZ v. 25.2. 1992, S. 13; Häberle, Die Kontroverse um die Reform des deutschen Grundgesetzes (1991/92), ZfP 1992, 233 (257 ff.); Scholz, Grundgesetz und europäische Einigung, NJW 1992, 2593 (2595 ff.); Zuleeg, Die Stellung der Länder und Regionen im europäischen Integrationsprozeß, DVBl. 1992, 1329.

16 Abgesehen von dem von der sog. Ernst-Kommission gutachtlich begründeten Versuch einer Neugliederung des Bundesgebietes; vgl. dazu BMI (Hrsg.), Sachverständigenkommission für die Neugliederung des Bundesgebietes, Vorschläge zur 
„Verfassungsreform“ von $1976^{17}$, die einen Mittelweg einzuhalten suchte zwischen den einander widerstreitenden Kraftfeldern, und deren Empfehlungen weitgehend ebenso unbeachtet blieben wie die Überlegungen einer Reihe weiterer Föderalismus-Gremien auf Landesebene ${ }^{18}$. Unter dem Eindruck, daß die 1969 insbesondere mit dem Begriff der Gemeinschaftsaufgaben verbundenen Hoffnungen auf eine effizienzsteigernde gemeinsame Aufgabenplanung und auf eine enge Koppelung der Finanzwirtschaft von Bund, Ländern und Gemeinden zum Zwecke der Konjunktursteuerung sich nicht angemessen erfüllt hatten ${ }^{19}$, verstand sich der Bund zwar Anfang der 80er Jahre zu einer bereichsweisen Entflechtung und Dezentralisierung $^{20}$. Die Disparitäten in der Leistungsfähigkeit der Länder, die infolge der Strukturkrisen einiger regionalspezifischer Branchen (Kohle, Stahl, Werften) immer ausgeprägter wurden ${ }^{21}$, setzten aber einem Fortgang der fiskalischen Entkoppelung von Bund und Ländern ${ }^{22}$ eine Grenze. Demgegenüber trat die Finanzmacht des Bun-

Neugliederung des Bundesgebiets gemäß Art. 29 des Grundgesetzes, 1972, passim; für einen Überblick Evers, in: BK, Art. 29 (Drittbearbeitung 1980) Rdn. $13 \mathrm{f}$.

$17 \mathrm{Vgl}$. Schlußbericht der Enquête-Kommission Verfassungsreform, BTDrucks. 7/5924, insb. S. 122 bis $218=$ Presse- und Informationszentrum des Deutschen Bundestages (Hrsg.), Beratungen und Empfehlungen zur Verfassungsreform, Teil II: Bund und Länder, Zur Sache 2/77.

18 Vgl. den Überblick bei H.P. Schneider (Fn. 4), S. 2454.

19 Vgl. Scharpf (Fn. 4), S. 149.

${ }^{20} \mathrm{Vgl}$. dazu Klatt, Interföderale Beziehungen im kooperativen Bundesstaat, VerwArch. 78 (1987), 186 (202 ff.); ders. (Fn. 4), S. 230.

${ }^{21}$ Vgl. dazu Peffekoven (Fn. 4), S. 181 (insb. S. 222 f.); Fischer, Sozialhilfe und Bund-Länder-Finanzausgleich, in: Kitterer (Fn.4), S.131 (insb. S. 137 f.); Benz (Fn. 4), S. 590 m. Fn. 29.

22 Vgl. für eine Entflechtung der bundesstaatlichen Finanzbeziehungen seit der Finanzreform 1969, jew. m. weit. Nachw., etwa Barbarino, Zur Reformbedürftigkeit der gegenwärtigen Finanzverfassung, in: Politikverflechtung zwischen Bund, Ländern und Gemeinden, Schriftenreihe der Hochschule Speyer, Bd.55, 1975, S. 103; Hinnendabl, Zum Steuerstreit zwischen Bund und Ländern, Wirtschaftsdienst 1975, 153; Scharpf/Reissert/Schnabel (Fn. 10), S. 232 ff.; Kisker, Kooperation zwischen Bund und Ländern in der Bundesrepubik Deutschland, DÖV 1977, 689; Heinsen, Die Reform der Finanzreform, in: Festschrift für F. Schäfer, 1980, S. 233 (insb. 238 ff.); Fischer-Menshausen, Zur Problematik der Steuerung und Finanzierung öffentlicher Investitionen im Bundesstaat, Finanzarchiv n. F. 40 (1982), 167 (insb. 170 ff.); Gaddum, in: Bundesrat (Hrsg.), Fn.4, S. 33; Hansmeyer/Kops, Interdependenzen im passiven Finanzausgleich, in: Festschrift für W.Ehrlicher, 1985, S.3 (27f.); Klatt (Fn.20), S.200ff.; Scharpf (Fn. 4), S. 148 ff. Zur Diskussion seit der Vereinigung s. unten Fn. 54. 
des nunmehr noch deutlicher hervor. Dabei wuchsen seine beträchtlich ausgeweiteten Mitfinanzierungen zusehends in eine finanzausgleichsubstituierende Funktion hinein. Das Strukturhilfegesetz ${ }^{23}$ bildete insoweit nur den Schlußpunkt einer kontinuierlichen Entwicklung ${ }^{24}$. Das finanzpolitische Klima zwischen Bund und Ländern sowie unter den Ländern verschärfte sich. Das Prinzip bündischer Solidarität geriet in einen ständigen Meinungsstreit, der das bislang funktionierende kooperative Verständigungsverfahren ${ }^{25}$ mehrfach sprengte. Die beiden Entscheidungen des BVerfG zum Länderfi-

${ }^{23}$ Gesetz über die Finanzhilfen des Bundes nach Art. 104 a IV des Grundgesetzes an die Länder Freistaat Bayern, Berlin, Freie Hansestadt Bremen, Freie und Hansestadt Hamburg, Niedersachsen, Nordrhein-Westfalen, Rheinland-Pfalz, Saarland und Schleswig-Holstein (Strukturhilfegesetz) = Art. 1 des Gesetzes zum Ausgleich unterschiedlicher Wirtschaftskraft in den Ländern vom 20.12.1988 (BGBl. I S. 2358). Das Strukturhilfegesetz wurde - unter Festlegung „pauschaler Überbrückungshilfen“ an die genannten Länder - im Hinblick auf die Wiedervereinigung vorzeitig (mit Wirkung ab 31.12.1991) aufgehoben durch Art. 1 des Gesetzes zur Aufhebung des Strukturhilfegesetzes und zur Aufstockung des Fonds „Deutsche Einheit“ vom 16.3.1992 (BGBl. I S. 674).

${ }_{24}$ Vgl. näher zum Strukturhilfegesetz Krautzberger, Das Strukturhilfeprogramm des Bundes, KStZ 1989, 124; Patzig, Regionale Ungleichgewichte und bundesstaatliche Finanzverfassung, DÖV 1989, 330; Carl, Förderung von Investitionen Privater durch Finanzhilfen nach Art. 104 a IV, DVBl. 1989, 589 (594); Mäding, Autonomie und Abhängigkeit in finanzpolitischen Entscheidungsprozessen im föderativen Staat: das Beispiel Strukturhilfe, Politische Vierteljahresschrift 1990, 567; Milbradt, Die kommunalen Sozialhilfeausgaben Das Für und Wider verschiedener Finanzausgleichskonzepte aus kommunaler Sicht -, in: Kitterer (Fn. 4), S. 153 (162 f.); Kitterer, Sozialhilfe und Finanzausgleich: Ausblick, in: ders. (Fn. 4), S. 187 (188); Peffekoven, Finanzausgleich und Sonderbedarfe, in: Festschrift für Pohmer, 1990, 323 (337f.); Renzsch, Finanzverfassung und Finanzausgleich (Fn. 4), S. 269 ff.; Henneke, Öffentliches Finanzwesen, Finanzverfassung, 1990, S. 57 ff.; Karrenberg, Vorzeitige Aufhebung des Strukturhilfegesetzes, der gemeindehaushalt 1992, 97. Zur verfassungsrechtlichen Notwendigkeit einer Anpassung des Strukturhilfegesetzes an die nach dem Beitritt der neuen Länder veränderten Förderungsnotwendigkeiten vgl. bereits Selmer, Die bundesstaatliche Finanzverfassung und die Kosten der deutschen Einheit, in: Stern (Hrsg.), Deutsche Wiedervereinigung, Bd. I, Eigentum - Neue Verfassung - Finanzverfassung, 1991, S. 189 (205f.).

25 Vgl. dazu Franke, Der Finanzausgleich: Problembereich im Spannungsfeld ökonomischer Rationalität und politischer Kompromißbildung, Hamburger Jahrbuch für Wirtschafts- und Gesellschaftspolitik 34 (1989), S. 75 f.; Benz, Umverteilung durch Verhandlungen? Kooperative Staatspraxis bei Verteilungskonflikten, Staatswissenschaften und Staatspraxis 1991, 46 (insb. 56, $70 \mathrm{ff}$.); ders. (Fn. 4), S. 586 (590 f.). 
nanzausgleich von $1986^{26}$ und $1992^{27}$ zeugen von der zwischenzeitlichen Härte der Verteilungskonflikte.

Der Beitritt der fünf neuen Bundesländer und Ost-Berlins hat das Problem strukturell bedingter Ungleichgewichte innerhalb der Bundesrepublik nun noch einmal entscheidend ausgeweitet. Er hat, eher gefördert als abgemildert durch die in Art. 7 EV i. V. mit dem Fonds „Deutscher Einheit“ begründete Übergangsfinanzverfassung für den Osten ${ }^{28}$, der zentralistischen Entwicklung des Finanzwesens einen zusätzlichen Impuls gegeben. Die daraus resultierende Besorgnis der Länder war Anlaß zu dem sog. Eckpunkte-Beschluß der Ministerpräsidenten vom 5.7.199029, der durch Art. 5 EV zu einer Empfehlung an den Gesetzgeber aufgewertet wurde ${ }^{30}$. Er forderte - dabei freilich

${ }^{26}$ BVerfGE 72, 330 (383 ff.). Vgl. zu dieser finanzausgleichsrechtlichen Leitentscheidung die Stellungnahmen von $M u ß g n u g$, Der horizontale Finanzausgleich auf dem Prüfstand des BVerfG, JuS 1986, 872; Renzsch (Fn. 4), S. 499 (522 ff.); Voss, Der Finanzausgleich im Bundesstaat, BB 1986, 1581; Peffekoven, Berücksichtigung der Seehafenlasten im Länderfinanzausgleich?, Finanzarchiv n. F. 46 (1988), 397 (414f.); Kops, Möglichkeiten und Restriktionen einer Berücksichtigung von Sonderbedarfen im Länderfinanzausgleich, 1989, S. $131 \mathrm{ff}$.

${ }^{27}$ BVerfG, DVBl. 1992, 965 = DÖV 1992, $743=$ JZ 1992, 962 m. Anm. Arndt $=$ NJW 1992, 2279 (nur Leitsätze). Vgl. dazu auch Peffekoven, Das Urteil des BVerfG zum Länderfinanzausgleich, Wirtschaftsdienst 1992, 349.

$28 \mathrm{Vgl}$. zu ihr, überwiegend krit., etwa Selmer (Fn. 24), S. 189; Wendt, Finanzverfassung und Art. 7 Einigungsvertrag, in: Stern (Hrsg.), Fn.24, S. 213; Fiedler, Die Regelung der bundesstaatlichen Finanzbeziehungen im Einigungsvertrag, DVBl. 1990, 1263; Peffekoven (Fn. 4), S. 346; ders., Einbeziehung der neuen Bundesländer in den Finanzausgleich, Volkswirtschaftliche Korrespondenz der AdolfWeber-Stiftung 3/1991, S.1; Thiel, Die Fondslösung kann nicht überzeugen, Wirtschaftsdienst 1990, 395; Patzig, Zwischen Solidität und Solidarität, DÖV 1991, 578; Korioth (Fn. 4), S. 1048; Kilian (Fn.4), S.425; Geske, Die Finanzierung der ostdeutschen Länder nach dem Einigungsvertrag, Wirtschaftsdienst 1991, 33; Henneke, Finanzverfassung im geeinten Deutschland, Jura 1991, 230; H.P. Schnei$\operatorname{der}$ (Fn. 4), S. 2448 (2453); Franke (Fn. 4), S. 311 (318); ders. (Fn. 4), S. 526 (532).

${ }_{29}$ Betr. die (von einer Arbeitsgruppe der Staats- und Senatskanzleien erarbeiteten) „Eckpunkte der Länder für die bundesstaatliche Ordnung im vereinten Deutschland“. Vgl. dazu, m. weit. Nachw., etwa Kisker (Fn. 4), S. 117 (122, 133, 137); H.P. Schneider (Fn. 4), S. 2448 (2454); Klatt (Fn. 4), S. 225 (231 f.).

30 Art. 5 EV lautet insoweit: „Die Regierungen der beiden Vertragsparteien empfehlen den gesetzgebenden Körperschaften des vereinten Deutschlands, sich innerhalb von zwei Jahren mit den im Zusammenhang mit der deutschen Einigung aufgeworfenen Fragen zur Änderung oder Ergänzung des Grundgesetzes zu befassen, insbesondere in bezug auf das Verhältnis zwischen Bund und Ländern entsprechend dem Gemeinsamen Beschluß der Ministerpräsidenten vom 5.7.1990, ...". 
seine gefährliche Ambivalenz gerade für die strukturschwachen Westund die Ostländer nicht genügend mitbedenkend - zu einer Stärkung der Finanzautonomie und Eigenverantwortlichkeit der Länder auf. Angeregt werden insbesondere ein weitergehendes SteuererschlieBungsrecht, eine klare Aufgabentrennung zwischen Bund und Ländern sowie eine größere Konkordanz zwischen Gesetzgebungszuständigkeit und finanzieller Lastentragung, im einzelnen vor allem auch eine sachgerechte Veränderung der Gemeinschaftsaufgaben und Mischfinanzierungen im Rahmen der Investitionshilfekompetenz sowie eine Überprüfung der Regelung für Geldleistungsgesetze. Manche Überlegungen des Sachverständigenrats zur Begutachtung der gesamtwirtschaftlichen Entwicklung ${ }^{31}$ sowie die finanzverfassungsrechtlichen Beschlüsse der Präsidentinnen und Präsidenten der deutschen Länderparlamente vom 24.9.1991 ${ }^{32}$ gehen in eine ähnliche Richtung.

Mein eigener Bericht wird sich, entsprechend der Vorgabe des Vorstandes der Vereinigung, vorrangig nicht mit allen erdenklichen Zukunftsmodellen der Finanzverfassung auseinandersetzen. Er wird vielmehr, wobei ich von der bald überholten Übergangsverfassung des Einigungsvertrages ${ }^{33}$ weitgehend absehe, grundsätzlich von der geltenden Verfassungsrechtslage ausgehen und von dieser Warte aus in gegebenem Zusammenhang einige Änderungs- bzw. Ergänzungsvorschläge machen.

$\mathrm{Da}$ sich die Tragfähigkeit unseres bestehenden finanzverfassungsrechtlichen Instrumentariums unter der jetzt bestehenden bundesstaatlichen Lage ernstlich in Frage gestellt sieht, liegt auf der Hand ${ }^{34}$. Gleichwohl wird der Erfolg der inneren Einigung wesentlich davon abhängen, daß es gelingt, den aufgrund des sozialen und wirtschaftlichen Gefälles bis auf weiteres immensen Finanzbedarf der neuen

31 Vgl. Jahresgutachten 1990/91 (Fn. 3), Tz. 432 ff.; Jahresgutachten 1991/92 (Fn. 3), Tz. $324 \mathrm{ff}$.

32 Abgedruckt etwa in NdsLT-Drucks. 12/2797 vom 4.12.1991, Anlage 4, S. $22 \mathrm{ff}$. ("Reform der Finanzverfassung“). Vgl. (ohne spezifischen Bezug zur Finanzverfassung) auch die Vorschläge der Verfassungskommission des Bundesrates (BR-Drucks. 360/92) zur Stärkung der (sachkompetenzrechtlichen) Gesetzgebungsbefugnisse der Länder, in: Bundesrat (Hrsg.), Stärkung des Föderalismus in Deutschland und Europa sowie weitere Vorschläge zur Änderung des Grundgesetzes, Bericht der Kommission Verfassungsreform des Bundesrates, Dokumentation, 1992, Rdn. $53 \mathrm{ff}$.

$33 \mathrm{Vgl}$. zu ihr die Nachw. in Fn. 28.

${ }_{34}$ Vgl. auch Klatt (Fn. 4), S. 227 f. 
Länder in die Finanzwirtschaft der Bundesrepublik so rechtlich einzubinden, daß die öffentliche Finanzordnung unter Wahrung der Interessen auch der alten Länder intakt bleibt. Dabei wird es auch darauf ankommen, für die zur Bewältigung der DDR-Erblasten notwendigen Transferleistungen in den Osten spezifische und verfassungsrechtlich ausgeformte Kanäle auch außerhalb des überforderten Regelwerks des Länderfinanzausgleichs zu schaffen ${ }^{35}$.

Das von der Bevölkerung der neuen Bundesländer ${ }^{36}$ erhoffte Ziel bundesstaatlicher Finanzwirtschaft liegt auf der Hand: Eine möglichst rasche Angleichung ihrer Lebensverhältnisse an das Leistungsniveau der Westländer. Mit dieser Ambition ist zugleich eine erste wesentliche Dimension auch der hier zu erörternden finanzverfassungsrechtlichen Fragestellungen genannt. Diesem vor allem sozialstaatlichen Aspekt des Themas zur Seite tritt seine bundesstaatliche Dimension, die sich mit der aufgabengerechten Verteilung des Finanzaufkommens auf Bund und Länder befaßt. Insoweit haben Herr Kirchhof und ich uns darauf verständigt, daß ersterer sich mehr der vertikalen, letzterer dagegen vorrangig der horizontalen Komponente zuwenden sollte. Schließlich wird auch die Neugliederungsproblematik jedenfalls kurz zu würdigen sein.

\section{B. Der Grundsatz der Herstellung „einheitlicher Lebensverhältnisse im Bundesgebiet “}

\section{Die Herstellung „einheitlicher Lebensverbältnisse im Bundesgebiet" - ungeschriebenes Rechtsgut der föderativen Finanzverfassung?}

Vor dem so skizzierten Hintergrund möchte ich im folgenden zunächst das Leitbild der Herstellung „einheitlicher Lebensverhältnisse im Bundesgebiet" ins Auge fassen. Obschon im Grundgesetz ${ }^{37}$ nur höchst unvollkommen ausgeformt, ist doch gerade seine Rezeption durch die Finanzverfassungswirklichkeit ersichtlich prägend für

\footnotetext{
35 Vgl. hierzu auch Geske, Der Länderfinanzausgleich wird ein Dauerthema, Wirtschaftsdienst 1992, 250 (259).

${ }^{36}$ Zum gegenwärtigen Politikmodell der Ostdeutschen vgl. die Untersuchung von U.Becker/H.Becker/W.Rubland, Zwischen Angst und Aufbruch - Das Lebensgefühl der Deutschen in Ost und West nach der Wiedervereinigung -, 1992, S. $118 \mathrm{ff}$.

37 Vgl. Art. 72 II Nr. 3, Art. 106 III S. 4 Nr.2 GG; Art. 91 a I GG spricht von der „Verbesserung der Lebensverhältnisse“.
} 
die konkrete Bewältigung der dem Bundesstaatsprinzip innewohnenden Spannungslage von Einheit und Vielfalt geworden ${ }^{38}$. Das auf soziale Gleichheit drängende und insoweit nachdrücklich unitarische Lebensgefühl der Bevölkerung versagte einer föderativen Vielfalt der Lebensverhältnisse, d.h. hier: unterschiedlichen Standards in den Leistungen der öffentlichen $\mathrm{Hand}$, von Beginn an seine Zustimmung ${ }^{39}$. Der unitarische Sozialstaat überwältigte mühelos die bundesstaatliche Differenzierungskomponente ${ }^{40}$. Der Bund förderte die Vereinheitlichungstendenz nach Kräften ${ }^{41}$. Die Länder ihrerseits setzten, unter dem Eindruck der Akzeptanz sozialstaatlich induzierter Einheitlichkeit der Lebensverhältnisse beim Wahlvolk, der Privilegierung der sozialen Egalisierung vor der regionalen Differenzierung bei allem sich formierenden Unbehagen ${ }^{42}$ bis in die jüngste Zeit kaum wirklichen Widerstand entgegen ${ }^{43}$.

Die rechtspolitische Durchschlagskraft der Formel von der „Einheitlichkeit der Lebensverhältnisse" im Bundesgebiet war, wie ich hier nicht vertiefend auszuführen brauche, immens ${ }^{44}$. Sie drückte auch der föderativen Finanzrechtsordnung unserer Republik entscheidende

${ }^{38}$ Vgl. dazu Reissert, Die finanzielle Beteiligung des Bundes an Aufgaben der Länder und das Postulat der „Einheitlichkeit der Lebensverhältnisse im Bundesgebiet", 1975, passim; Pagenkopf, Harmonisierungsgebote und Nivellierungsverbote im bundesstaatlichen Finanzausgleich, DÖV 1979, 613; Hofmann (Fn. 7), $\$ 7$ Rdn. 60; Wendt (Fn. 4), $\$ 104$ Rdn. 95; Renzsch (Fn. 4), S. 282 f. Vgl. auch Fn. 51 ff.

${ }^{39}$ Vgl. bereits die Feststellung von Hettlage (Fn. 1), S. 19: „Die öffentliche Meinung nimmt schon geringfügige Leistungs- oder Belastungsunterschiede nicht mehr widerspruchslos hin. Ein gleichmäßiger Verwaltungsstandard und eine gleichmäßige Steuerbelastung sind auch im Bundesstaat ein Ideal geworden. Der Kreis der Aufgaben, deren Vollzug keine regionale Mannigfaltigkeit mehr erträgt, wird immer größer". Entsprechend mußte die Troeger-Kommission in ihrem Reformgutachten 1966 (Fn. 9) konstatieren, es werde „das Prinzip der föderativen Freiheit zunehmend von den Forderungen des modernen Sozialstaats überlagert, der die Gleichmäßigkeit der öffentlichen Leistungen und die Einheitlichkeit der Lebensverhältnisse höher bewertet als die Rücksichtnahme auf regionale oder örtliche Besonderheiten" (a.a.O., Tz. 74). Ähnlich wie vorstehend vgl. die späteren Beobachtungen von Pagenkopf, Der Finanzausgleich im Bundesstaat, 1981, S. 158, 294.

${ }^{40}$ Hierzu vgl. insb. auch Isensee, Idee und Gestalt des Föderalismus im Grundgesetz, in: ders./Kirchbof, HStR, Bd. IV, 1990, \$98 Rdn. 251; s. ferner Zacher, Das soziale Staatsziel, in: Isensee/Kirchbof, HStR, Bd. I, 1987, $\$ 25 \mathrm{Rdn} .83$.

${ }^{41} \mathrm{Vgl}$. bei und in Fn. $45 \mathrm{ff}$.

${ }_{42}$ Vgl. die Nachw. in Fn. 14.

${ }_{43}$ Vgl. jetzt aber auch die oben bei und in Fn. 29 u. 32 genannten Tendenzen.

${ }^{44} \mathrm{Vgl}$. dazu bereits die Nachw. in Fn. 11. 
Stempel auf ${ }^{45}$. Nicht nur wurde die schließliche Zuordnung der steuerlichen Gesetzgebungsbefugnisse der Vereinheitlichungsambition des Bundes untergeordnet ${ }^{46}$. Auch auf die Verteilung der Aufgaben- und Ausgabenverantwortung übte die „Einheitlichkeit der Lebensverhältnisse" - Stichworte: Bundesfondswirtschaft und Gemeinschaftsaufgaben - eine beträchtliche Antriebskraft zugunsten des Bundes aus ${ }^{47}$. Zunehmend in den Sog unitarischer Egalität geriet aber auch der Finanzausgleich ${ }^{48}$. Die zu Regelelementen des Finanzausgleichs aufgewerteten Bundesergänzungszuweisungen mit ihrer gleichermaßen nivellierenden Wirkung auf horizontaler Ebene setzten den Schlußstein zu einem praktizierten Regelwerk, dessen wesentliches Ziel der Bund erklärtermaßen darin sieht, über eine aufgabenerfüllungsorientierte Finanzausstattung der Länder „öffentliche Lei-

${ }^{45}$ So legte der Bund dem Regierungsentwurf eines Finanzreformgesetzes vom 30. 4. 1968, BT-Drucks. V/2861, Tz. 10, vorab ausdrücklich die bis heute beherzigte Überlegung zugrunde: „Die öffentliche Meinung nimmt wesentliche Leistungsund Belastungsunterschiede als Preis für eine weitgehende eigenstaatliche Lösung der öffentlichen Aufgaben durch die Länder nicht mehr hin. Annähernd gleichmäßige öffentliche Leistungen ... und eine gleichmäßige Steuerbelastung sind auch im Bundesstaat zur selbstverständlichen Forderung geworden. Das Grundgesetz selbst verpflichtet zur Wahrung der Rechts- und Wirtschaftseinheit und zur Förderung der Einheitlichkeit der Lebensverhältnisse. Kein moderner Bundesstaat, der ein sozialer Rechtsstaat ist, kann sich auf die Dauer einer weitgehenden Angleichung der Lebensverhältnisse entziehen". Vgl. treffend insgesamt die von Franke (Fn.4), S. 311 (312), getroffene Feststellung, der finanzausgleichregelnde Bundesgesetzgeber gehe bislang von einer „recht strikten Interpretation“ des Gebots der „Einheitlichkeit der Lebensverhältnisse" aus.

$46 \mathrm{Vgl}$. dazu aus der Begründung des Regierungsentwurfs zum Finanzreformgesetz (Fn. 45), BT-Drucks. V/2861, die Tz.127ff.; ferner Jung, Die Finanzreform, WPM, Sonderbeilage Nr. 4/1969, S. 41; Strauß, Die Finanzverfassung, 1969, S. 115.

47 Zur Bedeutung (auch) des Postulats „Einheitlichkeit der Lebensverhältnisse“ für die Schaffung gerade der Art. 91 a und Art. 104 a IV GG vgl. aus der Begründung des Regierungsentwurfs zum Finanzreformgesetz (Fn. 45), BT-Drucks.V/ 2861, vor allem die Tz. 89 und 120 f.; s. entspr. auch Hettlage, VVDStRL 31 (1973), S. 100 (Diskussionsbeitrag); Biebl, Die Entwicklung des Finanzausgleichs in ausgewählten Bundesstaaten - a): Bundesrepubik Deutschland -, in: Handbuch der Finanzwissenschaft, 3. Aufl., Bd. IV (1981), S. 69 (113).

${ }^{48}$ Hierzu und zum Folgenden vgl. Renner, Finanzausgleich unter den Ländern und Bundesergänzungszuweisungen, in: Bundesministerium der Finanzen (Hrsg.), Die Finanzbeziehungen zwischen Bund, Ländern und Gemeinden aus finanzverfassungsrechtlicher und finanzwirtschaftlicher Sicht, 1982, S. $327 \mathrm{ff}$. (S. $335 \mathrm{ff}$, $351 \mathrm{ff}$.) = BMF, Dokumentation 6/82 v. 9.6.1982, S. 3 ff., $20 \mathrm{ff}$. 
stungen auf etwa gleichem Niveau in allen Teilen des Staatsgebietes“ zu erreichen ${ }^{49}$.

Verfassungsrechtlich konnte sich der kritische Betrachter dieses Bildes bislang damit beruhigen, die besondere Elastizität des Bundesstaatsprinzips trage jedenfalls diese recht deutliche Auflösung des in ihm angelegten Spannungsverhältnisses zu Lasten seiner Vielfaltskomponente ${ }^{50}$. Das Problem der verpflichtenden Kraft des Einheitlichkeitsgedankens blieb dagegen weithin außerhalb einer übergreifenden verfassungsrechtlichen Betrachtung. Es kommt nicht von ungefähr, daß die grundlegenden Untersuchungen von Lerche und FischerMenshausen aus den Jahren 1973 bzw. 1978 speziell gegen eine Überanstrengung des horizontalen Finanzausgleichs gerichteten Überlegungen Paul Kirchbofs von $1982^{52}$, ohne kongeniale Fortschreibungen geblieben $\operatorname{sind}^{53}$. Bereits die sich zunehmend verdichtende Diskussion einer verfassungs- und finanzpolitisch

${ }^{49}$ Renner (Fn. 48), S. $336=$ BMF (Fn. 48), S. 6.

50 Vgl. etwa Donner (Fn. 4), S. 328.

${ }^{51}$ Vgl. Lerche, Finanzausgleich und Einheitlichkeit der Lebensverhältnisse, in: Festschrift für Berber, 1973, S.299; Fischer-Menshausen, Unbestimmte Rechtsbegriffe in der bundesstaatlichen Finanzverfassung, in: Dreißig (Hrsg.), Probleme des Finanzausgleichs I, 1978, S. 135.

52 P. Kirchhof, Der Verfassungsauftrag zum Länderfinanzausgleich als Ergänzung fehlender und als Garant vorhandener Finanzautonomie, 1982, S.15 ff.

${ }^{53}$ An breiteren Darstellungen zum Thema „Einheitlichkeit der Lebensverhältnisse" (vor allem auch aus der Sicht der Wirtschafts-, insb. Finanzwissenschaften) vgl., abgesehen von den in Fn. 38 Genannten, immerhin ferner Neumark, Bemerkungen zu einigen ökonomischen Aspekten der grundgesetzlichen Vorschriften über die Einheitlichkeit der Lebensverhältnisse in der Bundesrepublik Deutschland, in: Dreißig (Hrsg.), Fn. 51, S. 165; Hübler/Scharmer/Weichtmann/Wirz, Zur Problematik der Herstellung gleichwertiger Lebensverhältnisse, Veröff. der Akademie für Raumforschung und Landesplanung, Bd. 80, 1980 (dort S.27ff. auch zur verfassungsrechtlichen Problematik); Stern, Staatsrecht II, 1980, S. 1166 ff.; Ossenbübl, Verfassungsrechtliche Grundfragen des Länderfinanzausgleichs gem. Art. 107 II GG, 1984, S. 25 ff.; Peffekoven (Fn.4), S. 181 f.; Zimmermann, Föderalismus und "Einheitlichkeit der Lebensverhältnisse“ - Das Verhältnis regionaler Ausgleichsziele zu den Zielen des föderativen Staatsaufbaus -, in: K. Schmidt (Hrsg.), Beiträge zu ökonomischen Problemen des Föderalismus, 1987, S. 35 ff. (S. 37 ff. auch zur rechtlichen Sicht); Carl, Kompetenz und Pflicht des Bundes zur Unterstützung strukturschwacher Regionen - Eine Untersuchung am Beispiel der Stahlregionen -, AöR 114 (1989), 450 (463 ff.); Fischer, Sozialhilfe und BundLänder-Finanzausgleich, in: Kitterer (Hrsg.), Fn. 4, S. 131 (135ff.). Zum Schrifttum seit Beginn des Einigungsprozesses vgl. Fn. 55. 
gebotenen fiskalischen Entflechtung zwischen Bund und Ländern ${ }^{54}$ hat aber dem Problem des Verpflichtungsgehaltes der These von der "Einheitlichkeit der Lebensverhältnisse" im Bundesgebiet seit einiger Zeit aktuellere Bedeutung verliehen. Der Beitritt der fünf neuen Länder mit ihrer tiefgreifenden Wirtschafts- und Finanzschwäche macht die Klärung dieses Problems nunmehr unausweichlich ${ }^{55}$. Welche Dynamik die Einheitlichkeitsformel hier gegebenenfalls entfalten kann, wird unschwer deutlich, berücksichtigt man nur, daß die Steuerkraft der neuen Bundesländer im Durchschnitt bei 30 v. H. des ProKopf-Steueraufkommens in den westlichen Bundesländern liegt, und stellt man ferner in Rechnung, daß, abgesehen von den Umweltaltlasten und anderen Sonderbedarfen, so dem aus einer Arbeitslosenquote von etwa 15 v. H. resultierenden, allein für die Schaffung einer dem Westniveau vergleichbaren Infrastrukturausstattung in den nächsten zehn Jahren an die 500 Mrd. DM benötigt werden ${ }^{56}$.

Angesichts dieses Befundes wird der Bund möglicherweise seine grundlegende politische Ambition zur Herstellung "einheitlicher Lebensverhältnisse im Bundesgebiet" künftig nicht mehr so apodiktisch als auch verfassungsgeboten ausgeben, wie er dies in der Vergangenheit verschiedentlich getan hat ${ }^{57}$. Dabei konnte er - und tat dies auch $^{58}$ - vor allem an Hettlage anknüpfen, der 1955 vor dieser

${ }^{54}$ Zur Diskussion bis zum Beginn des Einigungsprozesses vgl. oben bei und in Fn. 20, 22; seither s. insb. (abgesehen von Fn. 29 ff.) noch Peffekoven (Fn. 4), S. 485 (501 ff.) ders. (Fn. 4), S. 346 (351 f.); Benz (Fn. 4), S. 586 ff.; Franke (Fn. 4), S. 311 (320 f.); Kisker (Fn. 4), S. 128 ff., 132 ff.); Klatt (Fn. 4), S. 230 ff.; Littmann (Fn. 4), S. 40 ff. (dazu R. Wagener, DVBl. 1991, 152); Milbradt (Fn.4), S. 314 f.; H.P. Schneider (Fn. 4), S. 2453 ff.; s.a. FAZ v. 20.3.1992, S. 5 („Biedenkopf strebt Regionalisierung an").

${ }_{55}$ Das Thema „Einheitlichkeit der Lebensverhältnisse" und Wiedervereinigung wird erörtert insb. bei Hobmann, Der Verfassungsgrundsatz der Herstellung einheitlicher Lebensverhältnisse im Bundesgebiet - Erläutert anhand der fünf neuen Bundesländer -, DÖV 1991, 191; s. ferner dazu auch Korioth (Fn. 4), S. 1056f.; Milbradt (Fn. 4), S. 311; H.P. Schneider (Fn. 4), S. 2451 f., 2453; Kilian (Fn.4), S. 426; Ernst, Die Alternative: Neugliederung des Bundesgebiets, DVBl. 1991, 1024 (1028 ff.); Heun (Fn.4), S.214 m.Fn. 50; Wieland (Fn. 2), S. 1182, 1192; s. a. FAZ (Fn. 54).

${ }^{56} \mathrm{Zu}$ den Wirtschafts- und Finanzdaten der neuen Bundesländer vgl. Sachverständigenrat, Jahresgutachten 1990/91 (Fn.2), S.61 ff; Jahresgutachten 1991/92 (Fn. 2), Tz. 63 ff., $129 \mathrm{ff}$; $192 \mathrm{ff}$., $314 \mathrm{ff}$. (insb. Tz. $317 \mathrm{f}$.); Jahreswirtschaftsbericht 1992 der Bundesregierung, BT-Drucks. 12/2018, insb. Tz.28ff., $116 \mathrm{ff}$.; BMF (Hrsg.), Finanzbericht 1993, insb. S. 11, $127 \mathrm{ff}$.

57 Vgl. etwa BT-Drucks. V/2861, Tz. 10 (s. Fn. 45); ferner BMF (Fn. 48), S. 6.

58 Besonders deutlich in BT-Drucks. V/2861, Tz. 10. 
Vereinigung einen ersten Ansatz in jene Richtung machte ${ }^{59}$ und auf der Gemeinschaftsaufgaben-Tagung 1972 dem Grundgesetz ausdrücklich einen umfassenden Verfassungsauftrag zur Förderung der Einheitlichkeit der Lebensverhältnisse entnehmen zu können glaubte $^{60}$. Gelegentliche Bekundungen dieser und ähnlicher Art finden sich mit erstaunlicher Unbekümmertheit bis auf den heutigen Tag; so sprach noch vor kurzem auch der Sachverständigenrat in seinem Jahresgutachten 1991/92 ohne weiteres ganz allgemein von einem „Verfassungsgebot der ,Einheitlichkeit der Lebensverhältnisse“ “61. Mit gleicher Entschiedenheit ist indes seit Einsetzen der Entflechtungsdiskussion nicht selten der konträre Standpunkt vertreten worden, vor allem von seiten der finanzkräftigeren Länder und ihrer finanzpolitischen wie wissenschaftlichen - Protagonisten $^{62}$. Den einstweiligen Schlußpunkt setzte insoweit im Januar 1992 die Kommission Finanzverfassungsreform des Landes Baden-Württemberg. Sie findet in der Verfassung keinen Programmsatz, der den Bundesgesetzgeber „legitimieren oder gar verpflichten“ würde, über Maßnahmen im Bereich der Finanzausgleichsregelungen für eine Angleichung oder gar für die Einheitlichkeit der Lebensverhältnisse im Bundesgebiet Sorge zu tragen ${ }^{63}$.

Ich meine, man wird im Ergebnis keiner dieser beiden Extrempositionen uneingeschränkt zustimmen können. Ein übergreifendes finanzverfassungsrechtliches Vereinheitlichungsgebot im engeren Sinne einer Herstellung einheitlicher Lebensverhältnisse im gesamten Bundesgebiet läßt sich dem Grundgesetz nicht entnehmen. Daß ein im Einzugsbereich der Finanzreform 69 unternommener Versuch, die Einheitlichkeitsformel in bezug auf die horizontale Steuerertragsverteilung ausdrücklich in der Finanzverfassung zu veran-

59 Vgl. Hettlage (Fn. 1), S. 19 f. (s. oben Fn. 39).

60 Vgl. Hettlage, VVDStRL 31 (1973), S. 100 (Diskussionsbeitrag).

61 Vgl. Sachverständigenrat, Jahresgutachten 1991/92 (Fn.2), Tz.325 (etwas vorsichtiger noch Jahresgutachten 1990/91, Tz.434); recht weitgehend s. ferner etwa auch Kitterer (Fn. 24), S. 188; Stern, Staatsrecht II (Fn. 53), S. 1167 f.

$62 \mathrm{Vgl}$. etwa Heinsen (Fn. 22), S. 239.

${ }^{63}$ Vgl. Kommission Finanzverfassungsreform des Landes Baden-Württemberg, Zwischenbericht vom 16.1.1992, S. 14 ff. der mschr. Fassung; s. ähnlich zurückhaltend ferner Maunz, in: Maunz/Dürig/Herzog/Scholz, Grundgesetz, 1984, Art. 72 Rdn. 23 (S. 12); Scharpf (Fn. 4), S. 150; v. Mutius, in: Kitterer (Hrsg.), Fn. 4, S. 179 (Diskussionsbeitrag); Peffekoven (Fn. 4), S. 181. 
kern $^{64}$, ergebnislos blieb, ist allerdings noch ohne besondere Aussagekraft ${ }^{65}$. Denn dieser Versuch und sein Scheitern standen in einem ganz spezifischen Bezugsrahmen zu der seinerzeit vom Land Niedersachsen erhobenen, vom Bundestag übernommenen, schließlich aber vom Bundesrat abgelehnten Forderung, die Steuerertragsverteilung des Art.107 I GG unter letztlichem Verzicht auf einen horizontalen Finanzausgleich durch ein ausschließlich bedarfsorientiertes Verteilungssystem zu ersetzen ${ }^{66}$. Von größerem Gewicht ist, daß sich weder aus Art. 72 II Nr. 3 noch aus Art. 106 III S. 4 Nr. 2 GG, die beide allein den Vereinheitlichungsgedanken explizit aufnehmen, ein allgemeiner Grundsatz herleiten läßt. Erstere Bestimmung, wegen Art. 105 II GG für den Finanzbereich ohnehin nur von beschränkter Bedeutung, formuliert allein für die konkurrierende Gesetzgebung eine zudem als Kompetenzhürde für den Bund angelegte $^{67}$ Voraussetzung. Art. 106 III S. 4 Nr. 2 GG aber bezieht sich, wie immer man seine nur schwer zu deutende Wirkung ansonsten eingrenzt, auf eine vertikale Komponente des Finanzausgleichs. Er scheidet als Sitz einer übergreifenden Unitarisierungstendenz deshalb ebenfalls aus.

Der Geltungsgrund eines allgemeinen Einheitlichkeitsgebotes sieht sich damit auf die einigermaßen schmale Basis verwiesen, die ihm durch das Bundesstaatsprinzip selbst, das Sozialstaatsprinzip sowie durch die in Art.20 I GG verwendete, bisher noch unzureichend aufgehellte Wortkombination vom "sozialen Bundesstaat ${ }^{\text {"68 }}$ immerhin vermittelt wird ${ }^{69}$. Das schafft beträchtliche Distanz zu einem am Wortlaut der Herstellung „einheitlicher Lebensverhältnisse im Bundesgebiet" sich orientierenden Verständnis. Mehr als die Sicherung

${ }^{64} \mathrm{Vgl}$. dazu die Niederschriften über die Sitzung des Unterausschusses des Rechtsausschusses des Bundesrates v. 20.3.1968, S.16f., über die Sitzung des Rechtsausschusses des Bundesrates v. 27.3.1968, S.23, sowie über die 171. Sitzung - 5. Wahlperiode - des Bundestages v. 8.5.1968 (Sten. Ber. S. $9182 \mathrm{ff}$.)

${ }_{65}$ Ebenso Lerche (Fn. 51), S.303; Ossenbühl (Fn. 53), S. 27.

66 Vgl, dazu näher Selmer/Brodersen, Finanzverfassungsrechtliche Grundfragen des horizontalen Finanzausgleichs, 1984, S. 32 f.; Vogel/Kirchbof, in: BK, Art. 107 (Zweitbearbeitung 1971) Rdn. 13 ff.; Renzsch (Fn. 4), S. 236 ff.

67 Wenn auch nicht als solche praktizierte: vgl. BVerfGE 13, 230 (233f.); 26, $338(382 \mathrm{f}$.$) .$

${ }_{68} \mathrm{Vgl}$. zu ihr Isensee (Fn. 40), $\$ 98 \mathrm{Rdn} .250$; tiefer auslotend jetzt auch Zacher (Fn. 40), $\$ 25$ Rdn. $82 \mathrm{ff}$.

69 Vgl. mit obigem Verständnis auch Troeger-Gutachten (Fn. 9), Tz. 74; FischerMenshausen (Fn. 51), S. 148 f.; Donner (Fn. 4), S.330; Ossenbübl (Fn. 53), S. 25f.; Hübler/Scharmer/Weichtmann/Wirz (Fn. 53), S.35; Zimmermann (Fn. 53), S. 45; 
eines „Mindeststandards für wesentliche (keineswegs also für alle) Lebensverhältnisse ${ }^{\text {"70 }}$ dürfte das übergreifende finanzverfassungsrechtliche Einheitlichkeitsgebot damit kaum umfassen ${ }^{71}$. Die in Art. 104 a I GG vorausgesetzte Kongruenz von Aufgabenerfüllung und Finanzausstattung geht hierüber als solche nicht hinaus. Denn die Qualität der jedem Land obliegenden Aufgabenerfüllung wird eben gerade auch durch die sich aus seiner Eigenstaatlichkeit ergebenden Besonderheiten mitbestimmt ${ }^{72}$, soweit nicht die Finanzverfassung deren Eliminierung in spezieller Weise anordnet oder zuläßt.

Über Regelungen dieser Art verfügt die Finanzverfassung etwa mit den Art. 91 a, 104 a IV sowie Art. 107 II GG allerdings. Ihre Umsetzung fördert letztlich auch die Einheitlichkeit der Lebensverhältnisse im Bundesgebiet, ohne daß indes deren Herstellung ein unmittelbares Rechtsgut der genannten Vorschriften bildete. Das trifft vor allem für den horizontalen Finanzausgleich zu. Dessen nicht nur bundesstaatliche, sondern auch sozialstaatliche Funktion steht zwar als solche außer Streit ${ }^{73}$. Diese Funktion kann aber nur im Rahmen und unter Berücksichtigung der gerade mit Art. 107 II GG getroffenen Entscheidung für die Sicherstellung eines angemessenen Finanzkraftausgleichs unter den Ländern verwirklicht werden ${ }^{74}$. Das schließt es im Rahmen einer "gerade auf Vielfalt (also Uneinheitlichkeit) angelegten Bundes-

Isensee (Fn. 40), \$98 Rdn.251; ders. (Fn. 15), S.255; H.P. Schneider (Fn. 4), S. 2451, 2453; Carl (Fn. 53), S. 463, 490 f.; Kisker (Fn. 4), S. 138; Hobmann (Fn. 55), S. 195 f.; Kilian (Fn. 4), S. 426; Korioth (Fn. 4), S. 1056 f.

70 Vgl. Neumark (Fn. 53), S. 169, 174.

71 Vgl. so, neben Fn. 70, etwa auch Fischer-Menshausen (Fn. 51), S. 150; Hübler/ Scharmer/Weichtmann/Wirtz (Fn. 53), S. 36 ff.; Korioth (Fn. 4), S. 1057; Hobmann (Fn. 55), S. 195; Sacbverständigenrat (Fn. 2), Tz 434.

72 Hiergegen läßt sich der grundrechtliche Gleichbehandlungsanspruch der Einwohner (Art. 3 I GG), unbeschadet Art. 20 I, 28 I GG und der oben nachfolgend genannten Regelungen, nicht mobilisieren: Vgl. auch Kisker, Grundrechtsschutz gegen bundesstaatliche Vielfalt?, in: Festschrift für Bachof, 1984, S. 47 (55); Dittmann, Gleichheitssatz und Gesetzesvollzug im Bundesstaat, Festschrift für Dürig, 1990, S. 221 (222); s. ferner Stern, Staatsrecht I (Fn. 9), S.661 f.; Isensee (Fn. 40), $\$ 98$ Rdn. 247; a. A. wohl Vogel/Kirchbof (Fn. 66), Art. 107 Rdn. 54; P. Kirchbof (Fn. 52), S. 23; Renzsch (Fn. 4), S. 283 Fn. 3.

${ }^{73} \mathrm{Zu}$ dieser Doppelfunktion vgl. für viele Fischer-Menshausen, in: v. Münch (Hrsg.), Grundgesetz, 2. Aufl. (1983), Art. 107 Rdn. 2 f., 4 f.; Stern, Staatsrecht II (Fn. 53), S. 1166; Selmer/Brodersen (Fn. 66), S. 9 f.

74 Selmer/Brodersen (Fn. 66), S.11; s. in diesem Sinne ferner auch Maunz (Fn. 63), 1983, Art. 107 Rdn. 9; Hübler/Scharmer/Weichtmann/Wirz (Fn. 53), S. 33; Zimmermann (Fn. 53), S. 44. Vgl. auch Fn. 76. 
staatsordnung ${ }^{\text {"75 }}$ aus, die Verwirklichung dieses Ausgleichs in erster Linie unter Rückgriff auf ein in der Bestimmung nicht genanntes Leitziel „Einheitlichkeit der Lebensverhältnisse im Bundesgebiet“ vorzunehmen ${ }^{76}$.

Damit muß es bei der Feststellung sein Bewenden haben: Der Gesichtspunkt der „Herstellung einheitlicher Lebensverhältnisse im Bundesgebiet" ist als übergreifende Zielvorstellung grundsätzlich nur nach Maßgabe der Forderung nach einem "sozialen Bundesstaat“ unmittelbar verfassungsschwer. Im übrigen bildet er eine mögliche, keineswegs aber die von Verfassung wegen einzig in Betracht kommende regionalpolitische Staatszielbestimmung. Als solche ist er Abschwächungen und Umformungen durch den einfachen Gesetzgeber grundsätzlich zugänglich ${ }^{77}$. Dieser ist also im Rahmen der Grenzen, die ihm durch den "sozialen Bundesstaat" gezogen sind, auch finanzverfassungsrechtlich an sich nicht gehindert, das Schwergewicht künftig von einer Politik der Unitarisierung und sozialen Egalisierung im Bundesgebiet mehr auf eine solche der regionalen Differenzierung zu verlagern ${ }^{78}$.

Das Gewicht dieser Einsicht erscheint vor allem nach dem Beitritt der fünf neuen Bundesländer ${ }^{79}$ auf den ersten Blick beträchtlich. Es darf aber nicht überbewertet werden. Insbesondere kann es auch auf ihrer Grundlage nicht darum gehen, die neuen Länder nunmehr, abgesehen von der Sicherung des notwendigen Mindeststandards der Einrichtungen der Daseinsvorsorge, unversehens auf die mangelnde Verfassungskraft eines übergreifenden Einheitlichkeitsgebotes und die Stärkungsbedürftigkeit der Vielfaltskomponente des Bundesstaatsprinzips zu verweisen. Der Bund ist auch im Verhältnis zu den neuen Ländern an das aus dem Bundesstaatsprinzip und dem allgemeinen

75 Kisker, Neuordnung des bundesstaatlichen Kompetenzgefüges und BundLänder-Planung, Der Staat 1975, 169 (183); s. a. ders. (Fn. 4), S. 138.

${ }^{76}$ Mit Recht argumentiert denn auch das BVerfG im Zusammenhang mit der Erörterung des angemessenen Finanzkraftausgleichs unter den Ländern nicht mit der Formel „Einheitlichkeit der Lebensverhältnisse“, sondern mit dem „bündischen Prinzip des Einstehens füreinander “; vgl. BVerfGE 72, 330 (386, 397). Vgl. zum Länderfinanzausgleich näher unter C II.

77 Vgl. ähnlich auch Zimmermann (Fn. 53), S. 36, 61.

78 Vgl. dazu näher unter C II 4.

79 Die zumeist fordern, „die grundgesetzliche Staatszielbestimmung der ,Einheitlichkeit der Lebensverhältnisse' in einer gebotenen schnelleren Schrittfolge zu realisieren“ (Milbradt, Fn. 4, S. 311). 
Gleichheitssatz folgende föderative Gleichbehandlungsgebot ${ }^{80}$ gebunden. Dieses Gebot läßt dem - im weiteren Sinne - finanzausgleichsregelnden Bundesgesetzgeber im Grunde nur zwei Alternativen: Bleibt er ungeachtet des auf ihm zunehmend lastenden Differenzierungs- und Regionalisierungsdrucks ${ }^{81}$ im großen und ganzen bei seiner bisherigen politischen Linie einer weitgehenden Egalisierung der staatlich beeinflußbaren Lebensverhältnisse im Bundesgebiet, so darf er hiervon die neuen Bundesländer nicht ausnehmen - unbeschadet der verfassungsrechtlich nicht zu beanstandenden Möglichkeit, den Annäherungsprozeß über eine Reihe von Jahren zu strek$k^{2}{ }^{82}$. Nur bei einer grundsätzlichen Umorientierung der föderativen Finanzverfassung in eine ausgeprägt länderautonomiebetonte Richtung wird man schließlich auch für die neuen Bundesländer wesentliche Unterschiede im öffentlichen Leistungsangebot nach Maßgabe eigener Potenz und aufgrund autonomer Entscheidungsgewalt, deren strukturelle Voraussetzungen es freilich zuvor noch zu schaffen gälte, hinnehmen können.

Deutliche Anzeichen sprechen indessen dafür, daß der Bund, bei einer verfassungsrechtlich möglicherweise etwas zurückhaltenderen Position, grundsätzlich die Gestaltung des bundesstaatlichen Finanzausgleichs vorerst weiterhin auf eine intensive Praktizierung des Einheitlichkeitsgedankens auszurichten versuchen wird ${ }^{83}$. Dabei ist allerdings zu berücksichtigen, daß die aktuelle Entflechtungsdiskussion ${ }^{84}$, mit deren Ausgang die weitere Intensität der „Einheitlichkeit der Lebensverhältnisse im Bundesgebiet" eng verwoben ist, eben erst begonnen hat.

80 BVerfGE 72, 330 (404); s.a. BVerfGE 1, 14 (52f.); 21, 362 (372); 26, 228 (244); 35, 263 (271); zur Entwicklung vgl. näher Isensee (Fn. 40), \$98 Rdn. 132 ff.; Maunz, Gleichheit der Gliedstaaten im Bundesstaat, in: Wilke/Weber (Hrsg.), Gedächtnisschrift für F. Klein, 1977, S. 311, jew. m. w. Nachw.

81 Vgl. Fn. 22, 29 ff., 54.

82 Die Berücksichtigung der begrenzten finanziellen Möglichkeiten bildet insoweit ein sachgerechtes und damit auch gegenüber dem föderativen Gleichbehandlungsgebot durchgreifendes (s. Isensee, Fn. 80, Rdn. 135 f.), mit zeitlichem Fortgang freilich an Legitimationskraft abnehmendes Kriterium.

${ }^{83} \mathrm{Vgl}$. in diesem Sinne etwa BMF, Finanznachrichten 64/92 v. 6.7.1992, S.2, wo (speziell in bezug auf die neuen Bundesländer) vom "gemeinsamen Ziel der Angleichung der Lebensverhältnisse in Deutschland “ die Rede ist; s. ferner auch $\$ 1$ I Nr. 4 und $\$ 2$ I Nrn. 3 u. 4 des Raumordnungsgesetzes i.d. F. der Bekanntmachung v. 25.7.1991 (BGBl. I S. 1726, ber. 1883).

${ }^{84} \mathrm{Vgl}$. Fn. 54. 


\section{Die Finanzverantwortung für die Angleichung der Lebensverbältnisse im Bundesgebiet}

Wie immer indes die Verpflichtungskraft bundesstaatlicher Vereinheitlichungstendenz zu bemessen ist. Es bleibt das weitere Problem, wer für die Herstellung der Einheitlichkeit aufzukommen hat. In einem freilich sehr grundsätzlichen Sinne sind dies - unbeschadet der bündischen Beistandspflichten anderer - zunächst einmal die Länder selbst. Die ihnen in Art. 28 I GG auferlegte Homogenisierung schließt das soziale Staatsziel ein ${ }^{85}$. Einheitlichkeit der Lebensverhältnisse resultiert hieraus selbst bei etwa gleichem Pro-Kopf-Steueraufkommen in allen Ländern letztlich allerdings nur dann, wenn die Ausgaben der Länder ebenfalls nur wenig streuen oder entsprechende Durchbrechungen der allgemeinen Lastenverteilungsregel des Art. 104 a I GG zugelassen werden ${ }^{86}$. Erstere Voraussetzung mag im zeitlichen Einzugsbereich der Finanzreform 69 bei aller tatsächlichen Verschiedenheit der Länder ${ }^{87}$ noch annähernd gegeben gewesen sein. Die seit Ende der 70er Jahre einsetzenden Strukturkrisen haben indes, da sich die strukturschwachen Branchen auf wenige Regionen konzentrieren, zu einer zunehmend stärkeren Differenzierung z wischen den Ländern hinsichtlich der ihnen obliegenden Pro-Kopf-Ausgabenbelastung geführt. Das läßt sich paradigmatisch vor allem anhand ihrer Sozialhilfeausgaben überzeugend belegen $^{88}$. Die hieraus folgende Unfähigkeit strukturschwacher Länder, hinreichende Mittel für eine gezielte Strukturpolitik bereitzustellen, hat in einem circulus vitiosus ihre Unfähigkeit weiter verschärft, Einheitlichkeit der Lebensverhältnisse aus eigener Kraft zu verwirklichen. Daß diese Probleme mit dem Beitritt der fünf neuen Bundesländer nunmehr ein besonderes Gewicht haben, liegt auf der Hand.

${ }^{85}$ Dieses bildet eine verbindliche Direktive für die verantwortliche Erfüllung der den Ländern obliegenden Aufgaben und steuert damit im Hinblick auf Art. 104 a I GG auch ihr Ausgabenverhalten in Richtung auf den vom allgemeinen Konsens wie überwiegender Praxis getragenen Durchschnittsstandard des Bundesstaates und damit einheitsfördernd mit. Vgl. zur Sozialverpflichtung der Länder näher Zacher (Fn. 40), \$25 Rdn. 82; Isensee (Fn. 40), \$98 Rdn. 250.

86 Hierzu und zum Folgenden vgl. Peffekoven (Fn. 4), S. 181 (222).

${ }^{87}$ Folge ihrer unterschiedlichen Größe, Verkehrslage, Raumstruktur, Bevölkerungsdichte, wirtschaftlichen und kulturellen Gegebenheiten.

88 So bewegten sich die Sozialhilfeausgaben je Einwohner im Jahre 1989 (1986) zwischen 343,-DM(179, - DM) in Bayern sowie 350, - DM (205, - DM) in BadenWürttemberg auf der einen und 855,- DM $(589,-$ DM) in Bremen, 797,- DM $(668,-D M)$ in Hamburg und $653,-$ DM $(333,-D M)$ in Schleswig-Holstein auf der anderen Seite. 
Verfassungsrechtlich knüpft sich an diese Einsichten vor allem die Frage, ob und inwieweit dem Bund - d.h. gerade dem Bund und nicht auch den wirtschaftlich überlegenen anderen Ländern - die Aufgabe zukommt, mit eigenen Mitteln und nicht nur als einheitstiftender Gesetzgeber die finanziellen Standards zu sichern, deren die Einheitlichkeit der Lebensverhältnisse bedarf. Richtig ist gewiß, daß die bundesstaatliche Hauptfunktion des Bundes gerade auch „in der Sorge und Verantwortung für den Zusammenhalt des politischen Gemeinwesens in seiner Gesamtheit" und damit zugleich für "die Einheitlichkeit oder besser: Gleichwertigkeit der gesellschaftlichen Lebensbedingungen " 89 besteht. Aus dieser gesamtstaatlichen Ausgleichsfunktion des Bundes lassen sich aber noch keine konkreten Aufgaben- und Ausgabenzuweisungen ableiten. Der Bund ist vielmehr grundsätzlich verwiesen auf das beschränkte Instrumentarium, das ihm die Verfassung durch spezielle Einzelzuweisungen verliehen hat. Diese sind zwar bundesstaatsgetreu einzusetzen ${ }^{90}$. Es existiert aber keine übergreifende Aufgaben- und Lastenverteilungsregel, die dazu zwänge, einheitlichkeitserhebliche und berücksichtigungsfähige Sonderbedarfe einzelner Länder nach Maßgabe der verfassungsrechtlichen Möglichkeiten gerade auf die Schultern des Bundes zu laden oder unausgeglichen zu lassen. Daß die gesamte bundesstaatliche Kompetenzordnung auf dem konstitutionellen Grundgedanken ruhe, daß „Einheitlichkeit Sache des Bundes, Unterschiedlichkeit Sache der Länder" sei, wie dies eine Reihe von Autoren vertritt" ${ }^{91}$, erscheint mir mit dieser Konsequenz nicht überzeugungskräftig. Dem steht bereits entgegen, daß auch die Länder selbst, wie sich zeigte, im Rahmen ihrer eigenen Aufgabenerfüllung einen Einheitlichkeitsbeitrag zu leisten haben. Auch lassen sich nicht einzelne, im Grundgesetz jeweils gesondert aufgeführte und konzeptionell unabgestimmte Einwirkungsmöglichkeiten des Bundes (wie Art. 104 a III, IV, Art. 106 VIII, Art. 91 a, $91 \mathrm{~b}$ und 107 II S.3 GG), deren Benutzung im Ergebnis auch der Verwirklichung des Einheitlichkeitsgedankens dient, zu einem allgemeinen Prinzip ausweiten, das die Sorge für die Einheitlichkeit der

${ }^{89}$ H.P. Schneider (Fn. 4), S. 2451; s. a. Heinsen (Fn. 22), S. 233; Isensee (Fn. 15), S. 273; Kisker (Fn. 22), S. 696; Heun (Fn. 4), S. 223.

${ }^{90}$ Mit der vom BVerfG bestätigten Folge etwa, daß mit der Verrechtlichung der Bundesfondswirtschaft durch Art. 104 a IV GG dem Bund wegen der besonderen Bedeutung der dort betroffenen Investitionen für den Gesamtstaat eine Pflicht zur Finanzhilfe nach Maßgabe seiner Finanzkraft erwächst; vgl. BVerfGE 39, 96 (113).

${ }^{91} \mathrm{Vgl}$. Vogel/Walter, in: BK, Art. 106 (Zweitbearbeitung 1972) Rdn. 184; P. Kirchhof (Fn. 52), S. 23; Korioth (Fn. 4), S. 1058. 
Lebensverhältnisse im Bundesgebiet dann ausschließlich zur Sache des Bundes macht ${ }^{92}$. Eine solche finanzverantwortungsbegründende Generalzuweisung an den Bund ergibt sich übrigens entgegen gelegentlicher Ansicht ${ }^{93}$ auch nicht aus Art. 28 III GG. Die hier normierte Gewährpflicht des Bundes für die Wahrung u.a. des sozialen Rechtsstaats in den Ländern ist zwar Niederschlag der aus dem Bundesstaatsprinzip folgenden gesamtstaatlichen Verantwortung des Bun$\mathrm{des}^{94}$. Sie begründet aber wie diese selbst keine besonderen Verwaltungs- und damit Finanzierungskompetenzen ${ }^{95}$.

Der Befund, daß damit die „Einheitlichkeit der Lebensverhältnisse im Bundesgebiet" keineswegs a priori in den allgemeinen Verantwortungsbereich des Bundes fällt, läßt sich schließlich durch einen Rückgriff auf eine ungeschriebene Verwaltungskompetenz des Bundes kraft Natur der Sache nicht grundsätzlich aus den Angeln heben. Die entsprechende - etwa von Hettlage ${ }^{96}$ schon 1955 aufgeworfene Frage, ob nicht die Angleichung der Lebensverhältnisse innerhalb der Bundesrepublik „eine echte Bundesaufgabe des ungeschriebenen Bundesstaatsrechts" sei, ist in dieser Allgemeinheit nach wie vor zu verneinen. Ein - wenn auch nach Maßgabe der jeweiligen politischen Ambition möglicherweise: starkes - Bedürfnis nach zentraler Verwaltungskompetenz zwecks Sicherung überregional einheitlicher Lebensverhältnisse kann für sich allein eine ungeschriebene Bundesaufgabe ebensowenig begründen wie die überlegene Finanzkraft des Bundes als solche ${ }^{97}$.

\section{Insbesondere: Zur Finanzverantwortung für die einigungs-} bedingten "Einmalaufgaben " in den neuen Bundesländern

Dessen ungeachtet ist der Kompetenz des Bundes kraft Natur der Sache mit dem Beitritt der fünf neuen Bundesländer nun unversehens

92 Vgl. so bereits Selmer/Brodersen (Fn.66), S. 21; Ossenbübl (Fn. 53), S. 47 f.

93 Hettlage (Fn. 1), S. 18 f., 28.

94 Vgl. bei und in Fn. 89.

$95 \mathrm{Vgl}$. wie oben auch Isensee (Fn. 40), $\$ 98 \mathrm{Rdn} .125 \mathrm{f}$. m. w. Nachw.

\% Fn. 1, S. 29.

97 Ebenso Lerche (Fn. 10), Art. 83 Rdn. 10, 45; s. a. v. Arnim, Finanzzuständigkeit, in: HStR, Bd.IV, 1990, $\$ 103$ Rdn.55, 57. Der 1989 von Carl (Fn. 53) unternommene Versuch, aus dem Gesichtspunkt „Wahrung der Einheitlichkeit der Lebensverhältnisse" eine umfassende "ungeschriebene Bundeskompetenz zur regionalen Strukturpolitik“ samt entsprechender „ergänzender Hilfe für strukturschwache Räume" abzuleiten (a.a.O., S.466, 490 f.), verdient keinen Beifall und hat diesen, wenn ich recht sehe, bisher auch nicht gefunden. 
doch ein spezifischer Anwendungsbereich zugewachsen. Grundsätzlich obliegen freilich die in den neuen Ländern anfallenden Ausgaben nach Maßgabe der Art. 104 a I i.V. mit Art. 30 und 83 ff. GG diesen Ländern selbst, soweit nicht der Einigungsvertrag eine abweichende Regelung enthält oder zuläßt. Denn der Aufgabenbestand einer Gebietskörperschaft bestimmt die Finanzverantwortung - und nicht umgekehrt ${ }^{98}$. Davon sind auch die neuen Länder nicht grundsätzlich dispensiert, so schwierig sich ihre Finanzbedarfsentwicklung aufgrund der weitgehenden Herstellung der Rechtseinheit, der zur sozialstaatsgerechten Überleitung gebotenen Preisstützungsaktionen in den Bereichen Energie, Wohnung und öffentlicher Personennahverkehr, des gewaltigen infrastrukturellen Nachholbedarfs sowie der ökologischen und militärischen Altlasten, zu denen ab 1.1.1994 noch die Hälfte der verbleibenden Altschulden der DDR treten wird, insgesamt auch darstellen mag ${ }^{99}$. Nur bei einem Teil der hier in Rede stehenden Aufgaben handelt es sich allerdings um solche, die - wenn auch gelegentlich (wie die Sozialhilfe) in außergewöhnlicher Höhe zum Regelbestand öffentlicher Aufgabenlast gehören. Ihnen ist grundsätzlich im Rahmen des herkömmlichen Finanzausgleichs durch eine entsprechende Eigenausstattung der Länder ${ }^{100}$ zu genügen. Bei anderen Aufgaben indes, wie bei den Preisstützungsaktionen und den mannigfachen Altlasten der früheren DDR, geht es vor allem um die singuläre Vollzugsfolgenbewältigung des Vereinigungsprozesses. Die hier anfallenden Aufgaben sind denkbar kostenträchtig, aber eben nicht dauerhaft. Meine These ist, daß sie als einigungsbedingte „Einmalaufgaben "101 unter Wahrung der grundsätzlichen Eigenverantwortung der neuen Länder in die übergreifende Mitzuständigkeit des Bundes fallen ${ }^{102}$. Das bedarf kurzer Begründung.

Bereits die Troeger-Kommission hatte in Übereinstimmung mit

98 Henneke (Fn. 28), S. 231.

99 Instruktiv dazu Milbradt (Fn. 4), S. 305 ff.; s. a. FAZ v. 8.7. 1992, S. 4 („Die

Lasten für den Westen werden größer und von längerer Dauer sein“).

100 Gegebenenfalls durch eine verfassungsrechtliche Lastenverlagerung auf den Bund (s. zur Aufgabenverlagerung als einem Instrument des Finanzausgleichs grdl. Fischer-Menshausen, Fn. 3, S. 644 f.).

101 Den Begriff „Einmalkosten“" verwendet im vorliegenden Zusammenhang das Frankfurter Institut für wirtschaftspolitische Forschung e. V., Schriftenreihe Bd. 22 (Dez. 1990), Wirtschaftspolitik für das geeinte Deutschland, S. 36.

${ }_{102} \mathrm{Vgl}$. bereits Selmer (Fn. 24), S. 206 ff.; ebenso jetzt auch Isensee, Finanzverfassung und Sozialrecht, in: Sozialfinanzverfassung, Schriftenreihe des Deutschen Sozialrechtsverbandes e. V., Bd. 35, 1992, S. 7 (35). 
dem $B V e r f G^{103}$ in den Kreis der von ihr eingegrenzten „ungeschriebenen Finanzierungszuständigkeiten des Bundes aus der Natur der Sache" ausdrücklich auch die "gesamtdeutschen Aufgaben“ einbezogen $^{104}$. Der von ihr vorgelegte Entwurf einer entsprechenden Verwaltungsvereinbarung über das Zusammenwirken von Bund und Ländern bei der Finanzierung öffentlicher Aufgaben ${ }^{105}$ trat zwar formell nicht in $\mathrm{Kraft}^{106}$; er spielte aber in der Praxis eine beherrschende Rolle. Auch das Schrifttum bekannte sich $^{107}$, soweit ersichtlich ausnahmslos, zu der Rechtsauffassung, die Erfüllung gesamtdeutscher Belange, insbesondere die Förderung der Wiedervereinigung, falle unter dem Gesichtspunkt der Natur der Sache in die grundsätzliche Aufgaben- und damit Ausgabenverantwortung des Bundes ${ }^{108}$. Die dem zugrunde liegende Überlegung, daß nur der Bund zu einer übergreifenden und damit wirksamen Bewältigung der gesamtdeutschen Probleme in der Lage sei, hat auch unter der veränderten Situation und bei Inrechnungstellung der Aufgabenautonomie der neuen Bundesländer ihre Überzeugungskraft nicht verloren. Denn die "genuin staatliche Aufgabe ${ }^{\text {" } 109}$ der Systemliquidierung und Systemumstellung in der ehemaligen DDR und damit der inneren Wiedervereinigung geht nicht nur in ihren Auswirkungen über die Grenzen der einzelnen Länder hinaus - was nicht genügen würde ${ }^{110}$. Sie kann auch, soll eine unerträgliche, den Geboten des sozialen Bundesstaats

103 Vgl. BVerfGE 22, 180 (217).

104 Mit Recht ausgehend davon, daß diese immer als Aufgabe des Bundes angesehen worden seien (vgl. Troeger-Kommission, Fn. 9, Tz. 82, 86, 91, 93 und 100). S. $178 \mathrm{f}$.

${ }^{105}$ Abgedruckt als Anlage 2 zum Gutachten der Troeger-Kommission (Fn. 9),

106 Obschon sich die Bundesregierung den Vorschlag der Kommission im Entwurf des Finanzreformgesetzes zu eigen machte (BT-Drucks. V/2861, Tz. $73 \mathrm{ff} .$, 76) und ungeachtet einer 1971 von einer Bund/Länder-Kormmission vorgenommenen Überarbeitung (hier substantiell unerheblichen Inhalts: vgl. bei Maunz, Fn. 63, 1977, Art. 104 a Rdn. 16).

107 Bei manchen verfassungsrechtlichen Bedenken hinsichtlich anderer KatalogPunkte (vgl. dazu v.Armin, Fn.97, $\$ 103$ Rdn.62 Fn.162; Wieland, Fn.2, S. 1185 f.).

${ }_{108} \mathrm{Vgl}$. für viele Fischer-Menshausen (Fn.73), Art. 104 a Rdn. $11 \mathrm{ff}$.; v. Arnim (Fn. 97), \$103 Rdn. 55 ff.; Maunz (Fn. 63), Art. 104 a Rdn. 16 ff.; Vogel/Kirchbof, in: BK, Art. 104 a (Zweitbearbeitung 1971) Rdn. 61.

109 OVG Berlin, NJW 1991, 715 (716).

110 Fischer-Menshausen (Fn.73), Art. 104 a Rdn.10; Blümel, Verwaltungszuständigkeit, in: HStR, Bd. IV, 1990, $\$ 101$ Rdn. 116 m. w. Nachw. 
und der föderativen Gleichbehandlung widerstreitende Uneinheitlichkeit der Lebensverhältnisse im Verhältnis Ostländer/Westländer vermieden werden, nur mit der koordinierenden Unterstützung des Bundes wirksam ins Werk gesetzt werden. Ob die damit im Bereich der Vereinigungsfolgen bestehende Finanzierungsaufgabe des Bundes letztlich aus einer entsprechenden - die expliziten Verwaltungskompetenzen der neuen Bundesländer freilich unberührt lassenden übergreifenden Aufgabengesamtverantwortung für den Vereinigungsprozeß resultiert oder aus einer verwaltungskompetenzunabhängigen reinen Mitfinanzierungszuständigkeit, bedarf allerdings noch der weiteren Durchdringung ${ }^{11}$.

Die konkrete Umsetzung dieser jedenfalls finanzstaatlichen Bundesaufgabe stößt aus mehreren Gründen auf gewisse Schwierigkeiten: Zum einen, weil es jeweils der Bestimmung bedarf, ob und welche Aufgaben der neuen Länder sich nach Art und Umfang als besonders bereinigungsbedürftige Hinterlassenschaft des DDR-Regimes darstellen; zum anderen, weil sich der Bund bei der Bewältigung dieser Erblasten in einem entflechtungsbedürftigen Kondominium ${ }^{112}$ mit den gemäß Art. 104 a I GG zuvorderst verantwortlichen neuen Ländern sowie auch den bündisch verpflichteten Altländern befindet. Nun sind die gerade systembedingten Defizite in den neuen Ländern mit Händen zu greifen. Insoweit geht es also vor allem um die notwendige Gewichtung und die Prioritäten, die der Bund in koordinierendem Zusammenwirken mit den neuen Ländern zu setzen und im Rahmen seiner Finanzkraft unterstützend zu verwirklichen hat. Problematischer noch ist es, die finanzielle Mitverantwortung näher zu umreißen, die auch die alten Bundesländer - unbeschadet ihrer künftigen Regelpflichtigkeit im Rahmen des Finanzausgleichs - bei der Abtragung der DDR-Altlasten durch den Bund und damit bei der Angleichung der Lebensverhältnisse in den neuen Bundesländern an

111 Eine von einer (ungeschriebenen) Verwaltungszuständigkeit losgelöste (ungeschriebene) Finanzierungszuständigkeit lehnen im Hinblick auf den Konnexitätsgrundsatz in Art.104 a I GG ab Vogel, Grundzüge des Finanzrechts des Grundgesetzes, in: HStR, Bd.IV, 1990, $\$ 87$ Rdn. 25; Maunz (Fn. 63), 1977, Art. 104 a Rdn. 15; Henneke (Fn. 24), S. 46 Rdn. 212; Müller-Volbebr, Fonds- und Investitionshilfekompetenz des Bundes, 1975, S. 25. Das ist - wegen des seinerseits eben nicht eindeutig (verwaltungs-)aufgabenbezogenen Ausnahmevorbehalts in Art. 104 a I GG - durchaus problematisch; die Frage kann aber vorliegend nicht vertieft werden.

112 Zur Möglichkeit eines solchen vgl. auch Isensee (Fn. 40), $\$ 98 \mathrm{Rdn} .185$. 
das westdeutsche Niveau tragen ${ }^{113}$. Unzweifelhaft erscheint nur, daß die Altländer es verstanden haben, rechnet man für die Jahre 1991-1993 ihre Leistungen, insbesondere die aus dem Fonds „Deutsche Einheit" und die unmittelbar an die Ostländer erbrachten Hilfen, gegen die einigungsbedingten Steuermehreinnahmen auf ${ }^{114}$, „ihren Finanzierungsbeitrag in engen Grenzen zu halten"115.

Gewiß, gerade die bilateralen Hilfsmaßnahmen von Westländern an neue Bundesländer ${ }^{16}$ in Höhe von etwa $3 \mathrm{Mrd}$. DM in den genannten drei Jahren sind mit ihrer nicht seltenen Spontanität, obschon im Gesamtzusammenhang von eher untergeordneter Bedeutung, politisch auf der Habenseite des Vereinigungsprozesses zu verbuchen. Nur als „Verwaltungshilfen beim Aufbau der Landesverwaltung“ i.S. von Art. 15 II EV ${ }^{117}$ bewegen sie sich allerdings im Rahmen einer

${ }^{113}$ In diesem Sinne spricht bereits die dem Entwurf des Gesetzes über die Errichtung eines Fonds „Deutsche Einheit“ seinerzeit beigefügte Begründung im Grunde treffend (wenngleich nicht ganz präzise) von der $n$ gesamtstaatlichen Aufgabe" des deutschen Einigungsprozesses, insbesondere davon, daß „die Beteiligung der (sc. West-)Länder einschließlich der Gemeinden an den Lasten dem Gedanken der Solidargemeinschaft und ihrer gesamtstaatlichen Mitverantwortung innerhalb des sich bildenden gesamtdeutschen Bundesstaates Rechnung" trage (vgl. Stern/ Schmidt-Bleibtreu, Fn. 5, S. 309; vgl. ähnlich auch Sachverständigenrat, Fn.2, Jahresgutachten 1991/92, Tz. 329).

114 Vgl. dazu Karl-Bräuer-Institut des Bundes der Steuerzahler, Sonderinformation 13/1991, S. 16 m. Tabelle 2 des Anhangs; Sacbverständigenrat (Fn. 2), Jahresgutachten 1991/92, S. 135 f. mit Tabelle 36, S. 164 mit Tabelle 46.

115 Sachverständigenrat (Fn. 2), Jahresgutachten 1991/92, Tz. 328 ff. (334); ähnlich Frankfurter Institut für wirtschaftspolitische Forschung, Argumente zur Wirtschaftspolitik Nrn. 42/1992, S. 5, und 43/1992, S. 5; Karl-Bräuer-Institut (Fn. 114), S. 16; schärfer Möschel, Strukturwandel in den fünf neuen Bundesländern, JZ 1992, 489 (491), der u. a. von einem „unfaßbaren Egoismus der westlichen Bundesländer und der dazugehörenden Gemeinden“ spricht: „Sie agieren so, als ob nichts gewesen wäre“.

116 Sie reichen von der Abordnung von Beamten und Richtern auf Kosten des Entsendelandes über Personalkostenzuschüsse für Bedienstete des jeweiligen östlichen Partnerlandes bis zu direkten Leistungen, etwa auf den Gebieten der Denkmalpflege, des Natur- und Umweltschutzes sowie der Wissenschaft und Kultur; vgl. Meyer-Hesemann, Hilfen zum Aufbau von Verwaltung und Justiz in den neuen Ländern - Dargestellt am Beispiel der Zusammenarbeit zwischen den Ländern Brandenburg und Nordrhein-Westfalen -, VerwArch. 82 (1991), 578; Benz (Fn. 4), S. 593 ff.; Engel, Die Finanzverfassung im vereinten Deutschland und der Einigungsvertrag - Leistungen für die neuen Länder -, in: Stern (Hrsg.), Fn. 24, S. 169; Sachverständigenrat (Fn. 2), Jahresgutachten 1991/92, Tz. 330.

117 Vgl. zu dieser Bestimmung Stern/Schmidt-Bleibtreu, Einigungs- und Wahlvertrag, Verträge und Rechtsakte zur Deutschen Einheit, Bd.2, 1990, S. 140 f. 
verfassungsrechtlich zugelassenen Selbstkoordinierung der Länder. Diese deckt indes grundsätzlich keine Zwischenländerfinanzhilfen ${ }^{118}$. Sie verstoßen, wenn nicht auch gegen Art. 107 II GG und Art. 109 I GG, jedenfalls gegen die in Art. 104 a I GG angelegte Verpflichtung der in dieser Bestimmung angesprochenen Aufgabenträger, sich nicht an Aufgaben finanziell zu beteiligen, für deren Wahrnehmung sie keine Ausgabenlast tragen. Diese Verpflichtung gilt auch für das Verhältnis der Länder untereinander ${ }^{119}$. Die Überlegung, daß der den Art. $83 \mathrm{ff}$. GG immanente „Grundsatz eigenverantwortlicher Aufgabenwahrnehmung ${ }^{\alpha 120}$ in wesentlicher Weise entwertet würde, erlaubte man den Ländern, ihn durch - sehr wohl „politischen Einfluß" einschließende und "faktische Abhängigkeiten" schaffende ${ }^{121}$ - gegenseitige Finanzzuweisungen mittelbar zu unterlaufen, bestätigt dies. Die von der Normsituation des Art. 104 a I GG abweichende Notlage in den neuen Ländern mochte vorübergehend eine gewisse Abmilderung der grundgesetzlichen Sicherungen gestatten ${ }^{122}$. Das schließt nunmehr die Forderung nicht aus, direkte Subsidien von Westländern an neue Bundesländer mit zeitlichem Fortgang degressiv $\mathrm{zu}$ gestalten und so rasch als möglich ${ }^{123}$ ganz entfallen zu lassen. Demgegenüber unterliegt keiner verfassungsrechtlichen Kritik, daß der Bund versucht, die Westländer insgesamt auf die finanzielle Beteiligung an hinreichend präzise umrissenen Erblasten der Ostländer zu verpflichten ${ }^{124}$.

${ }_{118} \mathrm{Zu}$ ihrer verfassungsrechtlichen Problematik demnächst eingehender ein Festschriftbeitrag des Verf.

119 Art. 104 a I GG ist zwar insoweit dem Wortlaut nach nicht eindeutig. Aus seiner Entstehungsgeschichte sowie aus der hierin und in anderen Zusammenhängen erkennbaren Ratio des in ihm grundsätzlich verwirklichten Konnexitätsprinzips ergibt sich aber, daß in der Grundnorm des Art. 104 a I GG neben der vertikalen auch die horizontale Dimension gleichsam "mitgeregelt" wird.

120 BVerfGE 63, 1 (41) im Anschluß an Grawert, Verwaltungsabkommen zwischen Bund und Ländern, 1967, S. 195; s. dazu auch Lerche (Fn. 10), Art. 83 Rdn. 26 Fn. 93.

121 Benz (Fn. 4), S. 595.

122 So für einen "Beistand in Notfällen“ auch Fischer-Menshausen (Fn. 73), Art. 107 Rdn. 6, Art. 109 Rdn. 5.

${ }^{123}$ Spätestens aber mit Ablösung der für die neuen Bundesländer bis Ende 1994 geltenden Übergangsfinanzverfassung.

${ }_{124}$ Vgl. zur Diskussion FAZ v. 3.7.1992, S. 5 („Diese Erbschaft treten wir nicht an“); v. 4.7.1992, S.4 (Die Finanzminister gegen die vorgesehene Regelung der Altschulden); v. 8.7.1992, S.10 (Ein brauchbares Modell); zuletzt FAZ v. 2.11.1992, S. 15 (400 Milliarden DM Schulden als Erblast der DDR). 
Die beschriebene Aufgabenlast des Bundes und die finanzielle Mitverantwortung der Westländer für die die neuen Länder treffende Bereinigung ihres Erbes bestehen grundsätzlich unabhängig von einer ausdrücklichen verfassungsgesetzlichen Zuweisung. Gleichwohl ist deren Fehlen angesichts der in Rede stehenden Beträge ein gewiß ausgleichsbedürftiger Mangel. Das folgt aus der grundlegenden bundesstaatlichen "Ordnungsfunktion der Finanzverfassung " 125 ebenso wie aus der Notwendigkeit, bei einer Neufestsetzung der Umsatzsteueranteile von Bund und Ländern gemäß Art.106 IV GG die Entwicklung der sogenannten Deckungsquoten, in deren Bestimmung neben den "laufenden Einnahmen" die "notwendigen Ausgaben" eingehen, inhaltlich zu konkretisieren ${ }^{126}$. Es erscheint deshalb, wenn nicht sogar verfassungsrechtlich geboten, so doch jedenfalls naheliegend, die genannten Vereinigungslasten von Bund und Westländern ${ }^{127}$ in einer besonderen Verfassungsvorschrift nach Verwaltungs- und Finanzverantwortung $\mathrm{zu}$ verdeutlichen. Als geeigneter Standort dieser "Kriegsspätfolgelasten“ (Milbradt ${ }^{128}$ ), „Teilungsfolgelasten“ (H.P. Schneider ${ }^{129}$ ) oder, wie man schlicht sagen könnte, „DDRAltlasten" bietet sich im Anschluß an die Kriegsfolgelasten der Art. 120 und 120 a GG ein neuer Art.120 b GG an. Die nähere Regelung könnte einem einfachen Bundesgesetz überlassen bleiben, das ${ }^{130}$ der Zustimmung des Bundesrates zu unterwerfen wäre. Ihm obläge es zweckmäßigerweise auch, eine Einbeziehung der Bürger in die Verantwortung für die Ausräumung der DDR-Altlasten ins Werk zu setzen ${ }^{131}$.

Das Verfassungsrecht setzt der Einforderung einer solchen individuellen Mitverantwortung bei den Bürgern der erweiterten Bundesre-

${ }^{125}$ BVerfGE 72, 330 (388).

$126 \mathrm{Vgl}$. grds. zur Ausfüllungsbedürftigkeit dieser "Leerformeln" jetzt auch Sacbverständigenrat (Fn.2), Jahresgutachten 1991/92, Tz.334; s. dazu bereits Geiger, Zur Auslegung des Begriffs „notwendige Ausgaben“ in Art. 106 III S. 4 Nr.1 GG, in: Festschrift für Maunz, 1981, S. 89; Wendt (Fn. 4), \$104 Rdn. 56.

${ }_{127} \mathrm{Vgl}$. bei und in Fn. 99.

${ }_{128}$ Wiedergegeben in FAZ v. 8.7.1992, S. 4 („Die Lasten für den Westen werden größer und von längerer Dauer sein").

129 Fn. 4, S. 2455; s. a. Franke (Fn. 4), S. 311 (323); ders. (Fn. 4), S. 526 (542).

130 Auch im Hinblick darauf, daß schon die abschließende gesetzliche Regelung der DDR-Altschulden durch besonderes Gesetz gem. Art. 34 des Vertragsgesetzes v. 25.6.1990 mit Zustimmung des Bundesrates zu treffen ist (s.a. $\$ 11$ Kreditabwicklungsfondsgesetz).

${ }_{131}$ Zum Entwicklungsstand der Verantwortungsbereitschaft im Sommer 1992 vgl. Köcher, Opfern fällt den Westdeutschen schwer, FAZ v. 8.7.1992, S. 5. 
publik - also nicht nur bei denen der Westländer, der Gedanke des "Lastenausgleichs" ${ }^{\text {"132 }}$ paßt im vorliegenden Zusammenhang nicht ${ }^{133}$ - keinen Widerstand entgegen. Das gilt nicht nur für etwaige Erhöhungen der Steuersätze und eine Ergänzungsabgabe ${ }^{134}$. Auch eine sozialstaatsgerecht ausgestaltete „einmalige Vermögensabgabe“ i.S. des Art. 106 I Nr. 5 GG ${ }^{135}$ erscheint grundsätzlich verfassungsgerecht, hätte allerdings im Hinblick auf den allgemeinen Gleichheitssatz (Art. 3 I GG) das immer noch unerledigte Problem der Unterbewertung des Grundvermögens zu verarbeiten. Nur schwer verwirklichen läßt sich dagegen der vor einiger Zeit zuerst von wirtschaftswissenschaftlicher Seite ${ }^{136}$ gemachte Vorschlag einer auf den Westen beschränkten zinslosen Zwangsanleihe ${ }^{137}$. Denn der Weg zu ihr ist gegenwärtig nur über den schmalen Einlaß einer im Rahmen der Sachgesetzgebungskompetenzen sich bewegenden Sonderabgabe grundsätzlich offen ${ }^{138}$. Deren besondere Voraussetzungen ${ }^{139}$, insbesondere die der sachkompetenzgerechten gesetzlichen Ausgestaltung der Abgabe und die der "gruppennützigen" Verwendung des Auf-

${ }^{132} \mathrm{Zu}$ einer entsprechenden Anregung des Bundespräsidenten vgl. FAZ v. 22.5.1992, S. 15 (Weizsäcker für neuen Lastenausgleich zugunsten der neuen Länder).

133 Vgl. krit. auch Fromme, "Lastenausgleich“ paßt heute nicht, FAZ v. 25.5.1992, S.14; s. a. Barbier, Im Namen der Gerechtigkeit, FAZ v. 23.5.1992, S. 13; a. A. Kilian (Fn. 4), S. 431.

${ }_{134}$ Zur Verfassungsmäßigkeit des vom 1.7.1991 bis 30.6.1992 erhobenen Solidaritätszuschlags (s. Art. 1 des Solidaritätsgesetzes v. 24.6.1991, BGBI.I S. 318) vgl. Arndt, Die Rückwirkungsproblematik im Entwurf zum Solidaritätsgesetz, BB 1991, 877; Wieland, Solidarität gegen Vertrauen, StVj. 1992, 97; K. R. Wagner, Zur verfassungsrechtlichen Beurteilung des Solidaritätszuschlages, BB 1992, 2043; aus der Judikatur BFH, NJW 1992, 2655; zu seinem Auslaufen s. a. BFM, Finanznachrichten $64 / 92$ v. 6.7.1992, S. $1 \mathrm{f}$.

$135 \mathrm{Zu}$ ihrem (über den Lastenausgleich hinausgehenden) Anwendungsbereich s. näher Selmer, Steuerinterventionismus und Verfassungsrecht, 1972, S.330 ff.; Maunz (Fn. 63), 1978, Art. 106 Rdn. 27; a.A. Vogel/Walter (Fn. 91), Art. 106 Rdn. 237.

S. 15.

${ }_{136} \mathrm{Vgl}$. Albach, Für die Einheit eine zinslose Zwangsanleihe, FAZ v. 6. 7.1992,

137 Vgl. FAZ v. 26.8.1992, S. 4 (Investitionsanleihe für die neuen Länder verlangt).

138 BVerfGE 67, 256 (274ff.).

$139 \mathrm{Vgl}$. zum Stand der verfassungsrechtlichen Diskussion näher Selmer, Umweltschutz durch Abgaben und Steuern - Verfassungsrechtliche und finanzrechtliche Rahmenbedingungen -, in: Breuer/Kloepfer/Marburger/Schröder (Hrsg.), Umwelt- und Technikrecht Bd. 16, 1992, S. 15 (44-51 m. weit. Nachw.). 
kommens, werden sich indes vorliegend kaum überzeugend verwirklichen lassen ${ }^{140}$.

\section{Verfassungsrechtspolitischer Ausblick}

Es bleibt die verfassungsrechtspolitische Frage: Sollte die Finanzverfassung die Favorisierung des Einheitlichkeitsgedankens wie bisher auch künftig jedenfalls ermöglichen, oder sollten die Weichen unter Einleitung einer Entflechtung der vertikalen und horizontalen Finanzbeziehungen von Bund und Ländern deutlich in Richtung eines mehr kompetitiven Finanzföderalismus gestellt werden? Der gegenwärtige Diskussionsstand ${ }^{141}$ neigt, nimmt man den Bund aus, weit überwiegend so nachhaltig der letzteren Auffassung zu, daß es schwerfällt, dagegenzuhalten. Gleichwohl lautet meine These: Für eine Kursänderung der föderativen Finanzverfassung im Sinne einer entschiedenen Stärkung der Finanzautonomie der Länder im jetzigen Zeitpunkt ist es zu spät und zu früh zugleich: Zu spät, weil offenbar das „Gesetz der antizipierenden Reaktion " ${ }^{142}$ die Beteiligten bis zur Herstellung der deutschen Einheit daran gehindert hat, die seit Mitte der 70er Jahre diskutierte Entflechtung der föderativen Finanzverfassung ernsthaft zu betreiben, zu früh, weil nach Beitritt der neuen Länder die schon bisher zwischen den Bundesländern bestehenden Disparitäten bei Einräumung größerer Finanzautonomie, etwa bei Überlassung eines Zuschlagsrechts zur entsprechend gesenkten Einkommen- und Körperschaftsteuer, noch zunehmen müßten ${ }^{143}$. Denn jedenfalls die extrem finanzschwachen neuen Länder, wenn nicht selbst einige der alten, wären kaum in der Lage, diese finanzwirtschaftliche Gestaltungsfreiheit abwägend zu nutzen. Sie müßten sich - vor der Wahl, durch Steuerverzicht Gewerbe- und Industrieansiedlungspolitik zu betreiben oder den finanziellen Notwendigkeiten zu gehorchen regelmäßig für eine extensive fiskalische Ausnutzung ihrer Möglich-

140 Zum Ersatzmodell einer (freiwilligen) „niedrig verzinslichen, aber dafür steuerbefreiten ,Deutschland-Anleihe ${ }^{\iota \star}$ vgl. BMF, Finanznachrichten 82/92 v. 3. 9. 1992, S. 1-3.

$141 \mathrm{Vgl}$. bei und in Fn. 14, 15, 22, $29 \mathrm{ff} ., 54,81$ und 84.

${ }_{142}$ Das (vgl. Scharpf, Fn. 4, S. 152, unter Hinweis auf C.J. Friedrich, Constitutional Government and Politics, 1937) „intelligente Leute daran hindert, Vorhaben ernsthaft zu betreiben, die bei notwendigen anderen Beteiligten auf Ablehnung stoßen müssen“.

${ }^{143}$ Vgl. so im Ergebnis auch Benz (Fn. 4), S.597; Scharpf (Fn. 4), S. 151; Littmann (Fn. 4), S. 42; Wieland (Fn. 2), S. 1187. Vgl. aber auch Fn. 144. 
keiten entscheiden und gerieten damit in einem Konkurrenzföderalismus noch mehr ins wirtschaftliche Abseits ${ }^{144}$.

Damit stelle ich keineswegs in Frage, ohne das selbst weiter zu vertiefen, daß für die Stärkung der Finanzautonomie der Länder gute Gründe ihrer Eigenstaatlichkeit sprechen. Sie wird durch die Asymmetrie in den finanzverfassungsrechtlichen Regelungen über die Ausgaben- und die Einnahmenverantwortung sowie die Vermengung der Finanzierungslasten von Bund und Ländern in der Tat nachhaltig in Mitleidenschaft gezogen. Aber das Prinzip bündischer "Einheit ${ }^{\text {“145 }}$ gebietet, vor allem die neuen Bundesländer erst dann - ausgestattet mit einer erweiterten Finanzautonomie - in einen verstärkten Wettbewerb zwischen den Ländern und damit potentiell auch in eine größere Vielfalt der Lebensverhältnisse zu entlassen, wenn zuvor die enormen strukturellen Unterschiede angemessen abgebaut worden sind und damit eine gewisse Annäherung der Startbedingungen erreicht ist. Einer durchgreifenden Entflechtung der föderativen Finanzbeziehungen sollte deshalb eine etwa 10jährige Übergangsfrist vorangehen, in deren Verlauf die Länder je nach dem Stand der Entwicklung allmählich an eine größere Finanzautonomie herangeführt werden. Wie könnte ein solcher behutsamer Übergang aussehen?

Im Interesse eines ersten horizontalen Angleichungseffekts zugunsten der strukturschwachen, überdurchschnittlich mit Arbeitslosigkeit beschwerten Länder - das sind nicht nur die neuen Bundesländer sollte eine teilweise Ausgabenverlagerung der Sozialhilfe ${ }^{146}$ auf den

144 Diesen Gesichtspunkt zu gering gewichtend vgl. Sachverständigenrat (Fn. 2), Jahresgutachten 1990/91, Tz. 441, 445; Jahresgutachten 1991/92, Tz. 325; Peffekoven (Fn. 4), S. 181 (223 f.); ders. (Fn. 4), S. 346 (352); ders. (Fn. 4), S. 485 (505). Daß es „schon heute einen Subventionswettlauf zwischen den Ländern gibt, aus dem in der Regel die finanzstarken Länder als Sieger hervorgehen", kann (entgegen Peffekoven, a. a. O.) der obigen Argumentation schwerlich überzeugend entgegengehalten werden. Einlenkend denn auch ders., Fn.4, S. 485 (506), es gäbe "gute Gründe, den steuerpolitischen Wettbewerb zwischen den Ländern erst dann zuzulassen, wenn die enormen regionalen Disparitäten zuvor abgebaut worden sind und damit Chancengleichheit und faire Startbedingungen geschaffen worden sind"; in letzterem Sinne vgl. auch Milbradt (Fn. 4), S. 314 f.; Littmann (Fn.4), S. 42.

${ }_{145} \mathrm{Zu}$ ihm vgl. näher H.P. Schneider (Fn. 4), S. 2451 f.

${ }^{146}$ Zur gegenwärtigen Verteilung der Sozialhilfekosten auf die Gebietskörperschaften vgl. Klanberg/Prinz, Anatomie der Sozialhilfe, Finanzarchiv n. F. 41 (1983), 281 (300ff.); Prinz, Die Finanzierung der Sozialhilfe im Finanzverbund zwischen Bund, Ländern und Gemeinden, Finanzarchiv n.F. 41 (1983), 431; 
Bund erwogen werden ${ }^{147}$. Damit wäre - beschränkte man dies auf die nach bestimmten Richtgrößen pauschalierte Erstattung der laufenden Hilfen zum Lebensunterhalt, soweit sie Transfercharakter haben zugleich ein erster wichtiger Schritt zur Überführung der vom Bund gesetzlich vorgeschriebenen Geldleistungen in dessen alleinige Finanzverantwortung ${ }^{148}$ getan. Der in verschiedenen Bereichen bereits eingeleitete allmähliche Rückzug des Bundes aus den Gemeinschaftsaufgaben (i.w. S.) ${ }^{149}$ sollte grundsätzlich vorsichtig fortgesetzt werden ${ }^{150}$. Während der vorgeschlagenen Übergangszeit aufrechterhalten werden sollten die regionalpolitischen Mischfinanzierungen im Rahmen der Art. 91 a I Nr. 2 und 104 a IV GG. Sie sind seit jeher in ihrer Wirkung dem Gedanken der „Einheitlichkeit der Lebensverhältnisse“ in besonderer Weise entgegengekommen ${ }^{151}$. Daher lassen sie sich, bei allerdings verfassungsrechtlich gebotener Gleichbehandlung der strukturschwachen alten Bundesländer ${ }^{152}$, vorläufig gerade auch zur

Patzig, Zur Zielsetzung und Problematik der Pauschalierung von Finanzausgleichsleistungen, DÖV 1987, 1088 (1093 ff.); ders. (Fn. 24), S. 331 f.; Albers, Grundsätze der Aufgabenverteilung, in: Kitterer (Hrsg.), Fn. 4, S.1; HofmannHoeppel, Die (finanz-)verfassungsrechtliche Problematik des BSHG-Vollzugs durch kommunale Gebietskörperschaften, 1992, insb. S. $139 \mathrm{ff}$.

147 Vgl. auch Peffekoven (Fn. 4), S. 181 (222, 224); Scharpf (Fn. 4), S. 149; H.P. Schneider (Fn.4), S.2455; Wieland (Fn. 2), S. 1186; letztlich unentschieden Albers (Fn. 146), S. 3 f.; Fischer (Fn. 53), S. 133 ff.; Milbradt (Fn.24), S. 155 f., 157 ff.; Kitterer (Fn. 24), S. $188 \mathrm{ff}$.

${ }_{148}$ Vgl. mit dieser Tendenz etwa auch Heinsen (Fn. 22), S. 240f.; Peffekoven (Fn. 4), S. 181 (224); Scharpf (Fn. 4), S. 148; Wieland (Fn. 2), S. 1185; Sachverständigenrat (Fn. 2), Jahresgutachten 1990/91, Tz. 457.

149 Vgl. dazu Klatt (Fn. 20), S. 202 ff.; Peffekoven (Fn. 4), S. 181 (224); Kitterer (Fn. 24), S. 189; Birk, AKGG, 2. Aufl. (1989), Art. 104 a Rdn. 19; s. a. Sachverständigenrat, Jahresgutachten 1990/91, Tz. 457; Jahresgutachten 1991/92, Tz. 325.

150 Bei ihrer gebotenen Ersetzung durch eine anderweite Finanzkraftverstärkung der Länder sollten dann freilich ihre horizontalen Ausgleichswirkungen, d.h. ihre - vom BVerfG zunehmend tolerierten - Finanzausgleichswirkungen (vgl. BVerfGE 72, 330, 388; BVerfG, DVBl.1992, 965, 978; deutlich zurückhaltender noch BVerfGE 39, 96, 108) mit berücksichtigt werden; vgl. auch Geske, in: Bundesrat (Hrsg.), (Fn.4), S. 98 f.; Fischer-Menshausen (Fn.22), S. 171 f.; Klatt (Fn. 20), S. 205 f.

$151 \mathrm{Vgl}$. oben bei und in Fn. 47.

152 Vgl. BVerfGE 39, 96 (119f.); 41, 291 (308). Eine prinzipielle Beschränkung der Förderung auf die ostdeutschen Länder bedürfte daher einer Verfassungsergänzung (a. A. offenbar Wieland, Fn. 2, S.1193). Im Einklang mit dem föderativen Gleichbehandlungsgebot stünde es dagegen, die Förderung auf alle (!) Länder in extremer Haushaltsnotlage zu beschränken (so überzeugend BVerfG, DVBl. 1992, $965,978)$. 
Förderung der inneren Einheit der Bundesrepublik sinnvoll einsetzen. Sollte sich die Überzeugung bilden, daß die leistungsschwachen Länder insbesondere der früheren DDR durch den 50prozentigen Anteil der Sitzländer an der Finanzierung der Gemeinschaftsaufgabe übermäßig belastet werden, wäre in Anlehnung an eine Empfehlung der Troeger-Kommission auch eine teilweise Umlegung dieses Anteils auf die anderen Länder nach Maßgabe ihrer Steuerkraft in Betracht zu ziehen ${ }^{153}$. Einer substantiellen fiskalischen Entflechtung vorangehen könnte im Rahmen der geltenden Finanzverfassung am Ende der Übergangszeit schließlich ein erster Versuch größerer Steuerautonomie - so etwa der, jedenfalls eine der reinen Ländersteuern der konkurrierenden Bundessteuergesetzgebung - die Kraftfahrzeug-, die Vermögens- oder die Grunderwerbsteuer - hinsichtlich der Tarifgestaltung teilweise den Ländern zu überlassen ${ }^{154}$.

\section{Der Grundsatz einer bundesstaatsgerechten Finanzausstattung der Länder}

\section{Vorbemerkung}

Eine weitere Sicht des Themas tut sich auf, rückt man seine bundesstaatliche Dimension deutlicher in den Vordergrund. Nur ihrem horizontalen Aspekt werde ich mich im folgenden zuwenden. Bei ihm geht es um die Modalitäten der in der Finanzverfassung (vgl. insb. Art. 104 a I-III, IV, 107 I S. 4, 107 II, 109 I GG) angelegten Forderung, die einzelnen Länder so am Finanzaufkommen im Bundesstaat zu beteiligen, daß alle, also auch die schwächeren von ihnen, in der Lage sind, ihre verfassungsmäßigen Aufgaben sachgerecht wahrzunehmen und eine selbständige Haushaltswirtschaft zu führen. An einer inhaltlichen Präzisierung der Ausgleichsfunktion dieses Auftrages, die mit Wirkung ab 1.1.1995 auch für die neuen Länder uneingeschränkt Geltung beansprucht, läßt es die Finanzverfassung weitgehend fehlen. Sie beschränkt sich darauf, dem Bundesgesetzgeber die notwendigen Annäherungsinstrumente an die Hand zu geben. Die dem Länderfinanzausgleich als einer Konkretisierung des Bundes-

153 Vgl. zur Begründung Troeger-Kommission (Fn. 9), Tz. 208, 298 ff.

154 Dabei werden aber auch etwaige Ausweichreaktionen der Steuerpflichtigen und die gegebenenfalls eher für eine bundeseinheitliche Regelung sprechende interventionistische Ausgestaltung der betreffenden Steuer, etwa eine umweltpolitische Anreicherung der $\mathrm{Kfz}$-Steuer, zu bedenken sein. 
staatsprinzips eigentümliche Spannungslage von Eigenstaatlichkeit und Eigenverantwortlichkeit der Länder einerseits und wechselseitiger bündischer Solidarpflichtigkeit andererseits ${ }^{155}$ konkretisierend zum Ausgleich zu bringen, bleibt hingegen im Rahmen der verfassungsrechtlichen Vorgaben dem einfachen Gesetzgeber überlassen ${ }^{156}$.

Bei der Diskussion der diesem durch die Finanzverfassung gezogenen Richtlinien haben sich als besonders problematisch die Fragen erwiesen, die mit dem Finanzbedarf zusammenhängen, den die Länder als zur Wahrnehmung ihrer Aufgaben notwendig und damit als finanzausgleichserheblich annehmen. Angesiedelt sind sie wesentlich im horizontalen Finanzausgleich (Art. 107 II S. 1, 2 GG) und bei den Bundesergänzungszuweisungen (Art. 107 II S. 3 GG). Dabei kommt, zumal nach dem Beitritt der um ihre Existenz ringenden neuen Bundesländer, besondere Bedeutung dem auch in der Finanzwissenschaft zunehmend diskutierten Problem der „Sonderbedarfe“ zu, die einzelnen Ländern über ihren allgemeinen Finanzbedarf hinaus aufgrund atypischer Besonderheiten entstehen; ich nehme aus dem Fundus der von den Ländern als solche angemeldeten Sonderbedarfe nur die Stichworte: Küstenschutz, Kohle, Sozialhilfe, Arbeitslosigkeit, Hochschulen - allesamt Lasten betreffend, die in der außerordentlichen Höhe oder überhaupt nur in einigen Ländern anfallen; weitere Sonderbedarfskategorien vor allem struktureller Art werden im Zusammenhang mit der Etablierung eines gesamtdeutschen Länderfinanzausgleichs von den neuen Ländern in die Diskussion eingebracht werden.

\section{Insbesondere: Der Länderfinanzausgleich}

\section{Grundsätzliche Aufgaben- und Bedarfsbezogenheit des Finanzausgleichs}

Ausgangspunkt ist, daß der Finanzkraftausgleich des Art. 107 II S. 1, 2 GG kein reiner Ertragskraftausgleich ist. Da er entsprechend der Funktion des Finanzausgleichs nur auf die Aufgabenerfüllung bezogen und damit legitimiert werden kann, die Aufgabenerfüllung aber zu einem Ausgabenbedarf (= Finanzbedarf) führt, ist er vielmehr

$155 \mathrm{Vgl}$. auch Ossenbühl (Fn. 53), S. 22.

156 Vgl. das Gesetz über den Finanzausgleich zwischen Bund und Ländern i.d.F. der Bekanntmachung v. 28.1.1988 (BGBl. I S. 94), zuletzt geändert durch Gesetz v. 16.3.1992 (BGBl. I S. 674). 
von Verfassungs wegen auch bedarfsbezogen ${ }^{157}$. Dem trägt das geltende einfache Finanzausgleichsrecht dadurch Rechnung, daß nicht die Erträge der Länder in ihrer absoluten Höhe Grundlage des Finanzkraftvergleichs sind, sondern zur jeweiligen Zahl der Bewohner in Beziehung gesetzt werden ( $\$ \$ 6 \mathrm{II}, 9 \mathrm{FAG}$ ). Die Einführung gerade dieses Vergleichsmaßstabs erscheint naheliegend: Die den Ländern obliegenden öffentlichen Leistungen sind gegenüber ihren Einwohnern zu erbringen. Aus diesem Grund ${ }^{158}$ bildet die Einwohnerzahl einen grundsätzlich angemessenen Bezugspunkt für den vergleichserheblichen Finanzbedarf ${ }^{159}$.

Die Notwendigkeit einer hiervon abweichenden Betrachtung ergibt sich in zwei Fällen - einmal, wenn und soweit die Einwohnerzahl als Bedarfsmaßstab für die Aufgabenerfüllung ausnahmsweise von vornherein keine überzeugende Aussagekraft besitzt, zum anderen, wenn sie allein sich auch bei gebotener generalisierender und typisierender Betrachtungsweise als ein zwar grundsätzlich geeigneter, aber zu grob rasternder Indikator herausstellt, der daher von Verfassungs wegen der Verfeinerung bedarf.

\section{Finanzkraft und Finanzbedarf im borizontalen Finanzausgleich}

Als Anwendungsfall der ersteren Konstellation hat das BVerfG bekanntlich die Stadtstaaten ausgewiesen und in diesem Zusammenhang 1986 die Modifizierung der Einwohnerzahl als Bezugspunkt dort für gerechtfertigt gehalten, wo die Angemessenheit dieses Vergleichsmaßstabs „aus vorgegebener struktureller Eigenart von Ländern" von vornherein entfalle ${ }^{160}$. Diese Formel hat das Gericht in seiner jüngsten Entscheidung zum Länderfinanzausgleich dahin präzisiert, daß nur die „unverfügbar“ vorgegebene strukturelle Eigenart eines Landes finanzkrafterheblich i.S. des Art. 107 II S. 1 GG sei ${ }^{161}$.

157 Vgl. Selmer/Brodersen (Fn. 66), S.27; Friauf, Der bundesstaatliche Finanzausgleich, JA 1984, 618 (624).

$158 \mathrm{Vgl}$. aber a. A. Wendt (Fn. 4), $\$ 104$ Rdn. 78; Renner (Fn. 48), S. 339.

159 Vgl. im Ergebnis auch BVerfGE 72, 330 (400 f.); BVerfG, DVBl. 1992, 965 (972f.).

160 BVerfGE 72, 330 (401, 414 f.); zu den finanzausgleicherheblichen Besonderheiten der Stadtstaaten vgl. Selmer/Brodersen (Fn. 66), S. 45 ff.; Schuppert/Dahrendorf, Verfassungsrechtliche und finanzwissenschaftliche Aspekte des Länderfinanzausgleichs, 1985, S. $62 \mathrm{ff}$.

161 BVerfG, DVBl. 1992, 965 (973). 
Damit hat es der Einbringung konkreter strukturspezifischer Bedarfsprobleme einzelner Länder in den horizontalen Finanzausgleich endgültig einen Riegel vorgeschoben. Im Ergebnis ist das nicht zu beanstanden $^{162}$. Entscheidend für diese Bewertung ist allerdings nicht so sehr die gewiß sachgerechte Ambition, in dem besonders sensiblen und konfliktträchtigen horizontalen Finanzausgleich einen Bedarfswettlauf der Länder auszuschließen ${ }^{163}$ - der sich nunmehr bei den Bundesergänzungszuweisungen abspielt. Auch steht - in welcher Frage ich entgegen der 1986 vom BVerfG vertretenen Auffassung ${ }^{164}$ an einer früheren Darlegung festhalte - der Text des Art. 107 II S. 1 GG im Lichte seiner Entstehungsgeschichte einem Aufwerfen auch von Bedarfsfragen nicht grundsätzlich entgegen ${ }^{165}$.

Der Ausschluß konkreter strukturspezifischer Bedarfe einzelner Länder erscheint aber aus einem anderen Grunde als berechtigt: Traditioneller Ausgangspunkt des Länderfinanzausgleichs ist der Gedanke, daß aufgrund der "regional differenzierten Wirtschafts-, Verkehrs- und Siedlungsstruktur" der Bundesrepublik „einige Länder finanziell überdurchschnittlich ausgestattet sind", während die finanziell schlechter ausgestatteten Länder „ihre Aufgaben ohne fremde Hilfe nicht angemessen erfüllen können "166. Gegenstand und Ziel des Finanzausgleichs ist also der angemessene Ausgleich einer strukturbedingt unterschiedlichen Finanzausstattung, d. h. aber Einnahmekraft der Länder. Nicht gehört es danach zu seiner grundsätzlichen Funktion, weitere auftauchende Nachteile von Strukturschwächen, etwa konkrete strukturbedingte Sonderbedarfe einzelner Länder ebenfalls einzubeziehen und damit im Grunde deren Strukturschwäche selbst zum Gegenstand bündischen Solidarausgleichs zu machen.

162 Vgl. krit. zur Bewältigung von Strukturproblemen im Rahmen des horizontalen Finanzausgleichs aus ökonomischer Sicht insb. Peffekoven, Finanzausgleich und Sonderbedarfe, in: Bea/Kitterer (Hrsg.), Festschrift für Pohmer, 1990, S. 323 (335ff.); ders. (Fn. 4), S. 181 (204ff.); a. A. insoweit vor allem Kops (Fn. 26), S. $111 \mathrm{ff}$., $215 \mathrm{f}$., dabei vor allem auf die Unterscheidung zwischen von einem Land selbst verursachten (internen) und nicht selbst verursachten (externen) Bedarfen unterscheidend (s. dazu die Besprechung von Peffekoven, Finanzarchiv n. F. 48, 1990, S. 342).

163 Vgl. Peffekoven (Fn. 4), S. 181 (205); Franke (Fn.4), S. 311 (315 Fn. 43).

164 Vgl. BVerfGE 72, 330 (401 f.).

165 Selmer/Brodersen (Fn.66), S.31 ff.; übereinstimmend vgl. Ossenbühl (Fn.53), S. 51 ff.; Schuppert/Dabrendorf (Fn. 160), S.36ff.; s. a. Friauf (Fn. 157), S. $623 \mathrm{ff}$.

166 Troeger-Gutachten (Fn. 9), Tz. 277, 279; vgl. ferner etwa Fischer-Menshausen (Fn. 3), S. 654 f.; Isensee (Fn. 15), S. 273. 
Das heißt: Disparitäten in der Wirtschafts-, Verkehrs- und Siedlungsstruktur der Länder sind nach der Annäherung ihrer strukturbedingt unterschiedlichen Finanzausstattung als finanzausgleichsrelevante Gesichtspunkte grundsätzlich verbraucht.

Das gilt auch für die neuen Bundesländer. Die Größenordnung der von ihnen zugrunde zu legenden Finanzbedarfe rechtfertigt es nicht, vom Grundsatz der Berücksichtigungsunfähigkeit strukturell indizierter konkreter Bedarfe im Länderfinanzausgleich abzusehen ${ }^{167}$. Abgemildert wird dies dadurch, daß sie sich ihrer besonders drückenden „DDR-Altlasten“ zu einem guten Teil bereits durch die von der Verfassung getragene Mitverantwortung der anderen Aufgabenträger enthoben sehen, von der ich in anderem Zusammenhang ${ }^{168}$ gesprochen habe. Die insoweit von Bund und Westländern zugunsten der neuen Länder jeweils erbrachten Leistungen sollten dann andererseits aber auch, wie hinzuzufügen ist, bei der Ermittlung der Finanzkraft der letzteren ganz oder teilweise in Ansatz gebracht werden ${ }^{169}$. Das gebietet nicht nur eine sinnvolle aufgabenerfüllungsbezogene Anwendung des Finanzkraftbegriffs ${ }^{170}$, sondern auch die Einsicht, daß es gilt, eine ansonsten drohende explosionsartige Ausweitung des Ausgleichsvolumens auf etwa 25-30 Mrd. DM, verbunden mit einer einseitigen West/Ost-Verlagerung des Länderfinanzausgleichs ${ }^{171}$, zu vermeiden.

Bleiben einerseits strukturbegründete besondere Finanzbedarfe im horizontalen Finanzausgleich grundsätzlich außer Betracht ${ }^{172}$, so ist

\footnotetext{
167 A. A. Kilian (Fn. 4), S. 430.

168 Vgl. oben unter B III.

$169 \mathrm{Vgl}$. entspr. Erwägungen auch bei H.P. Schneider (Fn. 4), S. 2455; Kommission Finanzverfassungsreform des Landes Baden-Württemberg (Fn.63), S.78f.; Geske (Fn. 35), S.254f.

170 Für eine solche vgl. auch BVerfG, DVBl. 1992, 965 (967).

171 Zur Problematik des gesamtdeutschen horizontalen Finanzausgleichs vgl. (mit unterschiedlicher Tendenz) Peffekoven (Fn. 4), S. 485 (496 ff.); Korioth (Fn. 4), S. 1053 ff.; Kilian (Fn. 4), S. 429 ff.; H. P. Schneider (Fn. 4), S. 2455; Geske (Fn. 35), S. 256 ff.; Hobmann (Fn. 55), S. 197.

${ }^{172}$ Vernachlässigt werden hier die insgesamt mehr peripheren Bedarfsprobleme, die aus sog. Nutzenstreuungen, d. h. daraus resultieren, daß bestimmte Leistungen eines Landes positive Auswirkungen auch auf die Angehörigen anderer Länder haben (Spillover-Effekte bzw. externe Effekte). Das Grundgesetz berücksichtigt diese Effekte bisher nicht besonders, geht also implizite davon aus, daß Nutzenstreuungen dem Bundesstaat immanent sind und sich im allgemeinen bei typisierender Betrachtung gegenseitig ausgleichen. Das schließt freilich von Verfassungs wegen nicht aus, daß dort, wo sich ein abschätzbarer Saldo zu Lasten des leistenden
} 
der Begriff der Finanzkraft i. S. des Art. 107 II GG andererseits auch nicht der Ort, den rational wirtschaftenden Ländern die Vorteile dieser ihrer Politik zu sichern - etwa dadurch, daß den weniger ökonomisch agierenden Bundesländern Aufschläge auf ihr tatsächliches Finanzaufkommen angelastet werden. Im Rahmen des angemessenen horizontalen Finanzausgleichs gehört die gegenseitige Tolerierung autonomer, sei es auch objektiv verfehlter Prioritäts- und Dringlichkeitsentscheidungen grundsätzlich zu den politischen Kosten des Bundesstaates ${ }^{173}$. Sollte sich allerdings im Zusammenhang mit einer fiskalischen Entflechtung das Vorhaben einer größeren Steuerautonomie der Länder verwirklichen, wird von Verfassungs wegen auch zu prüfen sein, welches $\mathrm{Maß}$ an Steueranspannung den Ländern bei der Aktualisierung ihrer potentiellen Finanzkraft zugerechnet werden muß. Gegenwärtig wird vor allem zu überlegen sein, ob bundesgesetzliche Steuervergünstigungen, die nur in den neuen Bundesländern gewährt werden und das regionale Steueraufkommen als Indikator der tatsächlich vorhandenen Finanzkraft entsprechend beeinflussen, nicht jedenfalls teilweise im gesamtdeutschen Länderfinanzausgleich berücksichtigt, d. h. eliminiert werden sollten ${ }^{174}$. Im übrigen bleibt als finanzkraftrelevantes Korrektiv notfalls nur das Prinzip der Bundestreue $^{175}$. Es bewirkt, daß extrem finanzverantwortungsloses Ausgabenverhalten eines Landes ebenso zu dessen Lasten geht wie ein systematisch auf Mindereinnahmen gerichteter Landesvollzug der

Landes ergibt und eine Internalisierung durch kostendeckende Preise bzw. Gebühren nicht möglich ist, ein Ausgleich angestrebt wird. In Betracht kommen vor allem vertragliche Vereinbarungen zwischen den beteiligten Ländern, nach Maßgabe der jeweiligen Konstellation ggf. aber auch vertikale Leistungen des Bundes gem. Art. 91 a, 104 a IV oder 107 II S. 3 GG. Der horizontale Finanzausgleich scheidet dagegen, abgesehen vom Sonderfall der Seehafenlasten (vgl. BVerfGE 72, 330, 413; BVerfG, DVBl.1992, 965, 972) nach geltender Verfassungsrechtslage für die Bewältigung externer Effekte aus. Vgl. zur Finanzausgleichsproblematik der Nutzenstreuungen (vor allem aus ökonomischer Sicht) insb. Peffekoven (Fn. 4), S. 181 (187f., 202); ders. (Fn. 26), S. 406 ff.; ders. (Fn. 162), S. $329 \mathrm{ff} . ;$ Zimmermann (Fn. 53), S.54f.; Scharpf/Benz, Kooperation als Alternative zur Neugliederung, 1991, S. 42 ff.; Franke (Fn. 4), S. 311 (315); Heun (Fn. 4), S. 219 f.; instruktiv auch Sachverständigenrat (Fn. 2), Jahresgutachten 1990/91, Tz.436, 449 f., 456, 458; Jahresgutachten 1991/92, Tz. 325.

173 Vgl. dazu näher Selmer/Brodersen (Fn. 66), S. 22 f., 27, 38 f.; s. mit anderer Tendenz aber Ossenbübl (Fn. 53), S. 24 f. m. weit. Nachw.

$174 \mathrm{Vgl}$. in diesem Sinne auch Kommission Finanzverfassungsreform des Landes Baden-Württemberg (Fn. 63), S. 80; Heun (Fn. 4), S. 227 Fn. 124.

175 Vgl. Selmer/Brodersen (Fn. 66), S. 24. 
Steuergesetze durch abweichende Steuerfestsetzungen $(\$ 163 \mathrm{AO})$, Steuerstundungen $(\$ 222 \mathrm{AO})$ und Steuererlasse $(\$ 227 \mathrm{AO})^{176}$.

\section{Die Verfeinerungsbedürftigkeit der Einwobnerzahl als Bezugspunkt}

Von der grundsätzlichen Eignung der Einwohnerzahl als eines primären Bedarfsmaßstabes ist seine Ergänzungsbedürftigkeit durch weitere abstrakte Indikatoren zu unterscheiden. Eine solche Verfeinerung ist für den Fall in Erwägung zu ziehen, daß sich die Einwohnerzahl, gemessen an dem bei der Finanzverfassungsreform 1969 zugrundegelegten Bedarfsgefüge im Rahmen des Länderfinanzausgleichs ${ }^{177}$, in der Zwischenzeit für sich allein als ein allzu grober Bezugspunkt der Vergleichung herausgestellt hat. Dabei kann es allerdings nicht allgemein darum gehen, spezifische Lasten nur einzelner Länder nun in der Verkleidung typisierter Bemessungsfaktoren doch noch finanzkraftmindernd in den horizontalen Finanzausgleich einzubringen. Insofern ist es jedenfalls nicht ausreichend, nur auf „signifikante, von der Durchschnittsbetrachtung nicht erfaßte Abweichungen im Bedarf" abzustellen, wie ich dies selbst einmal erwogen habe ${ }^{178}$. Vielmehr muß es sich, das entspricht auch dem Gebot der bundesstaatlichen Gleichbehandlung der Länder, um abstrakte Bedarfskriterien handeln, und zwar um solche, die zunächst vernachlässigt werden durften, die aber aufgrund der neueren Entwicklung heute zusätzlich prägende, ihrerseits generalisierungs- und typisierungsfähige Maßstäbe des Bedarfs bilden. Sie dürfte es in der Tat geben ${ }^{179}$.

$176 \mathrm{Vgl}$. in bezug auf vollzugsbedingte Mindereinnahmen ebenso auch Dittmann (Fn. 72), S. 234, 238; zur Möglichkeit einer „Verfälschung des Finanzausgleichs“ durch eine entsprechend unterschiedliche Steuererhebungspraxis s. bereits BVerfGE 1, 117 (133).

177 Hierauf abstellend vgl. bereits Selmer/Brodersen (Fn. 66), S. 59.

178 Selmer/Brodersen (Fn. 66), S. 43; die obige Formel aufgreifend etwa Ossenbühl (Fn. 53), S. 56; Friauf (Fn. 157), S. 625; Henneke (Fn. 24), S. 164 (Rdn. 650); Wendt (Fn. 4), \$104 Rdn. 79.

179 Insoweit stellte sich die vom BMF (Fn. 48), S.9, getroffene Feststellung, daß „mit der Egalisierung der Leistungsansprüche an den Staat, u.a. auch durch weitgehende gesetzliche Festlegung staatlicher Leistungsverpflichtungen, Bedarfsunterschiede an Gewicht verloren haben“, angesichts der zunehmenden Disparitäten in der Wirtschaftskraft der Länder bereits vor der Vereinigung als fragwürdig heraus. 
Das sind in erster Linie die Kriterien, die - wie vor allem (wenn auch keineswegs allein $)^{180}$ der Faktor Arbeitslosigkeit - mit dem steilen, aber stark streuenden Anstieg der Sozialhilfeausgaben in einem UrsacheWirkungszusammenhang stehen. Die gebotene Berücksichtigung dieser Kriterien bei der Finanzkraftbestimmung des horizontalen Finanzausgleichs ist, soweit nicht die Sozialhilfelasten künftig in die Ausgabenverantwortung des Bundes übernommen werden ${ }^{181}$, gerade für die neuen Bundesländer, aber auch für die von sektoralen Wirtschaftsstrukturkrisen überzogenen alten Bundesländer von erheblichem Gewicht. Problematisch ist wohl, ob das BVerfG sich gegebenenfalls in diese Richtung wird bewegen lassen. Seine Entscheidung von 1986 könnte den Eindruck vermitteln - deutlicher in den Leitsätzen, weniger deutlich in den Urteilsgründen -, als halte das Gericht den „Einwohner" (abgesehen von den Stadtstaaten) für den von Verfassungs wegen ausschließlichen Bemessungsfaktor der Länderbedarfe ${ }^{182}$. $\mathrm{Daß}$ es in seiner jüngsten Entscheidung vom 27.5.1992 beim explizite zu berücksichtigenden Finanzbedarf der Gemeinden (vgl. Art. 107 II S. 1, 2. Halbs. GG) die Einbringung zusätzlicher oder sogar ersetzender Bedarfsmerkmale zugelassen, ja sogar für potentiell geboten erklärt hat ${ }^{183}$, besagt noch nicht ohne weiteres etwas. Indes erschiene es kaum sachgerecht, dem sozialhilfebedingten Mehrbedarf von Gemeinden durch die Einführung entsprechender abstrakter Bedarfskriterien Rechnung zu tragen, die Veranschlagung eines „abstrakten Mehrbedarfs“ ${ }^{184}$ von Ländern aber von vornherein zu versagen. Ergibt daher eine umfassende Prüfung, daß die Einführung die Einwohnerzahl verfeinernder Bedarfskriterien auch im Rahmen der Finanzkraftermittlung der Länder selbst notwendig ist, um ihre absoluten Erträge „angemessen vergleichbar zu machen “ ${ }^{185}$, so sollte der einfache Gesetzgeber gegebenenfalls mit einer Zustimmung des $B V e r f G$ rechnen dürfen.

\section{Der "angemessene" Ausgleich der Finanzkraft}

Ein wesentliches Problem des horizontalen Finanzausgleichs wird auch künftig darin bestehen, die verfassungsrechtlich gebotene

180 Vgl. etwa in bezug auf die Hochschullasten die auf die Zahl der Studierenden abstellende Anregung von Barbarino (Fn. 22), S. 113; zu früheren finanzausgleichsrechtlichen Ansätzen in dieser Richtung s. auch Reissert (Fn. 38), S. 80.

$181 \mathrm{Vgl}$. dazu oben bei und in Fn. $146 \mathrm{ff}$.

182 Vgl. BVerfGE 72, 330 (331 Ls. 7, 400f.).

183 Vgl. BVerfG, DVBl. 1992, 965 (972f.).

${ }_{184}$ Zum Terminus s. BVerfG, DVBl. 1992, 965 (972).

185 BVerfG (Fn. 184). 
"Angemessenheit" des Ausgleichs der unterschiedlichen Finanzkraft der Länder auszuloten ${ }^{186}$. Das gilt zumal nach Konstituierung eines gesamtdeutschen Länderfinanzausgleichs ab 1995. Er ist angesichts des bis auf weiteres steilen West/Ost-Gefälles der Steuerkraft ohnehin nur realisierbar, wenn, wie ich wiederholen darf ${ }^{187}$, die Leistungen des Bundes und der Westländer für die Bewältigung der DDRAltlasten der Finanzkraft der neuen Länder zugerechnet werden und damit eine gewissen Homogenität als immanente Voraussetzung eines bundesstaatlichen Finanzausgleichs erfüllt ist. Im übrigen wird es im Hinblick auf die Ordnungsfunktion der Finanzverfassung nach wie vor insbesondere darum gehen, sicherzustellen, daß die Anwendung des unbestimmten Verfassungsbegriffs „angemessen" nicht allein als Ergebnis eines vom Gesetzgeber nur noch umgesetzten "politischen Kompromisses"188, sondern eines sich nach gewissen rechtlichen Maßstäben vollziehenden Entscheidungsprozesses erscheint ${ }^{189}$. Hier liegt indes bekanntlich die besondere Schwierigkeit.

Der Begriff „angemessen“ ist für sich genommen ohne Inhalt. Er bekommt festere Konturen auch nicht durch den Bezugspunkt des Bundesstaatsprinzips, auf das er sich auszurichten hat und dessen innere Spannungslage ${ }^{190}$ sich auch seiner Anwendung mitteilt. Eine nur unscharfe Antwort ergibt sich, stellt man auf die auch hier ausstrahlende Funktion der bundesstaatlichen Finanzverfassung ab und fordert, es gehe beim Länderfinanzausgleich um „eine entsprechend ihren Aufgaben hinreichende Annäherung ihrer Finanz$\mathrm{kraft}^{\text {" }}{ }^{191}$. Immerhin dürfte sich aus diesem sozusagen geborenen Bezugspunkt der „Angemessenheit" als untere Grenze des Ausgleichs die Gebotenheit eines solchen nach Maßgabe der bundesgesetzlich

186 Vgl. zum „angemessenen“ horizontalen Finanzausgleich (mit unterschiedlichen Ansätzen) ausführlicher etwa Lerche (Fn. 51), S. 307 ff., 314f.; P. Kirchbof (Fn. 52), S. 54 ff.; Maunz (Fn. 63), 1983, Art. 107 Rdn.61 ff.; Selmer/Brodersen (Fn.66), S. 37 ff.; Ossenbübl (Fn. 53), S.80ff.; ders., Zur Justitiabilität der Finanzverfassung, in: Festschrift für Carstens, 1985, S.743 (753 ff.); Wendt (Fn. 4), $\$ 104$ Rdn. 84 f; Heun (Fn. 4), S. 228 f., jew. m. weit. Nachw.

187 Vgl. oben bei und in Fn. $169 \mathrm{ff}$.

${ }_{188} \mathrm{Vgl}$. (allzu betont) in diesem Sinne etwa Ossenbübl (Fn. 53), S.82, 91; ders. (Fn. 186), S. 753; Fischer (Fn. 53), S.136; Peffekoven (Fn.4), S.181 (210); Franke (Fn. 4), S.311 (312).

${ }_{189}$ Vgl. im Erg. ähnlich auch Vogel (Fn. 111), \$87 Rdn. 126.

190 Vgl. BVerfGE 72, 330 (398).

191 BVerfG, DVBl. 1992, 965 (966). 
notwendigen Ausgaben ${ }^{192}$ und der Mindestanforderungen eines sozialstaatlichen Leistungsangebots herleiten lassen, soweit eine so beschaffene Aufgabenerfüllung nicht bereits durch die primäre Verteilung des Steueraufkommens gewährleistet ist.

Jenseits dieser Grenze bis zum vollen Ausgleich der Finanzkraftunterschiede, der sich im Hinblick auf den geforderten ,angemessenen" Ausgleich verbietet, steht dem Finanzausgleichsgesetzgeber ein Beurteilungs- und Entscheidungsspielraum zur Verfügung ${ }^{193}$. Bei seiner Ausfüllung geht es nicht um die Maximierung eines verfassungsrechtlich vorgegebenen Gutes, etwa des der in Art. 107 II GG nicht thematisierten „Einheitlichkeit der Lebensverhältnisse“, sondern um eine Optimierung unter Abwägung miteinander in Konflikt stehender Ziele $^{194}$. Der jüngst wieder vertretenen Auffassung, das Grundgesetz habe sich im Ergebnis, mit der Konsequenz eines nur geringen Spielraums für eine autonome Gestaltung des Gesetzgebers, „für eine weitgehende Nivellierung der Finanzausstattung " entschieden ${ }^{195}$, vermag ich nicht zu folgen. Richtig ist, daß das Grundgesetz eine recht intensive Vereinheitlichung nach Maßgabe der zu berücksichtigenden Gesichtspunkte zuläßt, ohne sie indes, wie ich eingangs hoffe deutlich gemacht $\mathrm{zu}$ haben ${ }^{196}$, auch verfassungskräftig zu postulieren. Die Gesichtspunkte, die der Gesetzgeber in seine Entscheidung einzubringen und abwägend zu gewichten hat, sind die folgenden: In einer Hinsicht die bundesstaatliche Notwendigkeit, die Autonomie und finanzielle Eigenverantwortung der Länder nicht aus dem Auge zu verlieren, in diesem Zusammenhang insbesondere den Willen der ausgleichsberechtigten Länder zur Selbsthilfe und zum Wettbewerb zwischen den Regionen zu erhalten, aber auch den Willen der ausgleichspflichtigen Länder zur weiteren Produktivitäts- und Leistungssteigerung nicht in allokationspolitisch fragwürdiger Weise zu schwächen, in anderer Hinsicht das gleichermaßen bundesstaatliche Gebot, zwischen den Ländern übermäßiges Gefälle mit zu großen Disparitäten im öffentlichen Leistungsangebot und daraus potentiell resultierende gemeinwohlschädliche Binnenwanderungen innerhalb der Bundesrepublik zu verhindern; in diesem Zusammenhang ist es auch sachlich gerechtfertigt, die nach wie vor stark einheitlichkeitsorien-

\footnotetext{
192 Vgl. insoweit auch P. Kirchbof (Fn. 52), S. 59.

193 Vgl. für viele Stern (Fn. 53), S. 1171; Maunz (Fn. 63), 1983, Art. 107 Rdn. 61.

194 Treffend Kops (Fn. 26), S. 129 f.; s. a. Maunz (Fn. 193), Art. 107 Rdn. 9.

195 Heun (Fn. 4), S. 224.

$196 \mathrm{Vgl}$. oben bei und in Fn. $68 \mathrm{ff}$.
} 
tierte Erwartungshaltung der Bevölkerung, die gegebenenfalls erst mittelfristig Präferenzen für ein regional differenziertes Leistungsangebot entwickeln wird ${ }^{197}$, als einen mit zu berücksichtigenden Aspekt in den Entscheidungsprozeß einzubeziehen.

Der einfache Gesetzgeber ist, solange der verfassungsrechtlich gezogene äußerste Rahmen nicht überschritten wird, nicht gehindert, bei der gebotenen Abwägung einzelne der genannten Gesichtspunkte in den Vordergrund zu stellen, andere dagegen geringer zu gewichten ${ }^{198}$. Dies muß freilich mit sachgerechten Erwägungen geschehen; insbesondere müssen sich die selbstgesetzten Maßstäbe der "Angemessenheit" harmonisch in die bestehende föderative Gesamtordnung einfügen. So erschiene es kaum sachgerecht, das „Interesse des einzelnen Landes an der pfleglichen Entwicklung der eigenen Steuerkraft ${ }^{\star 199}$ nachhaltig zugunsten einer Reduzierung des horizontalen Finanzausgleichs in die Waagschale zu werfen, solange nicht die überwiegend angestrebte fiskalische Entflechtung mit einer substantiell größeren Steuerautonomie der Länder tatsächlich verwirklicht ist. Problematisch erscheint mir in diesem Zusammenhang der kürzlich gemachte Vorschlag, in die Finanzverfassung ausdrücklich als Ziel des Finanzausgleichs aufzunehmen, „daß die unterschiedliche Finanzkraft der alten und neuen Länder nach einer Übergangsfrist so ausgeglichen werden soll, wie es die Herstellung einheitlicher Lebensverhältnisse erfordert ${ }^{\prime 200}$. Die hierin liegende verfassungskräftige Ausrichtung des bundesstaatlich „angemessenen“ Ausgleichs vor allem auf den Aspekt sozialer Annäherung und Homogenität bedeutete eine sachlich nicht gerechtfertigte Reduzierung der gesetzgeberischen Freiheit, den Finanzausgleich je nach Lage der politischen Dinge mehr in Richtung Länderautonomie und föderale Vielfalt oder mehr in Richtung Unitarisierung auszugestalten. Ihrer bedarf es auch nicht, um den Interessen der neuen Länder gerecht zu werden. Denn der Bundesgesetzgeber ist - ich darf insoweit nach oben verweisen ${ }^{201}$ - schon im Hinblick auf

$197 \mathrm{Zu}$ Unrecht eine entsprechende Entwicklung bereits registrierend Peffekoven (Fn. 4), S. 181 (225 f.); im Sinne einer bundesstaatlich erwünschten Förderung einer solchen Entwicklung s. Sachverständigenrat (Fn. 2), Jahresgutachten 1990/91, Tz. 459; Klatt (Fn. 4), S.233.

198 Vgl. im obigen Sinne auch Korioth (Fn. 4), S. 1057; Kops (Fn. 26), S. 129 f.; Scharpf (Fn. 4), S. 150; Zimmermann (Fn.53), S.36, 61; s. auch bereits oben bei Fn. 77.

${ }_{199}$ Vgl. Selmer/Brodersen (Fn. 66), S. 37 m. Nachw. in Fn. 168 f.

200 Wieland (Fn. 2), S. 1192.

$201 \mathrm{Vgl}$. oben bei und in Fn. $81 \mathrm{f}$. 
das föderative Gleichbehandlungsgebot gehalten, in seine bislang konsequent betriebene Politik einer Egalisierung der Lebensverhältnisse im Bundesgebiet bis zu einem generellen Kurswechsel in Richtung Entflechtung auch die neuen Länder grundsätzlich einzubeziehen ${ }^{202}$.

\section{Zur Funktion der Bundesergänzungszuweisungen im Länderfinanzausgleich}

Etwaige Lücken zu einer aufgabengerechten Finanzausstattung weiter zu verringern, ist Aufgabe der Bundesergänzungszuweisungen $^{203}$, die sich mehr und mehr zu einem Auffangnetz für anders offenbar nicht zu bewältigende Finanzausgleichsfragen zu entwickeln beginnen. Das spiegelt sich auch in ihrem Volumen wider, das sich mit etwa 3,5 Mrd. DM inzwischen dem Umfang der Zahlungen im Länderfinanzausgleich angenähert hat ${ }^{204}$.

Die tatbestandliche Besonderheit der Bundesergänzungszuweisungen liegt ersichtlich darin, daß sie in Abweichung vom primär einnahmekraftorientierten horizontalen Finanzausgleich „leistungsschwachen "Ländern gewährt werden, womit über die abstrakte Bedarfslage hinaus auch die konkrete Relation zwischen Finanzaufkommen und Ausgabenlasten in das Blickfeld gerät. Dieser Umstand hat das BVerfG 1986 leider zur Voranstellung der in ihrer Allgemeinheit überpointierenden These veranlaßt, daß der Bund bei der Vergabe von Bundesergänzungszuweisungen neben oder anstelle einer allgemeinen Anhebung der Finanzkraft der leistungsschwachen Länder (Verteilung nach Fehlbetragsschlüssel) „auch Sonderbedarfe einzelner Länder berücksichtigten " dürfe ${ }^{205}$. Hinter ihr tritt - zumal angesichts des Leitsatzes, die vom Gesetzgeber benannten und begründeten Sonderlasten müßten „bei allen Ländern berücksichtigt werden, bei denen sie vorliegen" ${ }^{206}$ - allzusehr in den Hintergrund, daß das Gericht die

${ }^{202}$ Insoweit unzutreffend Hobmann (Fn. 55), S. 196, wenn er ("vor allem seit dem Beitritt der fünf neuen Bundesländer") auf die Sicherung eines „Mindeststandards für die wesentlichen Lebensverhältnisse" abhebt.

${ }^{203} \mathrm{Vgl}$. zu den Bundesergänzungszuweisungen, abgesehen von der Kommentarliteratur zu Art. 107 II S. 3 GG, Renner (Fn. 48), S. 351 ff.; Ossenbübl (Fn. 53), S. $110 \mathrm{ff}$; Wendt (Fn. 4), $\$ 104$ Rdn. $86 \mathrm{ff}$.; aus ökonomischer Sicht insb. Bartsch/ Probst (Fn. 4), S. 538 ff.; Peffekoven (Fn. 4), S. 181 (213 ff., 221 ff.); ders. (Fn. 4), S. 485 (499 ff.); Kops (Fn. 26), S. $211 \mathrm{ff}$; Littmann (Fn. 4), S. $42 \mathrm{ff}$.

$204 \mathrm{Vgl}$. zur Entwicklung von 1974 (0,75 Mrd. DM) bis 1991 (3, $53 \mathrm{Mrd}$. DM) instruktiv BMF (Hrsg.), Finanzbericht 1993, S. 132.

${ }^{205}$ BVerfGE 72, 330 (331 Ls. 9, 402).

206 BVerfGE 72, 330 (331 f. Ls. 10, 406). 
Berücksichtigung von Sonderlasten im folgenden mit einer Reihe recht verklausulierter Einschränkungen und Vorbehalte versehen hat ${ }^{207}$. Irrtümer und falsche Hoffnungen konnten da nicht ausbleiben. So findet sich erst im Urteil vom 27.5.1992 ${ }^{208}$ unmißverständlich ausgesprochen, daß ein Land mit einer nach horizontalem Finanzausgleich durchschnittlichen oder überdurchschnittlichen Finanzausstattung auch unter dem Regime des föderativen Gleichbehandlungsgebots nur dann sonderlastbezogene Bundesergänzungszuweisungen in Anspruch nehmen kann, wenn es sich gerade der Sonderlast wegen als leistungsschwach darstell $t^{209}$.

Nach wie vor nicht abschließend aufgehellt ist insbesondere aber die Feststellung des BVerfG von 1986, Bundesergänzungszuweisungen dienten "nicht dazu, finanziellen Schwächen abzuhelfen, die eine unmittelbare und voraussehbare Folge von politischen Entscheidungen bilden, die ein Land in Wahrnehmung seiner Aufgaben selbst

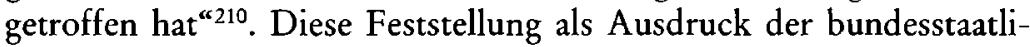
chen Antinomie von Eigenverantwortlichkeit und solidargemeinschaftlicher Annäherung ${ }^{211}$ ist dem Grundsatz nach gewiß plausibel, in der näheren Umsetzung aber problematisch. Einen gewissen Ansatz bietet in diesem Zusammenhang die Unterscheidung von intern verursachten und deshalb nicht ausgleichserheblichen Sonderlasten einerseits und extern verursachten andererseits, die dem Einfluß der Organe des Landes entzogen und daher grundsätzlich berücksichtigungsfähig sind ${ }^{212}$. Eindeutig externe Bedarfsfaktoren stehen etwa in Rede, wenn es um die Lasten des Küstenschutzes ${ }^{213}$ oder die bisher schon veranschlagten der politischen Führung in Ländern mit geringer Einwohnerzahl ${ }^{214}$ geht. Auch sind intern verursachte und daher zu vernachlässigende Sonderlasten gewiß die, die einem Land etwa aufgrund extensiver Ausschöpfung sozialgesetzlich eingeräumter Leistungsspielräume oder als direkte Konsequenz anderer finanzautono-

207 BVerfGE 72, 330 (404ff.).

208 BVerfG, DVBl. 1992, 965 (980).

209 Was Hamburg, a.a. O. (Fn. 208), um die Anerkennung seiner überdurchschnittlichen Kosten politischer Führung als berücksichtigungsfähige Sonderlast gebracht hat.

210 BVerfGE 72, 330 (405); die obige These wird wiederholt von BVerfG, DVBl. 1992, 965 (976).

${ }^{211}$ Hierzu für viele nur Isensee (Fn. 40), $\$ 98 \mathrm{Rdn} .149$; ders. (Fn. 15), S. 273.

212 Vgl. Kops (Fn. 26), S. $111 \mathrm{f}$.

213 Vgl. Sachverständigenrat (Fn. 2), Jahresgutachten 1990/91, Tz. 450.

214 BVerfGE 72, 330 (405); BVerfG, DVBl. 1992, 965 (979f.). 
mer Willensentscheidungen (vgl. Art. 109 I GG) entstehen ${ }^{215}$; dabei geht es übrigens um die objektive Zurechnung unmittelbar haushaltswirksamer Ausgabengebarung als solche, entgegen gelegentlicher Auffassung ${ }^{216}$ also nicht um deren Bewertung als ganz besonders leichtfertig oder gar verantwortungslos.

Schwerer einzuordnen sind indes vor allem die Sonderlasten infolge von Strukturschwächen, die seit einiger Zeit im Mittelpunkt des Interesses stehen. Ob die Strukturschwäche eines Landes auf externe Ursachen - etwa allgemeine wirtschaftspolitische Entwicklungen und außenwirtschaftliche Veränderungen - oder auf interne Faktoren etwa eine verfehlte Regional- und Wirtschaftspolitik des Landes zurückzuführen ist, möglicherweise sogar auf externe und interne Ursachen gleichzeitig, wird kaum einmal exakt zu klären und unter den Beteiligten zumeist umstritten $\operatorname{sein}^{217}$. Nur die neuen Bundesländer dürfen erwarten, daß ihre grundlegende Strukturschwäche ihnen bis auf weiteres durchweg nicht als im wesentlichen selbst zu bewältigende Konsequenz finanzstaatlicher Autonomie zugerechnet wird. Das dem Bundesstaatsprinzip eigentümliche Spannungsverhältnis dieser Autonomie zur bündischen Solidarität hat bei ihnen ersichtlich eine ganz spezifische Dimension. Der Finanzausgleichsgesetzgeber darf sich deshalb im Rahmen seiner Gestaltungsfreiheit ohne Verletzung des föderativen Gleichbehandlungsgebots vorerst darauf beschränken, neben der allgemeinen Verteilung von Ergänzungszuweisungen nach Fehlbetragsschlüssel allein die strukturschwächebedingten Sonderlasten der neuen Länder zu berücksichtigen ${ }^{218}$, soweit ihnen nicht bereits auf andere Weise gezielt Rechnung getragen wird ${ }^{219}$.

Mit Ablauf der vorgeschlagenen Übergangsfrist wird der Gesetzgeber die Frage der Kompensation von Strukturschwächen der Länder durch Bundesergänzungszuweisungen freilich allgemeingültig zu klä-

${ }^{215}$ Vgl. auch Peffekoven (Fn, 162), S. 334f.; s.a. Fn. 211.

216 Vgl. etwa Wendt (Fn. 4), $\$ 104$ Rdn. 87.

217 Vgl., hierauf hinweisend, auch Peffekoven (Fn. 162), S.336f.; Littmann (Fn. 4), S. 43 f.; Kops (Fn. 26), S. 125 ff; Selmer/Brodersen (Fn. 66), S. 38; in bezug auf die verantwortliche Zurechnung der Arbeitslosenhilfekosten s. wie oben insb. auch Fischer (Fn. 53), S. 135; Milbradt (Fn. 24), S. 160; Kitterer (Fn. 24), S. 188.

218 Dabei könnte für die gebotenen Indikatoren, an denen der Grad der Strukturschwäche gemessen wird, an die Bemessungsgrundlage des Strukturhilfegesetzes (vgl. oben bei und in Fn. 23f.) als auch hier brauchbaren, allerdings wohl ergänzungsbedürftigen (s. a. Peffekoven, Fn. 162, S. 337 f.) Ansatz angeknüpft werden.

219 Für eine Privilegierung der neuen Bundesländer bei den Bundesergänzungszuweisungen auch Kilian (Fn. 4), S. 430. 
ren haben. Dabei hat er, da dieses Instrument schon insgesamt nicht zwingender Bestandteil des finanzverfassungsrechtlichen Verteilungssystems ist, einen breiten Spielraum der Entscheidung. Er schließt die Möglichkeit, von der Einbeziehung strukturschwächebedingter Sonderlasten der Länder wie bisher abzusehen ${ }^{220}$, grundsätzlich ebenso ein wie die weitere, derartige Sonderlasten, soweit sie nicht nur kurzfristig auftreten, angesichts der Komplexität der Zurechnungsfrage unabhängig von den Ursachen der Strukturschwäche zu berücksichtigen ${ }^{221}$ - wenn möglicherweise auch bereinigt um einen pauschalierten Eigenverantwortungsanteil. Wie immer die angestrebte Lösung auch aussehen mag: Sie muß sich sinnvoll in das Gesamtkonzept der neuzuordnenden Finanzbeziehungen zwischen Bund und Ländern einfügen. Voll auf der Tagesordnung werden die strukturellen Sonderlasten einzelner Länder vor allem dann bleiben, wenn die Neuordnung der bundesstaatlichen Finanzverfassung auf eine substantielle Stärkung gliedstaatlicher Autonomie und Vielfalt wesentlich verzichten und statt dessen weiterhin einer vorrangigen Entfaltung des Einheitlichkeitsgedankens Raum geben oder den Finanzausgleichsgesetzgeber entgegen der jetzigen Verfassungsrechtslage sogar ausdrücklich auf dieses Ziel verpflichten sollte. Demgegenüber könnte das Problem der Übernahme strukturspezifischer Sonderlasten der Länder durch den Bund einiges von seiner Brisanz verlieren, wenn den Ländern im Rahmen einer generellen fiskalischen Entflechtung schließlich auch eine größere Steuerautonomie eingeräumt und damit die bisherige Asymmetrie im Verhältnis von Einnahmeerzielungs- und Ausgabenbefugnissen der Länder abgemildert wird ${ }^{222}$. In der Konsequenz einer Stärkung der Länderautonomie läge es gegebenenfalls ferner wohl, auch die Zahlung von Bundesergänzungszuweisungen nach Fehlbetragsschlüssel so weit als möglich zugunsten einer entsprechenden Erhöhung des Länderanteils an der Umsatzsteuer (vgl. Art. 106 III, S. 4 GG) zu reduzieren ${ }^{223}$.

220 Dafür haben sich ausgesprochen insb. Heilmann (Fn. 4), S. 59 f.; Peffekoven (Fn. 4), S. 181 (216 ff., 221); ders. (Fn. 162), S. 338 und passim.

${ }^{221}$ Hierfür (in dieser Allgemeinheit nicht unbedenklich) Peffekoven (Fn. 162), S. 337 .

${ }^{222}$ Hierauf verweist in seiner Besprechung von Kops (Fn. 26) mit Recht auch Peffekoven, Finanzarchiv n. F. 48 (1990), 342 (344).

${ }^{223}$ In diesem Sinne auch Angenendt, Neuordnung der Finanzbeziehungen zwischen Bund und Ländern, Wirtschaftsdienst 1982, 457 (461); Fischer-Menshausen (Fn. 73), Art. 107 Rdn.22; Peffekoven (Fn. 4), S. 181 (216); Starck (Fn.15), S. 13; s. im Erg. auch Heun (Fn. 4), S. 232. 
Auf die vom BVerfG jüngst besonders ausführlich erörterte Frage, ob gegebenenfalls die Haushaltsnotlage eines Landes eine hinsichtlich ihrer Folgen zuweisungsbegründende Sonderlast sein $\mathrm{kann}^{224}$, sei in diesem Zusammenhang jedenfalls ein kurzer Blick geworfen. Auch dieses Thema sollte im Ansatz nicht gänzlich von der Unterscheidung abgekoppelt werden, ob für ihre Entstehung interne oder externe Ursachen ausschlaggebend waren. Anderenfalls machte man die Zahlung von Bundesergänzungszuweisungen in dieser Hinsicht zu Lasten der auf Konsolidierung ihrer Haushalte bedachten Länder allzu strategieanfällig. Richtig ist allerdings, daß häufig auch hier letztlich undeutlich bleiben wird, worauf die Haushaltsnotlage vor allem zurückzuführen ist ${ }^{225}$. Angesichts dessen erscheint von besonderer Bedeutung, einen Sonderbedarf wegen der durch eine Haushaltsnotsituation bedingten Lasten nach Maßgabe des individuellen Einzelfalls nur als ultima ratio anzuerkennen und im Rahmen des bündischen Prinzips an rigide Voraussetzungen bzw. Konsequenzen zu knüpfen. $\mathrm{Zu}$ ihnen gehört eine Kooperationspflicht des betroffenen Landes im Verhältnis zum Bund ebenso wie seine Pflicht, dem Bund einen verbindlichen Plan zur Ausräumung der ungünstigen Haushaltslage vorzulegen. Sie hat das $B V \operatorname{rerf} G^{226}$ indes nur für den Fall einer „extremen" Haushaltsnotlage 227 ins Auge gefaßt. Bei einer so gearteten Haushaltssituation, deren Bewältigung das Gericht mit Recht außerhalb des Länderfinanzausgleichs unmittelbar im Bundesstaatsprinzip verwurzelt sieht ${ }^{228}$, dürfte indes die Auferlegung von Pflichten der genannten Art für sich allein nicht hinreichen, um das Land wirksam zu einem nachhaltigen Sanierungsbeitrag zu veranlassen. Im Ergebnis scheint mir angeraten, den Fall der „extremen Haushaltsnotlage“, bei der es sich um eine spezifische Ausprägung des inneren Staatsnotstandes handelt, künftig im Rahmen der Art. 109 ff. GG in den Grundzügen auch verfassungsrechtlich $\mathrm{zu}$ regeln ${ }^{229}$. Diese Regelung sollte neben einer begrifflichen Klärung der "extremen Haushaltsnotlage“ die Konturen der bündischen Solidarverpflichtung von Bund und Ländern wie die Obliegenheiten des betroffenen Landes und nicht

\footnotetext{
${ }^{224}$ BVerfG, DVBl. 1992, 965 (976 ff.); s. a. bereits BVerfGE 72, 330 (404).

${ }_{225}$ So auch Littmann (Fn. 4), S. 43 f.; Peffekoven (Fn. 27), S. 354.

226 DVBl. 1992, 965 (978).

227 Zum Begriff BVerfG, DVBl. 1992, 965 (976f.).

228 Vgl. BVerfG, DVBl. 1992, 965 (977).

$229 \mathrm{Vgl}$. auch Wieland (Fn.2), S. 1189.
} 
zuletzt ein subsidiäres Eingriffsrecht des Bundes als „Sparkommissar“ in die Haushaltsautonomie dieses Landes enthalten ${ }^{230}$.

\section{Verfassungsrechtspolitischer Ausblick}

Welche Änderungen des Länderfinanzausgleichs sollten darüber hinaus alsbald ins Auge gefaßt werden? Ist die Zeit für eine umfassende Finanzverfassungsreform, insbesondere eine entschiedene Reföderalisierung, nicht reif, so bleibt auch hier die Frage nach dem jetzt zwingend Gebotenen. Damit kann allerdings nicht, was die neuen Bundesländer anbetrifft, eine vorläufige Fortführung der ersten Übergangsphase über 1994 hinaus gemeint sein. Schon die wesentliche Prägung dieser Phase durch eine präterkonstitutionelle Fondswirtschaft war von verfassungsrechtlichen Bedenken nicht frei ${ }^{231}$. Nicht angängig erscheint es, den neuen Ländern mit einer fortdauernden Suspendierung des Länderfinanzausgleichs auch weiterhin ein entscheidendes Element föderaler Finanzverfassung und Staatlichkeit vorzuenthalten ${ }^{232}$. Das gilt jedenfalls für den Fall, daß durch eine finanzausgleichsrechtliche Berücksichtigung von Transferleistungen, die Bund und Westländer im Rahmen ihrer ungeschriebenen, grundgesetzlich nur noch zu präzisierenden Verantwortung für die Bewältigung der DDR-Altlasten erbringen, für eine gewissen Annäherung der Ostländerfinanzkraft an das Westländerniveau Sorge getragen und damit eine Denaturierung des horizontalen Finanzausgleichs vermieden wird ${ }^{233}$.

Bei aller verfassungsreformerischen Zurückhaltung: Angestrebt werden sollte für die etwa 10jährige Zwischenphase ab 1995 eine Änderung im Bereich der horizontalen Steuerertragsverteilung. Dabei ist von der Einsicht auszugehen, daß der für Ergänzungsanteile an steuerschwache Länder zur Verfügung stehende Anteil von bis zu 25 v.H. am Gesamtaufkommen der Umsatzsteuer (Art.107 I S.4, 2. Halbs. GG) gegebenenfalls in vollem Umfang an die neuen Bundesländer flösse, deren Steuerkraft auf absehbare Zeit so weit unter dem

${ }^{230} \mathrm{Zu}$ den hier in Rede stehenden Bezügen von bundesstaatlicher Hilfeleistung und "Dreinreden" in die Ausgabengestaltung des begünstigten Landes vgl. bereits Lerche (Fn. 51), S. $316 \mathrm{f}$.

${ }^{231}$ Vgl. zur Übergangsfinanzverfassung für die neuen Bundesländer oben bei und in Fn. 28, 33.

${ }^{232}$ A. A. Kommission Finanzverfassungsreform des Landes Baden-Württemberg (Fn. 63), S.84.

${ }^{233} \mathrm{Vgl}$. oben bei und in Fn. $169 \mathrm{ff} ., 187$. 
Bundesdurchschnitt liegen wird, daß die für Ergänzungsanteile zur Verfügung stehende Masse vollständig zu ihren Gunsten ausgeschöpft würde ${ }^{234}$. Hier bietet sich an, die Steuerschwäche als Maßstab des Bedarfs gegen andere, ost/west-neutralere Bedarfsindikatoren auszutauschen. Eine andere Frage ist, ob nicht nach Ablauf der Zwischenphase die Ergänzungsanteile als ein im Rahmen der Steuerertragsverteilung eigentlich systemfremdes Element horizontaler Umverteilung gestrichen werden und einer umfassenden Verteilung der Umsatzsteuer nach der Einwohnerzahl Platz machen sollten ${ }^{235}$.

Einstweilen sollte von einer derart gewichtigen Umgestaltung wie auch von anderen substantiellen Einschnitten in das bestehende System des Länderfinanzausgleichs abgesehen werden. Denn auch dessen Ausformung hat unbeschadet weitergehender Reformabsichten zunächst vor allem unter dem beschränkten Ziel zu stehen, geeignete verfassungsrechtliche Rahmenbedingungen für einen schnellen Prozeß der inneren Wiedervereinigung zu sichern, ohne dabei das sensible Gefüge der bestehenden Regelung mehr als unbedingt nötig zu verändern. Den Befürwortern einer alsbaldigen Gesamtreform der Finanzverfassung möchte ich entgegenhalten: „Wie kann man unter so vorläufigen Verhältnissen so grundsätzlich und so endgültig sein wollen!“ Dieses gegen voreilige Verfassungsfestlegungen gerichtete Wort Hettlages von $1955^{236}$ hat heute wiederum seine Berechtigung. Insbesondere der gesamtdeutsche Länderfinanzausgleich wird in den nächsten Jahren zu einer finanzpolitischen Daueraufgabe werden, deren schließlich beste Lösung ebenso schwer vorhersehbar ist wie die wirtschaftliche und soziale Entwicklung in den neuen Bundesländern ${ }^{237}$. Das Inkrafttreten einer die notwendige $\mathrm{Zwi}$ schenphase ablösenden, dann umfassend erneuerten bundesstaatlichen Finanzverfassung sollte dem nächsten Jahrzehnt vorbehalten bleiben $^{238}$.

234 Vgl. Franke (Fn. 4), S. 311 (319).

$235 \mathrm{Vgl}$, auch Peffekoven (Fn. 4), S. 181 (192 f.); ders. (Fn. 4), S. 485 (494); Franke (Fn. 4), S. 311 (319).

236 Vgl. Hettlage (Fn. 1), S. 31.

${ }^{237} \mathrm{Vgl}$. in diesem Sinne auch Geske (Fn. 35), S.257f.

238 Vgl. hierzu aus der jüngsten Diskussion Schmidt-Jortzig, Eckpunkte für den verfassungsrechtlichen Finanzausgleich im Bundesstaat, in: Nds. Institut für Wirtschaftsforschung (Hrsg.), Länderfinanzausgleich und Kommunalfinanzen, 1992, S. 55; mschr. Thesenpapier des Bundes zur Neuordnung der Bund/Länder-Finanzbeziehungen v. 8.9.1992; s. a. zum Regierungsentwurf eines Gesetzes zur Änderung des FAG v. 7. 10.1992 BMF, Finanznachrichten v. 8.10.1992, S. 2 f. 


\section{Schlußbemerkung: Finanzverfassung und Länderneugliederung}

Gestatten Sie mir zum Schluß einige Worte zu den Bezügen von bundesstaatlicher Finanzverfassung und dem Thema Länderneugliederung. Dieses Thema ist durch die deutsch-deutsche Vereinigung unversehens wieder auf die Tagesordnung bundesstaatlicher Fragestellungen gelangt ${ }^{239}$, nachdem Überlegungen, das Problem noch im Vorfeld des Beitritts DDR-intern zu bewältigen ${ }^{240}$, rasch wieder aufgegeben worden waren ${ }^{241}$. Wie stellt es sich aus der Sicht der Finanzverfassung und bezogen auf diese dar?

Konkreter verfassungsrechtlicher Handlungsbedarf in Richtung einer territorialen Umgestaltung ergibt sich aus der Finanzverfassung nicht. Die unter dem Regime von Art. 29 GG a.F. nie abschließend aufgehellte Frage, wie sich die Aufgabe der Finanzverfassung, die Länder zur Wahrnehmung der ihnen verfassungsrechtlich zukommenden Aufgaben zu befähigen, zu dem Ziel der gebotenen Neugliederung verhält, „Länder zu schaffen, die nach Größe und Leistungsfähigkeit die ihnen obliegenden Aufgaben wirksam erfüllen können “242, ist durch die 1976 vorgenommene Rückstufung der Vorschrift in eine bloße Kannbestimmung als solche im wesentlichen obsolet geworden - ebenso übrigens die Feststellung des BVerfG von $1952^{243}$, der Finanzausgleich dürfe „mit Rücksicht auf Art. 29 GG nicht zu dem Ergebnis führen, lebensunfähige Länder künstlich am Leben zu erhalten"244. Der Finanzausgleich ist allein nach Maßgabe der vorhandenen Länder zu gestalten - so wenig manche von ihnen (und dazu gehören

$239 \mathrm{Vgl}$. dazu insb. Ernst (Fn. 55), S. 1029 und passim; Hohmann (Fn. 55), S. 193, 197 f.; Benz (Fn. 4), S. 596; Franke (Fn. 4), S. 311 (322); ders. (Fn. 4), S. 526 (541 f.); Wieland (Fn. 2), S.1183 f.; Kisker (Fn. 4), S. 132 ff.; Kilian (Fn. 4), S. 429; Korioth (Fn.4), S. 1057; Häberle, Aktuelle Probleme des deutschen Föderalismus, Die Verwaltung 1991, 169 (200 ff.); ders. (Fn. 15), S. 256 f.; Peffekoven (Fn. 4), S. 485 (501f.); zu den Rechtsgrundlagen in bezug auf die neuen Bundesländer vgl. Hoppe/ Schulte, Rechtliche Grundlagen und Grenzen für Staatsgebietsänderungen von neuen Bundesländern, DVBl. 1991, 1041.

${ }^{240}$ Vgl. zur Problematik der Neugliederung im Rahmen des Einigungsprozesses Klatt (Fn. 4), S. 230 f. m. Nachw. in Fn. 34 f.; Kisker (Fn. 4), S. 132.

${ }^{241}$ Für den Sonderfall einer Neugliederung des Raums Berlin/Brandenburg vgl. die in Art. $5 \mathrm{EV}$ ausgesprochene Empfehlung an die gesetzgebenden Körperschaften.

${ }^{242}$ Vgl. dazu Lerche (Fn.51), S.310ff.; Vogel/Kirchbof (Fn.66), Art. 107 Rdn. $47 \mathrm{f}$.

${ }^{243} \mathrm{Vgl}$. BVerfGE 1, 117 (134).

244 A. A. offenbar Ernst (Fn. 55), S. 1029; Hohmann (Fn. 55), S. 197. 
jetzt die meisten ostdeutschen Länder) nach ihrer Größe und/oder Finanzkraft den Vorstellungen entsprechen, die mit einer bedarfsgerechten und wirtschaftlichen Aufgabenerfüllung verbunden wer$\operatorname{den}^{245}$. Das schließt gegebenenfalls und im Rahmen des bündischen Prinzips auch die Pflicht zu Daueralimentationen und entsprechenden strukturellen Stärkungen durch Bund und Bundesgenossen ein. Denn wie anders sollte die ökonomische Lebenserhaltung dieser Länder bewerkstelligt werden als durch eine entsprechende Praxis der Finanzverfassung, solange der Möglichkeit einer Neugliederung nicht entsprochen ist ${ }^{246}$ ? Das gilt zunächst auch de constitutione ferenda. Wie es nicht primäres Ziel einer Neugliederung sein kann, den Finanzausgleich zu entlasten ${ }^{247}$, so soll nicht seinerseits der Finanzausgleich eine Neugliederung erzwingen wollen ${ }^{248}$. Die Verteilung der Aufgaben, Ausgaben und Einnahmen in einem Bundesstaat „ist ein in vielfältiger Hinsicht gestaltbares Regelwerk" ${ }^{449}$. Soweit das bisher maßgebliche Instrumentarium, nunmehr gerade auch im Hinblick auf die neuen Bundesländer, Mängel aufweist, sind diese auf der Grundlage der bestehenden bundesstaatlichen Ordnung alsbald zu beheben. Ein direkter verfassungsrechtlich erheblicher Neugliederungsdruck erwächst aus ihnen nicht.

Auf weitere Sicht ist ein potentieller Zusammenhang zwischen der künftigen Gestaltung der bundesstaatlichen Finanzverfassung und dem Thema einer Länderneugliederung allerdings nicht von der Hand zu weisen. Maßgebend hierfür wird in erster Linie sein, ob sich nach dem gegenwärtigen Zentralisierungsschub letztlich die Tendenzen einer substantiellen Kräftigung des föderativ geprägten Bundesstaates durchsetzen werden. Die in diesem Falle zu erwartende fiskalische Entflechtung der bundesstaatlichen Finanzverfassung mit ihrer größeren Finanzautonomie für die Länder wird diese in einen in dieser Weise bislang unbekannten Wettbewerb entlassen, dem sie nur dann gewachsen sein werden, wenn sie nicht allein über politisch-administrative Leistungsfähigkeit ${ }^{250}$, sondern auch über genügende wirt-

${ }^{245} \mathrm{Vgl}$. zu diesen Vorstellungen Hohmann (Fn. 55), S. 193.

$246 \mathrm{Vgl}$. in diesem Sinne bereits Lerche (Fn. 51), S.311; für die jetzige Verfassungsrechtslage auch Evers (Fn. 16), Art. 29 Rdn. 40.

${ }^{247}$ Peffekoven (Fn. 4), S. 485 (502).

248 Häberle (Fn. 239), S. 202.

${ }^{249}$ Peffekoven (Fn. 247).

${ }^{250}$ Deren Notwendigkeit betonend vgl. insb. Franke (Fn. 4), S.311 (322); ders. (Fn. 4), S. 526 (542). 
schaftlich-finanzielle Eigenpotenz und Beweglichkeit verfügen ${ }^{251}$. Sollte diese sich im Verlaufe der anzustrebenden Zwischenphase nicht für alle Bundesländer in hinreichendem Maße einstellen, wird auch zu prüfen sein, ob nicht durch eine Neugliederung flankierend abgesichert werden muß, daß alle Länder ihre Funktion als wirklich autonome Subsysteme im Gesamtstaat überzeugend ausfüllen können ${ }^{252}$. Dabei wird man sich gegebenenfalls auch der Frage zu stellen haben, ob nicht Art. 29 GG wieder zu einer Mußvorschrift und ein widerstrebender Wille der betroffenen Bürger durch eine bundesweite Abstimmung überwindbar gemacht werden sollten ${ }^{253}$. Aber das ist ein anderes, nicht minder weites Feld.

251 In diesem Sinne läßt auch das BVerfG in seiner jüngsten Entscheidung zum Finanzausgleich (DVBl. 1992, 965) den Darlegungen zur bundesstaatskonformen Behebung "extremer Haushaltsnotlagen " von Ländern (a. a. O., S. 979) die Feststellung folgen: „Schließlich ist auf die Möglichkeit hinzuweisen, das Bundesgebiet neu zu gliedern, um, wie es in Art. 29 I GG heißt, zu gewährleisten, daß die Länder nach Größe und Leistungsfähigkeit die ihnen obliegenden Aufgaben wirksam erfüllen können".

${ }^{252} \mathrm{Vgl}$. in diesem Sinne insb. Kisker (Fn. 4), S. 132.

${ }^{253}$ Vgl. dazu etwa Ernst (Fn. 55), S. 1030; Benz (Fn.4), S. 596; Scharpf/Benz (Fn. 172), S. 28. 
Leitsätze des Berichterstatters über:

\title{
Grundsätze der Finanzverfassung des vereinten Deutschlands
}

\author{
$I$.
}

1. Unsere bundesstaatliche Finanzverfassung wird zunehmend kritisch auf ibre Tragfähigkeit für die heute an sie zu stellenden Anforderungen abgeklopft. Bund und Länder haben sich - auch, aber keineswegs nur unter dem Eindruck der deutschen Einigung - diese Einschätzung zu eigen gemacht. Gemäß Art.31 \$2 II des Gesetzes zum Staatsvertrag vom 18.5.1990 sollen deshalb mit Wirkung ab 1.1.1995 die Finanzbeziebungen zwischen Bund und Ländern neu geregelt werden.

2. Im Vordergrund steht, daß der Substanzverlust an föderativer Pluralität, der jedenfalls seit 1969 vor allem den Finanzbereich erfaßt bat, von den Ländern schon seit langem mit wachsendem und nur durch fiskalische Eigeninteressen gezügeltem Unbehagen betrachtet wird. Versuche einer fiskalischen Entflechtung von Bund und Ländern blieben in Ansätzen stecken. Die wachsenden Disparitäten in der Leistungsfäbigkeit der Länder, nicht zuletzt Begleiterscheinung regionalspezifischer Branchenkrisen, ließen die Finanzmacht des Bundes vielmebr noch deutlicher hervortreten. Das Strukturbilfegesetz bildete insoweit den Schlußpunkt einer kontinuierlichen Entwicklung.

3. Der Beitritt der fünf neuen Bundesländer und Ost-Berlins hat das Problem strukturell bedingter Ungleichgewichte innerbalb der Bundesrepublik nun noch einmal entscheidend ausgeweitet und der zentralistischen Entwicklung des Finanzwesens einen zusätzlichen Impuls gegeben. Hiervon ausgehend kommt nicht von ungefähr, daß die Ministerpräsidenten der Länder in ihrem sog. Eckpunkte-Beschluß vom 5.7.1990, der durch Art. 5 EV zu einer Empfehlung an den Gesetzgeber aufgewertet wurde, nachdrücklich eine Stärkung der Finanzautonomie und Eigenverantwortlichkeit der Länder gefordert baben.

4. Der Erfolg der inneren Einigung wird wesentlich davon abbängen, daß es gelingt, den aufgrund des sozialen und wirtschaftlichen Gefälles bis auf weiteres immensen Finanzbedarf der neuen Bundesländer in die Finanzwirtschaft der Bundesrepublik so recbtlich einzubin- 
den, daß die öffentliche Finanzordnung intakt bleibt. Dabei wird es auch darauf ankommen, für die zur Bewältigung der DDR-Erblasten notwendigen Transferleistungen in den Osten verfassungsrechtliche Kanäle auch außerbalb des überforderten Regelwerks des Finanzausgleichs zu schaffen.

5. Die zur Zeit wesentlichen finanzverfassungsrechtlichen Fragestellungen betreffen als sozialstaatlichen Aspekt vor allem den Gedanken der Herstellung „einheitlicher Lebensverbältnisse im Bundesgebiet", als bundesstaatliche Dimension die Forderung nach einer aufgabengerechten Verteilung des Finanzaufkommens auf Bund und Länder. Die Bezüge von föderativer Finanzverfassung und Länderneugliederung sind im Auge zu behalten.

\section{II.}

6. Das Leitbild der Herstellung „einheitlicher Lebensverbältnisse im Bundesgebiet" hat, obschon als solches im Grundgesetz (Art. $72 \mathrm{II}$ Nr.3, 106 III S.4 Nr.2 GG) nur unvollkommen ausgeformt, der föderativen Finanzordnung unserer Republik bisher entscheidende Stempel aufgedrückt. Die Frage seines finanzverfassungsrechtlichen Verpflichtungsgebaltes ist dabei weithin außerhalb einer übergreifenden Betrachtung geblieben. Sie bat aber nach dem Beitritt der neuen Länder mit ibrer tiefgreifenden Wirtschafts- und Finanzschwäche besondere Bedeutung gewonnen.

7. Den jeweils vertretenen Extrempositionen - Anerkennung eines umfassenden bzw. Leugnung jeglichen Verfassungsauftrages zur Herstellung „einheitlicher Lebensverhältnisse im Bundesgebiet" vermittels Maßnabmen im Bereich des Finanzausgleichs - ist nicht beizupflichten. Der Geltungsgrund eines übergreifenden Einheitlichkeitsgebotes siebt sich - nur, aber immerbin - auf die einigermaßen schmale Basis verwiesen, die ihm durch das Bundesstaatsprinzip selbst, das Sozialstaatsprinzip sowie durch die in Art. 20 I GG verwendete Wortkombination vom „sozialen Bundesstaat" vermittelt wird.

8. Demgegenüber wird etwa durch die Regelungen der Art.91 a, 104 a IV und 107 II GG sowie ibre legislatorische Umsetzung die Einheitlichkeit der Lebensverbältnisse im Bundesgebiet zwar gefördert, ohne daß indes deren Herstellung ein unmittelbares Rechtsgut der genannten Vorschriften bildete.

9. Unbeschadet der Forderung nach einem "sozialen Bundesstaat" bildet daber der Gesichtspunkt der Herstellung „einheitlicher Lebensverhältnisse im Bundesgebiet" nicht die einzige von Finanzverfassungs wegen in Betracht kommende regionalpolitische Staatszielbestimmung. Der einfache Gesetzgeber ist vielmehr finanzverfassungsrecht- 
lich an sich nicht gehindert, das Schwergewicht künftig von einer Politik der Unitarisierung und sozialen Egalisierung im Bundesgebiet mehr auf eine solche der regionalen Differenzierung zu verlagern.

10. Bleibt der Bundesgesetzgeber ungeachtet des auf ihm lastenden Differenzierungs- und Regionalisierungsdrucks bei seiner bisherigen Linie einer weitgehenden Egalisierung der staatlich beeinflußbaren Lebensverhältnisse im Bundesgebiet, so darf er unter Rücksichtnahme auf das aus dem Bundesstaatsprinzip und dem allgemeinen Gleichbeitssatz folgende föderative Gleichbehandlungsgebot hiervon die neuen Bundesländer nicht ausnehmen, unbeschadet der Möglichkeit, den Annäherungsprozeß über eine Reibe von Jahren zu strecken.

11. Die sich - abgeseben von der aus Art. 28 I GG folgenden Homogenitätspflicht der Länder selbst - stellende Frage, wer nach Maßgabe der Verpflicbtungskraft des Einheitlichkeitsgedankens für die Herstellung der Einbeitlichkeit der Lebensverbältnisse im Bundesgebiet finanziell aufzukommen hat, wird durch die gesamtstaatliche Verantwortung des Bundes nicht generell vorentschieden. Weder aus ibr und ibrer Ausprägung in Art.28 III GG noch aus solchen im Grundgesetz ausgefübrten konkreten finanziellen Einwirkungsmöglichkeiten des Bundes (wie Art. 104 a III, IV, 106 VIII, 91 a, 91 b und 107 II S.3 GG) oder aus der Natur der Sache ergibt sich eine übergreifende Aufgaben- und Lastenverteilungsregel, derzufolge von Finanzverfassungs wegen die Herstellung von Einheitlichkeit grundsätzlich Sache des Bundes ist.

12. Allerdings gebt die genuin staatliche Aufgabe der Systemliquidierung und Systemumstellung in der ehemaligen DDR nicht nur in ibren Auswirkungen über die Grenzen der einzelnen Länder binaus; sie kann auch nur mit der koordinierenden Unterstützung des Bundes wirksam ins Werk gesetzt werden. Das bedingt aus der Natur der Sache eine übergreifende Aufgabengesamtverantwortung, jedenfalls aber eine finanzstaatliche Aufgabe des Bundes, die neuen Bundesländer bei der Bewältigung ibrer DDR-Erblasten zu unterstützen. Hieran haben sich die alten Bundesländer in bündischer Solidarität angemessen zu beteiligen. Deren bislang als "Nachbarschaftsbilfen", "Paten-“ oder "Partnerschaften" bilateral gewährten Unterstützungen sind deimgegenüber, unbeschadet Art. 15 II EV, im Hinblick auf Art.104 a I GG verfassungsrechtlich fragwürdig, soweit es sich bei ibnen um Zwischenländerfinanzhilfen handelt.

13. Die besondere Aufgabenlast des Bundes und die finanzielle Mitverantwortung der Westländer für die die neuen Länder treffende Bereinigung ibres Erbes bestehen grundsätzlich unabbängig von einer ausdrücklichen verfassungsrechtlichen Zuweisung. Gleichwobl 
erscheint es jedenfalls nabeliegend, die spezifischen Vereinigungslasten von Bund und Westländern in einer besonderen Verfassungsvorschrift - etwa als neuer Art. 120 b GG - nach Verwaltungs- und Finanzverantwortung ausdrücklich $z u$ verdeutlichen. Die näbere Regelung könnte einem zustimmungsbedürftigen Bundesgesetz übertragen werden, dem es gegebenenfalls auch obliegen sollte, eine Einbeziehung der Bürger in die Verantwortung für die Ausräumung der DDR-Altlasten ins Werk zu setzen.

\section{III.}

14. Verfassungsrechtspolitisch ist es für die weithin geforderte Kursänderung der föderativen Finanzverfassung im Sinne einer entschiedenen Stärkung der Finanzautonomie der Länder gegenwärtig zu spät und zu früh zugleich - zu spät, weil offenbar das Gesetz der "antizipierenden Reaktion" die Beteiligten bis zur Herstellung der deutschen Einheit daran gebindert bat, die Entflechtung der föderativen Finanzverfassung ernsthaft $z u$ betreiben, zu früh, weil nach Beitritt der neuen Länder die schon bisher zwischen den Bundesländern bestebenden Disparitäten unter den berrschenden Gegebenheiten noch zunehmen müßten.

15. Die finanz- und leistungsschwachen Länder, insbesondere die neuen Bundesländer, können erst dann - ausgestattet mit einer erweiterten Finanzautonomie - in einen verstärkten Wettbewerb zwischen den Ländern und damit potentiell auch in eine größere Vielfalt der Lebensverbältnisse entlassen werden, wenn zuvor die enormen strukturellen Unterschiede angemessen abgebaut worden sind und damit eine Annäherung der Startbedingungen erreicht ist. Einer durchgreifenden Entflechtung der föderativen Finanzbeziehungen sollte deshalb eine etwa 10jäbrige Übergangsfrist ab 1995 vorangehen.

16. Für diese Übergangszeit sollte - im Interesse eines ersten horizontalen Angleichungseffekts zugunsten der strukturschwachen Länder und zugleich als erster Schritt zur Überfübrung der vom Bund gesetzlich vorgeschriebenen Geldleistungen in dessen alleinige Finanzverantwortung - eine teilweise Ausgabenverlagerung der Sozialbilfe auf den Bund erwogen werden. Der Rückzug des Bundes aus den Gemeinschaftsaufgaben sollte vorsichtig fortgesetzt werden. Aufrechterbalten werden sollten wäbrend der Übergangszeit die regionalpolitischen Mischfinanzierungen im Rabmen der Art. 91 a I Nr. 2 und 104 a IV GG. Am Abschluß der Zwischenphase könnte - im Bereich der reinen Landessteuern der konkurrierenden Bundessteuergesetzgebung - ein erster Versuch größerer Steuerautonomie der Länder stehen. 
IV.

17. Die bundesstaatliche Finanzverfassung fordert in ibrer borizontalen Dimension, die einzelnen Länder so am Finanzaufkommen im Bundesstaat zu beteiligen, daß alle Länder, also auch die schwächeren von ibnen, in der Lage sind, ibre verfassungsmäßigen Aufgaben sachgerecht wabrzunebmen.

18. Unbeschadet der wesensmäßigen Bedarfsbezogenheit des horizontalen Finanzausgleichs (Art.107 II S.1, 2 GG) können konkrete strukturspezifische Bedarfsprobleme einzelner Länder in seinem Rabmen keine Berücksichtigung finden. Denn Disparitäten in der Wirtschafts-, Verkebrs- und Siedlungsstruktur der Länder sind nach der Annäberung ibrer - daraus resultierenden - unterschiedlichen Finanzausstattung als länderfinanzausgleichsrelevante Gesichtspunkte grundsätzlich verbraucht.

19. Die Größenordnung der strukturbedingten Finanzbedarfe gerade der neuen Bundesländer recbtfertigt es als solche nicht, vom Grundsatz der Berücksichtigungsunfähigkeit strukturspezifischer Sonderbedarfe im horizontalen Finanzausgleich abzuseben. Abgemildert wird dies durch die aus der Natur der Sache folgende Aufgabenlast des Bundes und die finanzielle Mitverantwortung der Westländer für die die neuen Länder treffenden DDR-Erblasten (vgl. Leits. 12 und 13). Eine sinnvolle aufgabenerfüllungsbezogene Anwendung des Finanzkraftbegriffs gebietet andererseits, die insoweit von Bund und Westländern zugunsten der neuen Länder erbracbten Leistungen bei der Ermittlung der Finanzkraft der letzteren ganz oder teilweise in Ansatz $z u$ bringen. Damit wird zugleich einer ansonsten drobenden explosionsartigen Ausweitung des Ausgleichsvolumens und einer einseitigen West/Ost-Verlagerung des horizontalen Finanzausgleichs entgegengewirkt.

20. Abstrakte Bedarfskriterien, die zunächst zugunsten der Einwobnerzabl als eines allein tragfähigen Bedarfsindikators vernachlässigt werden durften, die aber aufgrund der neueren Entwicklung beute zusätzlich prägende, ibrerseits generalisierungs- und typisierungsfähige Maßstäbe des Bedarfs bilden, sind im Rabmen der Finanzkraftermittlung des borizontalen Finanzausgleichs vom Gesetzgeber ergänzend beranzuziehen, um die absoluten Erträge der Länder angemessen vergleichbar zu machen. Auf diese Weise könnten nach Maßgabe einer umfassenden Prüfung etwa die stark streuenden Lasten der Arbeitslosigkeit Berücksichtigung finden, soweit nicht die Sozialbilfelasten in die Ausgabenverantwortung des Bundes übernommen werden (vgl. Leits. 16). 
21. Bei der Bestimmung des, angemessenen “Finanzkraftausgleichs i.S. des Art. 107 II S.1 GG gebt es nicht um die Maximierung eines verfassungsrechtlich vorgegebenen Gutes, etwa der in Art.107 II GG nicht thematisierten "Einbeitlichkeit der Lebensverhältnisse“, sondern um eine Optimierung unter Abwägung miteinander in Konflikt stebender Ziele. Der einfache Gesetzgeber ist, solange der verfassungsrechtlich gezogene äußerste Rabmen nicht überschritten wird, nicht gebindert, bei der Abwägung einzelne Gesichtspunkte in den Vordergrund zu stellen, andere dagegen geringer zu gewichten. Das schließst grundsätzlich die gesetzgeberische Freibeit ein, den Finanzausgleich je nach Lage der politischen Dinge mebr in Richtung Länderautonomie und föderale Vielfalt oder mebr in Richtung Vereinbeitlichung auszugestalten. Die gegenwärtig besonderen Interessen der neuen Länder bedingen nicht, den Länderfinanzausgleich verfassungskräftig vor allem auf die „Herstellung einheitlicher Lebensverbältnisse" festzulegen (vgl. Leits. 10).

V.

22. Bei den Bundesergänzungszuweisungen (Art.107 II S.3 GG) bereitet vor allem die Berücksichtigungsfäbigkeit strukturbedingter Sonderlasten Scbwierigkeiten. Die sich ansonsten anbietende Unterscheidung zwischen intern verursachten und extern verursachten Sonderlasten läßt sich für sie kaum fruchtbar machen. Denn ob die Strukturschwäche eines Landes auf externe Ursachen oder auf interne Faktoren zurückzuführen ist, möglicherweise sogar auf externe und interne Ursachen gleichzeitig, wird kaum einmal zuverlässig zu klären sein. Nur die neuen Bundesländer dürfen erwarten, daß ibre grundlegende Strukturschwäche ibnen bis auf weiteres durchweg nicht als selbst zu bewältigende Konsequenz finanzstaatlicher Autonomie zugerechnet wird. Der Gesetzgeber darf sich deshalb vorerst darauf beschränken, neben der Verteilung von Ergänzungszuweisungen nach Feblbetragsschlüssel allein die strukturschwächebedingten Sonderlasten der neuen Länder $z$ berücksichtigen, soweit ibnen nicht bereits auf andere Weise Rechnung getragen wird.

23. Nach Ablauf der vorgeschlagenen Übergangsfrist wird der Gesetzgeber die Kompensation von Strukturschwächen der Länder durch Bundesergänzungszuweisungen allgemeingültig zu klären baben. Dabei könnte das Problem der Übernabme strukturbedingter Sonderlasten der Länder durch den Bund einiges von seiner Brisanz verlieren, wenn den Ländern im Rabmen einer fiskalischen Entflechtung schließlich auch eine größere Steuerautonomie eingeräumt und 
damit die bisherige Asymmetrie im Verhältnis von Einnabmeerzielungs- und Ausgabenverantwortung abgemildert wird. In der Konsequenz einer Stärkung der Länderautonomie läge es, die Zablung von Bundesergänzungszuweisungen nach Feblbetragsschlüssel so weit als möglich zugunsten einer entsprechenden Erböbung des Länderanteils an der Umsatzsteuer (vgl. Art. 106 III S.4 GG) zu reduzieren.

24. Die vom BVerfG neuestens herausgearbeitete Konstellation einer "extremen Haushaltsnotlage" sollte im Rabmen der Art.109ff. $G G$ in den Grundzügen verfassungsrechtlich geregelt werden.

\section{$V I$.}

25. Erscheint auch die Zeit für eine umfassende Reform der bundesstaatlichen Finanzverfassung nicht reif, so ist doch, was die neuen Länder anbetrifft, von einer Fortfübrung der bisherigen Eingangsphase über 1994 hinaus abzusehen. Insbesondere ist es grundsätzlich nicht angängig, den neuen Ländern mit einer fortdauernden Suspendierung des Länderfinanzausgleichs auch weiterbin ein entscheidendes Element föderativer Finanzverfassung und Staatlicbkeit vorzuentbalten.

26. Um auszuschließen, daß die für Ergänzungsanteile (Art.107 I S. 4, 2. Halbs.) zur Verfügung stehende Masse vollständig zugunsten der neuen Länder ausgeschöpft wird, sollte die Stenerschwäche als Maßstab des Bedarfs alsbald gegen andere, ost/west-neutralere Bedarfsindikatoren ausgetauscht werden. Nach Ablauf der Zwischenphase ist zu prïfen, ob nicht die Ergänzungsanteile als ein im Rabmen der Steuerertragsverteilung systemfremdes Element horizontaler Umverteilung überhaupt gestrichen werden und einer umfassenden Verteilung der Umsatzsteuer nach der Einwobnerzabl Platz machen können.

27. Der gesamtdeutsche Länderfinanzausgleich wird in den nächsten Jahren zu einer finanzpolitischen Daueraufgabe werden, deren schließlich beste Lösung ebenso schwer voraussehbar ist wie die wirtschaftliche und soziale Entwicklung in den neuen Bundesländern. Das Inkrafttreten einer die notwendige Zwischenphase ablösenden, dann umfassend erneuerten bundesstaatlichen Finanzverfassung sollte dem nächsten Jabrzehnt vorbehalten bleiben.

$V I I$.

28. Ein konkreter verfassungsrechtlicher Handlungsbedarf in Richtung einer territorialen Umgestaltung (Art. 29 GG) ergibt sich aus der Finanzverfassung nicht. Wie es nicht primäres Ziel einer Neugliede- 
rung sein kann, den Finanzausgleich zu entlasten, so soll nicht seinerseits der Finanzausgleich eine Neugliederung erzwingen wollen.

29. Sollten allerdings die Länder auf weitere Sicht mit einer fiskalischen Entflechtung der bundesstaatlichen Finanzbeziebungen in einen in dieser Weise bislang unbekannten Wettbewerb entlassen rerden, so wird auch zu prïfen sein, ob nicht durch eine Nengliederung von Ländern flankierend abgesichert werden muß, daß alle Länder nach wirtschaftlich-finanzieller Eigenpotenz und Beweglichkeit ibre Funktion als wirklich autonome Subsysteme im Gesamtstaat überzeugend ausfüllen können. 


\title{
Grundsätze der Finanzverfassung des vereinten Deutschlands
}

2. Bericht von Prof. Dr. Ferdinand Kirchbof, Tübingen

\author{
Inhalt
}

I. Die Ausgangslage: Konstitutionelle Kontinuität der Finanzordnung und aktuelle Finanzierung der deutschen Einheit ......................... 74

II. Die Grundbedingungen der Finanzverfassung. . . . . . 75

1. Die verfassungstypische Geltungskraft unter besonde-

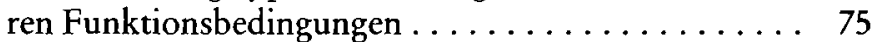

2. Die ökonomisch bedingte Offenheit der Finanzvorschriften ..................... 76

3. Die erweiterte Rolle des unbestimmten Rechtsbegriffs 76

4. Die Ordnung durch Verfahren in offener Zielsetzung . 77

5. Die Periodisierung und Segmentierung des Finanzwesens $\ldots \ldots \ldots \ldots \ldots \ldots \ldots \ldots \ldots \ldots \ldots$

III. Die Grundsätze der Finanzverfassung . . . . . . . 78

1. Die Bundesrepublik Deutschland als Finanzstaat ... 78

2. Das verfassungsrechtliche Bekenntnis zum Steuerstaat 78

3. Die Finanzgewalt als Ausdruck staatlicher Binnensouveränität . ................. 79

4. Das Prinzip der verläßlichen und kalkulierbaren Haushaltswirtschaft ................. 79

5. Die Funktion der Finanzartikel als Folgeverfassung . . 80

IV. Die staatliche Fundamentalordnung und die Folgeverfassung des Finanzwesens . . . . . . . . . . . . 81

1. Die Finanzierung im Bundesstaat . . . . . . . 81

a) Länderautonomie und Zentralstaatlichkeit . . . . . 81

b) Normative Letztverantwortung des Bundes . . . . 82

c) Enumerationsprinzip zur Sicherung der Bundesstaatlichkeit ................. 82

d) Monetäre „Einbahnstraße“ vom Bund zum Land . 83 
e) Pflicht zur Herstellung einheitlicher Lebensverhältnisse ................... 83

2. Das Finanzwesen als Instrument der Demokratie ... 85

3. Die Verfassungsordnung der Finanzen und das Verwaltungsrecht des Sozialstaats ............ 86

4. Die rechtsstaatlichen Schranken für die Finanzverfassung . . . . . . . . . . . . 87

a) Monetärer Maßstab und normative Rechtsregel . . 87

b) Prägung des Abgabensystems durch den Gleichheitssatz ................... 87

c) Wirkungsgrenzen des Übermaßverbots im Steuerrecht $\ldots \ldots \ldots \ldots \ldots \ldots \ldots \ldots \ldots, 88$

V. Die Reform des vertikalen Finanzausgleichs ....... 88

1. Die starre Verteilung der Steuern und die Übergangs-

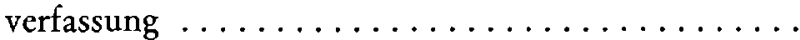

2. Notwendige Änderungen bei der Verteilung der Umsatzsteuer ........................

3. Funktionserweiterungen der Bundesergänzungszuweisungen $\ldots \ldots \ldots \ldots \ldots \ldots \ldots \ldots \ldots, 91$

a) Fortführung des Spitzenausgleichs ......... 91

b) Infrastrukturdotationen und Sonderbedarf der Länder ....................... 91

c) Hilfen im Finanznotstand . . . . . . . . . 92

4. Die Reduzierung der besonderen Finanztransfers . . . 93

5. Die Finanzierung der Ausführung von Bundesgesetzen durch die Länder . . . . . . . . . . . . . . . . 94

6. Der identische Leitgedanke aller vier Ausgleichsstufen 94

7. Die Einführung eines Gebots der Einheit des Transfergesetzes ..................... 94

VI. Die Reform des staatlichen Einnahmesystems ....... 95

1. Die Einbeziehung der Sonderlasten in die Finanzverfassung ................... 95

a) Expansion der Sonderlasten ............ 95

b) Fixierung der Gesetzgebungskompetenz für alle Abgaben ...................... 97

c) Ausdehnung der Ertragshoheitsregeln auf alle Einnahmequellen ................. 98

2. Die Gesetzgebungskompetenz bei lenkenden Steuern . 98

3. Die Ordnung der Umweltabgaben ........... 99

a) Das Vordringen der Umweltabgaben und die Zurückhaltung der Finanzverfassung ........ 99 
b) Der Vorrang der Finanzfunktion des Steuersystems .................... 100

c) Neue verfassungsrechtliche Kategorie der Umweltabgabe ................... 101

VII. Die Einheit des Staatshaushalts . . . . . . . . . . . . 102

1. Die Gefahren durch Sonderhaushalte .......... 102

2. Das Erfordernis sachlicher Rechtfertigung der Sonderhaushalte ........................ 103

3. Die Notwendigkeit einer Rückkehr zum Gesamthaushalt .......................... 105

a) Einheit in Verfahren und Haushalt . . . . . . . 105

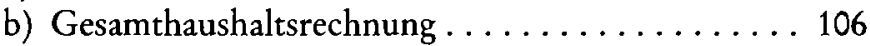

c) Gesamthaushaltsplan .............. 106

VIII. Staatsaufgaben und Staatsfinanzen $\ldots \ldots \ldots \ldots \ldots \ldots$ 


\section{Die Ausgangslage: Konstitutionelle Kontinuität der Finanzordnung und aktuelle Finanzierung der deutschen Einheit}

Funktionierende Staatswesen benötigen geordnete Finanzen. Das gilt vor allem, wenn die Aufgaben wachsen und damit die Ausgaben ansteigen. Das dafür erforderliche, solide Finanzierungssystem findet sein rechtliches Rückgrat in der Finanzverfassung. Sie verbindet den Finanz- mit dem Rechtsstaat, die ökonomische Realität mit der Staatsordnung.

Die Hoffnung, durch eine kurzfristige Anschubfinanzierung die östlichen Bundesländer auf die Beine zu bringen, hat getrogen. Eine desolate Infrastruktur, die zerrüttete Wirtschaft sowie zahlreiche ökologische und monetäre Altlasten standen entgegen. Zur Regelung der Finanzierung des Übergangs bedarf es deshalb mehr als nur eines vertraglichen ${ }^{1}$ Sonderrechts ab 1995. Zwar bleibt die Angleichung der wirtschaftlichen Strukturen zwischen Ost und West eine einmalige ${ }^{2}$, absehbare Aufgabe. Wegen ihrer Bedeutung für das Gemeinwesen und aufgrund ihres Finanzvolumens ${ }^{3}$ muß sie aber in der Finanzverfassung gelöst werden ${ }^{4}$.

Die Stichworte Sonderfonds, Schuldenkrise, Sonderabgaben und Ökosteuern belegen, daß weitere, allgemeine Fragen im Rahmen einer Novellierung zu klären sind. Hierbei sollte jedoch eine Überfrachtung des Grundgesetzes vermieden werden, um dessen Rahmen- und Grundsatzcharakter zu wahren ${ }^{5}$. So wäre es z. B. überzogen, den Grundsatz der Besteuerung nach der Leistungsfähigkeit einzufügen. Er entwickelt erst Konturen, und die Rechtsprechung ist auch ohne Positivierung bisher zurechtgekommen ${ }^{6}$.

1 Zum Inhalt des Sonderrechts z. B. Fiedler, DVBl. 1990, S. $1263 \mathrm{ff}$.

2 Vgl. Selmer, in: Stern (Hrsg.), Deutsche Wiedervereinigung, Band I, 1991, S. $189,203$.

31992 werden etwa $180 \mathrm{Mrd}$. DM vom Staat den fünf östlichen Bundesländern zugewendet; Monatsbericht Nr.3 der Deutschen Bundesbank, 1992, S. $15 \mathrm{ff}$. m.w.N. Zur Notwendigkeit einer Neuregelung wegen der Vereinigung Deutschlands z. B. Joachim Wieland, DVBl. 1992, S. 1181, $1182 \mathrm{f}$.

4 Vgl. Selmer, in: Stern (Hrsg.), Deutsche Wiedervereinigung, Band I, 1991, S. $189,196$.

5 Zur Offenheit der Finanzverfassung Hettlage, VVDStRL 14, S. 2, 31; Maunz, VVDStRL 14, S. 36, 60.

6 Z. B. BVerfGE 82, S. 60, 86; 55, S. 274, 302; 32, S. 303, 339; 27, S. 58, 64 u. 67; 8, S. 51, 68 f.; zu seinen normativen Grundlagen Vogel, Handbuch des Staatsrechts, Band IV, 1990, S. 3, 65; P. Kirchbof, StuW 1985, S. 319, $322 \mathrm{ff}$. 
Weil jede Finanzverfassung auf eine dauerhafte Finanzordnung ausgerichtet ist, hat die Novellierung zwei Teile zu umfassen: die Herstellung einer endgültigen Regelung für die Normallage im geeinten Deutschland und die finanzielle Eingliederung der neuen Bundesländer in den Gesamtstaat. Die Verfassung der Normalität ist das Grundanliegen konstitutionellen Bemühens, Übergangsvorschriften führen die östlichen Länder allein an die Normallage heran und verlieren danach ihre Legitimation. Sie dürfen nicht darüber hinaus perpetuiert werden.

Die Unterscheidung zwischen der Finanzverfassung des vereinten Deutschlands und dem Übergangsteil zur Vereinigung Deutschlands muß in der Systematik des Grundgesetzes erscheinen. Der zehnte Abschnitt sollte sich wie bisher der Normallage widmen, die besondere Aufgabe der finanziellen Vereinigung jedoch in den Übergangsund Schlußbestimmungen des Grundgesetzes fixiert werden. Das kennzeichnet die Singularität ${ }^{7}$ des Beitritts adäquat und sichert die Bedeutung der Übergangsregeln durch Verankerung im Grundgesetz. Die Trennung würde auch eine eventuell gesonderte Beratung des Problems der finanziellen Vereinigung im Parlament erleichtern.

Ich werde mein Referat auf die Verfassung der Normallage konzentrieren. Vorangestellt sind Ausführungen zu den Grundsätzen der Finanzverfassung, die für jegliche Novellierung gelten. Sodann wird der vertikale Finanzausgleich behandelt, zum Schluß Änderungsvorschläge zu den Krisengebieten der Einnahmen- und Haushaltsverfassung vorgetragen.

\section{Die Grundbedingungen der Finanzverfassung}

1. Die verfassungstypische Geltungskraft unter besonderen Funktionsbedingungen

Der deutschen Finanzverfassung wird einerseits nachgesagt, sie sei soft law minderer Geltungskraft ${ }^{8}$, andererseits spricht man ihr gerade wegen der Bedeutung des Finanzwesens besondere Geltung zu. Bei-

7 Die Rückgliederung des Saarlandes stellt keinen Vorläufer dar, der Maßstäbe für heute abgeben könnte; Fiedler, JZ 1990, S. 668, 669 f. Zu den dafür erlassenen Regeln s. $\$ 10 \mathrm{G}$ über die Eingliederung des Saarlandes v. 23.12.1956, BGBl. I S. 1011.

${ }^{8}$ Dagegen zu Recht Wendt, Handbuch des Staatsrechts, Band IV, 1990, S. 1021, 1025. 
des ist unzutreffend ${ }^{9}:$ Sie weist keine andersartige Geltungskraft auf; ihre Regelungsmaterie begründet aber Eigenheiten gegenüber anderen Bestandteilen der Verfassung. Sie steht unter speziellen Funktionsbedingungen, die sonst im Grundgesetz nicht herrschen und besondere Regelungstechniken verlangen.

\section{Die ökonomisch bedingte Offenbeit der Finanzvorschriften}

Ihre faktischen Prämissen beruhen auf ihrem wirtschaftlichen Regelungsgegenstand. Die deutsche Finanzverfassung ordnet die Erhebung und Verteilung von Finanzmitteln, die der Staat aus der Gesellschaft bezieht. Sie erwirtschaftet nicht eigene Geldquellen, sondern beteiligt sich über Abgaben an der Wirtschaftskraft im Lande ${ }^{10}$. Ihre Anpassung an ökonomische Gegebenheiten ist Bedingung ihres Funktionierens ${ }^{11}$. Deutlich tritt dies in der Finanzkrise der deutschen Einheit hervor: Die Finanzordnung beruht auf der Voraussetzung einer annähernd gleichmäßigen Wirtschaftskraft in den Bundesländern; im steilen Wirtschaftsgefälle versagen plötzlich ihre Normen. Die Abhängigkeit der Finanzverfassung von wirtschaftlichen Daten begrenzt die Steuerungsfähigkeit ihrer Normen, denn Rechtsregeln können keine Prosperität erzwingen ${ }^{12}$. Diese wirtschaftliche Prämisse gibt der Finanzverfassung ihre typische Offenheit. Sie muß sich über den Grundsatzcharakter aller Verfassungsregeln hinaus den aktuellen Wirtschaftsdaten öffnen, um aus einer variablen Wirtschaftskraft eine stetige Versorgung des Staates zu sichern. Steuerquellen können versiegen, Wirtschaftskraft kann sich verschieben, Geldbedarf sich ändern. Die Finanzverfassung muß alles tatbestandlich auffangen. Thre ökonomisch bedingte Offenheit gibt bekannten Rechtstechniken des Grundgesetzes ein besonderes Gepräge.

\section{Die erweiterte Rolle des unbestimmten Rechtsbegriffs}

Die Finanzverfassung erweitert die Rolle des unbestimmten Rechtsbegriffs. Solche Rechtsbegriffe sind in der Verfassung zwar verbreitet, denn es soll nur ein Rahmen für den Alltag des Gemeinwe-

9 Dazu BVerfGE 72, S. 330, 388.

10 BVerfGE 78, S. 249, 266.

11 Ähnlich BVerfGE 79, S. 311, 336 f.; 45, S. 1, 32; 34, S. 103, 117.

$12 \mathrm{Zu}$ den Grenzen staatlicher Wirtschaftslenkung durch den Haushalt Heinz Wagner, VVDStRL 27, S. 47, 56 ff. 
sens gesetzt werden. In der Finanzverfassung müssen sie aber die Variabilität der ökonomischen Daten auffangen und zugleich eine stabile Staatsfinanzierung garantieren. Die Verpflichtung des staatlichen Wirtschaftens auf das gesamtwirtschaftliche Gleichgewicht, die Lockerung der Kreditgrenzen bei dessen Störung und die Verteilung der staatlichen Finanzen anhand des Begriffs der Finanzkraft bilden keinen Webfehler in der Struktur der Finanzverfassung, der einem halbherzigen, politischen Kompromiß zu verdanken wäre. Sie spiegeln vielmehr die Notwendigkeit wider, variable, komplexe Wirtschaftsdaten in ein staatliches Finanzsystem einzubringen. Diese schwierige Erfaßbarkeit des ökonomischen Vorfelds gebietet der Gerichtskontrolle größere Zurückhaltung ${ }^{13}$. Unbestimmte Rechtsbegriffe bleiben auch künftig unentbehrlich, wenn wirtschaftliche Globalziele gesetzt oder veränderliche Wirtschaftslagen erfaßt werden sollen.

\section{Die Ordnung durch Verfabren in offener Zielsetzung}

Die Finanzverfassung enthält nur wenige abschließende, materielle Regeln, wie z. B. das starre Trennsystem zur Verteilung von Steuern. Statt endgültiger Entscheidungen sieht sie lieber Einigungsverfahren mit generellen Zielvorgaben vor. Der Finanzausgleich und das Budgetverfahren bieten dafür Beispiele. Das ist ebenfalls wegen des ökonomischen Umfelds erforderlich. Da die staatliche Entscheidung von zahlreichen außerrechtlichen, täglich wechselnden Vorgaben abhängt, kann die Verfassung das Finanzwesen nur durch Verfahren und in offener Zielsetzung ordnen. Selbst die rigide Verteilung der Steuern gelingt nur, weil daneben die Umsatzsteuer einfachgesetzlich verteilt wird und ausgleichen kann. Verfahren, die immer wieder neu betrieben werden müssen, geben der Verfassung den Anschein der Unvollständigkeit. Der Eindruck trügt, weil die Abhängigkeit von der jeweiligen ökonomischen Lage zu solchen Verfahren zwingt. Die Forderung an die Novellierung nach endgültigen, materiellen Regelungen ist zwar populär, aber unerfüllbar ${ }^{14}$. Abschließende Entscheidungen ergehen im Finanzwesen erst durch einfaches Steuer-, Haushalts- oder Finanzausgleichsgesetz. Nur dort wird die typische Frage des Finanzrechts entschieden, wie allgemeine Ordnungs- und Gerechtigkeitsvorstellungen monetär quantifiziert werden. Deshalb gleichen die

\footnotetext{
${ }_{13}$ S. dazu Ossenbü̈hl, in: FS für Carstens, Band 2, 1984, S. $743 \mathrm{ff}$.

14 Ähnlich aus der bundesstaatlichen Perspektive Lerche, VVDStRL 21, S.66, $97 \mathrm{f}$.
} 
abstrakten Fragen nach der gerechten Steuerhöhe oder der Angemessenheit der kommunalen Finanzausstattung auf der Verfassungsebene dem Problem der Quadratur des Kreises.

\section{Die Periodisierung und Segmentierung des Finanzwesens}

Diese Institutionalisierung von Verfahren führt zugleich zur Periodisierung des Finanzwesens. Es gliedert sich in ständig zu wiederholende, lückenlos aneinandergefügte Verfahren. Für jedes Jahr gibt es ein Budget, das Finanzausgleichsgesetz gilt für eine bestimmte Zeitspanne, Haushaltsrechnung und Finanzkontrolle geben über Jahresperioden Rechenschaft. Die allgemeine Dauerhaftigkeit des Gesetzes wird hier ins Gegenteil verkehrt. Die Finanzverfassung segmentiert das Finanzwesen in Zeitabschnitte, die Finanzgesetze sind typische Zeitgesetze.

\section{Die Grundsätze der Finanzverfassung}

\section{Die Bundesrepublik Deutschland als Finanzstaat}

Die Finanzverfassung bildet einen organischen Bestandteil des Grundgesetzes, der im Zusammenwirken mit den anderen Abschnitten einige Grundsatzaussagen über den Staat trifft. Sie konstituiert die Bundesrepublik Deutschland als Finanzstaat ${ }^{15}$, der seine Aufgaben regelmäßig auf monetärem Wege erledigt. Das entspricht der grundrechtlich gesicherten Freiheit von persönlichen Dienstleistungspflichten und dem Modell des mit einem eigenen Beamtenapparat ausgerüsteten Staates. Auch das Sozialstaatsprinzip, die Verpflichtung zu staatlicher Daseinsvorsorge und die Berechtigung zu wirtschaftlicher Intervention gehen davon aus, daß der Staat seine Aufgaben mit eigenen Geldmitteln erledigt.

\section{Das verfassungsrechtliche Bekenntnis zum Steuerstaat}

Die zur allgemeinen Staatsfinanzierung vorgesehene Steuer sowie die Eigentums- und Berufsfreiheit begründen den Steuerstaat ${ }^{16}$. Sie

${ }_{15}$ Schuppert, VVDStRL 42, S.216, 219.

16 Z.B. BVerfGE 78, S.249, 266f; Breuer, DVBl.1992, S.485, 488; Vogel (Fn.6), S.30; ders., Handbuch des Staatsrechts, Band I, 1987, S. 1151, 1181; Höfling, StuW 1992, S. 242, 243; Isensee, in: FS für Ipsen, 1977, S. 409 ff.; F. Kirch- 
geben ferner die grundsätzliche Trennung von Staat und Gesellschaft in den Finanzen vor. Denn der Staat wirtschaftet nicht selbst, sondern beteiligt sich lediglich durch hoheitliche Abgaben am Ertrag privaten Wirtschaftens ${ }^{17}$.

\section{Die Finanzgewalt als Ausdruck staatlicher Binnensouveränität}

Das Grundgesetz regelt die Finanzgewalt in einem eigenen Abschnitt, weil sie mittlerweile einen wesentlichen Bestandteil staatlicher Binnensouveränität darstellt ${ }^{18}$. Der moderne Staat greift mit Abgaben häufiger, intensiver und umfangreicher in bürgerliche Freiheiten ein als mit polizeilichen Mitteln. Interventionen in die Wirtschaft, Steuerlasten und Staatshaushalt wirken massiv auf Gesellschaft und Wirtschaft ein. Politik wird mit Geld betrieben. Der Souveränitätscharakter der Finanzgewalt erklärt, weshalb die Finanzverfassung als tragender Eckpfeiler staatlicher Struktur und politischer Machtverteilung bezeichnet wird ${ }^{19}$.

\section{Das Prinzip der verläßlichen und kalkulierbaren Haushaltswirtschaft}

Im Finanzwesen gilt der Grundsatz der verläßlichen und kalkulierbaren Haushaltswirtschaft mit verfassungsrechtlichem Rang, denn es dient in seiner Gesamtheit dem Zweck, jedem Glied des Bundesstaates ein stetiges und planbares Finanzaufkommen zu sichern ${ }^{20}$. So hat sich das Bundesverfassungsgericht zu Recht geweigert, einen Anspruch auf Nachholung unterbliebener Ausgleichszahlungen im horizontalen

hof, Die Verwaltung 1988, S. $137 \mathrm{ff}$.; Seidl, StuW 1987, S.185; kritisch dazu Püttner, Die öffentlichen Unternehmen, 2. Aufl. 1985, S. 197 f.; Hendler, AöR 115 (1990), S. 557, 595 ff. Zum Begriff Schumpeter, Aufsätze zur Soziologie, 1953, S. 1, $21 \mathrm{ff}$. Er besteht im Bereich der unmittelbaren Bundes- und Landesverwaltung, während Kommunen und mittelbare Staatsverwaltung bereits den Weg in den Abgabenstaat angetreten haben; F. Kirchhof, a. a. O., S. 141, $147 \mathrm{ff}$.

17 Vogel, Handbuch des Staatsrechts, Band I, 1987, S. 1151, 1173.

18 So schon Jean Bodin, Sechs Bücher über den Staat, übersetzt von Wimmer, 1981, Band I, S.313-315; zur historischen Entwicklung des Begriffs bei Steuern Quaritsch, Staat und Souveränität: Die Grundlagen, 1970, S. 432 ff.; für die aktuelle Situation z. B. Oppermann, Europarecht, 1991, S. 390.

${ }_{19}$ BVerfGE 78, S. 249, 266 m. w. N.; 72, S. 330, 388; 66, S. 274, 300 f.; 55, S. 274, $300 f$.

${ }^{20}$ Vgl. zu diesen Erwägungen BVerfG, DStR 1992, S. 1539, 1543; BVerfGE 72, S. 330,412 u. $422 ; 67$, S. 256,287 ff.; 39 , S. 96, 107. 
Finanzausgleich zuzuerkennen, da andernfalls wegen der Vielzahl der Beteiligten und der hohen Ausgleichsvolumina die Verläßlichkeit und Kalkulierbarkeit der aktuellen Haushaltswirtschaft gefährdet wäre ${ }^{21}$.

\section{Die Funktion der Finanzartikel als Folgeverfassung}

Weil Geld Mittel zum Zweck ist, fungiert die Finanzordnung des Grundgesetzes als Folgeverfassung. Grundlegende Strukturen eines Staates sind meist an seiner Finanzordnung abzulesen ${ }^{22}$, die sie mit monetären Kraftlinien nachzeichnet. Das Finanzwesen dient der verfassungsrechtlichen Organisation des Staates und seiner Aufgabenverteilung ${ }^{23}$. Art. 104 a GG bindet die Ausgabenkompetenz an die Aufgabenkompetenz. Art. 106 ff. GG verteilen die Finanzmittel nach einer anderweitig vorgezeichneten, föderalen Staatsstruktur. Die Finanzverfassung folgt den vorrangigen Organisations- und Aufgabennormen des Grundgesetzes ${ }^{24}$. Das Finanzwesen läßt sich deshalb auch durch eine Änderung der Staatsaufgaben reformieren, ohne daß man den Text der Finanzverfassung ändert. Eine Reduzierung der Staatsaufgaben ist sogar unerläßlich, denn sie wird am meisten zum Sparen im Haushalt beitragen. Die diskutierte Rückverlagerung von Kompetenzen auf die Länder wird einen Wechsel der Ausgabenlast mit sich bringen. Rechtlich sind dies jedoch keine Gegenstände der finanziellen Folgeverfassung mehr, sondern Materien der ihr vorgelagerten Ordnung der Staatsaufgaben. Weil die Finanzverfassung eine Folgeverfassung ist, bleibt $\mathrm{z}$. B. die mangelnde finanzielle Lebensfähigkeit kleiner Bundesländer ausschließlich Thema einer Änderung der Staatsorganisation; die Finanzverfassung muß den föderalen Aufbau akzeptieren und die Staatlichkeit aller Bundesländer sichern, solange diese bestehen ${ }^{25}$.

21 BVerfGE 72, S. 330, 422.

22 Hettlage bezeichnet die Finanzverfassung sogar als "Schwerpunkt" der gesamten Verfassung und den Finanzausgleich als "deutsche Gretchenfrage“, VVDStRL 14, S. 2, 6; Ronellenfitsch spricht vom „Spiegelbild der Staatsverfassung", Die Mischverwaltung im Bundesstaat, 1975, S. 184; Beispiele für die Kongruenz von Staatsform und Finanzverfassung bei P. Kirchbof, Handbuch des Staatsrechts, Band IV, 1990, S.87, 89 f.; ders., in: FS für Sendler, 1991, S. 65 ff.

${ }^{23}$ Wendt, in: Stern (Hrsg.), Deutsche Wiedervereinigung, Band I, 1991, S. 213.

${ }^{24} \mathrm{Zu}$ Einzelaspekten Friauf, in: FS für das Bundesverfassungsgericht, Band II, 1976, S. 300, 326; Starck, StuW 1974, S. 271, 272 f.; Lerche, in: FS für Berber, 1973, S. $299,310 \mathrm{ff}$.

${ }^{25}$ Lerche (Fn. 24), S. 299, 310 f. 


\section{Die staatliche Fundamentalordnung und die Folgeverfassung des Finanzwesens}

Als Folgeverfassung greift sie im monetären Thema vor allem die Fundamentalordnung des Staates auf: Sie verwirklicht das Bundesstaatsprinzip, sie verschafft der parlamentarischen Demokratie ein Werkzeug für die Politik, sie unitarisiert den Sozialstaat und versorgt ihn mit Finanzmitteln. Anders gestaltet sich nur ihr Verhältnis zum Rechtsstaatsprinzip: Hier begrenzt der Rechtsstaat die Finanzverfassung.

\section{Die Finanzierung im Bundesstaat}

\section{a) Länderautonomie und Zentralstaatlichkeit}

Die Finanzverfassung unterstützt das Bundesstaatsprinzip durch subtile Verteilung der Finanzhoheiten, weil erst die Finanzmacht den Gliedern des Bundesstaates zu Lebenskraft verhilft ${ }^{26}$. Sie sichert die Autonomie der Länder durch die Anordnung selbständiger Haushaltswirtschaft, das Konnexitätsprinzip, das Verbot der Mischfinanzierung, die starre Zuteilung von Steuererträgen sowie durch den Finanzausgleich. Dagegen zentralisiert die faktisch vollständige Bundeskompetenz zur Steuergesetzgebung, die Einheit der Steuerverwaltung sowie die überragende Finanzmacht des Bundes den Staat. Damit unterstützt die Finanzordnung das Konzept des gemischten Bundesstaates, der die Pole des föderalen und des zentralen Prinzips in einer Spannungslage austariert ${ }^{27}$. Wo sie ökonomisch flexibel reagieren muß, handeln Bund und Länder entsprechend der Ideale des Bundesstaates in Kooperation, indem der Bund über die Verteilung der Umsatzsteuer, über den Finanzausgleich und die Steuererhebung mit Zustimmung des Bundesrates beschließt. Zwischen den Ländern wird die Bundesstaatlichkeit durch die Gleichberechtigung ${ }^{28}$, das Einstimmigkeitserfordernis bei grundsätzlicher Pflicht zur Verständigung ${ }^{29}$ sowie das Gebot des Einstehens füreinander ${ }^{30}$ gewahrt.

Das vorrangige Bundesstaatsprinzip gibt der Finanzordnung weitere Konturen vor:

${ }^{26}$ BVerfGE 72, S. 330, 388; DVBl. 1992, S. 965, 966; BVerfGE 55, S. 274, 300; 32, S. 333, 338.

27 Zu diesem Konzept Häberle, Die Verwaltung 1991, S. 169, 185 f. und 1992, S. 1, 8.

\footnotetext{
28 BVerfGE 41, S. 291, 308 m.w. N.

29 BVerfGE 41, S. 291, 308 m. w. N.

30 BVerfGE 1, S. 117, 131.
} 


\section{b) Normative Letztverantwortung des Bundes}

Zwar sind Bund und Länder in grundsätzlicher Selbständigkeit miteinander finanziell verwoben. Die grundlegenden Regelungen in diesen Beziehungen werden aber durch Gesetze des Bundes getroffen. Es ist der Bund, der als letzte Instanz Ausgleichsleistungen, Ergänzungszuweisungen und Finanzhilfen gewähren darf. Er hat nach Art. 28 Abs. 3 GG die Staatlichkeit der Länder auch durch finanzielle Mittel zu garantieren ${ }^{31}$. Als Zentralinstanz trägt er die letzte Verantwortung für die Finanzen aller Staatsglieder. Sogar im Notstand gibt ihm Art. 115 c Abs. 3 GG auf, die finanzielle Lebensfähigkeit der Länder ${ }^{32}$ zu wahren. Das zwingt den Bund zwar nicht, allein aus eigener Tasche für Haushaltsdefizite der Länder oder die Kosten der deutschen Einheit aufzukommen, denn alle Beteiligten müssen füreinander einstehen ${ }^{33}$, verpflichtet ihn jedoch, Regeln für eine ausreichende Länderfinanzierung vorzusehen und im Verbund mit den leistungsfähigen Ländern Geldmittel für die leistungsschwachen bereitzustellen.

\section{c) Enumerationsprinzip zur Sicherung der Bundesstaatlichkeit}

Die meisten Finanzbeziehungen zwischen Bund und Ländern sind im Grundgesetz enumerativ aufgeführt ${ }^{34}$. Eine Finanzierung neben der Verfassung verstößt dann stets gegen die Verfassung. Enumerationen finden sich bei der Regelung der Ausgabe- und Steuerkompetenzen, im vertikalen Finanzausgleich und schließlich bei der Haushaltswirtschaft. Das Enumerationsprinzip verstärkt die Bundesstaatlichkeit. Es verbietet grundsätzlich Mischfinanzierung und Sonderfonds, verkürzt das Steuererfindungsrecht auf die in der Verfassung genannten Steuertypen ${ }^{35}$ und versagt zusätzliche, vertikale Finanzausgleiche. Die Eigenstaatlichkeit der Beteiligten wird dadurch gefördert.

31 Hettlage, VVDStRL 14, S.2, 35.

32 Davon war schon in Art. 8 Weimarer Reichsverfassung die Rede, um einen Einheitsstaat auszuschließen; Anschütz, Die Verfassung des Deutschen Reichs, 14. Aufl. 1933, Anm. 3 zu Art. 8 WRV.

${ }^{33}$ Statt vieler BVerfG, DVBI. 1992, S. 965, 966 u. 977; E 72, S. 330, 384 u. 386 f.; Korioth, DVBl. 1991, S. 1048, 1056.

${ }^{34}$ BVerfGE 67, S. 256, 275 u. 286 f.; 55, S. 274, 304; 39, S. 96, 107; für Art. 106 GG z. B. Vagel (Fn. 6), S. 3, 24 und 30 f.

${ }_{35}$ Vogel/Walter, in: Bonner Kommentar (Zweitbearbeitung), Rdn. $63 \mathrm{ff}$. zu Art. 105 GG; sehr weitgehend Wacke, DÖV 1955, S. 577, 579. 


\section{d) Monetäre "Einbabnstraße" vom Bund zum Land}

Finanzströme dürfen grundsätzlich nur vom Bund zum Land, nicht umgekehrt fließen ${ }^{36}$. Das Enumerationsprinzip errichtet zusammen mit vielen Einzelregelungen über vertikale Finanztransfers vom Bund an die Länder eine monetäre „Einbahnstraße “. Grundsätzlich ist nur dem Bund die Gewährung finanzieller Hilfen erlaubt. Der umgekehrte Weg wird allenfalls marginal und selten beschritten ${ }^{37}$. Dieser Grundsatz entspricht der Funktion des Bundes als dem Garanten des bundesstaatlichen Finanzwesens am besten und sollte beibehalten werden.

\section{e) Pflicht zur Herstellung einbeitlicher Lebensverbältnisse}

Zentralthema des Bundesstaates bleibt die Pflicht zur Herstellung einheitlicher Lebensverhältnisse im Bundesgebiet. Sie ist textlich zwar nur für einzelne Aspekte im Grundgesetz aufgeführt; sie bestimmt jedoch als allgemeiner, ungeschriebener Verfassungssatz das gesamte Finanzgeschehen. Die Notwendigkeit einheitlicher Lebensverhältnisse öffnet die Gesetzgebungskompetenz des Bundes für Steuern ${ }^{38}$ und führt damit zur Einheit im Steuerrecht. Bei der Aufteilung der Umsatzsteuer ${ }^{39}$ kann sich die Leitlinie zwar nur mittelbar auswirken, obwohl sie in Art. 106 Abs. 3 GG dafür unmittelbar genannt wird. Weil nicht die Binnenverteilung, sondern erst die Verwendung der Steuern im Außenbereich auf die Lebensverhältnisse einwirkt, wird die Einheitlichkeit aber letztlich als allgemeines Ziel angestrebt. Weitere Vorschriften greifen den Grundsatz mit anderem Wortlaut, aber identischem Ziel auf: Die Verpflichtung auf die Wahrung gesamtwirtschaftlichen Gleichgewichts soll u. a. ein Gleichgewicht innerhalb der

36 F. Kirchhof, in: FS für Dürig, 1990, S.447, 449 ff.; Vogel (Fn. 6), S. 3, $16 \mathrm{f}$. Bedenklich deshalb die vereinbarten Zahlungen der Länder von einer Mrd. DM an den Bund, die sich von 1962 bis 1972 erstreckten (Vogel, Finanzverfassung und politisches Ermessen, 1972, S. 20-27) und eine erneute Zahlung in etwa gleicher Höhe 1981 (S.Pagenkopf, Der Finanzausgleich im Bundesstaat, 1981, S. 208 und 314 f.); vgl. dazu ferner Vogel/Walter (Fn. 35), Rdn. 94 ff. zu Art. 106 GG; Renzsch, Finanzverfassung und Finanzausgleich, 1991, S. 75 ff., $175 \mathrm{ff}$. Das „EinbahnstraBen“-Prinzip wird vor allem im Bereich des Sozialversicherungsrechts verletzt, obwohl es in Art. 120 Abs. 1 S. 4 GG besonders verankert ist; BVerfGE 9, S. 305, 316 ff.; BSGE 47, S. 148, 154f. u. 157; 34, S. 177, 179 m. w. Nachw.; F. Kirchhof, Handbuch des Staatsrechts, Band IV, 1990, S. 395, 415 ff. m. w. N.

${ }^{37}$ Bei Gemeinschaftsaufgaben, dem Gewerbesteueranteil sowie Kriegsfolgelasten können Finanztransfers ausnahmsweise vom Land zum Bund laufen (Art. $91 \mathrm{~b}$ S. 2, 106 Abs. 6 S. 4 und 120 Abs. 1 S. 2 GG).

38 Art. 105 i.V.m. 72 GG.

39 Art. 106 Abs. 3 Nr. 2 GG. 
gesamten Wirtschaft herstellen, also Einheitlichkeit in der Wirtschaft hervorrufen. Wenn Finanzhilfen für Investitionen zum Ausgleich unterschiedlicher Wirtschaftskraft im Bundesgebiet gestattet werden, geht das Grundgesetz implizit davon aus, daß die Bundeseinheit bei unterschiedlicher Wirtschaftskraft gestört ist. Wenn der Bund die Zuschüsse zu den Lasten der Sozialversicherung tragen muß, wird finanziell deren Einheit dort hergestellt. Die Formel von der Einheitlichkeit der Lebensverhältnisse gilt also über den konkreten Einzelanlaß hinaus und ist mehr als eine politisch überhöhte Zielsetzung singulären Charakters. Sie ist deshalb in ihrer Bedeutung in der wissenschaftlichen Diskussion nicht überbewertet worden ${ }^{40}$. Man hat aber ihren Inhalt literarisch überstrapaziert. Sie bildet einen Verfassungsauftrag zur Regelung des Spannungsverhältnisses zwischen Länderautonomie und Staatseinheit im Finanzwesen.

Der Grundsatz der Einheitlichkeit sichert aber nur ein ökonomisches Mindestniveau ${ }^{41}$ im gesamten Bundesgebiet, ohne den Gliedern des Staates ihre Eigenständigkeit zu nehmen. Jedes Land muß über Finanzmittel disponieren können, die es ihm ermöglichen, eine Grundversorgung mit öffentlichen Leistungen für Einwohner und Wirtschaft bereitzustellen ${ }^{42}$. Trotz differenter Standortbedingungen in den einzelnen Bundesländern muß grundsätzlich zumindest die Möglichkeit ökonomischer Betätigung in allen Teilen des Bundesgebietes gewährleistet sein. Erforderlich ist eine in der Weise ähnliche Wirtschaftskraft jedes Staatsgliedes, daß die Verteilungsmechanismen der Finanzverfassung funktionieren. Diese Grundstandards müssen der Bundesrepublik Deutschland den Charakter eines einheitlichen Wirtschaftsraumes verleihen. Darüber hinaus kann sich dann der Wettbewerb unter den Ländern entfalten, die eigene Verantwortung für ihr Finanzhandeln tragen. Die Höhe des geforderten Mindestniveaus ist abstrakt nicht genauer darzustellen, weil sie von der gesamten Wirtschaftslage abhängt. Prosperiert z. B. die allgemeine Volkswirtschaft, sind einzelne Bundesländer berechtigt, auf Hilfe für ein höheres Niveau zu pochen, das sie in einer allgemeinen Rezession nicht einfordern könnten.

${ }^{40}$ Rechtspolitische Einwendungen gegen diesen Grundsatz bei Wendt (Fn. 8), S. $1050 \mathrm{f}$.

${ }^{41}$ Neumark, Schriften des Vereins für Socialpolitik, N.F. 96 (1978), S.165, 169 f.; Korioth, DVBl. 1991, S. 1048, 1057.

42 Harald Schneider, Gedächtnisschrift für Geck, 1989, S. 701, 707; Hohmann, DÖV 1991, S. 191, 193 ff.; Engel, in: Stern (Hrsg.), Deutsche Wiedervereinigung, Band I, 1991, S. 169, 170. 


\section{Das Finanzwesen als Instrument der Demokratie}

Die Finanzverfassung weist dem Parlament die Aufgabe zu, die finanziellen Grundentscheidungen zu treffen, denn die Finanzgewalt ist Bestandteil staatlicher Souveränität. Weil Geld Mittel der Politik ist, wandert die Macht über die Finanzen zur ersten Gewalt, obwohl das Einnehmen und Ausgeben an sich Administrativtätigkeit ist. Ihre Überleitung von der Exekutive zur Legislative war ein Hauptanliegen des Konstitutionalismus; das Schlagwort vom Budgetrecht als dem Königsrecht des Parlaments bringt dies zum Ausdruck. Heute wirkt die Macht der Legislative bis in Einzeltitel des Haushaltsplans, wie die Praxis der Sperrvermerke oder Einvernehmenserfordernisse zeigt ${ }^{43}$. Die Finanzverfassung fügt sich damit in das demokratische Prinzip ein. Die parlamentarische Demokratie enthält in der Finanzverfassung aber auch zwei gegenläufige Faktoren: Nachdem die Frontstellung zwischen Monarch und bürgerlichem Parlament aufgelöst ist, neigt das Legislativorgan heute zur Ausgabefreudigkeit; das Grundgesetz gibt deshalb ${ }^{44}$ der Bundesregierung das ausschließliche Initiativrecht für den Haushaltsplan sowie Ingerenzrechte bei ausgabenerhöhenden oder einnahmemindernden Gesetzen. Im Verbund mit der im Haushaltsverfahren überragenden Sachkenntnis der Gubernative hat sich die zweite Gewalt wieder ein Stück der Finanzhoheit zurückerobert. Zum anderen wird die Finanzgewalt des Parlaments durch das Institut einer weisungsungebundenen Bundesbank zur Sicherung der notwendigen Fachkompetenz und Unabhängigkeit begrenzt: Der Bundesbank steht die Selbständigkeit einer ministerialfreien Behörde zu, um die Stabilität des Geldwesens institutionell zu sichern ${ }^{45}$. Das mindert

${ }^{43}$ Dazu und zu deren rechtlichen Grenzen vgl. Friauf, VVDStRL 27, S. 1, 35; H. Schneider, Gesetzgebung, 2. Aufl. 1991, S. 147.

${ }_{44} \mathrm{Zu}$ den Vorläufern und Motiven des Art.113 GG Höpker-Aschoff, AöR 75 (1949), S. 306, 309.

$45 \$ 12$ S. 2 Bundesbankgesetz i.d. F.d. Bkm. v. 22. 10. 1992, BGBI. I, S. 1782, auf der Grundlage des Art. 88 GG. Die Verfassung gestattet die Unabhängigkeit, BVerwGE 41, S. 334, 349 ff., 354 ff. m. w. N.; das BVerfG spricht sogar (beiläufig) davon, daß die Bundesbank „kraft ihrer verfassungsrechtlichen unabhängigen Stellung keiner Aufsicht anderer Organe der Exekutive unterliegt" (E 62, S. 169, 183). Der Verfassungszusatz v. 21. 12.1992, BGBl. I, S. 2086, sieht nunmehr konsequenterweise als Art. 88 S.2 GG vor, daß „ihre Aufgaben und Befugnisse“ der Europäischen Zentralbank übertragen werden könnten, „die unabhängig ist“. Vgl. ferner z. B. zur Unabhängigkeit Herbert Scbönle, Bank- und Börsenrecht, 2. Aufl. 1976, S. 381; Carl-Theodor Samm, WM-Sonderbeilage Nr.5/1984, S. 13; Hans Jeckel, Die öffentliche Anstalt, 1963, S. 94; a. M. zuletzt Lucia Eckert, Bank-Archiv 1990, S. 415, 420 ff. jeweils m. w. Nachw. 
den Einfluß parlamentarischer Demokratie auf die Finanzgewalt, weil sie ökonomischen Einflüssen unterliegt und besonderen, professionellen Sachverstand erfordert. Diese auf Unabhängigkeit und Fachkompetenz gründenden Einschränkungen der Macht des Parlaments zeigen die Funktionsgrenzen der Demokratie und die notwendigen Ergänzungen dieses Prinzips im Staate auf. Es dürfte eine der spannendsten Fragen der Verfassungsentwicklung werden, ob sich der Einbau von Gegengewichten zum demokratischen Prinzip zu einem allgemeinen Trend entwickeln wird. Es erweist sich hier zumindest deutlich, daß jede Finanzordnung die allgemeine Struktur eines Staates widerspiegelt, vielleicht sogar deren sensibelster Seismograph ist.

\section{Die Verfassungsordnung der Finanzen und das Verwaltungsrecht des Sozialstaats}

Der leistende Sozialstaat verwirklicht sich in Deutschland vornehmlich durch Geld. Notwendige Sach- oder Dienstleistungen werden meistens von Dritten erbracht, vom Sozialstaat lediglich finanziert. Das Finanzwesen ist für ihn deshalb von großer Bedeutung. Die Finanzverfassung unterstützt das Sozialstaatsprinzip durch Bereitstellung von Geldern. Darüber hinaus prägt sie aber diesen Fundamentalgrundsatz des Staates kaum. Die finanziellen Transaktionen des Sozialstaates gehen von zahlreichen, separaten Sozialleistungsträgern aus, denen oft eigene Abgaben und autonome parafisci zustehen. Das drängt die finanzielle Ausgestaltung des Sozialstaatsprinzips vom Verfassungsrecht in das Verwaltungsrecht und ins Detail ${ }^{46}$. Allein Art. 120 GG bildet die Konturen des Sozialstaats weiter aus. Nach dieser Vorschrift hat der Bund alle Zuschüsse zur Sozialversicherung zu tragen, den Ländern stehen keine Befugnisse zur Finanzierung $\mathrm{zu}^{47}$. Wegen ihrer generellen Aussage gehört diese Vorschrift eigentlich nicht in den Schlußteil der Verfassung, sondern müßte in Art. 104 a GG aufgenommen werden ${ }^{48}$. Die in Art. 120 GG liegende Grundentscheidung fügt dem Sozialstaat ein egalisierendes Moment hinzu.

46 Der Sozialstaat verwirklicht sich primär durch einfaches Gesetz; s. z.B. Bachof, VVDStRL 12, S. 37, 43 f.; Badura, Die parteienstaatliche Demokratie und die Gesetzgebung, 1986, S. $8 \mathrm{f}$.

47 F. Kirchbof (Fn. 36), S. 395, $415 \mathrm{ff}$.

48 Die Regelung des Art. 120 GG wurde nicht in die allgemeine Vorschrift über die Lastenverteilung aufgenommen, weil die Kriegsfolgelasten auslaufen (vgl. Franz Klein, FR 1966, S. 166, 168). Das gilt aber nicht für die in Art. 120 Abs. 1 S. 4 GG verankerte Lastenregelung über die Zuschüsse zur Sozialversicherung. 


\section{Die rechtsstaatlichen Schranken für die Finanzverfassung \\ a) Monetärer Maßstab und normative Rechtsregel}

Die Finanzverfassung unterstützt den Rechtsstaat weder unmittelbar noch eigenständig. Sie sichert ihn zwar objektiv, indem sie Gelder für Gerichte und Rechtsgarantien ${ }^{49}$ bereitstellt. Geld gestaltet aber den Rechtsstaat nicht. Er darf gerade nicht nach monetärem Maßstab, sondern muß nach gesetzlichen Wertungen funktionieren. Lediglich Ansprüche gegen Behörden oder Teilhaberechte am Staat stehen unter der Bedingung des finanziell Möglichen, sind nämlich auf das beschränkt, „was der Einzelne vernünftigerweise von der Gesellschaft beanspruchen kann" ${ }^{\text {"50 }}$.

\section{b) Prägung des Abgabensystems durch den Gleichbeitssatz}

Im Gegenteil begrenzt das Rechtsstaatsprinzip das Finanzwesen. Vor allem im Abgabenrecht sichert es den Bürger durch Grundrechte und den Verhältnismäßigkeitsgrundsatz. Die Grundrechte werden vom Bundesverfassungsgericht allerdings immer noch zu zögerlich aktiviert. Art.14 GG spielt fast keine Rolle, weil die Rechtsprechung ihn mit der begrifflichen Trennung von Vermögen und Eigentum auf ein Verbot konfiskatorischer Abgaben reduziert hat $^{51}$. Andere Freiheitsrechte ${ }^{52}$ gewinnen in der Gerichtspraxis an Bedeutung; ihre stärkere Berücksichtigung im Abgabenrecht ist dringend angezeigt. Im Vordergrund steht aber der Gleichheitssatz $^{53}$. Er prägt die Gliederung des Systems aus allgemeinen und besonderen Abgaben und verpflichtet den Gesetzgeber, die Variation von Abgabesätzen systemgerecht zu gestalten. Als Prinzip der Steuergerechtigkeit erlaubt er eine Belastung nach der Leistungsfähigkeit des Steuerschuldners ${ }^{54}$. Andere Ziele der Besteuerung müs-

49 Z.B. Art. 2 Abs. 1 i.V.m. 1 Abs. 1 , Art. 5 Abs. 1 S. 2 und Abs. 3, Art. 6 Abs. 1 und 7 Abs. 4 GG.

50 BVerfGE 33, S. 303, 333.

51 Z. B. BVerfGE 82, S. 159, 190.

52 Z.B. Art. 2 GG: BVerfGE 82, S.159, 190; Art. 6 GG: BVerfG, DStR 1992, S. 1539; BVerfGE 82, S.60, 86 ff.; Art. 12 GG: BVerfGE 16, S. 147, 162.

${ }_{53}$ Z. B. BVerfGE 84, S. 239, $269 \mathrm{ff} . ; 82$, S. $60,86 \mathrm{ff}$.

${ }_{54}$ Z. B. BVerfGE 82, S.60, 86; 55, S.274, 302; 32, S. 303, 339; BVerwG, NJW 1989, S.1747, 1748; Maunz, VVDStRL 14, S.36, 59; Söbn, FinArch.46, S. $154 \mathrm{ff}$;; Tipke, StuW 1988, S.262, $269 \mathrm{ff} . ;$ Vogel, in: Gedächtnisschrift für Martens, 1987, S. 265, $273 \mathrm{ff}$.; Wendt, DÖV 1988, S.710, $712 \mathrm{ff}$. 
sen sich sachlich legitimieren, können aber mit der Anknüpfung an die Leistungsfähigkeit konkurrieren ${ }^{55}$.

\section{c) Wirkungsgrenzen des Übermaßverbots im Stewerrecht}

Das Übermaßverbot spielt eine geringere Rolle als im übrigen Recht staatlicher Eingriffe. Es greift zwar bei lenkenden Abgaben, denn dort gibt der Lenkungszweck die notwendigen Wertungsaspekte vor. Bei reinen Finanzzwecksteuern versagt es jedoch ${ }^{56}$. Auch wenn die Steuerschraube heftiger angezogen wird, bleibt die Steuer bei fast jedem Satz geeignet zur Finanzierung der Staatsaufgaben, ist sie erforderlicher Eingriff, weil eine geringere Last in der Regel weniger Einnahmen bewirkt, und bleibt sie wegen des höheren Ertrags angemessen. Allein der unscharfe, personenorientierte Maßstab der Zumutbarkeit kann noch wirken. Da das Verhältnismäßigkeitsprinzip so seinen mäßigenden Einfluß verliert, bindet der Rechtsstaat die Steuer enger an ein inhaltlich bestimmtes und förmliches Abgabenge$\operatorname{setz}^{57}$. Daneben ergibt sich ein weitergehender steuerrechtlicher Gesetzesvorbehalt aus der allgemeinen Schwierigkeit, materielle Gerechtigkeitsvorstellungen in Bemessungsgrundlage und Steuersatz zu quantifizieren. Insoweit lebt die Steuer tatsächlich vom Diktum des Gesetzgebers.

Mit diesen Mechanismen, welche die Staatsstrukturen finanziell abbilden und stärken, die Bewegungen der Wirtschaft normativ erfassen und ihrerseits vom Rechtsstaat in Schranken gehalten werden, erfüllt die Finanzverfassung ihren Auftrag.

\section{Die Reform des vertikalen Finanzausgleichs}

Die folgenden Erwägungen zu ihrer Reform werden ein Modell für den künftigen vertikalen Finanzausgleich sowie Verbesserungen im Einnahmen- und Haushaltsbereich vorstellen. Meine Überlegungen versuchen, dem System der Finanzverfassung und ihrem ökonomischen Vorfeld gerecht zu werden, indem sie die im Grundgesetz bereits angelegten Strukturen und Prinzipien fortführen. Sie müssen die Anpassung der Finanzordnung an die neue wirtschaftliche Lage

55 Dazu s. Birk, Das Leistungsfähigkeitsprinzip als Maßstab der Steuernormen, 1982, S. 237.

56 BVerfGE 84, S. 239, 268 f.; Vogel (Fn. 54), S. 265, 270.

57 Vogel (Fn. 54), S. 265, $268 \mathrm{ff}$. 
anleiten. Ferner sind die in zwei Jahrzehnten gewonnenen Erfahrungen mit der z.Z. geltenden Finanzverfassung zu berücksichtigen. Fragen, die nicht im Weiterdenken grundgesetzlicher Vorgaben, sondern nach politischem Ermessen zu entscheiden wären, bleiben deshalb unbeantwortet. Weil diese Erwägungen ausschließlich verfassungsrechtliche Tendenzen fortführen wollen, kann ich lediglich Grundsatzlösungen anbieten statt ausgefeilter Details; gerade in der Verfassungsdiskussion dürfen politische Entscheidungen nicht als konstitutionelle Notwendigkeiten ausgegeben werden.

Den vertikalen Finanzausgleich bewältigt das Grundgesetz in vier Stufen: durch Regeln über die feste Verteilung der Erträge einzelner Steuerarten im Grundgesetz selbst, durch einfachgesetzliche Aufteilung der Umsatzsteuer, mit Ergänzungszuweisungen des Bundes und schließlich mit einer Palette verschiedener, zusätzlicher Finanztransfers.

\section{Die starre Verteilung der Stenern und die Übergangsverfassung}

Die starre Steuerverteilung im Grundgesetz als erste Stufe hat sich bewährt. Sie wird weiter praktikabel bleiben, solange die Umsatzsteuer ein genügendes Volumen als Finanzpuffer zur Feinsteuerung aufweist. Das Trennsystem sichert die Autonomie der Länder, denen der jährliche Kampf um Steueranteile erspart wird; es garantiert ein planbares Finanzaufkommen und ermöglicht eine kontinuierliche Haushaltspolitik; es stimuliert das Interesse jedes Beteiligten am Gedeihen der eigenen Wirtschaft, weil daraus die Finanzquellen sprudeln. Da Ergänzungszuweisungen und sonstige Finanztransfers des Bundes nur zum Spitzenausgleich dienen oder sonstige Aushilfsdienste leisten sollen, würde das z.Z. herrschende, extreme Wirtschaftsgefälle zwischen Ost und West in der Vertikalen am besten bereits bei der Ertragsverteilung berücksichtigt. Die Übergangsverfassung könnte das Aufkommen einzelner Steuern ganz oder teilweise, nach örtlicher Vereinnahmung oder nach Prozenten des Gesamtaufkommens, befristet oder bedingt, den östlichen Bundesländern zusprechen. Hierfür ließen sich z. B. die Mineralöl- oder die Tabaksteuer des Bundes einsetzen ${ }^{58}$. Die Zuweisung auf der ersten Stufe fester Distri-

58 Sie haben 1991 folgende Erträge gebracht: Mineralölsteuer 47,3 Mrd. DM, Tabaksteuer 19,6 Mrd. DM (Monatsbericht Nr. 8 der Deutschen Bundesbank, 1992, S. 62). 
bution würde den neuen Ländern autonomieschonend ${ }^{59}$ einen grundgesetzlich fixierten Ertragsvorteil gewähren, der ihnen aus ihrer wirtschaftlichen Talsohle heraushelfen könnte. Die besondere Zuweisung einer Steuer des Bundes würde ihren Blick für die Belange der gesamten Wirtschaft des Bundes schärfen. Die Stabilität ihrer Haushalte würde durch die Übertragung einer Einnahmequelle gestärkt. Der befristete Verzicht auf die Gleichbehandlung aller Länder wäre aufgrund des extremen Wirtschaftsgefälles legitimiert.

Auch der Umsatzsteueranteil des Bundes würde sich für diesen Ausgleichszweck eignen; die höhere Beweglichkeit einfachgesetzlicher Zuweisung würde allerdings durch eine größere Unsicherheit und dauernde politische Abhängigkeit für die fünf Empfängerländer erkauft.

\section{Notwendige Änderungen bei der Verteilung der Umsatzsteuer}

Auf der zweiten Stufe, der Umsatzsteuerverteilung durch einfaches Gesetz, drängt sich eine Entrümpelung des Art. 106 Abs. 3 GG von den dort überreich aufgelisteten Gesetzeszielen auf ${ }^{60}$. Die Leitlinien - billiger Ausgleich, Vermeidung einer Überbelastung der Steuerpflichtigen und Einheitlichkeit der Lebensverhältnisse - sind zwar literarisch intensiv beäugt worden. Sie sind aber teilweise inhaltslos, harmonieren wenig oder können im vertikalen Ausgleich überhaupt nicht verwirklicht werden ${ }^{61}$. Die Praxis des politischen Kompromisses hat sie meist übergangen.

Ferner sollte man auf das Deckungsquotenverfahren zugunsten einer Orientierung am abstrakten Finanzbedarf verzichten. Die z.Z. geltende Verteilung durch Vergleich der laufenden Einnahmen mit den notwendigen Ausgaben reizt die Beteiligten, Ausgaben zu überhöhen und Defizite zu erzeugen, weil sie nur so die Quote ändern und Transferansprüche begründen können ${ }^{62}$. Die einem geringeren Finanzaufkommen zugrundeliegenden Strukturprobleme werden dadurch aber weder offengelegt noch gelöst. Der Sonderbedarf einzel-

59 Die ausreichende Finanzausstattung der Länder besitzt generell Vorrang vor der Zuteilung von Finanzhilfen; Friauf (Fn.24), S. 325 ff.; M. Kilian, JZ 1991, S. $425,429$.

60 Ähnlich Vogel (Fn.6), S. 21.

${ }^{61}$ Korioth, DVBl. 1991, S. 1048, 1056.

62 Bad.-Württ. Kommission „Finanzverfassungsreform“, Zwischenbericht v. 16. 1. 1992, S. 7; Sachverständigenrat zur Begutachtung der gesamtwirtschaftlichen Entwicklung, Jahresgutachten 1990/91, Tz. 444. 
ner Länder sollte zur Wahrung stabiler Ertragszuweisung erst auf späteren Stufen berücksichtigt werden.

\section{Funktionserweiterungen der Bundesergänzungszuweisungen}

a) Fortfübrung des Spitzenausgleichs

Die dritte Stufe der Bundesergänzungszuweisungen schließt sich an den horizontalen Finanzausgleich an. Die Bundesergänzungszuweisungen könnten künftig zu drei Zwecken eingesetzt werden: Zum ersten sollten sie - wie bisher - dem Spitzenausgleich von Finanzkraftunterschieden der Länder dienen; in dieser Funktion müssen sie den gleichen Berechnungsweisen wie der horizontale Finanzausgleich folgen ${ }^{63}$. Mit dem Ziel der Herstellung einheitlicher Lebensverhältnisse würden sie einen ausreichenden Leistungsstandard der Länder bewirken, der den Bundesstaat wirtschaftlich zum Gesamtstaat macht.

\section{b) Infrastrukturdotationen und Sonderbedarf der Länder}

Als zweite Zielsetzung ${ }^{64}$ sollte man die Ursachen der unterschiedlichen Wirtschaftskraft in den Ländern mit präzise bestimmten Infrastrukturdotationen bekämpfen. Angezeigt wäre es, eine Verpflichtung des Empfängerlandes festzulegen, welche Strukturdefizite damit abgebaut werden sollen; würde man sie durch zustimmungsbedürftiges Bundesgesetz schaffen, wäre die Autonomie der Länder genügend gewahrt. Diese Zwecksetzung würde es ermöglichen, zugleich auf die unscharfen Subventionstatbestände des Art. 104 a Abs. 4 GG zu verzichten, die - wie z.B. beim Strukturhilfegesetz ${ }^{65}$ - apokryphen Nebenfinanzausgleichen Tür und Tor öffnen. Ferner könnte hier ein unvermeidbarer Sonderbedarf ${ }^{66}$ einzelner Länder befriedigt werden, sofern er nicht auf eigenen, politischen Entscheidungen beruht ${ }^{6}$. Seine Unabweisbarkeit müßte allerdings nachgewiesen werden; die

${ }^{63}$ Vgl. BVerfG, DVBl. 1992, S. 965, 976.

${ }^{64}$ Das ginge über deren bisherige Zielsetzung subsidiärer Fortsetzung des vertikalen, allgemeinen Ausgleichs hinaus.

65 V. 20.12 .1988 (BGBI. I S. 2358); aufgehoben durch G v. 16. 3. 1992, BGBI. I S. 674, für das Jahr 1992, aber im Ergebnis weitergeführt durch G v. 25.8. 1992, BGBI. I S. 1547 .

66 Wie bereits jetzt möglich, BVerfGE 72, S.330, 402 u. 404 f.; DVBl. 1992, S. $965,976$.

67 BVerfGE 72, S. 330, 405; DVBl. 1992, S. 965, 976. 
Berufung auf allgemeine Erwägungen oder Herkömmlichkeit ${ }^{68}$ genügt nicht. Die Schwelle für die Berücksichtigung von Sonderbedarf sollte sehr hoch angesetzt werden; sonst besteht die Gefahr, daß die Länder die Büchse der Pandora öffnen und das Unheil in Gestalt von Gegenrechnungen herausquillt. Wenn man zuließe, daß Flughäfen und Bahnknotenpunkte gegen Seehäfen oder unterversorgte ländliche Gebiete gegen Ballungszentren aufgerechnet werden ${ }^{69}$, würde das Verfahren zersplittert und eine ausgewogene Gesamtlösung gehemmt.

\section{c) Hilfen im Finanznotstand}

Drittens sollten Bundesergänzungszuweisungen helfen, die Existenz der Länder zu retten, die in extreme Haushaltsnotlage geraten sind. Das Bundesstaatsprinzip und die besondere Verantwortung des Bundes zur Wahrung der Eigenstaatlichkeit der Länder aus Art. 28 Abs. 3 GG verpflichten zu derartigen $\mathrm{Hilfen}^{70}$. Sie können ohne Verfassungsnovelle im herkömmlichen Verfahren mit dem bisherigen Instrument der Bundesergänzungszuweisung geleistet werden ${ }^{71}$. Der Anspruch auf Gewährung von Finanzhilfen birgt allerdings Gefahren in sich. Da Ergänzungszuweisungen auch bei politisch verursachtem Haushaltsnotstand zu leisten sind, könnte ein Land zum munteren Schuldenmachen und zu aufwendigen Ausgaben verleitet werden ${ }^{72}$. Deshalb sollte es möglich sein, Finanzhilfen auf der Grundlage einer Finanznotstandsverfassung mit Auflagen zu versehen ${ }^{73}$. Die Zuweisungen müßten vor allem ein Sanierungsprogramm des Empfängers voraussetzen ${ }^{74}$. Bei nicht strukturell bedingtem Haushaltsnotstand sollte man sogar mit der Hilfeleistung ex constitutione die Finanzgewalt des Landes begrenzen. Z. B. würde eine derartige Finanznotstandsverfassung mit einem obligatorischen Einstellungsstop, dem Verbot der Höherbewertung von Dienstposten, der Plafondierung

68 So aber BVerfGE 72, S. 330, $413 \mathrm{ff}$. bei der Betrachtung des gesamten Finanzausgleichs.

69 Zur momentanen, unbefriedigenden Situation im Finanzausgleich s. BVerfGE 72, S. 330, $413 \mathrm{ff}$.; DVBl. 1992, S. 965, $971 \mathrm{ff}$.

70 BVerfGE 72, S. 330, 405; DVBl. 1992, S. 965, 977.

${ }_{11}$ Z.Z. müssen die Bundesergänzungszuweisungen dafür eingesetzt werden; BVerfG, DVBl. 1992, S. 965, 976 u. 978.

72 Vor allem weil die Finanzierungsquote, also das Verhältnis zwischen NettoKreditaufnahme und Einnahmen oder Ausgaben im Haushalt, einen Notstand indiziert (BVerfG, DVBl. 1992, S. 965, 976).

${ }_{73} \mathrm{Vgl}$. auch BVerfG, DVBl. 1992, S. 965, 978.

74 Ähnlich BVerfG, DVBl. 1992, S. 965, 978. 
gewisser Ausgaben oder dem Ausschluß bestimmter Subventionen zwar hart reagieren, aber die Haushaltsnotlage wirkungsvoll bekämpfen, vielleicht sogar vermeiden können.

\section{Die Reduzierung der besonderen Finanztransfers}

Auf der vierten Stufe des vertikalen Distributionssystems findet sich eine Vielfalt von speziellen Dotationsbefugnissen, Mischfinanzierungen und Gemeinschaftsaufgaben, die alle zu Finanztransfers vom Bund zu den Ländern führen ${ }^{75}$. Weil mit diesen Hilfen die vorangegangenen drei Stufen konterkariert und die Autonomie einzelner Bundesländer bedroht werden $\mathrm{kann}^{76}$, sollten sie radikal reduziert werden. Wo ein dringender Sonderbedarf Einzeltransfers unerläßlich macht, sollte er schon bei den Bundesergänzungszuweisungen auf der dritten Stufe berücksichtigt, statt in einem Sondertatbestand auf der vierten Stufe verfassungsrechtlich typisiert werden. Auf der dritten Stufe muß er nämlich in jedem Einzelfall benannt und im Detail begründet werden ${ }^{77}$, während bei den heutigen Dotationsbefugnissen das Grundgesetz bereits mit der Aufstellung des Dotationstatbestandes die Frage entschieden hat, daß bestimmte Arten des Sonderbedarfs von großem Gewicht und hoher Dringlichkeit sind. Heute kann die Verbesserung der regionalen Wirtschaftsstruktur stets nach Art. 91 a GG vom Bund mitfinanziert werden, selbst wenn das bezuschußte Land dafür genügend Finanzmittel besitzt, weil diese Aufgabe im Verfassungstext allgemein aufgeführt ist; fiele sie unter die Sonderbedarfszuweisungen der dritten Stufe, müßte jedes einzelne Verbesserungsvorhaben separat seine Besonderheit und Rechtfertigung begründen. Wo Einzelbefugnisse dennoch unerläßlich bleiben, müssen zumindest die dafür verwendeten unbestimmten Rechtsbegriffe präzisiert werden ${ }^{78}$, denn deren Offenheit ist nicht mehr in der allgemeinen Zielsetzung und im Erfassen beweglicher Wirtschaftsdaten begründet; hier werden konturenscharfe Tatbestandsvoraussetzungen für bundesstaatsgefährdende Finanzhilfen benötigt.

${ }^{75}$ F. Kirchhof, in: FS für Dürig, 1990, S. 447, 448f.; sie übertreffen in ihrer Gesamtheit das Volumen des Finanzausgleichs, Donner, ZRP 1985, S. 327, 329.

76 Z. B. Starck, StuW 1974, S. 271, $273 \mathrm{ff}$.

77 BVerfGE 72, S. 330,405 u. 420.

78 Über die rechtlichen Unfälle, zu denen unbestimmte Rechtsbegriffe als Tatbestandsvoraussetzungen von Dotationen führen, vgl. Fischer-Menshausen, Schriften des Vereins für Socialpolitik, N.F. 96 (1978), S. 135, 145 ff. 


\section{Die Finanzierung der Ausführung von Bundesgesetzen durch die Länder}

Die Ausgabenkompetenz in Art. 104 a GG veranlaßt einen vertikalen Finanztransfer, sobald der Bund den Ländern Zweckausgaben erstattet $^{79}$. Die Ausgabenlast sollte grundsätzlich dem zufallen, der die Aufgaben durch sein Gesetz verursacht hat, weil dies dem föderalen Wechselspiel von Autonomie und Verantwortung am besten entspricht. Die Zweckausgaben für die Ausführung von Bundesgesetzen durch die Länder trüge dann grundsätzlich der Bund ${ }^{80}$. Soweit den Ländern Spielraum bei der Ausführung bleibt oder Verwaltungsausgaben anfallen, hätten sie die Kosten zu tragen, da letztere in ihrem Bereich verursacht worden sind.

\section{Der identische Leitgedanke aller vier Ausgleichsstufen}

Sämtliche Regelungen auf den vier vertikalen Stufen verfolgen das gemeinsame Ziel, Kongruenz zwischen Ausgaben, Aufgaben und Finanzmitteln herzustellen ${ }^{81}$. Im Hinblick auf ihren einheitlichen Leitgedanken sind die unterschiedlichen Formulierungen der Zielbestimmungen für die einzelnen Transferschritte unglücklich gewählt. Das Abstellen auf Sonderbedarf, notwendige Ausgaben, Finanzkraft, Finanzbedarf oder Leistungsschwäche ist nur dort sinnvoll, wo das Gesamtziel in einem bestimmten Transferschritt gerade eine besondere Berechnungsweise verlangt. Die Begriffsvielfalt verursacht aber dann Verwirrung und Systembrüche, wenn das identische Gesamtziel lediglich mit unterschiedlichen Worten beschrieben wird ${ }^{82}$. Eine Reform sollte deshalb die begriffliche Ausformung dieser Zielbestimmungen durchforsten und vereinheitlichen.

\section{Die Einführung eines Gebots der Einheit des Transfergesetzes}

Ferner würde es das Gesamtziel der Distribution fördern, die zweite bis vierte Stufe zusammen mit dem horizontalen Finanzaus-

\footnotetext{
79 Dazu Starck, StuW 1974, S. 271, 278 u. 282.

${ }^{80} \mathrm{Vgl}$. Joachim Wieland, DVBl. 1992, S. 1181, 1185.

${ }^{81}$ Vgl. BVerfGE 72, S. 330, 385; DVBl. 1992, S. 965,966 u. S. 969.

${ }_{22}$ Der Rechtsprechung fällt in diesem Bereich in erster Linie die Aufgabe zu, in das unklare Dotationssystem bundes- und rechtsstaatliche Strukturen einzuziehen; Belege in BVerfGE 41, S.291, 304 ff.; 39, S. 96, 107 ff.; 26, S. 338, 390.
} 
gleich von Verfassungs wegen in einem Verfahren zu betreiben und in einem einzigen Gesetz abzuschließen. Ein grundgesetzliches Gebot der Einheit des Finanztransfergesetzes - nach dem Modell der Einheit des Haushalts - würde das Parlament veranlassen, nur einmal im Jahr die gesamte Transferproblematik aufzurollen, das Gesamtkonzept mit allen Details zu beraten und die Geldfragen insgesamt zu lösen, statt wie bisher neben dem Finanzausgleichsgesetz zahlreiche Sonderregeln nach den Art. $91 \mathrm{a}$ und b, Art. $104 \mathrm{a}$ Abs. 3 und 4, Art. 106 Abs. 6 und 8 sowie Art. 120 GG zu beschließen, die meist weder aufeinander abgestimmt noch zu überschauen sind. Die heutigen einzelnen Transferverfahren besitzen weder so gewichtige Charakteristika noch weisen sie eine so bedeutende Eigendynamik auf, daß der vertikale Finanzstrom in mehrere Einzelverfahren zerfasert werden müßte. $\mathrm{Da}$ alle Transfers letzten Endes das Ziel bedarfsgerechter Verteilung verfolgen ${ }^{83}$, genügt ein einziges Gesetz, um diese einheitliche Finanzfrage zu beantworten. In einem Verfahren würde das Gesamtkonzept transparent; nach dessen Abschluß wäre für eine Zeitspanne der Verteilungskampf beendet, isolierte Einzelmaßnahmen würden unzulässig.

\section{Die Reform des staatlichen Einnahmesystems}

Wenn ohnehin eine Novelle der Finanzverfassung ansteht, könnte man die Gelegenheit wahrnehmen, auch das Einnahme- und das Haushaltssystem zu revidieren, wo es sich als unzulänglich erwiesen hat oder Wildwuchs aufgetreten ist.

\section{Die Einbeziehung der Sonderlasten in die Finanzverfassung \\ a) Expansion der Sonderlasten}

Eine vollständige Finanzverfassung muß alle wesentlichen Einnahmen normieren; die gegenwärtige Verfassung der staatlichen Einnahmen regelt aber allein das Instrument der Steuer. Sie setzt die Allgemeinlast der Steuer zur Finanzierung allgemeiner Staatsaufgaben ein ${ }^{84}$ und glaubt, mit dieser Abgabeform alle Finanzquellen des Staates geregelt zu haben. Sonderlasten dürfen nur spezielle Aufgaben finan-

${ }^{83}$ Z. B. BVerfG, DVBl. 1992, S. 965, 966.

${ }_{84}$ Z.B. BVerfGE 84, S. 239, 269. 
zieren $^{85}$ und müssen rechtfertigen, warum sie einen Teil der Steuerpflichtigen zusätzlich belasten ${ }^{86}$. Obwohl neuartige Sonderlasten große Probleme mit ihrer Legitimation haben, ist ihre Bedeutung seit Beginn der achtziger Jahre derartig angewachsen, daß sie heute praktisch mit der Steuer konkurrieren. Die Art. 105 und 106 GG in der geltenden Fassung können dies nicht mehr verkraften; sie regeln fast nur die Steuer ${ }^{87}$ und orientieren sich an der Situation der ausgehenden sechziger Jahre, in denen es keine ins Gewicht fallenden, nichtsteuerlichen Einnahmen $\mathrm{gab}^{88}$. Sonderlasten sind auf die Sachkompetenzen der Art. 73 ff. GG verwiesen. Hier droht der sonst sorgsam ausbalancierten Finanzverfassung ${ }^{89}$ Gefahr.

Auch der Rechtsprechung ist es im Ergebnis nicht gelungen, dieser Zermürbung einer Steuerverfassung Einhalt zu gebieten, die ursprünglich als vollständige Regelung der staatlichen Finanzquellen gedacht war. Zwar betont das Bundesverfassungsgericht mit Recht, daß Sonderabgaben seltene Ausnahme sein müßten ${ }^{90}$; daß sie eine besondere Verantwortung der Belasteten voraussetzen würden, die sich aus der Realität ergibt und nicht vom Gesetzgeber "herbei-definiert" wird ${ }^{91}$; daß sie keine allgemeinen Staatsaufgaben finanzieren könnten und jederzeit rücknehmbar sein müßten ${ }^{92}$. Den acht Entscheidungen des Bundesverfassungsgerichts, die seit 1980 den Sonderabgaben Grenzen gezogen haben, ist die Rechtsprechung der Fachgerichte aber nicht mit gleicher Entschlossenheit gefolgt. Im selben Zeitraum haben schon 28 verwaltungsgerichtliche Erkenntnisse aus der zweiten und dritten Instanz Sonderabgaben akzeptiert und ihnen in der Praxis den Weg freigeräumt. In jedem der Prozesse werden sie zwar verbal als Sonderfall bezeichnet; die Zahl der akzeptierten Ausnahmefälle begründet jedoch mittlerweile den allgemeinen Verfassungsunfall, daß Sonderabgaben in Fülle und auf Dauer bestehen. Die Haushaltsnot des Gesetzgebers tut ein übriges und konzipiert unverdrossen weitere Sonderabgaben.

${ }_{85}$ BVerfGE 82, S. 159,$178 ; 75$, S. 108,$147 ; 67$, S. 256,$275 ; 55$, S. 174,300 u. $302 ; 37$, S. 1,$16 ; 18$, S. 315, 321 .

${ }_{86}$ Z. B. BVerfGE 82, S. 159, 179f.; 75, S. 108, 147 f.; 55, S. 274, 304; Osterloh, NVwZ 1991, S. 823, 825.

${ }^{87}$ Von Abgaben ist nur in den Sonderfällen des Art. 106 Abs. 1 Nrn. 5-7 und Abs. 2 Nr. 6 GG sowie in Art. 108 Abs. 1 GG die Rede.

${ }^{88}$ BVerfGE 72, S. 333, 393.

${ }^{89}$ BVerfGE 78, S. 249, 266 m. w. N.

${ }^{90}$ BVerfGE 82, S. 159, 181; 55, S. 274, 308.

91 BVerfGE 82, S. 159, 180.

92 BVerfGE 82, S. 159, 183; 55, S. 274, 308. 
Die instrumentale Verfassung der Steuer in den Art. $105 \mathrm{f}$. GG und die gegenständliche Bestimmung der Sonderlasten mit Hilfe der Art. $73 \mathrm{ff}$. GG vertragen sich deshalb heute nicht mehr. Es wird notwendig, alle wesentlichen Staatseinnahmen in die Finanzverfassung einzuschließen ${ }^{93}$, weil der früher berechtigte Versuch, mit Normen über die Steuer alle Finanzquellen zu verfassen, heute an den Wucherungen des Abgabensystems gescheitert ist. Diese Erweiterung würde die Regelung über die staatlichen Einnahmen wieder an die Vorschriften über den Haushalt und den Finanzausgleich heranführen, wo bereits jetzt alle staatlichen Einnahmen erfaßt werden ${ }^{94}$.

\section{b) Fixierung der Gesetzgebungskompetenz für alle Abgaben}

Art. 105 GG sollte die Gesetzgebungskompetenz für alle Abgaben enthalten ${ }^{95}$. Bei Steuern, den traditionellen Vorzugslasten und Sozialversicherungsabgaben könnte man den bisherigen Zustand fixieren; bei den frisch hinzugekommenen Arten, insbesondere den Sonderabgaben, wären dagegen zum ersten Mal Zuordnungen zu treffen, weil hier der rechtliche Sumpf beginnt.

Die Aufnahme nichtsteuerlicher Abgaben in die Finanzverfassung würde keinen Weg öffnen, jene künftig auch zur Finanzierung allgemeiner Staatsaufgaben zu benutzen. Die herkömmliche Funktion der Steuer als ausschließliches Finanzierungsmittel sowie ein stärker akzentuierter Grundsatz der Belastungsgleichheit mit seiner Differenzierung in grundsätzlich gerechtfertigte, steuerliche Gemeinlasten und jeweils besonderer Legitimation bedürfender Sonderlasten könnte künftig vermeiden, daß Sonderlasten zur Finanzierung allgemeiner Staatsaufgaben verwendet werden; die Erfassung der Sonderlasten in den Gesetzgebungskompetenzen würde aber die unzuständige Gebietskörperschaft von vornherein daran hindern, mit Hilfe von Sonderabgaben ihre Einnahmen zu mehren. Hier könnte der Verfassungsgeber sogar die Gelegenheit beim Schopf packen und neuen Abgabenarten gänzlich Einhalt gebieten, indem er einen numerus clausus schafft.

\footnotetext{
${ }_{93}$ Ebenso bezüglich der Sonderlasten Joachim Wieland, DVBl. 1992, S.1181, 1188.

${ }^{94}$ Mit den Begriffen der Finanzkraft und der Einnahmen; z. B. BVerfGE 72, S. $330,399$.

${ }_{95}$ Schon Art. 8 Abs. 1 Weimarer Reichsverfassung ging weiter und erfaßte alle Staatseinnahmen.
} 


\section{c) Ausdebnung der Ertragshobeitsregeln auf alle Einnabmequellen}

Die Regelung des Art. 106 GG über die Ertragshoheit müßte neben sämtlichen Erträgen aus staatlichen Abgaben noch weitere Einnahmen erfassen, weil der Staat mit vereinbarten Entgelten das Abgabensystem teilweise umgehen und sich ebenfalls Geldquellen erschließen kann. Wie weit man im einzelnen geht, bliebe der Verfassungspolitik vorbehalten. Es entspräche jedoch der Grundstruktur der Finanzordnung am ehesten, Art. 106 GG auf alle Einnahmequellen ${ }^{96}$ des Bundes und der Länder ${ }^{97}$ zu erstrecken, die Abgaben sind oder sie ersetzen und die dem Staat Gewinn bringen, also erfolgswirksam sind. Erfolgsneutrale Vermögensumschichtungen sowie kostendeckende Entgelte blieben ausgeklammert ${ }^{98}$. Erst wenn der Staat sich gewinnbringende Geldquellen erschließt, würde die Novellierung eingreifen.

\section{Die Gesetzgebungskompetenz bei lenkenden Steuern}

Endlich zu lösen wäre ferner das dauernde Problem der Kompetenzabstimmung bei lenkenden Steuern ${ }^{99}$. Solange die Steuer reines Finanzierungsmittel ist, genügt die Benennung des Instruments in Art. 105 GG zur materiellen Trennung der Finanzierungs- von anderen Kompetenzen. Bei lenkenden Steuern wird die Abgabenkompetenz aber für Verhaltensregelungen eingesetzt ${ }^{100}$. Das Instrument dringt unter Abstützung auf Art. $105 \mathrm{GG}$ in andere Gesetzgebungsmaterien ein ${ }^{101}$. Das bringt Probleme, wo auf Sachkompetenzen

96 Zur Auflistung staatlicher Einnahmearten vgl. Vogel (Fn. 6), S. 45 f.

97 Wie bisher sollten aber nur die Einnahmen von Bund und Ländern geregelt werden; das herkömmliche Finanzierungssystem anderer Körperschaften und juristischer Personen, vor allem der Kommunen und Sozialversicherungsträger, sollte für die Ertragshoheit kein Verfassungsthema werden, weil hier Sonderhaushalte fungible Staatseinnahmen verhindern; vgl. BVerfGE 75, S. 108, 148.

${ }_{98}$ Das entspräche den Parallelüberlegungen des BVerfG zur Einbeziehung von Einnahmequellen der Länder in den horizontalen Finanzausgleich; E 72, S.330, 410 ff.; DVBl. 1992, S. 965, 969.

${ }_{99} \mathrm{Zu}$ deren Anerkennung z. B. Friauf (Fn.24), S. $305 \mathrm{ff}$.

100 Zur grundsätzlichen Zulässigkeit lenkender Steuern z.B. BVerfGE 84, S. 239, 274; 36, S. 66, 70 f.; 31, S. 8, 23; 30, S. 250, 264 m. w. N.; 19, S. 119, 128; 16, S. 147,161 .

101 Das Phänomen, eine Kompetenz für ein Instrument statt für einen Sachbereich zu geben, taucht ein zweites $\mathrm{Mal}$ in der Zuständigkeit des Bundes für das Strafrecht nach Art. 74 Nr. 1 GG auf. Dieses Instrument wird ebenso zur Regelung von Materien ausgenützt, für die der Bund nach ihrem Gegenstand unzuständig ist (vgl. z. B. das EmbryonenschutzG v. 13.12.1990, BGBl. I S. 2746). Vgl. zu diesem 
gestützte Rechtsregeln mit steuerlichen Lenkungsbefehlen zusammenstoßen. Weil immer nur ein rechtliches $\mathrm{Ge}$ - und Verbot mit einer in der Steuer versteckten, ökonomischen Verhaltensempfehlung zusammentreffen kann, kollidieren niemals zwei Rechtsnormen miteinander. Der eventuelle Wertungswiderspruch zwischen Lenkungsziel der Steuer und gesetzlichem Ge- oder Verbot bleibt aber und muß aufgehoben werden. Wie man diese Kollision ausschließt, ist eine verfassungspolitische Entscheidung; daß man sie beseitigt, ist dagegen eine verfassungsstrukturelle Forderung. Lösungsmöglichkeiten sind genügend vorhanden: z. B. die Notwendigkeit beider Kompetenzen für lenkende Steuern ${ }^{102}$ oder das Erfordernis der Zustimmung des sachlich kompetenten Normsetzers zum Steuergesetz der anderen Körperschaft ${ }^{103}$.

\section{Die Ordnung der Umweltabgaben}

\section{a) Das Vordringen der Umweltabgaben und die Zurückhaltung der Finanzverfassung}

Das letzte Jahrzehnt hat an Umweltabgaben Geschmack gefunden. Sie lenken zur Vermeidung von Umweltschäden oder entgelten Umweltnutzungen zur Internalisierung externer Kosten. Etliche Umweltabgaben sind bereits eingeführt, Vorschläge für neue in Fülle vorhanden, sogar der ökologische Umbau der gesamten Steuerordnung wird angeregt. Die Finanzverfassung kann sich dieser Frage nicht mehr verschließen. Umweltabgaben werfen tiefgreifende Probleme und Bedenken auf, die sich mit dem bisherigen Bestand an allgemeinen Regeln nicht mehr bewältigen lassen. Die geltenden Vorschriften beschränken sich vielmehr darauf, in fast ausschließlich negativer Abgrenzung die Sonderlasten von den Steuern zu scheiden. Fest steht lediglich, daß Sonderlasten nicht zur Finanzierung allgemeiner Staatsaufgaben zu verwenden sind und aus Gründen der Bela-

Thema auch Friauf, Verfassungsrechtliche Grenzen der Wirtschaftslenkung und Sozialgestaltung durch Steuergesetze, 1966, S.29ff.

102 Diese Lösung würde z.B. dem Bund wegen seiner Zuständigkeit für das Recht der Wirtschaft (Art. 74 Nr.11 GG) weiterhin die wirtschaftliche Intervention gestatten, ihn in Kultur- und Umweltpolitik indes einschränken. Einige Kombinationen von Finanzinstrument und Lenkungsbefehl würden dann faktisch von Kompetenzregeln verboten, wenn Instrumenten- und Sachmaterienkompetenz auseinanderfallen.

103 Weitere Vorschläge bei Knies, Steuerzweck und Steuerbegriff, 1976, S. 142 f. 
stungsgleichheit einer besonderen Legitimation bedürfen. Das beschränkt sie auf die Regelung überschaubarer und individualisierbarer Rechtsverhältnisse - also auf den „kleinen“ Umweltschutz. Dagegen taugen Steuern für den überindividuellen, regionalen oder globalen - und damit für den "großen“ - Umweltschutz ${ }^{104}$, wie er bei den Medien von Luft und Wasser meist erforderlich ist.

\section{b) Der Vorrang der Finanzfunktion des Stenersystems}

Darüber erstreckt sich dann aber ein weites Feld noch ungelöster Fragen und grundsätzlicher Bedenken, die in Kontrast zur Euphorie der öffentlichen Meinung über Umweltabgaben stehen. Umweltnutzungsabgaben kommerzialisieren Naturressourcen zugunsten des Staates. Sie wecken seinen Finanzhunger, der sich durchaus nicht scheut, unter dem Etikett des Umweltschutzes Fiskalinteressen zu verfolgen. Als Vermeidungsabgaben tendieren sie zur Austrocknung ihrer Finanzquelle, obwohl das herkömmliche Abgabensystem dem Staat ein stetiges und planbares Finanzaufkommen sichern soll. Umweltsteuern passen schlecht in ein an Leistungsfähigkeit orientiertes Steuersystem: Finanzsteuern greifen nach der Leistungsfähigkeit des Pflichtigen zu, Umweltsteuern jedoch nach dem Maßstab ökologischer Schädlichkeit ${ }^{105}$. Beide Zielsetzungen sind in einem gemeinsamen Steuersystem nicht gleichwertig einzusetzen; insbesondere der Typus der Verbrauchsteuer stößt hier schnell an die Grenze seines verfassungsrechtlichen Bewegungsraumes ${ }^{106}$. Umweltschutz durch Steuern überträgt ferner den Finanzbehörden Aufgaben, für die sie nicht kompetent sind ${ }^{107}$. Der Betriebsprüfer des Finanzamtes würde nach einer Umstellung des Steuersystems auf ökologische Ziele nicht nur Bücher und Inventare kontrollieren, um Gewinne zu ermitteln. Er hätte vielmehr mit Meßpipette und Lackmusstreifen in Produktionsanlagen, Chemikalientanks und Abgasfiltern nach Gefahrstoffen zu suchen, um die Steuererhebung zu überprüfen. Selbst ein materiell gut gelungenes Gesetz darf die Verwaltungskraft der Ausführungsbehörde nicht überfordern, sonst wird sein $Z$ weck verfehlt. Ein völliger Umbau der Steuerordnung scheidet deshalb aus. Der moderate Ein-

${ }^{104}$ Dazu im einzelnen F. Kirchhof, Leistungsfähigkeit und Wirkungsweise von Umweltabgaben an ausgewählten Beispielen, in: Breuer u.a. (Hrsg.), Umweltschutz durch Abgaben und Steuern, 1992, S. 101, $109 \mathrm{f}$.

105 Trzaskalik, StuW 1992, S. 135, 141; F. Kirchbof (Fn. 104), S. 107 f.

106 Dazu s. Osterloh, NVwZ 1991, S. 823, $827 \mathrm{ff}$.

107 Art. 108 GG setzt dafür auch verfassungsrechtliche Grenzen. 
bau ökologischer Elemente in das Steuersystem, z. B. die Schaffung von Anreizen zur Verwendung umweltschonender Produkte in Verbrauchsteuern, kann aber durchaus Nutzen bringen ${ }^{108}$. Ein behutsamer, im Schutzziel deutlich akzentuierter Einsatz weniger Sonderlasten, beispielsweise von Sondermüllgebühren, kann ebenso sinnvoll sein, weil Wirtschaftssubjekte auf hoheitlich auferlegte Geldlasten in gleicher Weise wie auf Preisänderungen durch Wettbewerb reagieren. Die massive Anwendung steuerlicher Instrumente darf jedoch nicht das staatliche Finanzierungssystem in seiner Hauptfunktion der Alimentation des Staates ${ }^{109}$ in Unordnung bringen. Sie können nur behutsam eingesetzt werden, wo die an sich konträren Leitlinien der Leistungsfähigkeit und der Umweltschädlichkeit im konkreten Abgabentatbestand widerspruchsfrei verbunden werden können, und die Finanzfunktion des Steuersystems im Gesamten erhalten bleibt. Sie dürfen nur wenige, aber deutliche Akzente setzen, denn eine plötzliche, umfassende Lenkung und zahlreiche, sich überlagernde Lenkungsziele überschaut der Markt nicht mehr; dann bleibt die vom Staat gewünschte Reaktion völlig aus.

\section{c) Neue verfassungsrechtliche Kategorie der Umweltabgabe}

Soweit der Gesetzgeber besondere Umweltschutzabgaben einführt, muß die Finanzverfassung geändert werden, weil bei ihnen der allgemeine Finanzierungszweck gänzlich in den Hintergrund tritt. Da sie Abgabeformen für Umweltschutzzwecke verwenden, berühren sie das Finanzwesen, ohne ihm genuin zu dienen. Dieses Problem sollte in einem besonderen Artikel über Umweltabgaben aufgegriffen werden. Wenn man sich entschließt, ein Staatsziel „Umweltschutz" ins Grundgesetz aufzunehmen, müßte sich das - wie bei den Staatsfundamentalprinzipien des Art. 20 GG - ohnehin in der Finanzverfassung widerspiegeln ${ }^{110}$. Eine eigene verfassungsrechtliche Kategorie könnte Vorsorge treffen ${ }^{111}$, daß Umweltsonderlasten nicht unter der Hand zur Finanzierung allgemeiner Staatsaufgaben eingesetzt, daß die angestrebten Schutzziele im Gesetz offengelegt und zur Erfolgskontrolle und späteren Aufhebung der Abgabe quantifiziert werden. Hier

108 F. Kirchhof (Fn. 104), S. 108

109 BVerfGE 32, S. 302, 338 u. 340.

110 Es taucht spätestens dann die Frage auf, ob Sonderlasten zur Finanzierung der allgemeinen Staatsaufgabe „Umweltschutz" einsetzbar sind; vgl. Arndt, BB 1992, S. 1, 12 f.

11 Vorschläge dazu bei F. Kirchbof (Fn. 104), S. $117 \mathrm{ff}$. 
wäre auch ein Gebot ökologischer Belastungsgleichheit zu konturieren, um das momentan hektische und zügellose Geschehen wieder in rechtsstaatliche Bahnen zu lenken.

\section{Die Einheit des Staatshaushalts}

\section{Die Gefabren durch Sonderbaushalte}

Neben dem Einnahmesystem bedarf auch das Haushaltswesen aufgrund neuerer Erfahrungen einer Reform. Zweihundert Jahre Staatshaushalt führten es zu zwei historischen Errungenschaften: dem Budgetrecht des Parlaments und der Einheit des Haushalts ${ }^{112}$. Beide geraten heute in Gefahr durch Sonderhaushalte. Der Verfassungsgrundsatz der Einheit des Haushaltsplans gebietet nach Art. 110 GG, das gesamte Finanzgebaren des Bundes in einem Verfahren zu beraten und in einem Gesetz zu verabschieden. Er soll den Plan als finanzielles Gesamtprogramm der Regierung überschaubar machen ${ }^{113}$, damit das Parlament sein Budgetrecht umfassend und koordiniert ausüben kann $^{114}$. Der Grundsatz wird durchbrochen, wenn Einnahme- und Ausgabekreisläufe außerhalb des Haushaltsplans organisiert wer$\operatorname{den}^{115}$. De constitutione lata gilt er weder für Juristische Personen des Bundes noch für seine Betriebe und Sondervermögen ${ }^{116}$. Hierdurch

112 Eine Staatsgewalt sollte auch nur einen Haushalt besitzen; vgl. Kisker, Handbuch des Staatsrechts, Band IV, 1990, S. 235, 237.

${ }_{113} \mathrm{Zu}$ den Funktionen des Haushaltsplans BVerfGE 79, S. 311, 329; 70, S. 324, 355; 45, S. 1, 32; Stern, Das Staatsrecht der Bundesrepublik Deutschland, Band II, 1980, S. 1196.

${ }_{114}$ Zu den Zwecken des Grundsatzes Grupp, in: Achterberg/Püttner (Hrsg.), Besonderes Verwaltungsrecht, Band II, 1992, S. 141, 173.

115 BVerfGE 82, S. 159, 179; Vogt, in: F. Klein (Hrsg.), Lehrbuch des öffentlichen Finanzrechts, 1987, S. 117, $142 \mathrm{f}$.

116 Größere Sondervermögen des Bundes nichtbetrieblicher Art sind z. B. Ausgleichsfonds zur Durchführung des Lastenausgleichs, ERP-Sondervermögen, Ausgleichsfonds zur Sicherung des Steinkohleneinsatzes, Ausgleichsfonds für überregionale Maßnahmen zur Eingliederung Schwerbehinderter in Arbeit, Beruf und Gesellschaft, Fonds „Deutsche Einheit“, Kreditabwicklungsfonds, Zweckvermögen bei der Deutschen Siedlungs- und Landesrentenbank, Zweckvermögen bei der Landwirtschaftlichen Rentenbank, Treuhandvermögen für den Bergarbeiterwohnungsbau, Bergmannssiedlungsvermögen, Sondervermögen nach $\$ 29 \mathrm{a}$ VermögensG.

An Stiftungen des Bundes gibt es z. B. Deutsche Bundesstiftung Umwelt, Stiftung Mutter und Kind - Schutz des ungeborenen Lebens, Stiftung BundeskanzlerAdenauer-Haus, Stiftung Preußischer Kulturbesitz, Stiftung Hilfswerk für behinderte Kinder, Heimkehrerstiftung, Stiftung für ehemalige politische Häftlinge. 
werden die Bundesfinanzen in viele Haushalte aufgespalten. Manchmal erscheinen Nebenhaushalte in Form von Wirtschaftsplänen oder groben Übersichten noch in einer Anlage zum Bundeshaushaltsplan; es kommt aber häufig vor, daß ein Nebenhaushalt dort lediglich in einem Einzeltitel auftaucht oder sich überhaupt nicht mehr zeigt ${ }^{117}$. Dies unterminiert das Budgetrecht des Parlaments und die Funktionsfähigkeit des Haushaltsplans. Noch weiter geht Art. 115 GG, nach dem Sondervermögen durch einfaches Bundesgesetz vom Gesetzesvorbehalt für Kreditermächtigungen befreit werden dürfen. Eine darauf gestützte Selbstentmachtung des Parlaments gibt dem Träger des Nebenhaushalts freie Hand bei der Schuldenaufnahme ${ }^{118}$; der Leistungsstaat kann so seine Schulden vor sich selbst und vor der Öffentlichkeit verstecken.

Parafisci versprechen Effizienz und Sachnähe bei der Verwaltung; sie können besondere Aufgaben kostenecht und finanziell transparent erledigen. Die Technik des Nebenhaushalts wird deshalb seit langem angewendet; Sonderhaushalte haben aber in letzter Zeit gigantische Volumina angenommen. Schulden einzelner parafisci werden 1995 bis auf $250 \mathrm{Mrd}$. DM anwachsen, d.h. über die Hälfte des Umfangs des Staatshaushalts erreichen; der Schuldenstand aller Sonderhaushalte des Bundes belief sich bereits 1991 auf ungefähr $462 \mathrm{Mrd} \mathrm{DM}^{119}$.

\section{Das Erfordernis sachlicher Rechtfertigung der Sonderhaushalte}

Die Flucht aus dem Bundeshaushalt und aus der Bindung an ein Kreditgesetz bringt Verlust an Transparenz und Öffentlichkeit des Haushaltsverfahrens, nimmt dem Parlament das Budgetrecht ${ }^{120}$, ver-

An größeren Bundesbetrieben bestehen z. B. die drei Unternehmen der Deutschen Bundespost, die Deutsche Bundesbahn, die Deutsche Reichsbahn, die Kreditanstalt für Wiederaufbau, die Deutsche Ausgleichsbank.

Ferner bilden die Sozialversicherungsträger größere Sonderhaushalte. Eine Sonderstellung hat die Treuhandanstalt inne, die ebenfalls einen umfangreichen Nebenhaushalt bildet.

${ }_{117} \mathrm{Zu}$ den Techniken der Verbindungen von Staats- und Sonderhaushalten s. M. Kilian, Nebenhaushalte des Bundes, 1993, 1. Teil, 3. Kap., 2. Teil, 4. Kap.

118 Z. B. $\$ 5$ Abs. 2 G über die Errichtung eines Fonds „Deutsche Einheit“ i.d.F. des Einigungsvertrags v. 31.8.1990, BGBl.II S. 889.

119 Frankfurter Allgemeine Zeitung v. 29.11.1991, S. 17.

${ }_{120}$ Mußgnug, Der Haushaltsplan als Gesetz, 1976, S.369; Kilian, JZ 1991, S. 425,430 . 
ringert die Koordination der Gesamtfinanzen und verschleiert die Staatsverschuldung. Die Gefahren potenzieren sich, wenn dem Sonderhaushalt eigene Abgabenkompetenzen zustehen, wenn die Abgabenverwendung nach weitgefaßter Zweckfestlegung im Gesetz von der Exekutive bestimmt werden darf oder wenn sich Nebenhaushalte untereinander Kredite gewähren. Das staatsrechtliche Sachlichkeitsgebot $^{121}$ fordert für solche Ausnahmen vom Grundsatz der Einheit des Haushalts eine besondere Legitimation ${ }^{122}$; die Politik übergeht dies oft $^{123}$.

Neben einigen typischen Sachgründen für eine derartige Lockerung, z. B. der Verleihung von Autonomie ${ }^{124}$ an Kammern und Kommunen, der Bildung eigenfinanzierter Risikogemeinschaften bei der Sozialversicherung, der Notwendigkeit kaufmännischer Organisation bei öffentlichen Unternehmen und Bundesbetrieben oder der Zusammenfassung von Sachvermögen in Stiftungen zu Ausstellungszwekken, gibt es in der Praxis viele zweifelhafte Fälle. So berechtigte zwar die einmalige Aufgabe der deutschen Wiedervereinigung zur vorübergehenden Ausgliederung von Finanzmitteln, weil die anzugehende Aufgabe „in Ziel, Art und Größenordnung“ ganz anders als im gewöhnlichen Haushalt war ${ }^{125}$. Die damalige Prognose, nach kurzfristiger Anschubfinanzierung würde die Wirtschaft in den östlichen Bundesländern anspringen und die aufgenommenen Schulden abtragen können, legitimierte das Vorgehen. Nach heutiger Erkenntnis ist es aber nicht mehr gerechtfertigt, diese Sonderhaushalte über das Jahr 1995 hinaus zu perpetuieren und ihnen weitere Möglichkeiten zur Kreditaufnahme einzuräumen. Sie müssen in die allgemeinen Haushalte integriert werden ${ }^{126}$. Überhaupt nicht mehr zu legitimieren sind etwa Planungen, die Altschulden der Staatsbahnen zu deren Entlastung statt in den Bundeshaushalt in ein Sondervermögen einzubringen. So glättet man nur Haushaltszahlen und parkt letztlich Schulden,

${ }_{121} \mathrm{Zu}$ dessen Existenz und unterschiedlichen normativen Grundlagen s. BVerfGE 83, S. 367, 393 m.w. N.; 26, S. 172, 185; 23, S.12, 24 u. 353, 373.

122 von Mutius, VVDStRL 42, S. 147, $192 \mathrm{f}$.

${ }^{123}$ Sie beruft sich darauf, daß Sondervermögen nach dem Rechtsinstitut nicht im Haushaltsplan aufzuführen seien, statt die sachliche Legitimation eines Sondervermögens zu belegen; z. B. Antwort der Bundesregierung, BT-Drucks. 11/2710, S. 30 Nr. V.1. und 7.

${ }^{124} \mathrm{Zu}$ den Gründen vgl. H. H. Klein, in: FS für Forsthoff, 1972, S. 165, 175 f. u. $178 \mathrm{f}$.

125 BT-Drucks. 11/7350, S. 49.

126 Wendt (Fn. 23), S. 222. 
die vom Bund selbst beglichen werden müssen. Hier wird sogar begrifflich kein Sondervermögen mehr gebildet; vielmehr werden ohne sachlichen Grund Verbindlichkeiten verborgen. Bei der gebotenen, strikten Anwendung des Sachlichkeitsgebots wäre ferner auch der ERP-Fonds in den Bundeshaushalt einzubringen. Ihn binden von außen keine $Z$ wecke mehr, denn sein ursprüngliches Ziel, die deutsche Wirtschaft der Nachkriegszeit zu fördern, ist längst erreicht. Die Vereinigten Staaten von Amerika haben ihre Mitspracherechte über den Fonds schon seit langem aufgegeben ${ }^{127}$. Seine finanziellen Maßnahmen könnten ebensogut in einem Einzelplan des Bundeshaushalts vorgesehen werden. Die Eingliederung ist überfällig ${ }^{128}$.

Mit gleicher Sorgfalt müßte jeweils eine Rechtfertigung für die Exemtion von Art. 115 GG gefordert werden. Da Sonderkredite die Staatsverschuldung verschleiern, können nur gewichtige Gründe eine Ausnahme zulassen. Das häufig vorgetragene Argument fehlender Haftung des Bundes für die Außenstände seiner Sondervermögen sticht nicht, weil er gesetzlich oder faktisch in jedem Fall haftet. Wo Schulden nach der Eigenart der Tätigkeit eines Bundesbetriebes zum üblichen Geschäft gehören, wie bei den staatlichen Banken, wären allerdings solche Ausnahmen möglich und angebracht.

\section{Die Notwendigkeit einer Rückkehr zum Gesamthaushalt \\ a) Einheit in Verfabren und Haushalt}

Wenn das Grundgesetz derartige Lockerungen zuläßt, weil diese im Einzelfall tatsächlich legitimiert sind, sollte es künftig die Verluste an Haushaltseinheit nach Kräften eindämmen. Man könnte dem Grundsatz der Haushaltseinheit wieder zu größerer Wirkung verhelfen, wenn man den Staatshaushalt und die ausnahmsweise zulässigen Nebenhaushalte in einem Gesamtverfahren beraten und mit einem Haushalt abschließen würde; am Ende des Haushaltsjahres sollte eine Bilanz stehen, die - wie bei einem Konzern - auch Bruttoschulden und Vermögen verzeichnet. So würde Licht in die Schattenhaushalte gebracht, ohne sie zu beseitigen; der Haushalt des Bundes würde die Vermögenslage vollständig wiedergeben.

${ }^{127}$ F. Kirchbof, in: FS für Dürig, 1990, S. 447, 464 ff. m. w. N.

128 Vor allem, weil er sich im Zuge der deutschen Vereinigung vom revolvierenden zum Schuldenhaushalt entwickelt hat; Monatsbericht der Deutschen Bundesbank Nr. 8, August 1992, S. 25. 


\section{b) Gesamthaushaltsrechnung}

Ohne größere Probleme wäre eine Gesamthaushaltsrechnung möglich, die entsprechend dem Idealbild des Art.114 GG Rechnung über „alle Einnahmen und Ausgaben sowie über das Vermögen und die Schulden" legt; die Betriebswirtschaftslehre hat hierfür Konzepte aufgestellt ${ }^{129}$ und in Nordrhein-Westfalen erprobt ${ }^{130}$. Ohne die Selbständigkeit der parafisci zu berühren, könnte sie ein Gesamtbild der Staatsfinanzen liefern und obendrein das Institut der Haushaltsrechnung aus seinem bisherigen Dornröschenschlaf wecken.

\section{c) Gesamthaushaltsplan}

Ferner wäre zu erwägen, Bundes- und Sonderhaushalte auch in einem Gesamthaushaltsplan zu verbinden. Bei einigen Nebenhaushalten ließe sich das sofort durchführen. Schwierigkeiten entstünden erst, wo dem Träger eines Nebenhaushalts aus anderen Gründen Autonomie zugestanden werden oder wo er aufgrund kaufmännischer Erfordernisse mit unverbindlichen Wirtschaftsplänen arbeiten muß. Hier würde eine Festlegung der Einnahmen und Ausgaben durch den Bundesgesetzgeber zugleich Selbständigkeit und Eigenwirtschaftlichkeit des Verwaltungsträgers zerstören. Deshalb können die Werte dieser Sonderhaushalte nur nachrichtlich in den Bundeshaushalt übernommen werden. Der Bund würde ausschließlich seine eigenen Mittel festlegen, wäre aber imstande, anhand der von anderen Haushaltsträgern eingebrachten Daten seine Angelegenheiten in Kenntnis aller relevanten Finanzplanungen in einem Verfahren zu entscheiden, seinen eigenen Bedarf auf den anderer Autonomieträger abzustimmen und in einem Gesamtwerk zu verankern. Eine derartig umfassende Haushaltsplanung und -rechnung würde trotz der Beibehaltung von Sonderhaushalten den Grundsatz der Einheitlichkeit des Haushalts aufwerten und die Demokratie im Finanziellen stärken.

129 Klaus Lüder, Staatliches Rechnungswesen in der Bundesrepublik Deutschland vor dem Hintergrund neuerer internationaler Entwicklungen, 1991, S. 165 ff.; ders./Hinzmann/Kampmann/Otte, Vergleichende Analyse öffentlicher Rechnungssysteme, Speyrer Forschungsbericht Nr. 97, 1991.

130 Forschungsinstitut für öffentliche Verwaltung bei der Hochschule für Verwaltungswissenschaften Speyer/Landesrechnungshof Nordrhein-Westfalen, Finanzieller Jahresbericht für das Land Nordrhein-Westfalen, 1990. 


\section{Staatsaufgaben und Staatsfinanzen}

Würde man die Finanzverfassung nach diesen Vorschlägen im Finanzausgleich, im Einnahmesystem sowie im Haushaltswesen reformieren, so würde sie besser mit den anderen, vorrangigen Strukturen und Prinzipien des Grundgesetzes harmonieren. Zum Schluß bleibt aber festzuhalten: Eine Finanzverfassung kann lediglich Einnahmen ordnen und verteilen sowie Ausgaben festlegen, nicht jedoch Geld selbst schaffen. Deshalb bietet eine gute Wirtschaftspolitik die beste Einnahmensicherung und bleibt die Reduzierung der Staatsaufgaben optimale Ausgabenreform. Vielleicht gelingt es der Finanzkrise des Staates sogar, der Aufgabenvermehrung Einhalt zu gebieten, denn es besteht ein Zusammenhang zwischen Finanzen und Aufgaben. Diese Verbindung zwischen öffentlichen Geldern und Staatsaufgaben ist selten besser akzentuiert worden als durch Talleyrand, der einmal gegenüber einem Gesprächspartner äußerte ${ }^{131}$ : „Sie glauben gar nicht, wieviel Unsinn durch den Mangel an Geld verhindert wird." Auch dieses sollte eine Reform der Verfassung in ihre Erwägungen einbeziehen.

131 Zitiert nach Duwendag, Staatsverschuldung - Notwendigkeit und Gefahren, 1983, S. 13 . 
Leitsätze des 2. Berichterstatters über:

\section{Grundsätze der Finanzverfassung des vereinten Deutschlands}

I. Zur Finanzverfassung der Normallage und des Übergangs:

1. Die Reform der Finanzordnung der Normallage ist in den zebnten Abschnitt, die Übergangsverfassung zur deutschen Einbeit in die Scblußvorschriften des Grundgesetzes aufzunebmen.

2. Eine Übergangsverfassung muß die fünf neuen Bundesländer an die Normallage beranfübren und dann außer Kraft treten. Sie könnte den neuen Bundesländern am besten mit begrenzter Sonderzuweisung von Steuererträgen Hilfe leisten. Sie sollte die Sonderbaushalte der Deutschen Einigung 1995 auflösen und in den allgemeinen Staatshausbalt integrieren.

\section{Zu den Grundsätzen der Finanzverfassung:}

3. Die Verfassung der Finanzen folgt besonderen Funktionsbedingungen, besitzt aber dieselbe Geltungskraft wie die anderen Grundgesetzabschnitte.

4. Sie kann keine Finanzen schaffen, sondern nur deren Aufbringung und Verteilung ordnen. Ihre ökonomische Abhängigkeit gibt ibr eine besondere Offenbeit.

5. Ihre unbestimmten Rechtsbegriffe bringen variable Wirtschaftsdaten in ein staatliches Finanzsystem ein. Sie ordnet durch Verfabren mit allgemeinen Zielvorgaben statt mit materiellen Entscheidungen. Sie segmentiert das Finanzwesen in periodische Entscheidungsprozesse und mit Zeitgesetzen.

6. Der deutsche Finanz- und Steuerstaat trennt Gesellschaft und Staat. Seine Finanzgewalt ist Bestandteil seiner Binnensouveränität und muß ihm ein stetiges, kalkulierbares Finanzaufkommen sichern.

7. Die Finanzverfassung folgt den vorrangigen Aufgaben- und Organisationsnormen des Grundgesetzes und zieht die Konsequenz aus anderweitig vorgegebenen Staatszielen und -strukturen. Sie bat diese $z u$ unterstützen, nicht $z u$ ändern. 


\section{Finanzverfassung und staatliche Grundstrukturen:}

8. Sie realisiert den Bundesstaat, gibt der parlamentarischen Demokratie ein Werkzeng für die Gestaltung der Politik und unitarisiert den Sozialstaat. Der Rechtsstaat hingegen begrenzt ibre Offenheit.

9. Der Bund trägt als Zentralinstanz die letzte Verantwortung für die Finanzen aller Staatsglieder. I $\mathrm{bm}$ obliegt dabei die Normierungslast, aber nicht die Pflicht, alles aus eigener Tasche $z$ u finanzieren.

10. Die Finanzverfassung enumeriert die vertikalen Finanzströme und lenkt sie grundsätzlich auf eine "Einbahnstraße" vom Bund zu den Ländern.

11. Der Grundsatz der Einheitlichkeit der Lebensverbältnisse bestimmt die Finanzierung des Bundesstaates; er verpflichtet zur Herstellung eines einheitlichen Wirtschaftsraumes, in dem jedes Land über ein Mindestmaß an Wirtschaftskraft verfügen und eine Grundversorgung mit offentlichen Leistungen anbieten kann.

12. Die Demokratie ïberträgt die Finanzgewalt dem Parlament. Die Finanzverfassung bildet auch Gegengewalten: Sie gibt der Regierung exklusive Initiativ- und Ingerenzrechte. Sie vertraut das Geldwesen zur Sicherung von Fachkompetenz und Unabbängigkeit einer ministerialfreien Institution an.

13. Dem Rechtsstaat gibt die Finanzverfassung kaum Impulse, denn Recht soll nicht nach Maßgabe verfügbarer Mittel gelten. Er setzt umgekehrt dem Finanzwesen Grenzen.

14. Die Rechtsprechung hat bisher im Finanzwesen den Eigentumsschutz nicht, die Freiheitsrechte zu zögerlich aktiviert. Der Gleichbeitssatz systematisiert dagegen die Abgabentypik und orientiert die Steuerbelastung grundsätzlich am Maßstab der Leistungsfäbigkeit. Das Übermaßverbot versagt bei Finanzzwecksteuern; der Rechtsstaat kompensiert dies durch engere Bindung an Gesetzesvorbehalt und Bestimmtheitsgebot.

\section{Zum vertikalen Finanzausgleich:}

15. Die feste Zuteilung der Steuererträge ist angemessen, solange die Umsatzsteuerverteilung ibre Pufferfunktion erfüllt.

16. Die Umsatzsteuer ist zwischen Bund und Ländern nach ibrem allgemeinen Finanzbedarf aufzuteilen.

17. Bundesergänzungszuweisungen können im Spitzenausgleich den borizontalen Finanzausgleich fortsetzen, bei begründetem Sonderbedarf unzureichende Wirtschaftsstruktur verbessern sowie Existenzbilfe in extremer Haushaltsnotlage leisten. Zuweisungen im Finanznotstand sollten ein Sanierungsprogramm voraussetzen oder eine Einschränkung der Finanzgewalt des Empfängerlandes bewirken. 
18. Die Ausgabenkompetenz sollte sich nach der Aufgabenverursachung und -verantwortung richten. Die Zweckausgaben der Ausfübrung von Bundesgesetzen durch die Länder trägt dann der Bund, soweit den Ländern kein Spielraum bei deren Ausfübrung zusteht; die Verwaltungsausgaben bleiben den Ländern.

19. Mischfinanzierung und Einzeldotationen sind soweit wie möglich abzubauen.

20. Unterschiedliche Begriffe für identische Distributionszwecke sind $z u$ vermeiden.

21. Ein neues Gebot eines einheitlichen Transfergesetzes könnte die Gesamtproblematik aller vertikalen Transfers in einem einzigen Jabresverfabren darlegen und lösen.

V. Zur Reform des Einnahmesystems:

22. Wegen des Wildwuchses ertragbringender Sonderlasten müssen Art.105 GG sämtliche Abgaben des Staates, Art.106 GG weitere Geldquellen des Bundes und der Länder erfassen.

23. Ökonomische Lenkungsempfehlungen in Steuernormen müssen kompetenziell mit anderen rechtlichen $G e-u n d$ Verboten abgestimmt werden.

24. Umweltabgaben gefäbrden Steuersystematik und geordnete Staatsfinanzierung. Ein ökologischer Umbau der Steuerordnung ist nicht möglich; nur eine moderate Einfügung von Umweltschutzanreizen in das Abgabensystem ist sinnvoll.

25. Sonderlasten sind nur in überschaubaren Rechtsverbältnissen ("kleiner" Umweltschutz), Steuern für den regionalen und globalen ("großen") Umweltschutz einzusetzen.

26. Umweltsonderlasten sollten mit materiell schärferen Konturen und engeren Grenzen in einem eigenen Grundgesetzartikel geregelt werden. Sie sind von allgemeinen Finanzierungszwecken freizubalten.

\section{Zur Reform des Haushaltswesens:}

27. Nebenhaushalte gefäbrden den Grundsatz der Einheit des Haushaltsplans, den Gesetzesvorbehalt für die Kreditaufnabme und das Budgetrecht des Parlaments. Sie bedürfen von Verfassungs wegen besonderer Rechtfertigung. Die Autonomie eines Verwaltungsträgers und die kaufmännische Eigenwirtschaftlichkeit eines öffentlichen Unternehmens legitimieren in der Regel einen Nebenhaushalt.

28. Trotz bestebender Sonderhaushalte würde das Budgetrecht und die Einheit des Haushaltsplans durch Einfübrung von Gesamthausbaltsplänen und -rechnungen unter Einschluß von Vermögensaufstellungen und Bruttoschuldennachweisen gewabrt. 


\title{
Grundsätze der Finanzverfassung in Österreich ${ }^{1}$
}

\author{
3 a. Landesbericht von Prof. Dr. Herbert Haller, Wien
}

Steigender Zinsendienst für die Staatsschuld, steigende Personalkosten für die Staatsdiener, steigende Aufwendungen für den Sozialbereich sowie drohende Risiken aus Haftungsübernahmen im Bereich Außenhandel und bei großen Verkehrsprojekten, all das legt für den Bund nahe, eine Budgetkonsolidierung tatsächlich in Angriff zu nehmen. Geschieht das nicht, sind Aufgaben wie Umweltsanierung, Bewältigung des Flüchtlingszustromes und Hilfe für östliche und südöstliche Nachbarländer nicht zu finanzieren².

Die Position Österreichs als Beitrittswerber zu den Europäischen Gemeinschaften läßt den Bund überdies überlegen, wie denn ein Beitrag an das Gemeinschaftsbudget von $30 \mathrm{Mrd}$. Schilling bei einer jährlichen Neuverschuldung von über $60 \mathrm{Mrd}$. unterzubringen ist. Selbst wenn den Bund letztlich nur eine Beitragszahlung von netto etwas über 10 Milliarden träfe, würde das seine Neuverschuldung mit einem Schlag um $20 \%$ anheben $^{3}$.

\footnotetext{
1 Einen Überblick geben Schäffer, Die österreichische Finanzverfassung, in: FS Weber, 1986, 87 und Walter/Mayer, Grundriß des österreichischen Bundesverfassungsrechts, 7.Aufl. 1992, 111. Eine umfassende Behandlung findet sich bei Pernthaler, Österreichische Finanzverfassung, Theorie - Praxis - Reform, 1984 und Ruppe, Neuordnung der bundesstaatlichen Kompetenzverteilung, Teilbereich Finanzverfassung, in: Republik Österreich, Bundeskanzleramt - Verfassungsdienst (Hrsg.), Neuordnung der Kompetenzverteilung in Österreich, Grundlagen und Ergebnisse der Arbeitsgruppe für Fragen der Neuordnung der Kompetenzverteilung (Strukturreformkommission), 1991, 289.

2 Stübler, Kennzahlen aus dem Bereich der Statistik des öffentlichen Sektors, in: Gantner, Handbuch des öffentlichen Haushaltswesens, 1991, 135 sowie Heft 2/ 1992 der Wirtschaftspolitischen Blätter mit dem Themenschwerpunkt Ausgabenseitige Budgetkonsolidierung und Lebner, Die Budgetkonsolidierung - eine Notwendigkeit, in: Kohl u.a. (Hrsg.), Österreichisches Jahrbuch für Politik 1991, 1992, 551.

3 Vgl. dazu die Studie des Beirats für Wirtschafts- und Sozialfragen, Arbeitsgruppe Budgetpolitik, Finanzverfassung und Finanzausgleich - Herausforderungen und Anpassungserfordernisse, 25. Mai 1992, 69.
} 
Neben einem „Sparen auf allen Linien“, der Privatisierung öffentlicher Unternehmungen (Verkauf von „Familiensilber“, wie bisweilen kritisch vermerkt wird) und neben Maßnahmen zur Verwaltungsreform ${ }^{4}$ ) überlegt der Bund laut und deutlich, daß die anderen Gebietskörperschaften im Finanzausgleich zu gut gestellt sind. Diese Länder und Gemeinden - sind jedoch durchaus sachkundig und energisch vom Gegenteil überzeugt. Der derzeitige Ausgleich gereiche ihnen zum Nachteil, eine Änderung sei nötig5.

Schon allein die bei allen Gebietskörperschaften gegebenen Budgetprobleme machen den Finanzausgleich und die diesem vorangehenden Grundsätze der Finanzverfassung zu einem aktuellen Thema auch in Österreich. Eine sub specie Europäische Einigung aktualisierte Föderalismusdebatte trägt zu dieser Aktualität zusätzlich bei ${ }^{6}$.

Die als Bundesstaat nur schwach ausgebildete Republik Österreich hat es in den ersten Stunden ihrer Verfassungsschöpfung nicht verstanden, ein zumindest dieser reduzierten Bundesstaatlichkeit entsprechendes Finanzverfassungsrecht zu schaffen. Das Bundes-Verfassungsgesetz des Jahres 1920 enthielt nur rudimentäre und zentralistisch ausgelegte Regelungen der Kompetenzverteilung im Bereich Finanzwesen?

Die ursprünglichen Regelungen wurden zwar ergänzt und verfeinert, die als provisorisch gedachte zentralistische Ausrichtung blieb jedoch bestehen. Der zur Ânderung kompetente und von der Rechtslage begünstigte Bund hatte kein Interesse an substantiellen Änderungen. Es ergab sich als Handlungsmaxime - gültig für die rechtliche Regelung wie auch für die finanziellen Auswirkungen - eine nie

${ }^{4}$ S. die vom Bundeskanzleramt herausgegebene Schriftenreihe zur Verwaltungsreform und die Entschließung des Bundespräsidenten, BGBl.571 a/1991, mit der einem eigenen Bundesminister im Bundeskanzleramt Föderalismusangelegenheiten und Agenden der Verwaltungsreform übertragen wurden.

5 S. das Ländermemorandum zum Finanzausgleich 1993 (Beilage zum Akt der beim Amt der Niederösterreichischen Landesregierung eingerichteten Verbindungsstelle der österreichischen Bundesländer 13/984 vom 13. Mai 1992 oder das Forderungsprogramm des Österreichischen Städtebundes bezüglich des nächsten Finanzausgleichs vom 16.10.1991.

6 Vgl. die Bände der Schriftenreihe des Instituts für Föderalismusforschung, insbesondere von Bd.47, Perntbaler, Auswirkungen eines EG-Beitrittes auf die föderalistische Struktur Österreichs, 1989 bis Bd. 53, Pernthaler, Das Länderbeteiligungsverfahren an der europäischen Integration, 1992.

7 Vgl. dazu Pölsterl, Die Finanzverfassung 1922. Ein Beitrag zur verfassungsgeschichtlichen Entwicklung, Diplomarbeit der Wirtschaftsuniversität Wien, 1980. 
revolutionäre, sondern stets vorsichtig evolutionäre Veränderung des finanziellen Ausgleichs ${ }^{8}$. Die Länder sind jedoch heute dabei, mit einem klugen Schachzug Änderungen zu erzwingen, an die vor kurzem noch nicht zu denken war. Darüber jedoch ist erst abschließend zu berichten, vorher soll der status quo dargelegt werden.

\section{Der Kostentragungsgrundsatz}

Als erster Grundsatz der Finanzverfassung ${ }^{9}$ läßt sich die Verpflichtung der Gebietskörperschaft nennen, die sich aus der Besorgung der eigenen Aufgaben ergebenden Kosten selbst zu tragen. Diesem Grundsatz liegt die Vorstellung einer gerechten Verteilung, aber auch die Überlegung zugrunde, daß mit dieser Anordnung Bemühungen einer Verwaltungsökonomie am wirkungsvollsten unterstützt würden.

Die Anknüpfung an Aufgaben kann freilich ein Kostenvolumen stets nur vage andeuten. Es kommt auf das Ausmaß der Erfüllung der Aufgaben in quantitativer und qualitativer Sicht an und selbstverständlich auch auf die wechselnden Verhältnisse, unter denen diese Aufgaben zu erfüllen sind. Die das Finanz-Verfassungsgesetz ausführenden Finanzausgleichsgesetze des Bundes im einfachen Gesetzesrang sind deshalb auf wenige Jahre befristete Gesetze.

Im Bereich der hoheitlich zu vollziehenden Aufgaben ergeben sich immer wieder dadurch Spannungsfelder, daß die Länder während einer Finanzausgleichsperiode ohne Anpassung dadurch zusätzlich belastet werden, daß ihre Organe neu geschaffenes Bundesrecht zu vollziehen haben ${ }^{10}$. Im Bereich der Privatwirtschaftsverwaltung - wo

' S. z. B. die Aussage von Luther, Bund-Länder-Beziehungen: Formal- und Realverfassung, in: Dachs u.a. (Hrsg.), Handbuch des politischen Systems Österreichs, 1991, 816 (818): „Zu den Auswirkungen dieses Systems wäre zunächst zu bemerken, daß das Gesamtergebnis ausgesprochen stabil ist. Seit 1973 bewegen sich die Änderungen der Anteile der ordentlichen Einnahmen der Gebietskörperschaften an den Gesamteinnahmen sowie ihrer Anteile am Gesamtabgabenertrag in einer Größenordnung von selten mehr als $\pm 1 \%$.“

${ }^{9}$ Art. 13 des Bundes-Verfassungsgesetzes verweist auf ein eigenes FinanzVerfassungsgesetz. Dieses, BGBl. 45/1948 i.d.F. BGBl.686/1988, enthält in $\$ 2$ diesen Grundsatz.

10 Das ist Teil eines sogenannten „stillen Finanzausgleichs“, vgl. Schäffer, Finanzverfassung, 94 und umfassend Ruppe, Erscheinungsformen und Rechtsprobleme des stillen Finanzausgleichs (Abschnitt), in: Matzner (Hrsg.), Öffentliche Aufgaben und Finanzausgleich, 1977, 329. 
transkompetentes Handeln möglich ist - ergibt sich die Kostenbelastung noch stärker als im hoheitlichen Bereich aus dem Handeln selbst, weniger aus der rechtlichen Verpflichtung hierzu ${ }^{11}$.

Der Kostentragungsgrundsatz oder Konnexitätsgrundsatz gilt jedoch nur subsidiär. Der einfache Bundesgesetzgeber kann anderes bestimmen und dabei die Kosten auf Länder und Gemeinden verlagern. Dies ohne Möglichkeit des Bundesrates, dies wirksam zu verhindern ${ }^{12}$.

Schon der erste Grundsatz des österreichischen Finanzverfassungsrechts zeigt an, daß der einfache Bundesgesetzgeber in einer für einen Bundesstaat unerträglichen Weise dominiert.

\section{Ertragsverteilung durch den einfachen Gesetzgeber}

Das Finanz-Verfassungsgesetz gibt dem einfachen Bundesgesetzgeber nicht nur das Recht, den Grundsatz der Kostentragung zu modifizieren, also die Belastungsseite zu gestalten, sondern macht ihn auch zuständig zur Gestaltung der Ertragsseite. Er hat die Verteilung der Besteuerungsrechte und die Verteilung der Abgabenerträge vorzunehmen ${ }^{13}$.

Für diese Aufgabe werden auf Verfassungsstufe Abgabentypen bereitgestellt, derer sich der Bundesgesetzgeber zu bedienen hat. Diese Typen sind danach unterscheidbar, wem der Ertrag der Abgabe zukommt: den ausschließlichen Bundes-, Landes- und Gemeindeabgaben steht die Gruppe der von der Ertragshoheit her gemeinschaftlichen Abgaben gegenüber. Hier gibt es die Unterformen der gemeinschaftlichen Abgaben (Ertragsteilung), der Zuschlagsabgaben (Zuschlag für nachgeordnete Gebietskörperschaft/en) und der Abgaben von demselben Besteuerungsgegenstand (durch mehrere Gebietskörperschaften). Eine konkrete Abgabe einem Abgabentyp zuzuweisen und die Teilung zu

${ }_{11} \mathrm{Zu}$ einer ausnahmsweisen Abkehr von der Grundregel des $\$ 2$ F-VG im Zusammenhang mit der Übertragung privatwirtschaftlicher Aufgaben des Bundes an die Landeshauptleute und die ihnen unterstellten Landesbehörden nach Art. 104 Abs. 2 B-VG vgl. Walter/Mayer, Grundriß, 304 und umfassend Wenger/Höß, Juristische Grundlagen der Verwaltungsorganisation und Aufgabenverteilung, in: Matzner, Öffentliche Aufgaben, 53 sowie Thöni, Privatwirtschaftsverwaltung und Finanzausgleich, 1978.

12 Die Länderkammer hat hier nur ein suspensives Veto.

13 Vgl. $\$ 3$ F-VG. 
bestimmen, obliegt damit dem Bundesgesetzgeber. Dem Landesgesetzgeber steht nur eine Restkompetenz dort zu, wo das Verhältnis Land - Gemeinde näher auszugestalten ist ${ }^{14}$.

Die wichtigsten Steuern - veranlagte Einkommensteuer, Lohnsteuer, Umsatzsteuer und Mineralölsteuer - hat der Bundesgesetzgeber dem Typ der gemeinschaftlichen Abgabe zugewiesen. Bund, Ländern und Gemeinden kommen perzentuelle Anteile zu. Man spricht dabei gerne vom System oder Grundsatz einer verbundenen Steuerwirtschaft. Im Hintergrund steht die Überlegung, allenfalls ungünstige Entwicklungen bei einer Steuer nicht alleine tragen zu müssen und positive Entwicklungen nicht zu versäumen. Diese vom einfachen Bundesgesetzgeber gewählte Gemeinsamkeit wird von den Ländern und Gemeinden nicht prinzipiell abgelehnt, gehen sie doch durch die Beteiligung des Bundes auch sicher, daß seine Anstrengungen bei der Steuereinhebung schon im eigenen Interesse nicht erlahmen und daß die Bundesfinanzverwaltung nicht allzugroße Nachsicht walten läßt. Mit ihren Anteilen sind die Länder und Gemeinden freilich nicht zufrieden - demgegenüber droht wiederum der Bund, das unpopuläre Inkasso nicht weiterhin zum Hauptteil zu übernehmen. Er weist darauf hin, daß die Verteilung der vom Bund zugewiesenen Ertragsanteile der bessere Part sei; ein „Inkassoföderalismus“ werde wohlweislich nicht begehrt ${ }^{15}$.

Zusammenfassend läßt sich als zweiter Grundsatz des Finanzverfassungsrechts festhalten, daß dem Bund die Dominanz bei der Bestimmung der Rechte zur Besteuerung und - vor allem - bei der Aufteilung der Erträge zukommt. In diesem Rahmen hat der einfache

14 Die Länder sind nach $\$ 3$ Abs. 2 F-VG berechtigt, ihren durch sonstige Einnahmen nicht gedeckten Bedarf auf die Gemeinden umzulegen. Für diese Umlage kann durch Bundesgesetz - vgl. $\$ 4$ FAG 1989, BGBl.687/1988 - eine Höchstgrenze festgelegt werden. Zu den weiteren relativ bedeutungslosen Länderkompetenzen vgl. etwa Ruppe, Finanzverfassung im Bundesstaat, 1977, 40, der auch das Abgabenerfindungsrecht der Länder untersucht. Zu den Gemeinden vgl. etwa Zeh, Die Stellung der Gemeinden im Finanzausgleich, Diplomarbeit der Wirtschaftsuniversität Wien, 1990 und Schanovsky (Hrsg.), Der Finanzausgleich aus der Sicht der Gemeinden, 1984.

15 Daten zum Finanzausgleich sind dem jährlich erscheinenden Statistischen Handbuch für die Republik Österreich (Herausgegeben vom Österreichischen Statistischen Zentralamt) oder dem Statistischen Jahrbuch der Stadt Wien (Magistrat der Stadt Wien) oder dem Statistischen Jahrbuch Österreichischer Städte (Österreichischer Städtebund) zu entnehmen. Vgl. auch Hüttner, Die Ertragsanteile der Länder und Gemeinden, Österreichische Gemeindezeitung 1991, H 4, 10. 
Gesetzgeber weitestgehend ein System der verbundenen Steuerwirtschaft geschaffen ${ }^{16}$.

\section{Finanzausgleichsgerechtigkeit}

Als juristische Determinante für die Ausübung der Machtbefugnisse des einfachen Bundesgesetzgebers ist zuletzt noch der Grundsatz der Finanzausgleichsgerechtigkeit zu nennen. Die Regelungen des Finanzausgleichsgesetzes haben in Übereinstimmung mit der Verteilung der Lasten der öffentlichen Verwaltung zu erfolgen und darauf Bedacht zu nehmen, daß die Grenzen der Leistungsfähigkeit der beteiligten Gebietskörperschaften nicht überschritten werden ${ }^{17}$.

Diese Anordnung wurde lange als politischer Grundsatz mißverstanden. Der Verfassungsgerichtshof hat jedoch seine Justitiabilität zunehmend ab Mitte der 80er Jahre - erwiesen, und Ruppe stellt dazu fest: „Die Finanzverfassung dient in der verfassungsrechtlichen (verfassungsgerichtlichen) Realität nicht nur als Instrument der föderalistischen Kompetenzabgrenzung, sondern ist neben den Grundrechten eine weitere verfassungsrechtliche Schranke, die den einzelnen vor Eingriffen des Steuergläubigers schützt. Insofern scheint es nicht abwegig, von einem Funktionswandel, zumindest aber von einer Funktionsanreicherung der Finanzverfassung zu sprechen, die durch die Judikatur des Verfassungsgerichtshofes getragen wird."18

Gerade in letzter Zeit hat der Verfassungsgerichtshof erneut die Anforderungen der Finanzausgleichsgerechtigkeit an das Finanzausgleichsgesetz spezifiziert und als Ausprägung des Gleichheits- oder Sachlichkeitsgebotes ${ }^{19}$ gezeigt. Auf Grund hier nicht näher auszubrei-

${ }^{16} \mathrm{Zu}$ den positivsten Auswirkungen dieses Verbundes gehört eine gewisse wechselseitige Bedachtnahme bei wirtschaftspolitischen und damit zumeist abgabenwirksamen Maßnahmen.

$17 \$ 4$ F-VG enthält dieses Gebot einer Finanzausgleichsgerechtigkeit oder den Paritätsgrundsatz. S. dazu Schäffer, Finanzverfassung, 87.

18 Ruppe, Finanzverfassung und Verfassungsgerichtshof - Funktionswandel der Finanzverfassung?, in: Mayer (Hrsg.), Staatsrecht in Theorie und Praxis; FS Walter, 1991, 587 (601) mit weiteren Hinweisen, insbes. einer Dokumentation der Entscheidungen des Verfassungsgerichtshofes.

19 Zum Gleichheitssatz s. Holoubeck, Die Sachlichkeitsprüfung des allgemeinen Gleichheitssatzes, Österreichische Zeitschrift für Wirtschaftsrecht, 1991, 72 und Korinek/Holoubeck, Gleichheitsgrundsatz und Abgabenrecht, in: Gassner/Lechner (Hrsg.), Steuerbilanzreform und Verfassungsrecht, 1991, 73. 
tender grundsätzlicher Erwägungen und spezieller Gegebenheiten des Einzelfalles hat er dargelegt, wann das Finanzausgleichsgesetz "mit einem in die Verfassungssphäre reichenden Fehler behaftet wäre: Die Partner der Finanzausgleichsverhandlungen (und ihnen folgend der Gesetzgeber) sind von völlig unrichtigen faktischen Gegebenheiten ausgegangen; es wurden offenkundig extrem verfehlte Mittel zur Erzielung eines sachgerechten Finanzausgleiches eingesetzt; einzelne Gebietskörperschaften wurden gezielt benachteiligt oder bevorzugt; die notwendigen Anpassungen an die geänderten tatsächlichen Verhältnisse wurden - auch unter Beachtung des Zeithorizontes - nicht vorgenommen oder in die Wege geleitet." Im selben Erkenntnis spricht der Gerichtshof freilich auch davon, daß „schließlich der Finanzausgleich ein Gesamtsystem bildet, dessen Elemente im Prinzip nicht einzeln betrachtet werden können " 20 . Er zeigt damit auf, daß die politischen Gesamtentscheidungen weniger seinem Zugriff ausgesetzt sind als die in einem engen Vergleichsrahmen getroffenen Einzelregelungen. Auch bei diesen wird die Beurteilung schwierig, wenn sie nicht isoliert, sondern in ein Bündel von Regelungen integriert gesehen werden müssen.

Wie im Grundrechtsbereich ${ }^{21}$, so vertieft der Verfassungsgerichtshof auch hier seine Judikatur durch Bildung von Fallgruppen und Entwicklung von Formeln, durch die er das Prüffeld zu strukturieren sucht $^{22}$. Dazu bringt er weiterführende Wertungsgesichtspunkte ein, etwa die legitimierende Funktion von der Regelung vorangehenden Verhandlungen und Paktierungen oder das aus einem Vertrauensschutz erwachsende Gebot, selbst gebotene Änderungen und Anpassungen nur schrittweise durchzuführen. Ansatzweise könnte man auch von einem Prozeß der beginnenden Verwissenschaftlichung der

20 Entscheidung vom 12.10.1990, G 66/90. Bestätigend Erkenntnis vom 27.6. 1991, G 158-162/91, mit ausführlicher Kommentierung von Schulev/Steindl, in: Österreichische Zeitschrift für Wirtschaftsrecht 1991, 118.

${ }_{21}$ Als Beispiel sei hier die Judikatur zur Freiheit der Erwerbsbetätigung genannt; vgl. Strejcek, Freiheit der Erwerbsbetätigung, Forschungsbericht des Ludwig-Boltzmann-Instituts zur Analyse wirtschaftspolitischer Aktivitäten, 1989. Zur verfassungsgerichtlichen Interpretation m.w. H. Korinek, Zur Interpretation von Verfassungsrecht, in: Mayer (Hrsg.), FS Walter, 363.

22 Als Ansatz zu einer Formel vgl. etwa die Unterscheidung in Erkenntnis G 158-162/91 zwischen Maßnahmen des Gesetzgebers, die von vornherein untauglich waren, und solchen, die sich nicht a priori als solche zeigten, auch wenn sie sich ex post als verfehlt erwiesen haben. Eine Zusammenstellung von Formeln findet sich bei Machacek, Verfahren vor dem Verfassungsgerichtshof, 2. Aufl. 1992. 
Judikatur sprechen, da gerade im Bereich der Finanzfragen zunehmend ökonomischer Sachverstand einbezogen wird ${ }^{23}$.

Das Gesamtsystem, auf das der Verfassungsgerichtshof verweist, ist vielfältig und komplizierter als bisher angedeutet. Eine Andeutung sei deshalb noch erlaubt:

Wie werden die Ertragsanteile der Länder und Gemeinden, die ihnen aus den gemeinschaftlichen Aufgaben vom Bund im Rahmen des vertikalen Finanzausgleichs zugewiesen werden, dann horizontal verteilt? Diese Verteilung erfolgt nach verschiedenen Schlüsseln, denen unterschiedliche Prinzipien oder Anknüpfungspunkte zugrunde liegen ${ }^{24}$. Bei der Verteilung der Länderanteile spielt im Umfang von $75 \%$ der Anteile die Volkszahl die entscheidende Rolle; das Aufkommensprinzip entscheidet nur bei ca. $20 \%$ der Länderertragsanteile. Es ergibt sich daraus ein beträchtlicher Umverteilungseffekt. Das Burgenland erhält beispielsweise im Wege dieser Umverteilung um etwa $54 \%$ mehr an Ertragsanteilen, als es seinem Aufkommen entsprechen würde, Wien gibt hingegen $18 \%$ seines Aufkommens an die anderen Länder und Gemeinden $a b^{25}$. Durch einen Kopfquotenausgleich wird dieser Umverteilungseffekt noch zum Teil verstärkt. Erreicht ein Land unterdurchschnittliche Ertragsanteile pro Kopf seiner Bevölkerung, dann erhält es die Differenz zum Durchschnittsbetrag über Finanzzuweisungen des Bundes ${ }^{26}$. Damit wird in einem außerordentlich hohen Maß eine Einheitlichkeit der Lebensbedingungen via Finanzausgleich gestützt. Das freilich ist eine vom Gesetzgeber weitestgehend frei getroffene politische Entscheidung. Das zeigte sich auch bei der Beurteilung des abgestuften Bevölkerungsschlüssels als Instrument der Verteilung der Ertragsanteile unter den Gemeinden. Bevölkerungsstarke Gemeinden erhalten bei der Verteilung von etwa $25 \%$ der gemeindlichen Ertragsanteile pro Kopf

${ }^{23}$ Zur Heranziehung von außerjuristischem Sachverstand vgl. Korinek, Die Tatsachenermittlung im verfassungsgerichtlichen Verfahren, in: Stern (Hrsg.), 40 Jahre Grundgesetz - Entstehung, Bewährung und internationale Ausstrahlung, 1990, 107 sowie zum „sachfernsten“ Fall der österreichischen verfassungsgerichtlichen Judikatur - VfSlg. 6541/71 - die Bemerkungen von Haller, Beförderungssteuer in fast siebenfacher Höhe des Bruttoertrages - Keine Gleichheitsverletzung!, Quartalshefte der Girozentrale 1972, H. 1, 49.

${ }^{24}$ S. $\$ 8$ Abs. 2 FAG.

${ }^{25}$ S. Hüttner, Die Ertragsanteile der Länder und Gemeinden 1990/91, Österreichische Gemeinde-Zeitung 1991, H. 4, 10.

26 Schäffer, Finanzverfassung, 93 hält fest, daß sich letztlich die Verteilung nur marginal von einer Verteilung der Ertragsanteile nach der Volkszahl unterscheidet. 
ihrer Wohnbevölkerung einen höheren Betrag (Vervielfältiger 21/3) als bevölkerungsschwache Gemeinden (niedrigster Vervielfältiger 11/3). Dem liegt die Argumentation zugrunde, daß die Belastung der Gemeinden mit höherer Bevölkerung überproportional steigt. Der Verfassungsgerichtshof hat diese Regelung im Gesamtgefüge mit anderen, die wieder kleinere Gemeinden begünstigen, gesehen und sie nicht als verfassungswidrig aufgehoben ${ }^{27}$. Wohl aber hat er jüngst eine Begünstigung für Randgemeinden einer Großgemeinde aufgehoben, da sie nach der Ausgliederung zu lange - Übergangsfrist über 30 Jahre! - begünstigt blieben ${ }^{28}$. Der Verfassungsgerichtshof kann und das läßt sich diesem Beispiel entnehmen - sub specie Finanzausgleichsgerechtigkeit nicht so sehr grundlegende Weichenstellungen, sondern eher von der inneren Systematik her fragliche Regelungen korrigieren. Er soll ja nicht politische Entscheidungen an sich ziehen. Damit aber finden die Länder in ihm keine volle Stütze in ihrem Bemühen um eine dem bundesstaatlichen Denken adäquate Gestaltung der Finanzverfassung und des Finanzausgleichs.

\section{Die Paktierung und „Das pactum“}

Ungeachtet der gebotenen Finanzausgleichsgerechtigkeit, die vom Bund zu beachten ist, ist dieser der von der Bundesverfassung eingesetzte juristische Dominator der Ausgestaltung des Finanzausgleichs. Er hat eine im wesentlichen verbundene Steuerwirtschaft geschaffen ${ }^{29}$ und die horizontale Verteilung der Ertragsanteile an der Volkszahl ausgerichtet.

Die schwache Stellung der Länder und Gemeinden erfährt eine Verbesserung durch die nunmehr auch im Finanzausgleichsgesetz gebotene Praxis, daß der Bund mit ihnen vor der Inangriffnahme steuerpolitischer Maßnahmen, die für diese Gebietskörperschaften mit einem Ausfall an Steuern verknüpft sein können, Verhandlungen

$27 \mathrm{Vgl}$. mit weiterführenden Angaben Obermann, Läßt sich der abgestufte Bevölkerungsschlüssel im österreichischen Finanzausgleich sachlich rechtfertigen und mit dem Gleichheitssatz vereinbaren?, Zeitschrift für Verwaltung 1982, 230. Vgl. auch das erste in Fn. 20 zitierte Erkenntnis.

$28 \mathrm{Vgl}$. das zweite in Fn. 20 zitierte Erkenntnis.

29 Die Anteile am „Steuerkuchen“ betragen jeweils etwas mehr als $64 \%$ für den Bund, $20 \%$ für die Länder und $15 \%$ für die Gemeinden. 
zu führen hat ${ }^{30}$. Diese Finanzausgleichsverhandlungen, insbesondere bedeutsam vor dem Auslaufen des zeitlich begrenzten Finanzausgleichsgesetzes, sind freilich kein Garant für ein bestimmtes Ergebnis. Man kommt jedoch stets zu Einigungen, auch wenn diese keinen der Partner zufriedenstellen. Der Einigung gehen deutliche und wissenschaftlich mehr oder weniger abgesicherte Medienoffensiven voran ${ }^{31}$. Die Verhandlungen werden gegen Ende zunehmend stiller, und in den letzten Phasen sind es Geheimverhandlungen. Es zeigt sich eine Streitkultur, die sich auch im System der österreichischen Sozialpartnerschaft findet - Sozialpartnervertreter sind ja auch hier eingebunden. Zuletzt bleibt oft das Problem der Verhandler, der eigenen Seite zu erklären, weshalb man sich geeinigt hat; auch dafür lassen sich in den Verhandlungen Sprachregelungen finden ${ }^{32}$.

Absichten, die juristische Situation zu verändern, gibt es schon lange. Jedes Forderungsprogramm der Bundesländer ${ }^{33}$, zuletzt ein spezielles Ländermemorandum zum Finanzausgleich 1993, enthält Wünsche nach einer Stärkung des Föderalismus. Dabei sind freilich die Größenordnungen zu bedenken. Während Bayern über 10 Millionen Einwohner aufweist, sind es in Österreich keine 8 Millionen, und Österreich ist in 9 Länder geteilt, von denen zwei nur um die 300000 an Wohnbevölkerung aufweisen. Ungeachtet dieser Umstände hat der Bund im Zuge angesichts der gemeinsam in Auftrag gegebenen Arbeit einer Strukturreformkommission Verständnis signalisiert ${ }^{34}$.

Heute am 8. Oktober 1992 um $11 \mathrm{Uhr}$ - zuverlässig abgestimmt auf Thema und Tag der Tagung der Vereinigung der Deutschen Staatsrechtslehrer - wird der entscheidende Schritt gesetzt: Der

${ }^{30} \mathrm{~S}$. $\$ 5$ FAG. Zur Teilnahme an den Verhandlungen sind für die Gemeinden der Österreichische Städtetag und der Österreichische Gemeindebund berechtigt.

${ }^{31} \mathrm{Vgl}$. etwa die Vielzahl von Berichten in den Salzburger Nachrichten vom 6., 14., 18., 20., 26., 29. und 31. August 1992, in denen von den Verhandlungspartnern ein recht dramatisches Szenario gezeichnet wird. Der Bund darf sich aus seiner Verantwortung nicht flüchten, es gibt Konflikte, Demonstrationen werden angedroht, Maßnahmen und Gegenmaßnahmen.

32 Das Ergebnis ist praktisch eine Verlängerung des bestehenden Finanzausgleichs mit Laufzeit von 3 Jahren ab 1.1.1993. Vgl. dazu Informationsblatt des Instituts für Föderalismusforschung 5/1992: „Fortschreibung unbefriedigender Zustände“.

${ }_{33} \mathrm{Vgl}$. Berchtold, Die Verhandlungen zum Forderungsprogramm der Bundesländer seit 1956, 1988.

${ }^{34}$ Republik Österreich (Hrsg.), Neuordnung der Kompetenzverteilung in Österreich. Grundlagen und Ergebnisse der Arbeitsgruppe für Fragen der Neuordnung der Kompetenzverteilung (Strukturreformkommission), 1991. 
Bundeskanzler der Republik Österreich und der Landeshauptmann von Niederösterreich als Vorsitzender der Landeshauptmännerkonferenz schließen ein politisches pactum zur Neuordnung des Bundesstaates $^{35}$. Sie treten darin für eine Vielzahl revolutionärer Veränderungen ein. Es finden sich die Ziele, geschlossene und abgerundete Kompetenz- und Verantwortungsbereiche im Sinne des Subsidiaritätsprinzips zu schaffen, die mittelbare Bundesverwaltung grundsätzlich zu beseitigen, den Spielraum für die Landesverfassungen zu erweitern, eine Weiterentwicklung der unabhängigen Verwaltungssenate zur Landesverwaltungsgerichtsbarkeit anzustreben, die Mitwirkung der Länder an der europäischen Integration - insbesondere hinsichtlich der Zusammenarbeit der europäischen Regionen sicherzustellen und die Stellung des Bundesrates zu stärken. Für die Finanzverfassung wird vereinbart: „Die mit der Neuordnung der Kompetenzverteilung zusammenhängende Neugestaltung der Finanzverfassung und des Finanzausgleichs wird in dem zwischen den Finanzausgleichspartnern (Bund, Ländern und Gemeinden) zu beschließenden Finanzausgleichspakt festzulegen sein." Einvernehmen ist angesagt, nicht Bundesvorrang!

Wird dieses "pactum" auch realisiert werden?

Es ist unter der Überschrift „Umsetzung“ im pactum selbst vorgesehen, daß die "genannten bundesverfassungsgesetzlichen Maßnahmen bis längstens zur Volksabstimmung über die bundesverfassungsgesetzliche Ermächtigung zum EG-Beitritt als beschlußreife Regierungsvorlage textlich fixiert und spätestens in der aus Anlaß des EG-Beitritts erforderlichen Novelle zum B-VG beschlossen werden". ${ }^{36}$

Sollte der Bund dieses pactum nicht im Einvernehmen mit den Ländern erfüllen, könnte man sich wohl vorstellen, daß dem jeweiligen Landesvolk ein Ja zum EG-Beitritt nicht empfohlen wird oder die EG-Verfassungsnovelle die Zustimmung im Bundesrat nicht erhält. Das ist der kluge Schachzug, der auch zur Verbesserung der Stellung

35 „Politische Vereinbarung über die Neuordnung des Bundesstaates“.

${ }^{36}$ Die EG-Novelle benötigt nach der $2 / 3$-Mehrheit im Nationalrat auch eine Zustimmung im Bundesrat mit eben diesem Konsensquorum (Art. 44 Abs. 2 BVG). Der hier genannte zweistufige Weg in Richtung EG sucht die strittige Frage unbeantwortet zu lassen, ob ein durch Staatsvertrag vorgenommener EGBeitritt einer Volksabstimmung bedarf. Für den vorgesehenen Weg über ein Verfassungsgesetz bedarf es einer Volksabstimmung, da mit dem Beitritt jedenfalls eine Gesamtänderung der Bundesverfassung verbunden ist. 
der Länder im Bereich der Finanzverfassung führen wird ${ }^{37}$. Ein Weg in die EG ohne finanzielle Absicherung des Föderalismus würde den Ländern sicherlich zu schwer fallen. Dem hat der Bund Rechnung zu tragen.

37 Vgl. die Meldungen, in: Die Presse, „Verfassungsreform kommt“ und Tiroler Tageszeitung, "Stärkung der Länder vor EG-Beitritt eingemahnt“ vom 17. Dezember 1992. Der Föderalismusminister kündigt die Regierungsvorlage über eine „tiefgreifende Verfassungsreform" an. 


\title{
Grundsätze der Finanzverfassung in der Schweiz
}

\author{
3 b. Landesbericht von Prof. Dr. Tobias Jaag, Zürich
}

\section{Einleitung}

In Anbetracht der sehr knappen Zeit, die mir zur Verfügung steht, beschränke ich mich in meinem Länderbericht auf die beiden meines Erachtens zentralen Fragen der schweizerischen Finanzverfassung oder Finanzordnung, auf die Verteilung der Einnahmequellen zwischen Bund und Kantonen und auf den Finanzausgleich ${ }^{1}$. Die beiden Bereiche lassen sich nicht scharf voneinander trennen. Sie greifen teilweise ineinander, indem mit der Regelung der Zuständigkeit zur Erhebung von Abgaben gleichzeitig Finanzausgleich betrieben wird.

Ich habe eine Tabelle mit den wichtigsten Einnahmequellen von Bund und Kantonen aufgelegt. Zur Illustration sind die Zahlen aus dem Jahre 1989 für den Bund, für die Kantone gesamthaft sowie für je einen finanzstarken, mittelstarken und finanzschwachen Kanton eingetragen ${ }^{2}$.

\section{Die Aufteilung der Einnahmequellen zwischen Bund und Kantonen}

1. Nach dem Konzept von Artikel 3 der schweizerischen Bundesverfassung (BV) sind die Zuständigkeiten des Bundes abschließend in der Bundesverfassung aufgeführt. Demgemäß stehen dem Bund grundsätzlich nur diejenigen Einnahmequellen zur Verfügung, die ihm die Bundesverfassung ausdrücklich zuweist ${ }^{3}$.

1 In der Schweiz obliegt die Regelung der Stellung der Gemeinden den Kantonen. Demgemäß richtet sich auch die finanzielle Situation der Gemeinden nach kantonalem Recht. Die Gemeinden bilden deshalb nicht Gegenstand der nachfolgenden Ausführungen; sie sind in den angeführten Zahlen nicht mitberücksichtigt.

$2 \mathrm{Vgl}$. Anhang.

${ }^{3}$ Vgl. dazu Peter Saladin, Bund und Kantone, Zeitschrift für Schweizerisches Recht (ZSR) 103/1984 II, S. 431 ff., 486; ders., in: Kommentar zur Bundesverfassung der Schweizerischen Eidgenossenschaft, Basel/Zürich/Bern $1987 \mathrm{ff}$. (BV- 
Artikel 42 der Bundesverfassung enthält eine Liste der Einnahmequellen des Bundes. Sie lassen sich in zwei Hauptkategorien aufteilen: in Fiskalabgaben (Steuern und Zölle) einerseits und in weitere Einnahmen andererseits.

Der Bund ist gemäß Artikel 41 bis und 41 ter der Bundesverfassung befugt, insbesondere die folgenden Steuern zu erheben":

- die direkte Bundessteuer auf dem Einkommen von natürlichen

Personen sowie auf dem Reinertrag, auf dem Kapital und auf den

Reserven juristischer Personen,

- die Warenumsatzsteuer,

- eine Verrechnungssteuer auf dem Ertrag beweglicher Kapitalvermögen,

- die Stempelabgaben auf Wertpapieren,

- eine Tabaksteuer und eine Biersteuer.

Dazu kommen die Ein- und Ausfuhrzölle, der Zollzuschlag auf Treibstoffen sowie die fiskalische Belastung gebrannter Wasser gestützt auf das Alkoholmonopol'. Mit Ausnahme der direkten Bundessteuer handelt es sich bei all diesen Besteuerungsbefugnissen um ausschließliche Kompetenzen des Bundes ${ }^{6}$.

Betragsmäßig fällt die Warenumsatzsteuer mit Abstand am meisten ins Gewicht. In den letzten Jahren hatte sie einen Anteil von fast einem Drittel an den Gesamteinnahmen des Bundes. An zweiter Stelle folgt die direkte Bundessteuer mit einem Anteil von rund $20 \%{ }^{7}$. Die Befugnis zur Erhebung dieser beiden Steuern, die zusammen also mehr als die Hälfte der gesamten Bundeseinnahmen ausmachen, ist zeitlich befristet; sie läuft Ende 1994 aus $^{8}$. Die Verlängerung bedarf einer Verfassungsänderung; sie erfolgt jeweils auf zwölf Jahre.

Kommentar), Art. 3 Rdn. 81 ff., $128 \mathrm{ff}$.; Peter Locher, in: BV-Kommentar, Art. 41bis Rdn. $1 \mathrm{f}$.

${ }^{4}$ Die in Art. 41 bis Abs. 1 lit. d BV vorgesehenen Retorsionssteuern zur Abwehr von Besteuerungsmaßnahmen des Auslandes sowie die besonderen Verbrauchssteuern für Brenn- und Treibstoffe gemäß Art. 41 ter Abs. 4 lit. a BV sind zur Zeit nicht von praktischer Bedeutung; die fiskalische Belastung der Brenn- und Treibstoffe erfolgt durch Zölle sowie durch den Zollzuschlag auf Treibstoffen (Art. 36ter BV).

5 Art. 30, 36ter und 32bis BV.

6 Vgl. dazu Locher (Fn. 3), Art. 41 bis Rdn. 6.

7 Offentliche Finanzen der Schweiz 1989, Statistische Resultate, herausgegeben von der Eidgenössischen Finanzverwaltung, Bern 1991, S. 30 f.; vgl. Anhang.

${ }^{8}$ Art. 41 ter Abs. 1 letzter Satz BV. Die beiden Steuern sind auf Verfassungsstufe sehr detailliert geregelt: Die Warenumsatzsteuer in Art. 41 ter Abs. 3 BV sowie in Art. 8 Abs. 2 der Übergangsbestimmungen der BV (ÜbBest BV), die direkte 
Versuche, die zeitliche Befristung aufzuheben, werden regelmäßig unternommen; ebenso regelmäßig scheitern sie in der für Verfassungsänderungen obligatorischen Volksabstimmung, letztmals im Sommer 1991. Ebenfalls noch von einigem finanziellem Gewicht sind die Verrechnungsstener sowie die Stempelabgabe, die je knapp 10\% an die Einnahmen des Bundes beitragen'. Von noch etwas größerer Bedeutung sind sodann die Zollerträge des Bundes, davon allein die Zölle sowie der Zollzuschlag auf Treibstoffen mit einem Anteil von über $10 \%$ an den Gesamteinnahmen.

Den weiteren Einnabmequellen des Bundes neben den Fiskalabgaben kommt betragsmäßig eine geringe Bedeutung $\mathrm{zu}^{10}$. Sie hatten in den letzten Jahren einen Anteil von insgesamt weniger als $10 \%$ an den Bundeseinnahmen.

2. Die Kantone sind von der Erhebung derjenigen Stenern ausgeschlossen, die der Bund erhebt ${ }^{11}$. Gewichtige Ausnahmen bilden die direkten Steuern auf dem Einkommen natürlicher Personen sowie auf dem Ertrag und Kapital juristischer Personen. Diese bilden denn auch zusammen mit der direkten Steuer auf dem Vermögen natürlicher Personen die wichtigste Einnahmequelle der Kantone. Daneben sind die Grundstückgewinnsteuern sowie die Erbschafts- und Schenkungssteuern als Finanzquellen der Kantone und Gemeinden von Bedeutung. Insgesamt sind mehr als $50 \%$ der Einnahmen der Kantone Steuererträge ${ }^{12}$.

Bundessteuer in Art. 41ter Abs. 5 BV sowie in Art. 8 Abs. 3 ÜbBest BV. Die weiteren Regelungen sind in Bundesratsbeschlüssen, d.h. in Verordnungen der Regierung enthalten, die unter dem Notrechtsregime des Zweiten Weltkrieges entstanden sind. Der Bundesratsbeschluß über die direkte Bundessteuer wird auf den 1. Januar 1995 durch das neue Bundesgesetz über die direkte Bundessteuer vom 14. Dezember 1990 abgelöst (Amtliche Sammlung des Bundesrechts [AS] 1991, S. 1184). Für die Warenumsatzsteuer gibt es weiterhin kein formelles Gesetz.

9 Deren Regelung findet sich in Art. 41bis Abs. 1 lit. a und b BV, in Art. 7 und 10 ÜbBest BV sowie im Bundesgesetz über die Verrechnungssteuer vom 13. Oktober 1965 (Verrechnungssteuergesetz; Systematische Sammlung des Bundesrechts [SR] 642.21) und im Bundesgesetz über die Stempelabgaben vom 27. Juni 1973 (SR 641.10).

10 Es handelt sich um den Ertrag des Bundesvermögens, den Reinertrag der PTT sowie der Pulververwaltung, den Reinertrag des Militärpflichtersatzes, den Bundesanteil an den Roheinnahmen aus dem Spielbetrieb der Spielbanken, den Bundesanteil am Reinertrag der Nationalbank sowie den Ertrag von Gebühren, insbesondere der Schwerverkehrsabgabe und der Autobahngebühr (Art. 42 BV, Art. 17 und 18 ÜbBest BV).

1 Art. 41 bis Abs. 2 und Art. 41ter Abs. 2 BV.

12 Öffentliche Finanzen 1989 (Fn. 7), S. 48 f.; vgl. Anhang. 
Die Gesetzgebungskompetenz für die kantonalen und kommunalen Steuern liegt bei den Kantonen. Bis heute waren sie in der Gestaltung ihrer Steuerordnung weitgehend frei. Schranken bildeten das Rechtsgleichheitsgebot und das Willkürverbot gemäß Artikel 4 der Bundesverfassung, die Eigentumsgarantie (Art.22ter BV) als Schutz gegen konfiskatorische Besteuerung, das Verbot der Beeinträchtigung der Handels- und Gewerbefreiheit (Art. 31 Abs. 2 BV), das Doppelbesteuerungsverbot (Art. 46 Abs. $2 \mathrm{BV}$ ) sowie das Verbot von Kultussteuern (Art. 49 Abs. 6 BV) ${ }^{13}$. Auf den 1. Januar 1993 wird nun ein neues Bundesgesetz über die Steuerharmonisierung in $\mathrm{Kraft}$ treten $^{14}$, das als Rahmengesetz eine formelle, nicht aber eine materielle Steuerharmonisierung ${ }^{15}$ bringen wird. Das Gesetz wird deshalb keine Angleichung der erheblichen Unterschiede der Steuerbelastung in den Kantonen zur Folge haben. Wird die gesamtschweizerisch durchschnittliche Steuerbelastung mit 100 angenommen, so betrug sie 1990 im steuergünstigsten Kanton Zug lediglich 57, im steuerschwächsten Kanton Wallis dagegen 143, d. h. rund 2,5mal mehr ${ }^{16}$.

Von den weiteren eigenen Einnabmequellen der Kantone fallen lediglich die Gebühreneinnahmen mit einem Anteil von durchschnittlich rund $14 \%$ noch ins Gewicht. Insgesamt decken die Kantone im Durchschnitt rund vier Fünftel ihres Budgets mit eigenständigen Einnahmen. Der verbleibende Fünftel stammt aus dem Finanzausgleich ${ }^{17}$.

\section{Finanzausgleich}

1. Wie in den benachbarten Bundesstaaten spielt auch in der Schweiz der Finanzausgleich eine lebenswichtige Rolle ${ }^{18}$. Einerseits

${ }_{13} \mathrm{Vgl}$. Saladin, Bund und Kantone (Fn. 3), S. 491.

14 Bundesgesetz über die Harmonisierung der direkten Steuern der Kantone und Gemeinden (StHG) vom 14. Dezember 1990 (SR 642.14).

${ }^{15}$ Die Harmonisierung beschränkt sich auf einheitliche Regeln betreffend Steuerpflicht, Gegenstand und zeitliche Bemessung der Steuern, Verfahrensrecht und Steuerstrafrecht; nicht harmonisiert werden dagegen gemäß ausdrücklicher Vorschrift in Art. 42quinquies BV die Steuertarife, die Steuersätze und die Steuerfreibeträge. Vgl. dazu Ernst Blumenstein/Peter Locher, System des Steuerrechts, 4. Aufl., Zürich 1992, S.75f.; Francis Cagianut, in: BV-Kommentar (Fn.3), Art. 42quinquies Rdn. $7 \mathrm{ff}$.

16 Statistisches Jahrbuch der Schweiz 1992, herausgegeben vom Bundesamt für Statistik, Zürich 1991, S. 365.

17 Öffentliche Finanzen 1989 (Fn. 7), S. 48 f.; vgl. Anhang.

${ }^{18}$ Dazu Saladin, Bund und Kantone (Fn. 3), S. 492 ff., 530 ff.; Alfred Meier, Die Entwicklung des Finanzausgleichs in der Schweiz, in: Handbuch der Finanzwissenschaft, Band IV, Tübingen 1983, S. 163 ff. 
sind die Kantone zur Erfüllung ihrer Aufgaben generell auf finanzielle Unterstützung seitens des Bundes angewiesen. Das ist darauf zurückzuführen, daß den Kantonen immer wieder neue Aufgaben, insbesondere im Bereich des Vollzugs von Bundesrecht, übertragen werden, ohne daß sie - abgesehen von Leistungen des Bundes - zusätzliche Einnahmequellen erschließen können. Der finanziellen Unterstützung der Kantone durch den Bund dient der vertikale Finanzausgleich.

Wegen der großen Unterschiede in der Finanzkraft der Kantone ist es anderseits erforderlich, daß die finanzschwachen Kantone zusätzlich Unterstützung erfahren. Artikel 42ter der Bundesverfassung verpflichtet denn auch den Bund, den Finanzausgleich unter den Kantonen zu fördern; bei der Gewährung von Bundesbeiträgen hat er auf die Finanzkraft der Kantone und auf die Berggebiete angemessen Rücksicht zu nehmen ${ }^{19}$. Dem Ausgleich zwischen den Kantonen dient der borizontale Finanzausgleich. Auch bei diesem erhalten zwar die Kantone Leistungen des Bundes; insofern ist auch hier das Verhältnis vertikal. Eine horizontale Ausgleichswirkung wird indessen durch die Abstufung der Leistungen nach Maßgabe der Finanzkraft der Kantone erreicht.

Der Finanzausgleich erfolgt nicht nur, aber doch schwergewichtig von oben nach unten, vom Bund zu den Kantonen ${ }^{20}$. Einerseits sind die Kantone an einzelnen Bundeseinnahmen beteiligt, und andererseits leistet der Bund den Kantonen unter verschiedenen Titeln Zahlungen.

19 Die Finanzkraft der Kantone wird alle zwei Jahre nach einem komplizierten Schlüssel neu ermittelt. Dabei sind das Volkseinkommen, die Steuerkraft, die Steuerbelastung und der Anteil der im Berggebiet liegenden Kulturfläche maßgebend. Gestützt auf diesen Schlüssel werden die Kantone in drei Gruppen (finanzstarke, mittelstarke und finanzschwache) aufgeteilt. Vgl. Art. 2 ff. des Bundesgesetzes über den Finanzausgleich unter den Kantonen vom 19. Juni 1959 (Finanzausgleichsgesetz; SR 613.1) sowie die Verordnung über die Festsetzung der Finanzkraft der Kantone für die Jahre 1992 und 1993 vom 20. November 1991 (SR 613.11).

20 Finanzausgleich von unten nach oben gibt es noch bei den kantonalen Beiträgen an die Invalidenversicherung gemäß Art. 78bis des Bundesgesetzes über die Invalidenversicherung (IVG) vom 19. Juni 1959 (SR 831.20). Rein horizontaler Finanzausgleich, d.h. Leistungen von Kanton zu Kanton, ist ebenfalls selten. Ein Beispiel findet sich in der Interkantonalen Vereinbarung über Hochschulbeiträge für die Jahre 1987-1992 vom 26. Oktober 1984 (SR 414.23). Diese sieht einen Beitrag des Herkunftskantons in der Höhe von Fr. 8'000.- (für 1992) pro Studierenden an den Kanton vor, an dessen Universität der Student immatrikuliert ist. 
2. Die Kantone haben Anspruch auf einen Anteil an verscbiedenen Einnabmequellen der Eidgenossenschaft: an der direkten Bundessteuer, an der Verrechnungssteuer, am Militärpflichtersatz, am Reinertrag der Eidg. Alkoholverwaltung aus der fiskalischen Belastung gebrannter Wasser sowie am Reingewinn der Nationalbank.

Finanziell mit Abstand am meisten ins Gewicht fällt der Anteil der Kantone am Ertrag der direkten Bundesstewer in der Höhe von insgesamt $30 \%$. Hier gelangt eine Kombination von vertikalem und horizontalem Finanzausgleich zur Anwendung: Die Kantone erheben die Bundessteuer im Auftrag des Bundes. Vom Ertrag liefern sie $70 \%$ dem Bund ab. Jeder Kanton kann 17\% seiner Einnahmen an Bundessteuern für sich behalten. Dadurch werden die Kantone mit hohem Steueraufkommen begünstigt; nicht finanzschwache, sondern finanzstarke Kantone erhalten hier höhere Anteile. Die verbleibenden $13 \%$ werden unter Berücksichtigung der Finanzkraft unter den Kantonen verteilt ${ }^{21}$. Dadurch reduziert sich der Anteil der finanzstarken Kantone an ihrem Bundessteuerertrag auf rund $20 \%$; der Anteil der finanzschwachen Kantone dagegen erhöht sich auf über $50 \%$, für den Kanton Jura sogar auf $84 \%$ seiner Bundessteuereinnahmen ${ }^{22}$. Trotzdem ist der Anteil finanzstarker Kantone am Ertrag der Bundessteuer insgesamt oft größer als derjenige mittelstarker und finanzschwacher Kantone ${ }^{23}$.

Ebenfalls eine Mischung von vertikalem und horizontalem Finanzausgleich gibt es bei der Verrechnungssteuer: Der Kantonsanteil beträgt insgesamt $10 \%$ des Steuerertrags. Die Hälfte davon wird auf sämtliche Kantone nach Maßgabe ihrer Bevölkerungszahl verteilt, die andere Hälfte auf die finanzschwächeren Kantone nach einer abgestuften Skala ${ }^{24}$. Hier ist die Ausgleichswirkung zugunsten der finanzschwachen Kantone wesentlich besser als bei der direkten Bundessteuer. Wegen der viel geringeren Beträge fällt sie aber weniger ins Gewicht.

21 Art. 41 ter Abs. 5 lit. b BV; Art. 8 f. Finanzausgleichsgesetz. Vgl. dazu die Verordnung über den Finanzausgleich mit dem Kantonsanteil an der direkten Bundessteuer vom 27. November 1989 (SR 613.13).

22 Bundesblatt (BBl) 1992 I, S. 805.

23 Öffentliche Finanzen 1989 (Fn. 7), S.32f.; vgl. Anhang.

${ }^{24}$ Art. 10 ÜbBest BV; Art. 2 Verrechnungssteuergesetz. Vgl. dazu die Verordnung über den Finanzausgleich mit dem Kantonsanteil an der Verrechnungssteuer vom 2. Dezember 1985 (SR 613.14). 
Bei den Kantonsanteilen an weiteren Bundeseinnabmen spielt die Finanzkraft keine Rolle; es handelt sich dort um rein vertikalen Finanzausgleich ${ }^{25}$.

3. Vor allem für die finanzschwachen Kantone fallen die Bundesbeiträge finanziell wesentlich stärker ins Gewicht als die Anteile an Bundeseinnahmen. Der Bund unterstützt die Kantone bei der Erfüllung zahlreicher Aufgaben durch zweckgebundene Subventionen. Er beteiligt sich beispielsweise an den Aufwendungen der Kantone im Bereich des höheren Bildungswesens (Beiträge an Institutionen der Hochschul-, Mittelschul- und Berufsausbildung), beim Bau und Unterhalt von Nationalstraßen und anderen Hauptstraßen, für die Landwirtschaft, für die Sozialversicherung und im Bereich der militärischen Landesverteidigung und des Zivilschutzes ${ }^{26}$. Insgesamt beliefen sich die Beiträge und Rückvergütungen des Bundes an die Kantone im Jahre 1989 auf über 5 Milliarden Franken ${ }^{27}$.

Gemäß Vorschrift in der Bundesverfassung sind solche Beiträge nach der Finanzkraft der Kantone abzustufen; sie haben somit regelmäßig einen horizontalen Finanzausgleichseffekt. Daneben ergeben sich selbstverständlich dadurch erhebliche Unterschiede in den Beiträgen, daß nicht alle Kantone in gleichem $\mathrm{Maß}$ an der Erfüllung subventionierter Aufgaben mitwirken. So gibt es Kantone, in welchen nur wenige Kilometer Nationalstraßen zu erstellen und zu unterhalten sind, und die Hochschulbeiträge gehen zur Hauptsache an die Hochschulkantone.

${ }_{25}$ Mit einem Anteil von $20 \%$ der von ihnen vereinnahmten Beträge partizipieren die Kantone am Rohertrag des Militärpflichtersatzes. Mit diesem Betrag werden ihre Aufwendungen für den Bezug abgegolten; es handelt sich um eine Bezugsprovision (Art. 6 ÜbBest BV). Mit 10\% sind die Kantone nach Maßgabe ihrer Bevölkerungszahl am Reinertrag der Alkoholverwaltung aus der fiskalischen Belastung gebrannter Wasser beteiligt. Der Betrag ist zweckgebunden für die Bekämpfung des Alkoholismus und des Suchtmittel-, Betäubungsmittel- und Medikamentenmißbrauchs (Art. 32bis Abs. 9 BV). Schließlich erhalten die Kantone aus dem Reingewinn der Nationalbank jährlich eine Abgeltung in der Höhe von 80 Rappen pro Einwohner; der zusätzlich vorgesehene Anteil von mindestens zwei Dritteln an einem verbleibenden Überschuß gelangte letztmals 1932 zur Auszahlung (Art. 39 Abs. 4 BV; Art. 27 Abs. 3 des Nationalbankgesetzes [NBG] vom 23. Dezember 1953 [SR 951.11]; dazu Charles-André Junod, in: BV-Kommentar [Fn. 3], Art. 39 Rdn. 58 ff.).

${ }^{26} \mathrm{Vgl}$. die Liste der Finanzhilfen und Abgeltungen in der Botschaft des Bundesrates zu einem Bundesgesetz über Finanzhilfen und Abgeltungen vom 15. Dezember 1986, BBl 1987 I, S. $369 \mathrm{ff}$., $422 \mathrm{ff}$.

27 Öffentliche Finanzen 1989 (Fn. 7), S.66f.; vgl. Anhang. 
Im Durchschnitt beläuft sich der Anteil von Bundesbeiträgen an den Einnahmen eines Kantons auf rund $14 \%$. Bei finanzschwachen Kantonen mit einem hohen Anteil an beitragsberechtigten Aufwendungen machen sie indessen bis rund einen Drittel, im Extremfall des Kantons Uri sogar fast die Hälfte der kantonalen Einnahmen aus ${ }^{28}$.

\section{Zusammenfassende Würdigung}

Wie ist nun die in groben Zügen skizzierte Finanzverfassung der Schweiz zu beurteilen? Unschwer festzustellen ist, daß sie wenig übersichtlich ist. Die Kompetenzen zur Erhebung von Abgaben sind zwar klar gegeneinander abgegrenzt, indem die Befugnisse des Bundes in der Bundesverfassung abschließend aufgelistet sind. Ein kompliziertes System von Leistungen und Gegenleistungen führt aber dazu, daß Geldströme von den Kantonen zum Bund und vom Bund zu den Kantonen fließen ${ }^{29}$. Dadurch wird zwar eine gewisse Finanzausgleichswirkung erzielt. Das „System“ ist aber kaum rational; es ist nur von seiner Entstehungsgeschichte her verständlich ${ }^{30}$. Immer, wenn dem Bund oder den Kantonen neue Aufgaben übertragen werden, muß deren Finanzierung sichergestellt werden; wenn das Defizit des Bundes zu groß wird, werden die Leistungen an die Kantone gekürzt. Dabei sucht man jeweils Lösungen, die den politischen Möglichkeiten und Gegebenheiten Rechnung tragen und deshalb oft Kompromißcharakter aufweisen.

Versuche, die schweizerische Finanzverfassung auf solidere Grundlagen zu stellen und ein dauerhaftes und sachlich überzeugendes System zu schaffen, sind bis heute immer in den Anfängen steckengeblieben oder sogar vollständig gescheitert ${ }^{31}$. Aus diesem Grunde halte ich es für zweifelhaft, ob sich aus der gegenwärtigen schweizerischen Finanzverfassung irgendwelche positiven Lehren für die Diskussion über die Finanzverfassung im vereinten Deutschland ableiten lassen.

\footnotetext{
28 Öfentliche Finanzen 1989 (Fn. 7), S. 66 f.

${ }^{29} \mathrm{Vgl}$. dazu Saladin, Bund und Kantone (Fn. 3), S. 530 ff.

30 Vgl. dazu Meier (Fn. 18), S. 163 ff., $178 \mathrm{ff}$.

${ }^{31}$ Die vor rund zwanzig Jahren eingeleiteten Bestrebungen um eine Neuverteilung der Aufgaben und der Finanzierungsquellen zwischen Bund und Kantonen haben nur geringfügige Verbesserungen gebracht. Jean-François Aubert zieht dazu folgende ernüchternde Bilanz: „Das ganze Unternehmen wird schließlich zwanzig Jahre gedauert haben und in erster Linie die Erinnerung an enttäuschte Hoffnungen hinterlassen" (Bundesstaatsrecht der Schweiz, Band I, Basel/Frankfurt a. M. 1991, S. 506 Rdn. 732bis). Vgl. dazu auch Saladin, Bund und Kantone (Fn. 3), S. 554 ff.
} 


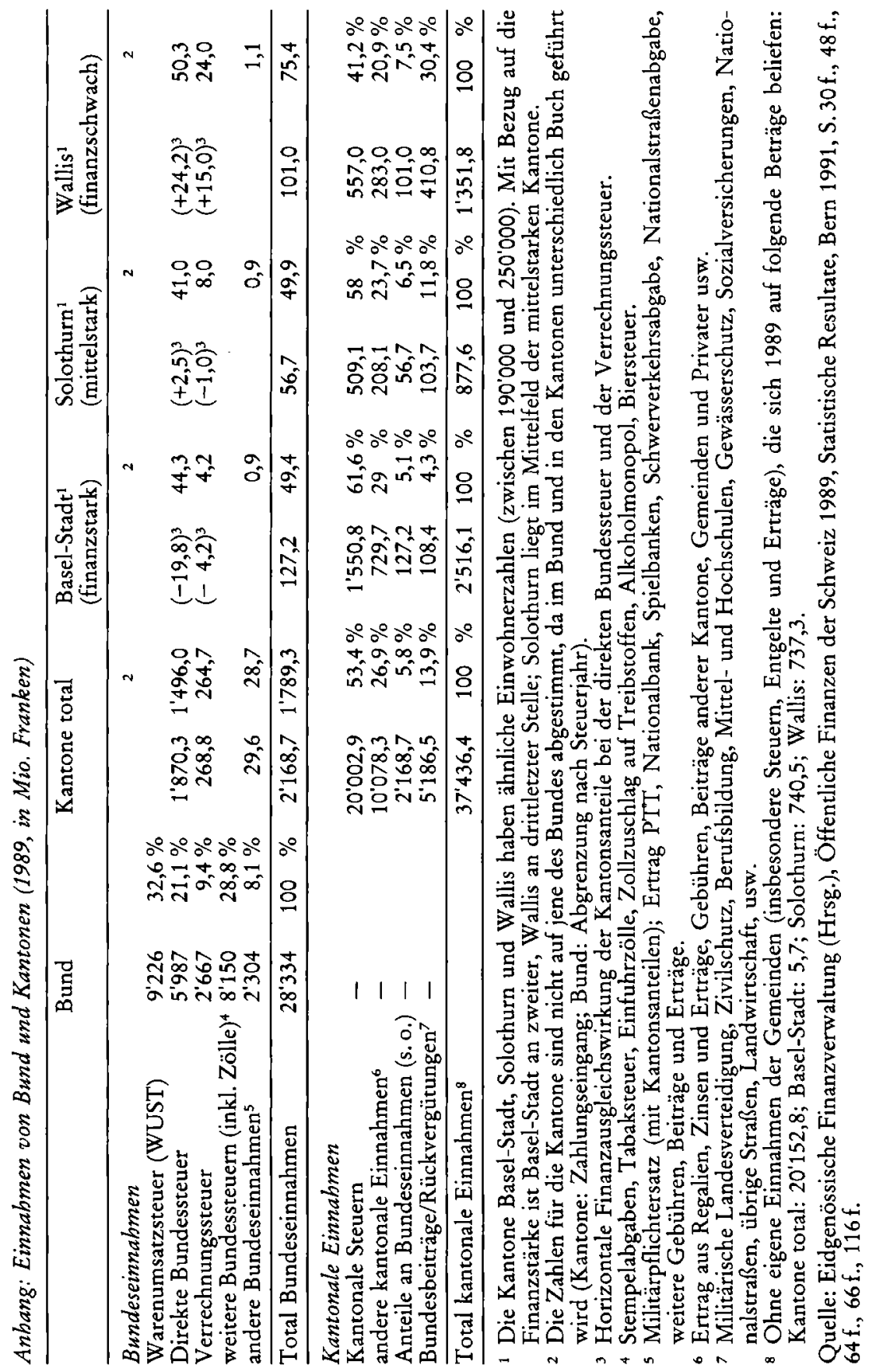




\section{Aussprache und Schlußworte \\ Grundsätze der Finanzverfassung des vereinten Deutschlands}

Vorsitzender: Meine Damen und Herren, diese Diskussion zu leiten, ist für einen Schweizer eine schwierige Sache. Wir haben gehört, daß es offenbar recht wenig Geld zu verteilen gibt, was kann also ein Schweizer bei einer Diskussionsleitung tun, in der es darum geht, Geld zu verteilen, wo es keines gibt. Ich werde versuchen, mich an den Grundsatz der Neutralität zu halten, und ich hoffe, nach den sehr guten einleitenden Voten beziehungsweise eindrücklichen Referaten die Diskussion möglichst gut über die Bühne zu bringen. Wir beginnen mit dem Punkt 1, "Grundsätzliches“, dann behandeln wir unter Punkt 2 die „besonderen Probleme der Wiedervereinigung“ und unter Punkt 3 „Sonderprobleme“, wie u. a. Umweltschutz. Zunächst darf ich Herrn Vogel das Wort geben.

Vogel: Das Thema ist hochaktuell und es ist äußerst konkret. Dem Vorstand ist deshalb sehr dafür zu danken, daß er es ausgewählt und zwei Referenten bestellt hat, die uns die anstehenden Probleme nahegebracht haben: zwar mit unterschiedlichem Temperament, aber doch übereinstimmend eindringlich und auf hohem Niveau. Ausgespart blieb der europäische Aspekt, die Einordnung der bundesdeutschen Finanzverfassung in die europäische Ordnung. Eine Ausdehnung darauf hätte aber einen Diskussionstag auch gewiß überfordert, und deswegen meine ich, daß es richtig war, im Hinblick auf die drängenden Probleme der deutschen Finanzverfassung nicht noch zusätzlich Europa in die Thematik einzubeziehen.

Inhaltlich fällt es mir schwer, Punkte auszumachen, in denen ich grundsätzlich von den Referenten abweichen würde. Vor allem was Herr Kirchbof an Allgemeinem zur Finanzverfassung vorgetragen hat, hätte ich selber gern so gesagt, aber womöglich nicht so konkret sagen können. Deswegen muß ich mich auf ergänzende Bemerkungen zu den beiden Referaten beschränken. Beide Referenten haben mit Recht darauf hingewiesen, daß wir in unserer derzeitigen Situation unter- 
scheiden müssen zwischen einer grundsätzlichen Reform der Finanzverfassung, die wünschenswert wäre, und den Problemen einer Übergangsfinanzverfassung für einige Jahre als Folge der deutschen Einheit, möglicherweise auch für etwas länger, jedenfalls aber für eine begrenzte Zeit. Dringend ist es vor allem, die neuen Länder bei der Verteilung des Finanzaufkommens, also beim primären Finanzausgleich, sachgerecht auszustatten. Art.107 Abs. 1 GG sieht bekanntlich für die Steuerverteilung zwei Maßstäbe vor, grundsätzlich das örtliche Aufkommen, abweichend davon für die Umsatzsteuer einen groben Bedarfsmaßstab, die Verteilung nach Köpfen. In der gegenwärtigen Situation sollte im Verhältnis der alten zu den neuen Ländern dieser Bedarfsmaßstab generell gelten, d.h. für die Zeit der Übergangsverfassung sollte das Aufkommen aller Gemeinschaftssteuern zwischen alten und neuen Ländern nach der Kopfzahl aufgeteilt werden; innerhalb der Gruppe der alten Länder mag es dann bei der Verteilung dessen, was ihnen zufällt, nach dem örtlichen Aufkommen bleiben. Man könnte daran denken, solch eine Regelung auch nur für $90 \%$ des Einkommen- und Körperschaftsteueraufkommens zu treffen und dann über die Jahre hinweg diesen Anteil, der nach der Kopfzahl verteilt wird, graduell zu senken. Aber man muß jedenfalls für die Übergangszeit von der Regel des Art. 107 GG abgehen, die die alten Länder bevorzugt und die neuen deutlich benachteiligt.

Daß dann Bundesergänzungszuweisungen hinzutreten müssen, haben beide Referenten zu Recht erwähnt. Hinzu kommen aufgabenbezogene Bundeszuschüsse. Ich hätte übrigens keine Bedenken, die Aufgaben, die sich heute in den neuen Ländern stellen, noch zu den Kriegsfolgelasten zu zählen, aber man mag die Bundeszuständigkeit zur Finanzierung dieses Wiederaufbaus durch eine besondere Verfassungsvorschrift klarstellen. Natürlich ist hierfür eine ausreichende Finanzausstattung des Bundes nötig, und Steuererhöhungen zu diesem Zweck dürfen gewiß kein Tabu sein. Wir stehen nur wirtschaftlich vor dem Problem, daß bei uns die Staatsquote, der Anteil der öffentlichen Haushalte am Sozialprodukt, schon ohnehin über $50 \%$ liegt. Von 1972 bis 1982 ist diese Quote von $33 \%$ auf $50 \%$ gestiegen; das war 1972 ein Programmpunkt des Langzeitprogramms der SPD und jedenfalls dieser Punkt des Programms ist durchgeführt worden. Die Rückführung unter der neuen Koalition ist dann nicht recht vorangekommen, unter anderem deswegen, weil der Personalbestand des öffentlichen Dienstes auch nach 1982 kontinuierlich gewachsen ist. Hätten wir heute noch oder wieder eine Staatsquote von $33 \%$, dann wäre es wirtschaftlich einfacher, Steuern 
zu erhöhen, als in unserer gegenwärtigen Lage. Das sollte bedacht werden, und auch für die Zukunft sollte man es im Blick behalten.

Soweit der Finanzbedarf des Bundes für die Finanzierung der deutschen Einheit nicht durch Steuererhöhungen gedeckt werden kann oder soll, muß er bei der Umsatzsteuerverteilung berücksichtigt werden, und notfalls müßte, entgegen der Regel des Art. 106 GG, der Bund vorübergehend verstärkt an der Einkommen- und Körperschaftsteuer beteiligt werden. Auch das sollte meiner Meinung nach kein Tabu sein. Sollte das alles die alten Länder noch nicht veranlassen, mit den ihnen zur Verfügung stehenden Finanzmitteln endlich sparsamer umzugehen (zu „teilen um zu einigen“), sollte es m.a.W. dabei bleiben, daß für viele Politiker der Rückbau von Straßen in den alten Bundesländern Vorrang vor dem Neubau von Straßen in den neuen Bundesländern hat, dann, meine ich, müßte dem Bund die Möglichkeit gegeben werden, durch Gesetz Höchstbeträge, gegebenenfalls Höchstzuwachsraten, für die Haushalte der Länder festzusetzen. Die Möglichkeiten des Stabilitätsgesetzes reichen dafür nicht aus. Die Ermächtigung in Art. 109 Abs. 4 GG, das Notwendige zur Wahrung des gesamtwirtschaftlichen Gleichgewichts zu regeln, wäre eine ausreichende Ermächtigung, wenn Sie einer Mindermeinung folgen; da sich dieser Meinung aber bisher noch niemand angeschlossen hat (nämlich meiner), wäre es wohl vernünftig, eine besondere Kompetenz des Bundes in der Übergangsfinanzverfassung und nur für diesen Übergangszeitraum vorzusehen. Natürlich bliebe eine Blockade durch den Bundesrat möglich; sie müßte durch geeignete Regelungen verhindert werden.

Bei der "großen“ Finanzverfassungsreform für die Zeit nach Vollendung der deutschen Einheit sollten dann, darin stimme ich mit Herrn Selmer überein, im Interesse einer stärkeren Föderalisierung eigene Steuererfindungsrechte der Länder ernsthaft erwogen werden. Die Schweiz ebenso wie die USA kennen Landeseinkommensteuern und Landeskörperschaftsteuern, ohne daß die Einheitlichkeit des Wirtschaftsgebietes dadurch beeinträchtigt würde, wie es der Parlamentarische Rat seinerzeit befürchtet hatte. Am zweckmäßigsten wären Hebesätze, oder genauer: Abschlagsrechte der Länder, durch deren Wahrnehmung sie geringere Einkommen- und Körperschaftsteuern als die ihnen zustehenden Höchstbeträge erheben könnten; das könnte zu einem wünschenswerten Wettbewerb unter den Ländern über die steuergünstigsten Bedingungen für individuelle wie gewerbliche Ansiedlung führen. - Für den Fall des extremen Haushaltsnotstands stimme ich ganz mit den Vorschlägen von Herrn Kirchbof überein und würde sie gern noch ergänzen um eine Regel, 
die, wenn am Ende alles nichts hilft, eine Neugliederung zur Pflicht macht (so wie beim Konkurs eines Privatunternehmers das Unternehmen ja auch meistbietend vergeben wird oder seine Wertgegenstände versilbert werden). - Zum Abschluß: längst hat sich die Gesetzgebung als ein untaugliches Mittel zur Regelung des Finanzausgleichs unter den Ländern erwiesen. $\mathrm{Zu}$ einem wesentlichen Teil ist die Regelung inzwischen an das Bundesverfassungsgericht übergegangen. Mir scheint, die einzige Lösung, um Blockaden zu vermeiden wie 1979 oder Erpressungen, wie die, mit denen bei der letzten Steuerreform der verfassungswidrige Strukturhilfefonds durchgesetzt worden ist, wäre die Einrichtung eines Finanzausgleichshofes, für dessen Zusammensetzung und Bestellung Ähnliches wie für das Bundesverfassungsgericht gelten könnte.

Meine Damen und Herren, wir müssen und wollen natürlich Realisten sein. Aber das darf kein Denkverbot zur Folge haben. Und auch wenn wir die Aussicht sicher skeptisch beurteilen müssen, Vorschläge, wie ich Sie eben skizziert habe, politisch zu realisieren: wenn wir nicht an solche Möglichkeiten zu denken und über sie zu reden wagen, werden wir nie etwas erreichen. Ich danke Ihnen.

Vorsitzender: Ich danke Ihnen. Herr Badura.

Badura: Herr Vorsitzender, verehrte Kollegen, beide Referenten haben dem Verfassungssatz von der "Wahrung der Einheitlichkeit der Lebensverhältnisse" eine besondere Bedeutung zugemessen und dazu möchte ich mich etwas äußern, insbesondere im Hinblick darauf, daß hierin eine Art konkludente Staatsaufgabe oder Staatszielnorm gesehen worden ist. Und dazu bitte, erlauben Sie mir drei Fragen: Im Grundgesetz kommt zwar dieser Begriff im Bereich des Finanzwesens vor, aber er kommt auch vor im Bereich von Art. 72 Abs. 2 des Grundgesetzes und dort wird er eingefügt in das Prinzip der Wahrung der Rechts- und Wirtschaftseinheit. Das haben Sie nicht erwähnt oder jedenfalls daraus keine Folgerung gezogen. Es müßte doch vielleicht die Frage gestellt werden, ob es richtig ist, dieses Ziel der Wahrung der Einheitlichkeit der Lebensverhältnisse herauszulösen aus dem bundesstaatlichen Grundgedanken der Rechts- und Wirtschaftseinheit im Bundesgebiet. Die Beachtung dieses Zusammenhangs würde meiner Ansicht nach eine gewisse Relativierung der Vorstellung der Einheitlichkeit der Lebensverhältnisse bedeuten müssen. Herr Selmer hat in seiner These 9 den Punkt darauf gelegt und Herr Vogel hat eben sogar ein Beispiel dafür angegeben, daß er für eine Verlagerung in Richtung auf regionale Differenzierung wäre. Ich wäre dankbar zu erfahren, 
was man sich darunter vorzustellen hat. Im Rahmen der Wahrung der Rechts- und Wirtschaftseinheit kann ja das wohl nicht bedeuten, daß nun im Osten und im Westen oder in einzelnen Ländern, groß oder klein, stark oder schwach, nun plötzlich unterschiedliche Bedingungen von seiten der staatlichen Finanzpolitik geschaffen werden würden, nicht nur für Unternehmer, sondern auch für die Menschen, die Steuern zu zahlen haben. Das ist der erste Punkt.

Der zweite Punkt: Im Rahmen der Beratungen der gemeinsamen Verfassungskommission ist der Begriff der Wahrung der einheitlichen Lebensverhältnisse im Bundesgebiet jedenfalls für Art. 72 Abs. 2 GG fallengelassen worden. An seine Stelle gertreten ist eine neue Formel, die von der „Herstellung gleichwertiger Lebensverhältnisse" spricht. Das klingt ein bißchen anders, schärfer vielleicht, und man könnte das auch unter Umständen als eine besondere Aufgabe, Aufgabennorm oder vielleicht sogar Gesetzgebungsverpflichtung oder Finanzpolitiksverpflichtung verstehen. Ich wäre dankbar, wenn Sie erläutern könnten - vor allem wende ich mich an Herrn Selmer, der diesen Punkt ja ausgiebig erörtert hat -, ob Sie meinen, daß das eigentlich etwas anderes ist: Wahrung der Einheitlichkeit der Lebensverhältnisse im Bundesgebiet oder Herstellung gleichwertiger Lebensverhältnisse. Ob damit also möglicherweise ein Auftrag auch in Richtung Punkt 2 "Vereinigung" abgelesen werden könnte und damit, was ich an sich begrüßen würde, gesagt würde, es kann nicht auf längere Zeit oder gar auf Dauer eine Art Sondergebiet der früheren DDR bestehen. Denn das meine ich, sollte eindeutig sein und Sie haben, Herr Selmer, das, glaube ich, auch betont, daß es auf keinen Fall in Frage kommen kann, diesen Unterschied im Bereich der Finanzordnung der Bundesrepublik irgendwie auf Dauer bestehen zu lassen, die Unterschiedlichkeit, meine ich, der Bedingungen der Finanzpolitik und der Besteuerung in Ost und West.

Und mein dritter Punkt bezieht sich darauf, und das hat vor allem Herr Kirchbof gesagt, daß wir ja im Art. 109 Abs. 2 GG auch die Erfordernisse des gesamtwirtschaftlichen Gleichgewichtes, also eine Art Staatsziel haben, so daß sich für mich schon die Frage stellen würde: gibt es irgendwie die Möglichkeit, diese beiden Staatsaufgaben in einen Einklang zu setzen oder in eine Beziehung zu setzen. Die Herstellung einheitlicher Lebensverhältnisse im Bundesgebiet und die Wahrung der Erfordernisse des gesamtwirtschaftlichen Gleichgewichts könnten unter Umständen unterschiedliche Maßnahmen des Staates empfehlen. Das ist mir unklar. Ich wäre also dankbar, wenn man erläutern würde, wie sich diese beiden Staatsaufgabennormen, wenn sie schon so etwas sind, zueinander verhalten. Und ich schließe 
nur die Bemerkung an, daß gerade dieser dritte Punkt für mich besonders deutlich zeigt, wie schwierig es ist, von Staatsaufgabennormen zu erwarten, daß sie einen justiziablen Maßstab für die Tätigkeit des Staates im Bereich der Gesetzgebung oder Finanzpolitik sein können.

Vorsitzender: Ich danke Herrn Badura. Herr Thieme.

Thieme: Herr Kirchhof hat vor allem die alten, guten und bewährten Grundsätze des Finanzrechts, des Haushaltsrechts berufen. Freilich sind mir dabei Probleme gekommen. Sie, Herr Kirchhof, haben selbst gesagt, es sind die vor $200 \mathrm{Jahren}$ in der modernen Finanzverfassung entwickelten Grundsätze. Es ist die Frage, ob wir nicht auch darüber nachdenken müssen, ob diese Grundsätze eigentlich noch so gelten. Ich beginne mit dem Grundsatz der Einheit des Haushalts. Sonderhaushalte hat es immer gegeben. Ich denke etwa an den Allgemeinen Hannoverschen Klosterfond oder an die Sozialversicherung, die mit Sonderhaushalten arbeitet, oder an die öffentlich-rechtlichen Banken. Es wird uns dabei klar, daß Sonderhaushalte zugleich ein Steuerungsproblem sind, nämlich wer sie verwaltet und wie sie verwaltet werden und wer darauf Einfluß hat. Jedenfalls gibt es aber auch moderne Beispiele und eines, das uns aufrührt oder aufregt, sind die hohen Schulden, die die Treuhandanstalt macht.

Ich war jetzt gerade jüngst in Polen und habe gehört, wie die Polen das Privatisierungsproblem regeln. Die Polen haben auch die Parlamentsabhängigkeit und haben da ungeheure Schwierigkeiten. Man kann natürlich sagen, diese großen Schulden sollte die Treuhandanstalt nicht machen. Aber es ist die Frage, wie man dann eigentlich privatisieren will, wenn man nicht gleichzeitig saniert und damit die Schulden macht. Da wickelt sich das bei der Treuhandanstalt ohne Parlament wesentlich besser ab durch den Sonderhaushalt. Darüber kann man diskutieren, nur, diese Alternative muß man auch sehen. Ich möchte warnen, hier gleich den Demokratiegrundsatz zu berufen, weil unsere Parlamentarier letztlich doch nur bedingt vom Volke gesteuert werden, sondern weitgehend von den Parteien, und das ist etwas anderes.

Ich möchte fragen, ob es nicht auch einen Grundsatz der Flexibilität geben muß, der wichtig für alle finanzpolitischen Erwägungen ist. Gerade die Sonderhaushalte können dabei eine große Rolle spielen. Wir haben ständig wechselnde, sich ändernde Lagen zu berücksichtigen, und diese sich ändernden Lagen können wir nicht mit der Normalität unserer alten Prinzipien bewältigen. Und dann ist die 
weitere Frage, ob wir nicht noch stärker, als das in Ihrem Referat herausgekommen ist, Herr Kirchbof, betonen müssen, daß es auch einen Grundsatz der aufgabengerechten Finanzierung gibt. Ich denke etwa an die Sozialhilfe, das ist ein typisches Beispiel. Früher war es die Solidargemeinschaft in der Gemeinde, die den Ortsarmen mitversorgen mußte. Aber wenn wir heute die Hunderttausenden von Asylbewerbern haben; dann ist das keine lokale Aufgabe. Es ist die Frage, ob etwa die Sozialhilfe nicht dem Bund als eine politische Aufgabe, die in starkem Maße von der allgemeinen Wirtschaftspolitik abhängt, aufzulasten ist. Das ist nur ein Beispiel; aber gerade dieses Beispiel zeigt, wie wichtig die aufgabengerechte Finanzierung ist, die vor der Finanzierungsentscheidung im einzelnen und ihren Instrumenten steht.

Vorsitzender: Ich danke Herrn Thieme, bevor Herr Starck zu Wort kommt, ein Spontanvotum von Herrn Bartlsperger zu Herrn Badura.

Bartlsperger: Herr Vorsitzender, vielen Dank. Ich möchte von Ihrem Angebot spontaner Zwischenrufe Gebrauch machen und im Anschluß an die Ausführungen von Herrn Badura eine Frage an Herrn Selmer richten: Wir haben heute im Verwaltungsrecht eine andere wichtige Staatsaufgabe, nämlich die Raumordnung, die ganz entscheidend auf der Säule "gleichwertiger Lebensbedingungen“ steht. Wenn die Finanzverfassung akzessorisch zu Staatsaufgaben ist und die Gewährleistung gleichwertiger Lebensbedingungen für die Finanzverfassung in Frage gestellt werden soll, muß natürlich auch zu dieser raumordnerischen Aufgabenbestimmung Stellung genommen werden. Dabei weiß ich, daß die Raumordnung sich wesentlich auf der Ebene der Landesplanung einschließlich der Regionalplanung abspielt. Aber ich weise darauf hin, daß wir auf der Bundesebene die vierjährigen Raumordnungsberichte der Bundesregierung an den Bundestag haben. Diese Raumordnungsberichte enthalten eine wesentliche Aufgabenbestimmung des Bundes, die irgendwie finanzverfassungsrechtliche Verpflichtungen nach sich ziehen will. Deshalb eine Frage: In Ihrer These 6 sprechen Sie den finanzverfassungsrechtlichen Verpflichtungsinhalt an. Wie ist das dort Gesagte mit den Aufgaben der Raumordnung zur Gewährleistung gleichwertiger Lebensbedingungen in Einklang zu bringen? Auch noch eine Anschlußfrage: In These 17 ist von der „Mindestgewährleistung einer sachgerechten, verfassungsmäßigen Aufgabenwahrnehmung" die Rede. Läßt sich das mit diesem Begriff Bezeichnete im konkreten Falle von der Gewährleistung gleichwertiger Lebensbedingungen abgrenzen? 


\section{Vorsitzender: Danke! Herr Starck.}

Starck: Meine Damen und Herren, wir haben heute vormittag zwei glänzende Vorträge gehört. Beide Referenten haben die große Linie ausgezogen und haben gleichzeitig konkrete Vorschläge gemacht, wobei Herr Kirchbof nicht davor zurückgeschreckt ist vorzuschlagen, die Tabaksteuer den neuen Ländern zuzuweisen; das hätte die Wirkung, daß der Raucher ein gutes Gewissen bekommt und sagt: „Ich rauche für den Osten." Aber das gehört schon zum dritten Punkt, zu dem ich nicht sprechen will; ich habe mich zu dem ersten Punkt gemeldet, und zwar möchte ich mir drei Bemerkungen erlauben, die allerdings etwas allgemeiner sind als die Bemerkungen, die meine Vorredner gemacht haben.

Das erste betrifft das Thema „Grundsätze der Finanzverfassung für das vereinte Deutschland". Herr Selmer hat für eine Zweiphasigkeit plädiert, wonach man jetzt zunächst einmal die Finanzverfassung sozusagen als Instrument für die innere Vereinigung ändert und, wenn diese stattgefunden hat, in einer zweiten Phase eine grundsätzliche allgemeine Finanzverfassungsreform vornimmt. Dagegen ist Herr Kirchbof, wenn ich ihn richtig verstanden habe, so vorgegangen, daß er die Finanzverfassungsprobleme auf einen Schlag regeln möchte, indem gleichzeitig eine Übergangsfinanzverfassung für die innere Wiedervereinigung und eine ordentliche neue allgemeine Finanzverfassung in dem 10. Teil des Grundgesetzes geregelt wird. Hierin sehe ich einen wesentlichen Unterschied der beiden Referate; das wird sicher im Laufe der Diskussion noch zum Ausdruck kommen. Ich selbst möchte nicht verhehlen, daß ich mehr der pragmatischen Lösung von Herrn Selmer zuneige, weil ich glaube, daß man eine Finanzverfassung nicht auf Vorrat für eine Periode nach Ablauf von 10 Jahren machen kann. Man macht immer neue Erfahrungen und wir wissen nicht, was die nächsten 10 Jahre bringen werden. Ich glaube, daß der Weg von Herrn Selmer insoweit der bessere ist, den man vorziehen muß. Selbstverständlich hat Herr Kirchbof, was die Reform der Finanzverfassung anbelangt, so viele interessante Vorschläge gemacht, daß einige davon bei dem ersten Zugang berücksichtigt werden können.

Die zweite Frage, auf die ich hier besonders hinweisen möchte, ist die, daß man, wenn man eine Finanzverfassung im Bundesstaat macht, immer zwischen zwei Polen steht: Finanzautonomie der Länder auf der einen Seite, auf der anderen Seite Einheitlichkeit der Lebensverhältnisse. Das sage ich jetzt ganz ungeachtet einschlägiger verfassungsrechtlicher Bestimmungen, über die wir ja bei unseren verfas- 
sungspolitischen Vorschlägen disponieren können. Bei jeder Finanzverfassung für einen Bundesstaat bewegen wir uns zwischen diesen beiden Polen. Man könnte es verkürzt sagen: Autonomie und Solidarität. Solidarität bedeutet eben Herstellung weitgehend einheitlicher Lebensverhältnisse. Wendet man diesen Gedanken auf das zweiphasige Modell von Herrn Selmer an, so geht es bei der ersten Phase entscheidend um die Angleichung der Lebensverhältnisse, um Solidarität also. Das ist gewissermaßen der Vollzug des Wiedervereinigungsgebots des Grundgesetzes. Bei dieser starken Betonung der Einheitlichkeit der Lebensverhältnisse oder der Solidarität in der Übergangsfinanzverfassung besteht eine große Gefahr für unser allgemeines bundesstaatliches Verfassungssystem. Die Übergangsfinanzverfassung wird zu einem großen Übergewicht des Bundes führen, weil er auf allen möglichen Schienen - Art. 104 a Abs. 4, Art. 91 a GG und was es sonst noch gibt und was die Übergangsfinanzverfassung einführen wird - Geld verteilen wird, das zunächst einmal ihm zufließen muß. Ich frage mich, ob man dieses Übergewicht nicht dadurch abbauen könnte, daß ein Stück Herstellung der inneren wirtschaftlichen Einheit Deutschlands nicht von dem Bund finanziert und damit regiert wird, sondern daß einiges horizontal zu bewirken versucht wird, indem Ländergruppen gebildet werden, damit westliche Länder östlichen helfen. Und zwar möchte ich das Modell der Landeszentralbanken, wie man sie jetzt neu festgelegt hat, in Erwägung stellen. Danach ist jedes Land des Ostens mit Ausnahme von Sachsen mit einem westlichen Land zusammengespannt. Man könnte sich in der Tat vorstellen, daß in diesem Rahmen horizontale Hilfsprogramme gebildet werden, die dann selbstverständlich bei der allgemeinen Finanzverteilung zwischen Bund und Ländern, insbesondere in der Übergangszeit, berücksichtigt werden müssen. Das hätte gewiß den Vorteil, daß nicht der Bund für alles zuständig ist. Damit könnte der in der Wiedervereinigung steckende starke Zentralisierungsschub abgebremst werden.

Das dritte, was ich sagen wollte, bezieht sich auf die Europäische Gemeinschaft. Ich will freilich nichts über die Finanzverfassung der Europäischen Union sagen, wie sie kommen wird, sondern ich möchte nur kurz zu bedenken geben, welche Wirkung das, was wir hier diskutieren, auf die auch dort stattfindenden Diskussionen über einen Finanzausgleich hat. Selbstverständlich setzen wir politisch auf Finanzautonomie Deutschlands im Rahmen der Europäischen Gemeinschaft, u. a. auch weil wir ein Zahlerland sind. Aber es gibt auch in Europa einen Zwang zur Solidarität. Und gerade, wenn uns die innere Wiedervereinigung über eine Übergangsfinanzverfassung 
gelingen sollte, wird man darin möglicherweise ein Modell oder auch nur Modellelemente sehen, die auf die Europäische Gemeinschaft angewandt werden können: „Behandeln wir doch die armen Mitgliedsstaaten wie ihr eure östlichen Länder behandelt habt und dann sind jene in 10-15 Jahren auch so weit, wie die anderen Länder. “Das ist ein ganz ernsthaftes Problem, das selbstverständlich nicht zu der Aufgabe der Referenten gehörte, das aber einmal angesprochen werden sollte. Man könnte die Integration der östlichen Länder als ein Exemplum für die Europäische Gemeinschaft sehen. Ich meine, wir müßten hier wohl erkennen, daß es sich auch in Europa um Solidarität handelt, müßten aber den anderen klarmachen, daß ein Unterschied besteht zwischen der Solidarität innerhalb eines Nationalstaates, insbesondere eines Nationalstaates, der nach langer Trennung wiederhergestellt worden ist und in dem ganz bestimmte Notwendigkeiten bestehen, und der Solidarität innerhalb der Europäischen Gemeinschaft. Dabei kann man die große Bedeutung, die der Nationalstaat auch bei einer europäischen Vereinigung noch hat, ganz deutlich ins Licht rücken. Die finanzpolitischen Probleme zeigen, daß der Nationalstaat weiterhin unverzichtbar ist.

Vorsitzender: Ich danke Herrn Starck. Herr Bayer.

Bayer: Herr Vorsitzender, ich möchte zwei Bemerkungen machen, je eine Bemerkung im Maunzschen Sinne zur Finanz- und zur Staatsverfassung, im Selmerschen Sinne zu Punkt 6 und Punkt 28, im Kirchhofschen Sinne zu den entsprechenden Punkten. Ich möchte mich vor allem auf drei Minuten beschränken.

Zunächst zur Finanzverfassung. Ich bin der Meinung, daß das Finanzverfassungsrecht auf zwei ganz schlichten, zwei ganz einfachen Sätzen beruht. Der erste Satz lautet: In der Bundesrepublik Deutschland soll es einheitliche Lebensverhältnisse geben. Der zweite Satz lautet: Der Finanzausgleich, insbesondere der sekundäre Finanzausgleich, ist geeignet, diese Einheitlichkeit zu „wahren“, das wäre seine Formulierung in einem rückwärtsgerichteten Sinne, bzw. sie „herzustellen“, das wäre, Herr Badura, dann wohl seine Formulierung ,in die Zukunft hinein". Was den ersten Satz anbetrifft, so kann man dessen Richtigkeit sicherlich in Frage stellen, das ist hier im Laufe des Vormittags ja auch schon mehrfach geschehen. Man würde auf den Bundesstaatsgedanken kommen und sich etwa fragen: Ist es nicht von einem gewissen föderalen Charme, daß es auf der einen Seite moderne Mammutbauwerke wie die Bundeskunsthalle in Bonn und auf der anderen Seite solche Bleiben wie die des Justizministers in Schwerin 
gibt? Ich möchte diesen Punkt indessen hier auf sich beruhen lassen, täte ich es nicht, brächte mich Herr Häberle noch in die Verlegenheit, wieder einmal auf meinen eigenen nick-name zurückkommen zu müssen.

Deshalb gleich zum zweiten Punkt. Ich bin der Meinung, daß der Satz, der Finanzausgleich sei ein geeignetes Instrument zur Herstellung einheitlicher Lebensverhältnisse, in dieser Form falsch ist. Er ist deshalb falsch, weil die Verhältnisse, die gegenwärtigen Verhältnisse, seine Anwendbarkeit in dieser Form nicht erlauben. Ich darf das mit zwei Zahlen, beziehungsweise im Sinne von Ihnen, Herr Kirchbof, mit zwei Wirtschaftsdaten unterstreichen, zwei Daten, die vielleicht nicht jedem hier bekannt sind. Nach den jüngsten Erhebungen des Statistischen Bundesamtes verhalten sich das Pro-Kopf-Bruttoinlandsprodukt im reichsten Bundesland, nämlich in Hamburg, und das entsprechende Pro-Kopf-Bruttoinlandsprodukt im ärmsten Bundesland, nämlich in Thüringen, wie 6,7 zu 1 zueinander. Es stehen sich 67000 und 10000 gegenüber. Das zweite Datum: Das Pro-Kopf-Bruttoinlandsprodukt im ärmsten westlichen Bundesland, nämlich in Niedersachsen, verhält sich zu der entsprechenden Größe im reichsten östlichen Bundesland, nämlich in Brandenburg, immer noch wie $3 \mathrm{zu} 1$ zueinander, 33000 stehen 11000 gegenüber. Wenn man sich diese Zahlen vor Augen führt, dann kann man daraus nur einen Schluß ziehen: Die Hansestadt Hamburg müßte einen Beitrag zur Herstellung einheitlicher Lebensverhältnisse in Deutschland dadurch leisten, daß sie per saldo nicht nur auf jeden künftigen Zuwachs im Einkommen ihrer Bürger verzichtet, sondern sie müßte sogar einen erheblichen Abwachs in Kauf zu nehmen bereit sein. Dieses indessen wird die Hansestadt Hamburg nicht tun. Sie darf es überhaupt nicht, täte sie es, käme sie nämlich mit dem Sozialstaatsprinzip in Konflikt, sie müßte das, was man das soziale Netz nennt, „lösen “, es weitmaschiger als bisher knüpfen. Das Fazit für mich lautet: Der Finanzausgleich ist unter den gegenwärtigen Umständen nicht dazu angetan, einen wirksamen Beitrag zur Herstellung einheitlicher Lebensverhältnisse zu leisten.

Ganz kurz noch eine Bemerkung zu meinem zweiten Punkt, nämlich zur allgemeinen Staatsverfassung. Wenn man zu dem Schlusse kommt, über den Finanzausgleich läßt sich die Einheit nicht erreichen, dann wird man in der Tat fragen müssen: Welche anderen Instrumente stehen zur Verfügung? Ich möchte damit auf eine Bemerkung von Herrn Vogel zurückkommen. Mir fällt auf, daß in Kreisen der Wirtschaft in zunehmendem Maße darauf hingewiesen wird, Einheitlichkeit der Lebensverhältnisse lasse sich am ehesten auf dem Wege über die Neugliederung des Bundesgebietes „garantieren“. So 
hat etwa der Präses der Industrie- und Handelskammer zu Hamburg sehr vehement erklärt: Zwei Unternehmer, die feststellen, daß sie je für sich nicht lebensfähig sind, denken an einen Unternehmenszusammenschluß, rechnen schlicht und einfach zumindest mit dem, was die Betriebswirtschaftslehre einen Synergieeffekt nennt, also in concreto: die Forderung nach dem sog. Nordstaat. Ich wundere mich ein bißchen, daß die Referenten des Morgens diese Möglichkeit, Neugliederung des Bundesgebietes anstelle eines Finanzausgleichs, von vornherein nicht ernsthaft haben bedenken wollen. Ich jedenfalls würde genau zu dem tendieren, was Herr Vogel gesagt hat: Es kann aus finanziellen Gründen die Verpflichtung entstehen, eine Neugliederung des Bundesgebietes vorzunehmen. Danke.

Vorsitzender: Ich danke Ihnen. Ich bitte alle Votanten dafür zu sorgen, daß ich am Schluß nicht Budgetausgleich, d. h. Zeitbudgetausgleich, zwischen den Votanten machen muß. Herr Mantl.

Mantl: Herr Vorsitzender, meine Damen und Herren! Es gibt wenige Politik- und Rechtsbereiche, auf die das Schmitt Glaesersche Bonmot von der Befriedungsfunktion der Undurchschaubarkeit so zutrifft, wie auf die Finanzverfassung. Und es gibt wenige Politikund Rechtsbereiche, auf die auch die Betonung des Prozeduralen so zutrifft, wie auf die Finanzverfassung. Man könnte geradezu sagen, $\mathrm{da} ß$ rationale Ordnungspolitik, die wir uns als Wissenschaftler alle irgendwie wünschen, sich verschiebt zu politisch erzeugtem Konsens in ganz kleinem Kreis. Es ist bezeichnend, daß die von Herbert Haller erwähnte österreichische Verfassungsgerichtshofsjudikatur, vor allem in dem Erkenntnis vom 12. Oktober 1990, G 66/90-13, sehr deutlich zum Ausdruck bringt, daß Sachgerechtigkeit und finanzausgleichsrechtliche Gleichbehandlung erzielt werden können -- um jetzt nur die leitenden Substantive zu zitieren -: durch „Kooperation der Gebietskörperschaften“, „durch politische Einsicht und gegenseitige Rücksichtnahme“, durch „Beratungen“ und „Gespräche“, die schließlich zum „Einvernehmen“ führen. Hochgestochen könnte man von einer föderalistischen Diskursethik sprechen. Herr Kollege Vogel würde das wahrscheinlich drastischer und negativer ausdrücken.

Nun kann man einwenden, das sei ja Kennzeichen pluralistischer Rechtserzeugung überhaupt. Ja, jedoch mit vier Besonderbeiten, die nicht nur auf Österreich zutreffen, sondern zum Gutteil generalisierbar sind. Erstens: Die finanz- und rechtswissenschaftlich erwünschte sachadäquate Verkettung von Aufgaben und Kompetenzen, von Aufgabenerfüllung und Kompetenzwahrnehmung, dem dafür erfor- 
derlichen Aufwand, der Ermittlung des Finanzbedarfs, der Finanzkraft und der Einnahmenerzielung läßt sich in praxi nicht sacblogisch herstellen, dieser gordische Knoten muß vielmehr politisch durchschlagen werden. Und daher ist hier ein bargaining erforderlich, das noch stärker und intensiver als sonst in der pluralistischen Rechtserzeugung ist.

Das Zweite, ganz einfach und trivial: In Steuerverbundsystemen spielt das Prozedurale begreiflicherweise eine besonders verstärkte Rolle. Und drittens - österreichisch gesprochen - haben wir in Finanzverfassung und Finanzausgleich einen Bereich, in dem die konkordanzdemokratischen Entscheidungsmuster nach wie vor auch heute noch fortbestehen, obwohl sich das politische System sonst in den letzten Jahren drastisch in Richtung auf die Konkurrenzdemokratie hin verändert hat. Hier sind die Verhandlungspartner in den einzelnen Gebietskörperschaften noch immer die alten Parteien, die Großparteien zu nennen nach den letzten Wahlergebnissen schwerfällt, nicht jedoch die Neuparteien, nicht die Verbände, nicht die Bürger, nicht die Medien. Und diese Parteienvertreter agieren mit einem beamteten Sachverstand an ihrer Seite, der durch Jahrzehnte tätig ist und eine unerhörte Erfahrung akkumuliert hat. Es handelt sich also um ein entparlamentarisiertes Elitenmodell, das wohl überhaupt und nicht nur in Österreich für diesen Politik- und Rechtsbereich im modernen Staat als Weg zum Kompromiß charakteristisch sein dürfte.

Schließlich ist viertens die Kontinuität und Stabilität des Handelns auffallend, eine besondere Änderungsscheu, obwohl es sich um typische Zeitgesetze handelt, worauf uns Ferdinand Kirchbof heute ja deutlich aufmerksam gemacht hat, die eigentlich dergestalt dynamisierend wirken müßten, daß sich immer wieder etwas ändert. Das bricht sich aber an der besonderen politischen Vorsicht der kleinen handelnden Eliten. Die Dynamisierung - jetzt wieder österreichisch gesprochen - ist wahrscheinlich nur exogen zu erwarten, etwa durch den EG-Beitritt, genauso wie Dynamisierungsprozesse durch die Völkerbundauflagen nach der Genfer Sanierung 1922 in Österreich auftraten.

Der Herr Vorsitzende war so liebenswürdig, mir zu erlauben, noch zwei Annexmaterien zu behandeln, die eigentlich unter Punkt 3 gehören: In einer österreichischen Diskussion hätte bei der Behandlung des Tagesordnungspunktes „Finanzverfassung“ die Frage der Gemeinden eine sehr, sehr viel größere Rolle gespielt als hier und heute. Herbert Haller hat dies ja anklingen lassen. Ich glaube, daß die Gemeinden nicht zuletzt deshalb so wichtig sind, weil sie gerade in postkommunistischen Reformstaaten jene Einheiten sein werden, in 
denen der ersehnte Wohlstand der Menschen durch funktionierende Versorgungs- und Entsorgungsleistungen seine Abstützung erfährt.

Und letzter Punkt: Neugliederung. Es ist auffallend, daß wir in Österreich keine Neugliederungsdiskussion haben. Hier zeigt sich das Gewicht der Geschichte. Die Bundesländer mögen in ihrer rechtlichen Ausstattung keine großen Staaten sein, eher schwache Gebietskörperschaften, aber sie sind doch durch Jahrhunderte gewachsene Identitätsgemeinschaften, die jede Diskussion über eine Neugliederung von vornherein ausschließen. Die Versuche, die während der nationalsozialistischen Herrschaft diesbezüglich unternommen wurden, sind nach 1945 sehr rasch wieder rückgängig gemacht und nie mehr wieder zur Diskussion gestellt worden. In der Schweiz ist es wohl ähnlich. Dort gab es freilich die Schaffung des neuen Kantons Jura, aus alten historischen Problemen heraus und aufbauend auf einer starken rechtsstaatlichen und demokratischen Tradition sowie auf sozialem Frieden und großem Wohlstand, so daß der Hinweis auf die Bildung des Kantons Jura - wie es manchmal in der Diskussion geschieht als Modell für erodierende Staaten wie Jugoslawien oder Rußland reiner Zynismus ist.

Vorsitzender: Ich danke Ihnen, Herr Mantl. Herr Schoch.

Schoch: Ich möchte mich an Ihre Zeitvorgaben halten. Ich habe eine Frage zunächst an Herrn Selmer, dann an Herrn Kirchbof. Herr Selmer, müßten wir nicht eine grundsätzliche Änderung in einer Weichenstellung bei der Eingangsbestimmung zum Finanzverfassungsrecht ins Auge fassen, nämlich bei Art. 104 a Abs. 1 GG? Ich verspreche mir davon eine Entlastung der Komplexität, eine teilweise Problemlösung im Vorfeld der Finanzausgleichsthematik. Meine These ist, daß die Ausgabenverantwortung nicht mehr allein der Verwaltungsverantwortung folgen soll, sondern stärker der Ausgabenverursachung. Dieses Modell beinhaltet natürlich, daß teilweise die Ausgabenverantwortung nach wie vor mit der Verwaltungsverantwortung einhergeht, aber teilweise eben doch gewisse Änderungen erfährt. Die Prämisse, die dem geltenden Verständnis von Art. 104 a Abs. $1 \mathrm{GG}$ zugrunde liegt, stimmt ja nicht mehr, die Idee nämlich, daß die Ausgaben großenteils verursacht werden durch das Ermessen, das im Zuge der Verwaltungstätigkeit ausgeübt wird. Wie sieht es heute aus? Wir haben eine Vielzahl von Leistungsgesetzen mit subjektiven Ansprüchen. Ich darf nur auf das Bundessozialhilfegesetz hinweisen; 1990 entstanden Ausgaben etwa in der Höhe von 32 Milliarden DM, um die Dimensionen anzudeuten. Ich möchte das Wohngeldgesetz 
anfügen und weitere Gesetze, das Bundesausbildungsförderungsgesetz, wo wir entsprechend Art. 104 a Abs.3 GG eine Teilung der Ausgabenverantwortung zwischen Bund und Ländern haben.

Wenn man das skizzierte Modell ins Auge fassen würde, stellt sich die Frage an Herrn Kirchhof, und ich fühle mich durch Ihre These 18 zu meinem Beitrag ermuntert, ob denn dies im Wege einer Neuinterpretation des geltenden Art. 104 a Abs. 1 GG möglich ist, oder ob wir eine Verfassungsänderung benötigten. Sie haben von „sollte“ gesprochen; mir wird nicht ganz deutlich, ob das rechtspolitisch zu verstehen ist oder ob eine Neuinterpretation stattfinden könnte. Ein letzter Hinweis im Anschluß an das, was Herr Mantl gesagt hat: Diese Änderung im Grundverständnis des Art. 104 a Abs. 1 GG schlägt natürlich durch auf das Verhältnis der Länder zu den Kommunen. Wir würden auch eine Entlastung erzielen beim Finanzausgleich, der innerhalb der Länder stattfindet. Vielen Dank.

Vorsitzender: Danke. Herr Kisker.

Kisker: Es freut mich, daß in den Diskussionsbeiträgen jetzt schon zweimal gefordert wurde, im Rahmen der Debatte über den Finanzausgleich auch die Möglichkeit einer Neugliederung des Bundesgebietes ernsthaft in Erwägung zu ziehen. Ich plädiere dafür seit geraumer Zeit. Aber dann kommt der Kollege Hans Meyer aus Frankfurt daher und sagt: „Neugliederung; das ist politisch nicht durchzusetzen; eine Illusion; kaum noch diskussionswürdig." - Das leuchtet mir nicht ein: Die kleinen Länder, die Miniländer, stehen unter einem beträchtlichen wirtschaftlichen Druck, der sie in Richtung Kooperation und schließlich Neugliederung drängt. So z. B. Bremen und das Saarland. Da stöhnt man unter dem Zwang zur Sparsamkeit und empfindet es als äußerst lästig, daß man haushaltspolitisch mehr und mehr „entmündigt" wird. Das erhöht auch in diesen Ländern die Bereitschaft, erneut über die Vorteile einer Neugliederung nachzudenken. - Wenn Sie nun allerdings sagen, Herr Kirchhof, das Instrumentarium der Finanzverfassung habe die vorgegebene Ordung zu unterstützen, es dürfe aber nicht auf deren Umgestaltung hinwirken, so könnte das heißen, daß Bund und Länder verpflichtet sind, Bremen und das Saarland sowie andere Betroffene mit Hilfe des Finanzausgleichsinstrumentariums von dem heilsamen Zwang zu befreien, darüber nachzudenken, ob ihnen nicht Neugliederung aus ihrer Misere heraushelfen könnte. Eine so weitgehende Verpflichtung sehe ich nicht: Wer Wert darauf legt, sich den „Luxus der Kleinheit“ zu bewahren, muß bereit sein, dafür auch Opfer zu bringen. 
Ein zweiter Punkt: Wenn ich Sie richtig verstanden habe, so wollen Sie, Herr Selmer, die neuen Bundesländer vorläufig noch im Rahmen des herkömmlichen Finanzausgleichs mit dem herkömmlichen Instrumentarium bedienen, z.B. mit Hilfe von Ergänzungszuweisungen. Herr Kirchbof hingegen plädiert für eine vom herkömmlichen Finanzausgleich abgesetzte Sonderausstattung der neuen Bundesländer, z. B. für deren Ausstattung mit neuen Steuerquellen (Tabaksteuer etc.). Mir scheint der zweite Weg besser. Ein Bedienen der neuen Bundesländer im Rahmen des alten Systems wird dieses alte System korrumpieren, z. B. dadurch, daß es in diesem System die Position des Bundes erheblich verstärkt. Das läßt sich dann kaum wieder rückgängig machen. - Die Frage ist freilich, ob die neuen Bundesländer sich weiterhin auf eine Sonderlösung einlassen werden. Im Einigungsvertrag ist ihnen ja die volle Eingliederung in den herkömmlichen Finanzausgleich zugesagt worden. Gegen ihren Willen läßt sich diese Zusage möglicherweise nicht einmal durch Verfassungsänderung korrigieren. Es wird schwer halten, die neuen Bundesländer davon zu überzeugen, daß sie (auch im eigenen Interesse) vorläufig weiterhin einen Sonderstatus akzeptieren sollten.

\section{Vorsitzender: Danke Herr Kisker. Herr Kirchhof.}

P. Kirchhof: Ich würde gern zu drei Grundthesen Stellung nehmen, die heute morgen entwickelt worden sind, und die sich so gut bewährt haben, daß wir sie auch in der Phase des einigungsbedingten Übergangs beibehalten und zur weiteren Bewährung aufrufen sollten. Die erste These enthält die Aussage, daß die Finanzverfassung Folgeverfassung zur Sachverfassung ist. Der Staat gewinnt heute einen wesentlichen Teil seiner Mächtigkeit aus seiner Finanzkraft. Er lenkt den Bürger durch das Angebot von Geld; dieses Angebot aber scheint weder an Gesetz und Verwaltungsakt noch an Kompetenzen und Befugnisse gebunden. Geld wird überall gern entgegengenommen; deswegen kann die Macht des Geldes die Sachverfassung unterlaufen. Unser Schwerpunktthema, die Bundesstaatlichkeit, bietet ein anschauliches Beispiel für das Regime des Bundes mit dem goldenen Zügel. Der Bund bietet einen Bundessportplan und zugleich eine Bundesmitfinanzierung an und veranlaßt so alle Länder, Sportplätze zu bauen. Kein Land hat die Kraft, die Bundesfinanzierung zurückzuweisen, um seine Entscheidungsautonomie zu wahren. Dann bietet der Bund einen Bundesmusikplan an, und alle Länder bauen Musikschulen; wiederum hat der Bund finanzmächtig in den Landeskompetenzbereich hineinregiert. Dieses Regime kraft Finanzmacht betrifft 
nicht nur das Bundesstaatsprinzip, sondern - das sage ich insbesondere im Anschluß an die Bemerkung von Herrn Thieme - auch den Parlamentarismus. Wir kennen Bewilligungsvorbehalte der Regierung, wir dulden Nebenabsprachen zwischen Parlament und Regierung, wir räumen ein, daß Sonderhaushalte nötig sein können. Wenn aber das Gesamtvolumen der Sonderhaushalte das des Bundeshaushaltes übersteigt, so ist eine der zentralen Aufgaben und Befugnisse des Parlaments, das Budgetrecht, gefährdet. Wenn das Parlament dann zusätzlich - auch im Finanzwesen - Kompetenzen an die EuropaExekutive verliert, es vielleicht auch durch Staatszielbestimmungen Entscheidungsmacht an die Verfassungsgerichtsbarkeit abgibt, dann wird diese Entwicklung langsam bedrohlich. Es entsteht hier ein an die Wurzeln des demokratischen Parlamentarismus greifendes Problem und demokratische Defizite werfen meist auch rechtsstaatliche Schatten.

Die Sonderabgabe berührt auch das verfassungsrechtliche Verhältnis zwischen Staat und Bürger, das heute morgen zu Recht schon angesprochen worden ist. Wenn der Staat z. B. einem Umweltbelaster nicht mehr durch Verwaltungsakt sagt: „Du darfst nicht“, sondern wenn er ihm eine Abgabe auferlegt, der er nur durch Tatbestandsvermeidung ausweichen kann, so bleibt es dem Abgabenschuldner unbenommen, sich von dem abgabenrechtlich überbrachten Verhaltensbefehl „freizukaufen“. Verwaltungsprogramme können durch die Abgaben immer nur unter der Voraussetzung verwirklicht werden, daß ihr Scheitern hingenommen wird, ein Scheitern bei denjenigen, die bereit und in der Lage sind, sich durch Abgabenzahlung weiterhin die Immissionsberechtigung zu erhalten.

Der zweite Grundsatz - hier fand ich die Abstimmung der beiden Referenten sehr glücklich - besagt, daß jeder Verteilung von öffentlichen Geldern zunächst ein Zugriff auf private Gelder vorausgeht. Die Finanzverfassung darf nicht, wie es gelegentlich geschieht, nur als Verteilungsproblem behandelt werden; vielmehr rückt sie in ihrem systematischen Aufbau und in ihren Kernaussagen nachdrücklich ins Bewußtsein, daß der Umverteilung die Nahme vorausgeht. Finanzstaatlichkeit beginnt mit Besteuerung.

Gegenüber dem wiederholt formulierten Postulat nach mehr Landessteuerautonomie habe ich allerdings Zweifel. Unsere Wirtschaft ist nicht nur über die Grenzen der Bundesländer, sondern auch in einem europäischen Binnenmarkt und einem darüber hinausgreifenden Weltmarkt verflochten. $\mathrm{Ob}$ wir für dieses Zusammenwirken und diesen Wettbewerb ein Gleichheitsgefälle organisieren dürfen, ob insbesondere das Bundesstaatsprinzip hier die Kraft hat, der unitari- 
sierenden Wirkung des Gleichheitssatzes entgegenzuwirken, bedürfte näherer Prüfung. Jedenfalls in unserer Augenblickslage, in der ein wirtschaftserhebliches Gefälle zwischen Ost- und Westdeutschland bewältigt werden soll, erscheint mir eine Landessteuergesetzgebung nicht das richtige Instrument. Was nämlich sollte ein wirtschaftlich schwaches Land mit seiner Besteuerungskompetenz bewirken? Es wird zunächst Arbeitsplatzpolitik betreiben müssen. Das aber heißt Industrieansiedlung, die wiederum eine steuerliche Entlastung, damit eine Minderung des Aufkommens für den Landeshaushalt voraussetzt. Ein Land könnte also allenfalls durch indirekte Steuern auf die Verbraucher, die seiner Besteuerungsgewalt nicht ausweichen, zugreifen. Eine indirekte Besteuerung aber stößt auf enge Rechtsgrenzen, nicht zuletzt durch das EG-Recht.

Das Grundgesetz fordert sodann - wiederum auch zum Schutz des Steuerzahlers -, daß die Abgabengesetzgebungsgewalt insgesamt wieder in einer Kompetenz - dem Art.105 GG - angesiedelt wird. Wenn jede Auferlegung von Abgaben - auch die der Sonderabgaben - allein in der Finanzverfassung ihren Kompetenztitel gewinnt, so ist die Verantwortlichkeit für die Gesamtbelastung des Abgabenschuldners kompetenzrechtlich klargestellt, zugleich ein wichtiges politisches Gestaltungsmittel bundesstaatlich zugeordnet.

Auf ein drittes Problem des Zusammenwirkens zwischen staatlichem Geben und Nehmen hat Herr Selmer ausdrücklich hingewiesen: die Verschonungssubvention. Der Staat erbringt an den Bedürftigen nicht Leistungen, sondern erlaubt ihm, weniger an Steuern zu zahlen als die steuerliche Regelbelastung eigentlich fordert. Dieses Lenkungsinstrument scheint beim Bundesgesetzgeber deshalb so beliebt, weil der Bund hier Subventionen zu Lasten fremder Kassen anbieten kann. Begünstigt er z. B. bei der $\mathrm{Kfz}_{-}$ Steuer die Verwendung abgasarmer Motoren, so gewährt der Bundesgesetzgeber einen finanziellen Anreiz, die Finanzlast hingegen liegt ausschließlich bei den Ländern. Bietet der Bundesgesetzgeber Subventionen bei den Gemeinschaftsteuern an, so tragen die Länder die Finanzierungslast dieses Subventionsprogramms zur Hälfte. Verfassungsrechtlich besonders fragwürdig wird das Subventionsangebot im Rahmen einer progressiven Steuer. Mindern hier die Subventionstatbestände die steuerliche Bemessungsgrundlage, so empfängt der steuerlich Hochbelastete, also der höher Leistungsfähige, höhere Subventionen als der gering Belastete, der weniger leistungsfähig ist und deshalb in der Regel eher einen höheren Subventionsbedarf hat. Auch diese materiellen Verwerfungen wird man bedenken müssen, wenn der Bund darangeht, die vor ihm liegenden Auf- 
gaben der Regional- und Strukturpolitik mit Hilfe steuerlicher Verschonungssubvention anzugehen.

Schließlich noch eine kurze Bemerkung zur Einheitlichkeit der Lebensverhältnisse. Hier haben wir zwischen beiden Referenten deutliche Akzentverschiebungen beobachtet. In dem entscheidenden Punkt allerdings stimmen beide Referate überein: Es kommt nicht darauf an, daß wir ein solches Prinzip definieren; ich würde sogar hinzufügen, es kommt nicht einmal darauf an, daß wir ein solches Prinzip rechtsverbindlich machen. Wesentlich ist vielmehr, auf welchem Niveau die Einheitlichkeit hergestellt werden soll. Eine Einheitlichkeit auf minderem Niveau ist schnell erreichbar; die Bemühungen gehen jedoch naturgemäß dahin, die Einheitlichkeit auf dem uns vertrauten Niveau zu erhalten und möglichst ein darüber hinausweisendes stetiges und angemessenes Wirtschaftswachstum zu erzielen. Bei diesem Handlungsauftrag aber kommt es weniger auf die Zieldefinition als auf die Instrumentarien an: die Bundesgesetzgebungskompetenz, den Art. 109 Abs. 2 GG, den Finanzausgleich, Privatisierungen, Bundesbeteiligungen und Finanzhilfen.

$\mathrm{Zu}$ diesem Finanzausgleich füge ich abschließend zwei kurze Bemerkungen an: Solange wir das Haushaltsdeckungsprinzip haben, also nur danach fragen, wie groß das Gesamtdefizit im jeweiligen Haushalt ist, nicht aber prüfen, ob der jeweilige Haushaltsgesetzgeber verschwenderisch oder sparsam gewirtschaftet hat, kann der Finanzausgleich ein sachgerechtes Annähern und Ausgleichen nicht leisten. Solange der Sparsame verpflichtet wird, die Defizite des Verschwenders zu refinanzieren und der Finanzausgleich sich nicht auf die vorgefundenen, politisch nicht verantwortbaren Unterschiede beschränkt, gefährdet er die bundesstaatliche Autonomie. Etwas anderes gilt selbstverständlich, wenn ein Land aus eigener Kraft schlechthin nicht mehr in der Lage ist, finanzautonom zu handeln.

Solange das Bedarfskriterium nicht allein im Tatbestand des Einwohners gesehen, also die rechtsstaatlich gebotene und demokratisch vorausgesetzte Gleichheit jedes Einwohners nicht anerkannt wird, die gleiche Verantwortlichkeit der Länder gegenüber jedem Landeseinwohner vielmehr durch Sonderbedarfsansätze verfremdet wird, fehlt dem Ausgleichskonzept die Plausibilität, vielleicht auch die materielle Richtigkeit. Deswegen haben wir zustimmend gehört, daß man nicht Seehäfen gegen Flughäfen aufrechnen, nicht Schiffe gegen Flugzeuge abgrenzen sollte. Und um bei dem Hafen zu bleiben, wir können auch nicht Singles gegen den Hafen der Ehe normativ abheben. Die Singles sind in den Erschließungslasten teuer, als Steuerzahler ergiebig. Die Ehe ist im Erschließungsaufwand - pro Kopf gerechnet - billiger, 
erwirtschaftet aber im Pro-Kopf-Aufkommen in der Gegenwart ein geringeres Steueraufkommen. Sie erbringt für die Zukunft um so mehr Ertrag, wenn aus der Ehe eine Familie geworden ist. Insofern könnte der Finanzausgleich neben der Angleichung für das gegenwärtige Haushaltsjahr auch eine Gleichheit für die Zukunft herstellen

Vorsitzender: Danke. Herr Bullinger, ein Spontanvotum.

Bullinger: Beide Brüder Kirchbof haben gegen die Umweltabgaben Bedenken erhoben. Eben haben wir gehört, man könne sich dadurch freikaufen. Ich glaube, die Dinge werden so nicht ganz richtig gesehen. Durch die Möglichkeit kostenloser Nutzung der Umwelt wird ein ökonomischer Anreiz zu übermäßiger Nutzung geschaffen, der durch die Umweltabgaben beseitigt werden soll. Infolgedessen darf man die Dinge nicht unter Steueraspekten sehen.

Vorsitzender: Ich danke. Herr Ress.

Ress: Herr Vorsitzender, ich werde versuchen, Ihre Zeitvorgabe einzuhalten. Ich möchte kurz drei Punkte berühren: einmal den EGGesichtspunkt. Wir werden, falls der Maastrichter Vertrag über die Europäische Union ratifiziert wird oder in einer geänderten Form in Kraft tritt, voraussichtlich auf der EG-Ebene nach Art.104 c EG.-V. ein Finanzkontrollsystem bekommen, welches über das hinausgeht, was wir zur Zeit in der Bundesrepublik haben und praktizieren. Im Unionsvertrag sind Maßstäbe und Maßnahmen für die Finanzkontrolle der einzelnen Mitgliedstaaten vorgesehen, zunächst die Einhaltung gewisser Stabilitätsreferenzkriterien, die Voraussetzung für den Eintritt und für die Beibehaltung dieses Systems sind. Sodann die Verpflichtung der Mitgliedstaaten, ein exzessives Haushaltsdefizit zu vermeiden. Eine Nichtbeachtung dieser gebotenen Haushaltsdisziplin kann dazu führen, daß vom Rat der EG gegenüber diesem Mitgliedstaat (ich nehme an, in der Bundesrepublik sowohl gegenüber dem Bund als auch gegenüber den Ländern - soweit die Haushaltsautonomie reicht -) entsprechende $Z$ wangsmaßnahmen einschließlich Kürzung von EG-Zuweisungen und Bußen verhängt werden können. Dies bedeutet, daß demjenigen Mitgliedstaat, der ohnedies schon mit einem Haushaltsdefizit extremer Art belastet ist, zusätzliche Abgaben abverlangt werden. $\mathrm{Ob}$ das finanzwissenschaftlich sinnvoll ist, bezweifeln viele Kollegen der Finanzwissenschaft, die argumentieren: wer erhebliche Schulden hat, den kümmert es nicht, noch weitere $z u$ machen. Ich stelle diese Entwicklung hier zur Diskussion, da wir bei 
der Betrachtung des kommenden finanzverfassungsrechtlichen Systems nicht nur die Zweistufigkeit unseres Bund/Länderverhältnisses, sondern noch die Stufe der EG in dem fast schon dreistöckigen Bundesstaat mit in die Betrachtung einbeziehen müssen, auch mit den anderen europarechtlichen Maßstäben der Stabilitätskontrolle durch den EuGH, der dazu ausschließlich berufen ist. Damit hängt die Frage zusammen, ob wir eine Finanzverfassung überhaupt würdigen können, ohne uns zu fragen, wo der Schwerpunkt der diffusen Inflationskompetenz liegt. Viele hoch verschuldete Staaten haben die Inflation als die biligste Art der Entschuldung (durch Auflegung einer unsichtbaren "Steuer" auf Geldvermögen) benutzt. Dieser Weg der Wertabschöpfung und Verlagerung ist ebenso wichtig wie die formale Besteuerung. Der Schwerpunkt dieser „Kompetenz“ lag bisher bei der Bundesbank. In der Europäischen Währungsunion wird sie zwischen der Europäischen Zentralbank und den Mitgliedstaaten, die ihre Haushaltsautonomie (und damit Verschuldungsfähigkeit) behalten, aufgeteilt und damit in ein multipolares und ebenfalls dreistöckiges System überführt.

Ist diese Entwicklung nicht bei einer Gesamtbetrachtung mit zu berücksichtigen? Hinzu kommt, daß es in der EG den Grundsatz der Einheitlichkeit der Lebensverhältnisse als verbindlichen EG-Grundsatz noch nicht gibt. Man strebt ihn EG-politisch an, indem weniger auf der horizontalen als auf der vertikalen Ebene gewisse Fonds und Ausgleichssysteme eingerichtet werden. Aber bislang kann auf der EG-Ebene von einem europarechtlichen Grundsatz der Einheitlichkeit der Lebensverhältnisse als einem allgemeinen Rechtsgrundsatz noch nicht verpflichtend ausgegangen werden.

Das führt mich zum zweiten Punkt: Einheitlichkeit der Lebensverbältnisse. Dieser Grundsatz ist von den beiden Referenten doch deutlich unterschiedlich bewertet worden, bei Herrn Kirchbof als ein allgemeines verfassungsrechtliches Prinzip, bei Herrn Selmer doch eher als eine verfassungspolitische Orientierungsentscheidung, die, wie er gesagt hat, die Möglichkeit offenläßt, sich entweder für die Einheitlichkeit oder aber für die Vielfalt zu entscheiden. In seinem Referat klang es so an, als ob diese Wahl eine fundamentale Grundsatzentscheidung wäre, etwa des Gesetzgebers, sich entweder für das eine oder das andere Modell mit entsprechenden Konsequenzen zu entscheiden, die er insbesondere dann auch mit der Pflicht der Länder, einen Einheitsbeitrag zu leisten, in These 11 unterstrichen hat. Ich glaube, wenn man diese Wahl auf der Ebene der einfachen Gesetzgebung, Herr Selmer, ansiedelt, dann gibt es eine solche verfassungsrechtliche Pflicht zu einem solchen Einheitsbeitrag nicht. Jedenfalls läßt sie sich dann nicht begründen, wenn diese Wahl-Entscheidung im 
Bereich der einfachen Gesetzgebung bleibt. Und zweitens: Ist es denn wirklich eine solche Grundsatzentscheidung? Wir leben doch auch im einfachen Gesetzesrecht mit unserem Bundesrahmenrecht auf vielen Gebieten in einer Art Halb-Einheitlichkeit. Wir streben Einheitlichkeit an, aber doch nicht total, so daß wir auch nach unserem jetzigen Rechtszustand nicht eine derartige Alternative im extremen Sinne vor uns haben.

Die dritte Frage: die Neugliederung als Ersatz zur Vermeidung von extremen Haushaltsdefiziten. Die Frage war streitig und ist vor dem Bundesverfassungsgericht zwischen Herrn Kisker und anderen im letzten Verfahren um den Länderfinanzausgleich diskutiert worden. Ich schließe nicht aus, daß man an eine Änderung des Art. 29 GG ernsthaft denken kann. Aber diese Lösung ist sicher keine echte Alternative, sondern allenfalls eine parallele Möglichkeit zur Verbesserung der Finanzsituation, um Synergieeffekte herbeizuführen. Nur hat diese Lösung auch staats- und gesellschaftspolitische Auswirkungen. Ist die „landsmannschaftliche“ Situation bei uns nicht doch schon jetzt so gewachsen und ähnlich wie bei den Ländern in Österreich und der Schweiz, daß man nicht mehr beliebig die Länder und Länderzugehörigkeit verschieben kann? Wir haben seit dem Zweiten Weltkrieg gewachsene Identitäten in den einzelnen Bundesländern entwickelt. Es ist folglich notwendig, eine Gewinn- und Verlustrechnung auch auf der Seite der Identitäten der einzelnen Bundesländer aufzumachen, wenn man wirklich eine durch ein Bundesvotum aufoktroyierte Länderneugliederung ins Auge faßt.

Vorsitzender: Ich danke Herrn Ress. Wir haben jetzt schon sehr viele Voten gehabt, die beiden Referenten möchten sich deshalb kurz äußern, soweit das im jetzigen Zeitpunkt notwendig ist. Nachher werden wir mit Punkt 1 weiterfahren.

Selmer: Herzlichen Dank. Herr Vogel: In Ihrem Beitrag kommt soviel Zustimmung zum Ausdruck, daß ich, glaube ich, darauf verzichten kann, auf einzelne Fragen näher einzugehen. Ich freue mich insbesondere darüber, daß Sie - und ich glaube, das ist in nachfolgenden Beiträgen vielleicht etwas zu kurz gekommen - meiner Ambition beigepflichtet haben, gewisse Dinge der DDR-Erblasten aus der engeren Finanzverfassung auszulagern und einem besonderen Transferkanal zu überlassen, d. h. dem von mir erwähnten neuen Art. $120 \mathrm{~b}$ GG. Ein stärkeres Steuererhebungsrecht der Länder wird von Ihnen ebenfalls befürwortet, auch ein solches in Form eines Hebesatzrechts auf die den Ländern zufließenden Anteile an der Einkommen- und der 
Körperschaftsteuer. Damit treten Sie zugleich in Gegensatz zu einigen der nachfolgenden Debattenredner. Ich befürworte, und vielleicht darf ich in diesem Zusammenhang gleich zu einem späteren Beitrag Stellung nehmen, ein solches Steuererhebungsrecht allerdings erst für die Zeit nach Ablauf einer Übergangsphase von etwa 10 Jahren. Während dieser Zeit sollte eine allmähliche Heranführung an eine weitergehende Autonomie erfolgen. Daß die vom BVerfG als besonderer Begriff kreierte extreme Haushaltsnotlage in eine ausdrückliche Verfassungsvorschrift verlagert werden sollte, darin sind Herr Kirchbof und ich uns einig. Ich war in diesem Zusammenhang übrigens erstaunt darüber, daß nicht thematisiert worden ist in der Debatte die von uns beiden befürwortete Möglichkeit des Bundes, gegebenenfalls in die Haushaltsautonomie der Länder intervenierend hineinzugreifen. Hier geht es ja in der Tat um ein sehr weitgehendes Eingriffsrecht des Bundes, mag es möglicherweise auch wie bei Art. 37 GG an die Zustimmung des Bundesrates gebunden sein. Hier liegt gewiß noch ein Problem.

Herr Badura, Sie sind eingegangen auf meine These 9. Dort habe ich ausgeführt, der einfache Gesetzgeber sei verfassungsrechtlich nicht gehindert, das Schwergewicht künftig von einer Politik der Unitarisierung und sozialen Egalisierung im Bundesgebiet mehr auf eine solche der regionalen Differenzierung zu verlagern. Sie fragen, was darunter zu verstehen sei. Ich meine damit etwa, daß der Bund sehr wohl die Möglichkeit hat, sich - ohne Verfassungsänderung - aus gewissen Aufgaben, Ausgaben und Steuern zurückzuziehen, um auf diesem Wege für die einzelnen Länder eine größere Autonomie zu schaffen, insbesondere auch die bisherige Asymmetrie im Verhältnis von Aufgaben- und Ausgabenzuweisung einerseits und Einnahmeregelung andererseits angemessen zu überbrücken. Ich meine, daß so eine Umpolung der Bundespolitik auch ohne Verfassungsänderung möglich ist; das war gemeint. Den von Ihnen angesprochenen Unterschied zwischen der „Einheitlichkeit der Lebensverhältnisse“ und der Herstellung "gleichwertiger Lebensbedingungen" hat auch Herr Bartlsperger berührt. Der Ausdruck gleichwertige Lebensbedingungen wird ja im \$1 I Nr. 4 des Raumordnungsgesetzes seit langem ausdrücklich formuliert und hat auch nach der Vereinigung in der neuesten Fassung vom 25. Juli 1991 Aufnahme gefunden. Dies kann man gewiß als Beleg dafür nehmen, daß der Bund grundsätzlich bei seiner bisherigen Politik einer weitgehenden Vereinheitlichung bleiben wird. Auch die im letzten Monat bekanntgewordenen Leitsätze des Bundes zu der künftigen Finanzverfassung scheinen darauf hinzudeuten. Der Unterschied zwischen der Wahrung „einheitlicher Lebensverhältnisse" und 
der Herstellung "gleichwertiger Lebensbedingungen" scheint mir darin zu liegen, daß der Begriff der Gleichwertigkeit eine gewisse Freiheit der Länder nach Maßgabe ihrer spezifischen Gegebenheiten involviert. Die Gleichwertigkeit bedeutet insoweit eine autonomieorientierte Abschwächung des Begriffs der Einheitlichkeit. Ich habe freilich den Eindruck gewonnen, daß in der Diskussion diese Begriffe bisher weitgehend synonym verwendet worden sind.

Herr Thieme, Sie haben angeraten, einige Dinge auf den Bund zu verlagern. Sie haben dabei vor allem die Sozialhilfe angesprochen. Das entspricht meinen Vorstellungen. Auch ich habe ja empfohlen, die besonders stark streuende Sozialhilfe als einen ersten Testfall für eine etwaige Verlagerung von Geldleistungsgesetzen auf den Bund zu werten, soweit sie betragsmäßig gesetzlich fest vorformuliert ist. In diesem Zusammenhang darf ich zugleich einen späteren Beitrag vorwegnehmen, der darauf hinauslief, alle Geldleistungsgesetze in Änderung des Art. 104 a III GG auf den Bund zu überführen. Das ist völlig in Ordnung. Meine These lautete ja: Während der zehnjährigen Zwischenphase sollte man das zunächst einmal versuchen mit der Sozialhilfe als Testfall für die spätere Stärkung des Veranlassungsprinzips im Bereich der Geldleistungsgesetze.

Herr Starck, die von Ihnen registrierte Zentralisierungstendenz, die zur Zeit die bundesstaatliche Szene beherrscht, ist von Ihnen treffend gesehen. Für mich ist gerade diese seit der Vereinigung zu beobachtende Zentralisierung auf den Bund einer der Gründe dafür, daß ich eine zehnjährige $Z$ wischenphase eingeschaltet wissen möchte, um zu verhindern, daß das im Augenblick kaum zu beseitigende Übergewicht des Bundes im Finanzbereich sozusagen Wurzeln schlägt, d.h. zu einer finanzverfassungsrechtlichen Dauererscheinung des Bundesstaates wird. Von einem Solidaritätsmodell für die EG, Herr Starck, haben Sie ferner gesprochen. In der Tat: Hier liegt ein Aspekt, der zur Nachdenklichkeit anregen mag. Die Finanzwissenschaftler haben in den vergangenen Jahren sehr viel deutlicher gesehen, daß der Grad an bündischer Solidarität, den wir innerstaatlich herausarbeiten, sehr wohl aufmerksam von unseren EG-Nachbarn beobachtet werden wird, und wir uns später möglicherweise einmal an den Maßstäben messen lassen müssen, die wir innerstaatlich ausgeformt haben. Auch wir werden das im Auge behalten müssen.

Herr Bayer, in bezug auf die Neugliederungsproblematik, glaube ich, haben Sie mich nicht richtig verstanden. Ich habe bei der Neugliederung zunächst die Frage aufgeworfen, ob und inwieweit aus der Finanzverfassung, insbesondere aus deren Regeln über den Finanzausgleich, ein unmittelbar verfassungsrechtlich erheblicher Neugliede- 
rungsdruck abzuleiten ist, und habe diese Frage meinerseits verneint. Das erscheint mir nach wie vor zutreffend. Anschließend habe ich indes sehr wohl auch zu bedenken gegeben, ob nicht nach Ablauf der Übergangsphase, sofern bis dahin eine angemessene Homogenität der neuen Bundesländer nicht eingetreten ist, die Frage der Neugliederung ihrerseits mit Nachdruck aufgeworfen und gegebenenfalls selbst eine erneute Änderung des Art. 29 GG erwogen werden muß.

Herr Kisker, Sie neigen anders als ich schon für die nächste Zukunft einer größeren Steuerautonomie der Länder zu. Ich kann demgegenüber nur noch einmal auf meine Begründung für den gegenteiligen Standpunkt verweisen. Wir kommen hier natürlich in Fragen hinein, die fast schon solche des verfassungsrechtspolitischen Geschmacks sind. Ich neige nach wie vor der These zu, daß man angesichts der zur Zeit übergroßen Disparitäten zwischen den Bundesländern zunächst einmal über vertikale Hilfen, d.h. etwa Bundesergänzungszuweisungen, daneben über den Weg der aus dem Finanzausgleich ausgelagerten Erblastenregelung des von mir vorgeschlagenen Art. $120 \mathrm{~b}$ GG neuer Fassung die Dinge im Sinne eines angemessenen Abbaus der strukturellen Unterschiede klären sollte. Aber das ist eine Antwort, die schwerlich mit richtig oder falsch bewertet werden kann.

Herr Kirchbof, Sie sind grundsätzlich gegen eine Steuerautonomie der Länder. Hierfür gibt es gewiß gute Gründe der einheitlichen Besteuerung in einem einheitlichen Wirtschaftsgebiet. Ich meine aber, daß nach Ablauf der Übergangszeit und Verwirklichung einer ausreichenden Grundhomogenität sehr wohl untersucht werden sollte, ob nicht jedenfalls eine beschränkte Steuerautonomie der Länder notwendig ist, um ihnen eine gewisse Beweglichkeit und Wettbewerbsfähigkeit auch auf der Einnahmenseite zu verschaffen. Damit gewönne dann auch die Haushaltsautonomie nach Art. 109 Abs. 1 GG einen weiteren materiellen Inhalt und größere Bedeutung. Angesichts der fortgeschrittenen Zeit will ich es hierbei vorliegend belassen.

F. Kirchhof: Die Trennung zwischen einer künftigen Verfassung der Normallage und einer Übergangsfassung zur Finanzierung der deutschen Vereinigung beschreibt in erster Linie zwei Problemkreise. Deren Existenz sollte sich auch in der Systematik des Grundgesetzes niederschlagen, um zu zeigen, daß die Übergangsverfassung ihre innere Legitimation verlieren wird, wenn die Normallage wirtschaftlich hergestellt ist, und daß sie dann auch ihre äußere Geltung beenden muß. Hier stimme ich mit Herrn Selmer überein. Ich hatte allerdings den zeitlichen Akzent etwas anderes gesetzt, daß man nämlich beide 
Verfassungsteile zugleich in Angriff nehmen sollte. Ich halte das für zweckmäßig, weil bereits ab 1995 der vertikale Finanzausgleich in seiner heutigen Gestalt nicht mehr funktionieren wird. Bis zu diesem Zeitpunkt müssen alle Probleme sowohl grundsätzlich als auch in der Interimsphase, für den Bund und für alle sechzehn Bundesländer berücksichtigt sein.

Auch die verfassungsrechtliche Stellung der Nebenhaushalte, die zur Finanzierung der deutschen Einheit bekanntlich ausgedehnt genutzt wurden, wird man grundsätzlich bedenken müssen, wenn man kein Flickwerk einer Verfassungsnovelle herstellen will. Allenfalls die Probleme des Einnahmesystems könnten noch warten, weil sie von anderen Ursachen hervorgerufen wurden. Die Verfassung der Lenkungs- und Umweltabgaben ist vielleicht nicht von solcher Dringlichkeit, daß man sie sogleich mitlösen müßte. Völlig vermeiden kann man die Bewältigung dieser Probleme aber auch nicht, weil der Wildwuchs im Einnahmesystem sonst zu groß wird. Ansonsten sehe ich aber keine Möglichkeit, erst die Übergangsverfassung zu erlassen, um dann eine zehnjährige Denkpause zur Meditation über die Verfassung der Normallage einzulegen.

Zur Frage des Verhältnisses der Grundsätze des gesamtwirtschaftlichen Gleichgewichts und der Herstellung einheitlicher Lebensverhältnisse im Bundesgebiet: Ich hatte den Grundsatz der Einheitlichkeit im vertikalen Ausgleich zu erörtern, während Herr Selmer sich dessen horizontalen Aspekten widmete. Das ergibt eine unterschiedliche Akzentuierung, denn der Bund muß letztlich wegen seiner zentralstaatlichen Stellung und seiner hervorgehobenen Finanzmacht immer die Länder irgendwie (mit-)finanzieren. Hier bestimmt der Grundsatz der Einheitlichkeit mehr das Wie der Finanzierung. Der Bund hat hier vor allem die grundsätzliche Gleichberechtigung der Länder zu wahren, während der Grundsatz der Einheitlichkeit der Lebensverhältnisse im horizontalen Finanzausgleich vor allem die Schwelle vorzeichnet, ob einige Länder anderen überhaupt finanziell beispringen müssen, und erst dann den Umfang der Finanzierung vorgibt. Unter diesem Aspekt bekommt der Grundsatz ein anderes Gewicht. Die Grundsätze der Einheitlichkeit der Lebensverhältnisse, des gesamtwirtschaftlichen Gleichgewichts und der Wahrung der Rechts- und Wirtschaftseinheit besitzen gewiß gemeinsame Wurzeln. Sie überlagern sich auch teilweise. Vor allem zwei der vier Eckpunkte des gesamtwirtschaftlichen Gleichgewichts - Stabilität des Preisniveaus und hoher Beschäftigungsstand - wirken binnenstaatlich ebenfalls auf eine Einheitlichkeit der Lebensverhältnisse hin, während die beiden anderen auch nach außen gerichtete Zielsetzungen aufweisen. 
Bei disparaten Zielsetzungen der Grundsätze bedarf es einer Abwägung in der Anwendung, wenn sie beide das staatliche Handeln beeinflussen müssen. Ferner sind die für jene Grundsätze vorgesehenen Wirkmechanismen - Gesetzgebung, Haushaltswirtschaft, Steueraufteilung - als Grenzen ihrer Aussage zu bedenken.

Mit dem Begriff der Finanzverfassung als Folgeverfassung will ich ihre dienende Funktion für die Aufgaben- und Organisationsnormen des Grundgesetzes erfassen. In der Normallage bleibt sie grundsätzlich auf diese Folgefunktion beschränkt. Würde man eine Finanznotstandsverfassung einrichten, so würden die Finanzartikel in der Tat eine qualitative Veränderung erfahren, denn im Notstand "gehen die Uhren anders". Im besonders qualifizierten, nämlich extremen Finanznotstand, würde nach meinem Vorschlag die Finanzgewalt des betreffenden Landes beschränkt oder - wie Herr Vogel noch mutiger zur Diskussion gestellt hat - im Staatskonkurs die Existenz eines Landes beendet werden. In diesen Ausnahmefällen würde die Finanzverfassung aus ihrer Rolle als Folgeverfassung heraustreten und auf die Organisation des Bundesstaates durchschlagen. In solchen Extremsituationen halte ich es verfassungspolitisch für durchaus angebracht, wegen der Haushaltslage strukturelle Veränderungen im Bundesstaat vorzunehmen.

Den Umfang der Ausgabekompetenzen könnte man sicher durch Neuinterpretationen des Art. 104 a Abs. 1 GG teilweise ändern. Aus Legitimations- und Rechtssicherheitsgründen halte ich es aber für besser, gerade die kritischen Fälle des Art. 104 a GG, nämlich die Ausführung von Bundesgesetzen durch die Länder, im Wege der Novellierung neu zu regeln; eine Änderung der Auslegung des Wortlauts des Art. 104 a Abs. 2 und 3 GG würde kaum helfen, denn hier soll eine inhaltlich grundlegend andere Lösung als bisher gefunden werden, nach der die Ausgabenlast grundsätzlich an die Ausübung der Gesetzgebungskompetenz anknüpft und allenfalls Spielräume der Länder bei der Ausführung von Bundesgesetzen in die Finanzverantwortung der Länder fallen.

Ich habe mich nicht gänzlich gegen Sonderhaushalte ausgesprochen. Ich bin nur besorgt wegen der extensiven Benutzung dieses verfassungsrechtlich an sich zulässigen Instruments. Solange nur wenige, überschaubare Sonderhaushalte geringen Volumens mit kleinem Schuldenstand existieren, kann man ihnen großzügiger und wohlwollender gegenüberstehen. Die Flexibilität wird aber bedenklich, wenn der Staat gezielt Sonderhaushalte mit riesigen Volumina schafft und damit das gesamte Gefüge des Staatshaushalts erschüttert. An dieser Situation setzt mein Versuch an, Sonderhaushalte auf zwei 
Wegen zu begrenzen, sie aber nicht grundsätzlich auszuschließen. Ein gewisser Bestand an Nebenhaushalten wird immer gerechtfertigt sein, vor allem wenn der dahinter stehende Verwaltungsträger autonom sein soll oder wenn er mit eigenem Haushalt effizienter, transparenter und aufgabennäher handeln kann. Die Ausgliederung in einen Nebenhaushalt muß aber immer sachlich gerechtfertigt werden; hier scheint mir in den letzten Jahren das Sachlichkeitsgebot etwas aus dem Blick geraten zu sein. Die zweite Überlegung zur Eindämmung zielt auf eine Novellierung der Finanzverfassung. Wenn die heile Welt eines einzigen Staatshaushalts nicht in der Realität zu erreichen ist, weil gewisse Sonderhaushalte sachlich angebracht, vielleicht sogar zwingend erforderlich sind, dann könnte man den Zweck des Grundsatzes der Einheit des Haushalts dadurch wieder herstellen, daß man zumindest im Rechenwerk, vielleicht auch in der Haushaltsplanung, in Form und Verfahren wieder Einheit herstellt. Auch das enthält kein striktes Votum gegen Sonderhaushalte, sondern versucht lediglich eine Einbindung in ein Gesamtverfahren.

Vorsitzender: Ich danke Ihnen. Darf ich Herrn Meyer das Wort geben.

Meyer: Die Referenten sind in einem Punkt ins Jahr 1949 zurückgekehrt: sie haben die Kommunen überhaupt nicht erwähnt. Schon der Parlamentarische Rat hatte das nicht geschafft; mittlerweile wissen wir aber, daß die Kommunen notwendig die dritte Säule im Finanzverfassungssystem sind.

Zur Sache möchte ich einige strategische Überlegungen anstellen und gehe von der These Kirchhofs aus: „Die Verfassung der Finanzen folgt besonderen Funktionsbedingungen, besitzt aber dieselbe Geltungskraft wie die anderen Grundgesetzabschnitte." Herr Kirchbof, wäre es nicht besser zu sagen, die Finanzverfassung besitze denselben Geltungsanspruch. Der Witz besteht nämlich darin, daß sie nicht dieselbe Geltungskraft besitzt; kein Abschnitt des Grundgesetzes ist so oft gebrochen worden wie der Abschnitt „Das Finanzwesen“. Die Verfassung kann also in diesem Punkt ihre Geltungskraft nicht immer durchsetzen. Und wenn ich es recht sehe, ist der Einigungsvertrag von dieser "Tradition" nicht abgewichen. Art. $7 \mathrm{EV}$ hat nämlich vom Grundgesetz abweichende Regelungen zur Umsatzsteuerverteilung auch für die Altländer getroffen, und zwar nicht im Wege einer Verfassungsänderung. Daraus folgt, daß Verfassungsänderungen im Bereich der Finanzverfassung offensichtlich sehr schwierig sind. Sie sind regelmäßig auch nicht systematischen Gedanken verpflichtet. 
Insofern haben Sie, Herr Jaag, uns nur bestätigt; auch unser Finanzverfassungssystem ist außerordentlich unsystematisch. Es ist eine Art Wildwuchs. Es nimmt daher auch nicht wunder, daß die einzige unsinnige Bestimmung des Grundgesetzes, nämlich Art.106 Abs.5 Satz 3 GG, im Finanzverfassungsabschnitt steht; in ihr ist von einem Hebesatz für die Gemeinden die Rede, der sich auf eine Steuerverteilungsquote bezieht, die aber formal eine Finanzzuweisung ist.

Aus diesem Befund schließe ich, daß es einen Kairos geben muß, wenn überhaupt so etwas wie eine totale Finanzverfassungsreform durchgeführt werden kann, die ja in Wirklichkeit von Ihnen, Herr Kirchbof, vielleicht nicht in dem Maße von Herrn Selmer, vorgeschlagen worden ist. Ich sehe diesen Kairos nicht und ich sehe auch nicht, wie in dem Verfahren, das wir uns vorgenommen haben, nämlich schon erste Überlegungen unter der Drohung der notwendigen 2/3Mehrheit anzustellen, wie wir überhaupt zu einer einigermaßen vernünftigen neuen Finanzverfassung kommen werden. Das ist dasselbe Problem, das übrigens auch für die Länderneugliederung gilt. Wenn aber Änderungen der Finanzverfassung schon so schwierig sind, spricht alles dafür nach dem Motto Kirchbof zu verfahren, nämlich beides, die Lösung für die Dauer und die Lösung für die Übergangszeit, zusammen zu erledigen. In einem Punkt habe ich allerdings meine Bedenken, Herr Kirchbof. Ich denke, die Übergangszeit kann man schon in der endgültigen Verfassung mitregeln. Nebenbei: damit sie endlich von dem hier erhobenen Vorwurf „rauchet für den Osten“ wegkommen, können sie sehr einfach sagen, der Bund habe in der Höhe seines Tabaksteueraufkommens Ergänzungszuweisungen zu geben. Dann haben sie das Problem gelöst, und sie brauchen in diesem Punkt auch nicht die Finanzverfassung temporär zu ändern.

$\mathrm{Zu}$ einigen Einzelfragen ganz kurz meine Gegenstellungnahme: In These 10 behaupten Sie, wenn ich das richtig verstehe, daß die Bundesbank von Verfassungs wegen unabhängig ist. Das halte ich für außerordentlich übertrieben. Es ist sogar sehr schwer, die einfachgesetzliche Unabhängigkeitsregelung noch einigermaßen vor der Verfassung zu rechtfertigen. Auf einem anderen Blatt steht, daß wir die Unabhängigkeit aus den bekannten Gründen gerne sehen.

These 14 habe ich nicht verstanden. Sie sagen, der Gleichheitssatz systematisiert die Abgabentypik. Ich habe erst einmal nicht verstanden, was Sie meinen. Aber selbst, wenn ich es verstanden hätte, können Sie höchstens sagen: "sollte das Abgabenrecht typisieren“. Denn er tut es nun wirklich nicht. Ich bin froh, daß mittlerweile so viel Sachverstand in den zweiten Senat des Bundesverfassungsgerichts eingezogen ist, daß wir hier leichte Fortschritte erwarten können. 
$\mathrm{Zu}$ These 22 möchte ich ebenfalls insofern widersprechen, als Sie behaupten, daß der Art. 106 GG die Steuergesetzgebung und damit Art. 105 GG absolut dominiert. Ich glaube nicht, daß das der Fall ist, und ich meine auch, wenn wir noch etwas mit der Eigenstaatlichkeit der Länder im Sinn haben, müssen wir hier großzügiger sein, denn ein Steuererfindungsrecht der Länder ist absolut wertlos, wenn Sie es auf die Typik des Art.106 GG beziehen; im Grunde sind sämtliche Steuern, die nach dieser Typik überhaupt denkbar sind, vom Bund in Anspruch genommen.

Der letzte Punkt: Die Schuldenfrage ist viel zu sanft behandelt worden. Sie wird der Sprengsatz sein, der möglicherweise nicht unsere Generation, aber schon die nächste Generation mit voller Wucht trifft. Es scheint zwar möglich zu sein, daß die Länder einzelnen Kommunen den Geldhahn durch die Genehmigung oder Nichtgenehmigung der Haushalte so zudrehen können, daß hier langsam Besserung eintreten wird. Es scheint auch, daß der Bund mit Hilfe des Bundesverfassungsgerichtes so etwas wie einen Zwang auf ganz schwache Länder ausüben kann, aber ich frage mich, wer denn die Kraft hat, den Bund dazu zu bringen, seine Schulden zu reduzieren. In diesem Zusammenhang unterstütze ich sehr die Aussagen zu den Sonderfonds; es sind gar keine Sonderfonds, sondern es sind Sonderschuldenfonds. Die Fonds sind nur gemacht worden, um die Schulden aus dem Haushalt herauszuhalten, und sie haben eine Höhe erreicht, die wirklich mit der Verfassung nicht mehr zu vereinbaren ist. Das Problem dieser Schuldenmacherei des Staates ist im übrigen nicht, wie die Wirtschaftswissenschaftler meinen, das allgemeine Problem, wie viele Schulden eigentlich eine Volkswirtschaft ertragen kann. Deshalb ist auch die Bezugnahme auf das Bruttosozialprodukt außerordentlich irreführend. Es ist natürlich eine sehr angenehme Bezugsgröße, weil sie so wunderbar groß ist. Sie ist deswegen unangemessen, weil das Problem darin besteht, daß die Schulden, die heute von der Regierung gemacht werden, die ersparten Steuern von heute sind und die Steuern, die den späteren Regierungen abverlangt werden. Auch wenn es nicht die nächste oder übernächste Regierung ist, irgendwann müssen diese Schulden qua Steuern, also über Mehreinnahmen, zurückgezahlt werden, es sei denn, daß man tatsächlich sehenden Auges in den Staatsbankrott hineinschlittert. Daher meine ich, daß der Problemekomplex bei einer Reform der Finanzverfassung fast an oberster Stelle zu stehen hätte.

Vorsitzender: Ich danke Herrn Meyer. Herr Wendt. 
Wendt: Herr Selmer, ich unterstütze nachdrücklich Ihr Konzept einer Reföderalisierung unseres Staatswesens, weil ich meine, daß eine Entflechtung des heute zwischen Bund und Ländern bestehenden Entscheidungs- und Finanzierungsverbunds, eine Stärkung der Autonomie der Länder sowie ein vermehrter Einsatz von Wettbewerbselementen heilsame Wirkungen zeitigen würden. Auch die Ökonomen sagen uns ja, daß ein größeres $\mathrm{Maß}$ an Selbstbestimmung und finanzwirtschaftlicher Eigenverantwortung der Länder einschließlich nennenswerter eigener steuerpolitischer Kompetenzen und die auf einen hohen Autonomiegrad der Länder gestützte dezentrale Aufgabenerledigung zu einem sparsamen und effektiveren Einsatz der vorhandenen Ressourcen führen. Wenn dies richtig ist, dann müßten angesichts der gewaltigen Herausforderung der öffentlichen Finanzwirtschaft im Gefolge der Wiedervereinigung diese finanzwirtschaftlichen Effekte allerdings möglichst rasch wirksam werden. Daher finde ich, daß die von Ihnen bis zum Inkrafttreten einer erneuerten bundesstaatlichen Finanzverfassung - und möglicherweise auch einer umfassenderen Bundesstaatsreform - ins Auge gefaßte Übergangszeit zu lang bemessen ist. Was den Art. 104 a Abs. 3 GG angeht, so scheint sich hier immer stärker die Auffassung durchzusetzen, daß man dem Bund stärker als das heute der Fall ist, die Kosten der Finanzierung von Geldleistungsgesetzen, die er durch seine Gesetzgebung veranlaßt, auferlegen sollte. Ich frage mich, ob man überhaupt immer vernünftig unterscheiden kann zwischen vom Bund veranlaßten Geldleistungen und von ihm veranlaßten Sachleistungen, an deren Kosten eine Beteiligung des Bundes de constitutione lata ja von vornherein ausscheidet. Ich frage überdies nach der Gerechtigkeitsregel, die diese Differenzierung tragen soll. Die Schwierigkeiten einer Differenzierung und einer hieran anknüpfenden Mitfinanzierungsverpflichtung des Bundes zeigen sich etwa im besonders umstrittenen Bereich des Bundessozialhilfegesetzes; in diesem Gesetz sind Geldleistungs- und Sachleistungsbestimmungen eng miteinander verwoben, eine Trennung zum Zwecke der Begründung unterschiedlicher Ausgabeverantwortlichkeiten erscheint daher kaum möglich. Ein weiteres Hindernis für eine weitgehende Beteiligung des Bundes an den Aufwendungen nach dem Bundessozialhilfegesetz liegt im übrigen darin, daß hier auch die Länder noch eigene Bestimmungskompetenzen über die Höhe der Geldleistungen haben.

Zur Frage der Neugliederung bin ich anders als Sie, Herr Kirchbof, der Auffassung, daß ein eklatanter Mangel an finanzwirtschaftlicher Eigenständigkeit eines Bundeslandes früher oder später dazu führen wird, daß die Frage nach der Notwendigkeit einer territorialen Neu- 
gliederung gestellt wird. Ich meine, wir sollten die Länder in eine größere Eigenständigkeit entlassen und einem verstärkten Wettbewerb aussetzen. Erfüllen auch die schwächeren Länder diese Eigenständigkeit mit Leben, behaupten sie sich in diesem Wettbewerb und gelingt es ihnen, die Kosten der Verwaltung pro Kopf der Bevölkerung nicht wesentlich über den Durchschnitt steigen zu lassen, werden neben anderen auch die finanzwirtschaftlichen Gründe für eine Neugliederung entscheidend an Gewicht verlieren.

Gestatten Sie mir bitte noch eine letzte Bemerkung. Herr Kirchbof, ich bezweifle, ob man, wie dies ja auch Herr Vogel unterstützt hat, schon die primäre Steuerertragsverteilung stärker als bisher mit Finanzausgleichselementen und -effekten anreichern sollte. Ich glaube, damit würden Verantwortlichkeiten verwischt. Das Interesse der Länder an einem pfleglichen Umgang mit ihren Steuerquellen würde geschwächt oder sogar erlahmen. Die finanzwirtschaftlichen Konsequenzen wären unabsehbar. Daher möchte ich mich, jedenfalls grundsätzlich, nachdrücklich für die Beibehaltung des heute weitgehend verfolgten Prinzips der Verteilung der Steuererträge nach dem örtlichen Aufkommen einsetzen. Danke sehr.

Vorsitzender: Ich danke. Herr Schmidt-Jortzig.

Schmidt-Jortzig: Ich greife wieder auf, was Herr Schoch bereits angesprochen hat, nämlich die Sache des Konnexitätsprinzips, und spreche dazu in Ihre Richtung, Herr Kirchhof. Daß Friedrich Schoch darauf bereits abgehoben hat, ist übrigens nicht verwunderlich, weil er von dem hierfür sehr empfindlichen Kieler Nährboden kommt; das mag - mit Verlaub - vielleicht angemerkt werden. Es geht beim Konnexitätsprinzip, Herr Kirchhof, das ist Ihre These 18 Unterabteilung 4, m.E. weniger um ein Spezialproblem auf der vierten Stufe vertikalen Finanzausgleichs als um ein elementares Grundprinzip des Gesamtfinanzausgleichs im gegliederten Staat. Wenn es richtig ist, daß die Finanzverfassung eine Folgeverfassung darstellt, also den Sachregelungen nachfolgt und dieselben unterstützt, wenn es weiterhin richtig ist, daß dadurch namentlich auch die Bundesstaatlichkeit Stabilisierung findet, weil deren Aufgabenordnung und -allokation abgesichert wird, dann kann es wirklich nur so sein, wie der Zweite Senat des Bundesverfassungsgerichts „mit in der Tat großem Sachverstand“, Herr Meyer, immer wieder betont, und zwar zuletzt auch in der Entscheidung vom Mai dieses Jahres, daß es sich nämlich um eine für die Finanzverfassung grundlegende Lastenverteilungsregel handelt. Wenn dem aber so ist, dann kann es eigentlich auch nicht fraglich sein, daß das Konnexitätsprinzip voll durchschlägt auf sämtliche am 
Finanzausgleich beteiligten Ebenen, d. h. speziell auch auf die hier den staatlichen Subjekten weitgehend gleichstehende kommunale Ebene. Auch die Kommunen also, Herr Mantl, als unvollkommene dritte Stufe der Finanzverfassung, sind da mit von der Partie. Und wenn es denn nötig ist, dies noch zu unterstreichen, dann sollte man es in den Art. 104 a Abs. 1 GG als tragenden Gehalt auch ruhig ausdrücklich hineinschreiben. Ich denke freilich, es steht schon jetzt darin, wenn man die Norm nur richtig und nachdrücklich interpretiert.

Ich möchte weiter, wenn ich darf, noch zum sachlichen Inhalt des Konnexitätsprinzips Stellung nehmen. Und wenn ich eben ein wenig kritisch in Ihre Richtung gesprochen habe, Herr Kirchbof, weil Sie meines Erachtens dem Grundsätzlichen nicht genügend Aufmerksamkeit schenkten, will ich nun für Ihre These 18 vollste Unterstützung sagen und herzlichen Dank für diese Formulierung. Bei dem Prinzip nach Art. 104 a Abs. 1 GG, „die Ausgabenlast folgt der Aufgabe“, ist es nämlich wirklich dringend geboten, daß wir wegkommen von der Ansicht der überkommenen Interpretation, „Aufgabe“ sei hier im Sinne von „Verwaltungszuständigkeit“ zu verstehen. Das ist weder vom Verfassungswortlaut $z$ wingend angelegt noch erscheint es für die von Ihnen ja eindringlich geschilderten Beispiele einer mehrstufigen Aufgabenwahrnehmung sinnvoll. Insofern kann nur voll unterstrichen werden, was Sie gesagt haben, es komme eben auf die Aufgabenverursachung und Aufgabenverantwortung an, d.h. nicht so sehr auf statische, exogene, formale Kriterien wie die Verwaltungszuständigkeit, sondern auf die realen Steuerungspotentiale, wie sie sich in einer Aufgabenverwirklichung und den dabei in Gang gesetzten Verteuerungs- oder Verbilligungseffekten ausdrücken. Ich würde auch hier meinen, man brauchte eigentlich für diese Sicht keine Verfassungsänderung, sondern nur eine gewandelte, problembewußte Interpretation bei Art. 104 a Abs. 1 GG. Aber wenn es denn hilfreich sein mag und der neuen Problemlage angemessener, daß man es verdeutlichte, dann könnte, ja sollte man den Wortlaut ruhig ändern; notwendig wäre es allerdings, glaube ich, nicht. Also Fazit meines Erachtens: Das Konnexitätsprinzip ist ein ganz tragender Grundsatz für die Finanzverfassung im gegliederten Staatswesen, und den kann man durchaus auch ganz problembewußt auslegen und anwenden. Vielen Dank.

Vorsitzender: Danke. Herr Trzaskalik.

Trzaskalik: Es ist von beiden Referenten viel über finanzwirtschaftliche Autonomie gesprochen worden, Herr Wendt hat das auch noch einmal unterstrichen. Mehr Autonomie klingt immer gut, nur 
muß man sich überlegen, was darunter zu verstehen ist, und ich meine, daß man finanzwirtschaftliche Autonomie sehr unterschiedlich verstehen kann. Man kann sie nach dem Prinzip verstehen, daß ein Land, das gute Politik macht, etwas von den erwirtschafteten Früchten haben soll. Das ist der Standpunkt der reichen Länder. Sie können aber auch finanzwirtschaftliche Autonomie ganz anders verstehen, Sie können sagen, ich will aus dem großen Topf viel Geld haben, damit ich überhaupt Autonompolitik machen kann. Das eine $\mathrm{Mal}$ sind die Finanzen Folge autonomer Landespolitik, das andere Mal sind sie Voraussetzung für autonome Landespolitik. Und wenn Sie sich anschauen, welche Vorstellung in der Verfassung verwirklicht ist, kann man sehr zweifeln. Art. 104 a GG hat mit der Autonomie im erstgenannten Sinne nicht sehr viel zu tun. Ferner tendiert die Steuergesetzgebungskompetenz der Länder gegen Null. Bei der Ertragsverteilung wird das Prinzip der Zuweisung nach Maßgabe „selbsterwirtschafteter Einkünfte" allenfalls vordergründig bei der Einkommen- und Körperschaftsteuer praktiziert (Art. 107 Abs. 1 S.1 GG). Auch das kann man viel besser machen, etwa durch Anwendung der DBA-Regeln auf die verschiedenen Einkünfte. Bei den Landessteuern ist es geradezu ein Witz, wenn man annimmt, die Verteilung nach dem örtlichen Aufkommen sei identisch mit einer Verteilung nach Maßgabe von Verdiensten der Landespolitik. Wenn Sie etwa den Nachlaßfall Flick nehmen: Von dem Erbschaftssteueraufkommen von rund 100 Millionen sind Nordrhein-Westfalen dank des horizontalen Finanzausgleichs nur ca. 18 Millionen verblieben. Was in derartigen Fällen der Wohnsitz des Erblassers mit der Landespolitik zu tun hat, sehe ich nicht. Die Umsatzsteuer wird überhaupt nicht nach „Verdienstgesichtspunkten“ verteilt. Im Grunde bleibt von dem Gedanken der Ertragsverteilung als Folge autonomer Landespolitik wenig übrig. Der horizontale Finanzausgleich zielt auf einen angemessenen Ausgleich der Finanzkraft der Länder. Er nimmt gerade keine Rücksicht darauf, ob Finanzkraftunterschiede „verdient" oder „unverdient" sind.

Wer Steuern nach dem Motto verteilen will, daß sich Leistung lohnen soll, muß auch bereit sein, über Sinn und Unsinn der jeweiligen Landespolitik zu diskutieren. Ich kann mir eine ernsthafte - mit finanziellen Konsequenzen verbundene - Diskussion darüber nicht vorstellen. Vor allen Dingen müßte sich dann auch die Einstellung zum Landeskonkurs ändern. Das Land müßte „geschlachtet“ werden. Wenn man überhaupt von „fehlerhafter" Landespolitik reden kann, dann doch beim Konkursfall. Man müßte ferner sagen, wie man strukturbedingte Nachteile von Folgen schlechter Politik abheben kann. Auch das halte ich für ausgeschlossen. 
Herr Kirchbof - Paul Kirchbof - hat auf die engen wirtschaftlichen Verflechtungen in Deutschland hingewiesen. Angesichts dessen beschränken sich die Möglichkeiten eines Landes darauf, ein günstiges wirtschaftspolitisches Klima zu schaffen. Davon die Steuerverteilung abhängig zu machen, halte ich nicht für sinnvoll.

\section{Vorsitzender: Danke. Herr Schachtschneider.}

Schachtschneider: Ich möchte noch einmal den finanzverfassungsrechtlichen Grundsatz des Sozialprinzips ansprechen. Man kann dieses Prinzip, das die meisten auf ein Sozialstaatsprinzip verengen, auch das Prinzip der Brüderlichkeit nennen. Ich möchte mit Herrn Selmer darauf hinweisen, daß im Art. 20 GG vom sozialen und demokratischen Bundesstaat die Rede ist. „Bundesstaat“ ist das Hauptwort und das Wort „sozial“ das Adjektiv. Diese Wortverbindung läßt sich nicht in „bundesstaatlichen Sozialstaat" umdrehen, ohne ihren Sinn zu verfälschen. Das Bundesverfassungsgericht sollte das Sozialprinzip im stärkeren Maße seiner Rechtsprechung zugrunde legen, insbesondere um eine vernünftige Finanzverfassung zu fördern. Der wichtigste Motor der sozialen Entwicklung aber scheint mir immer noch das allgemeine Wahlrecht zu sein. Das Wahlrecht ist in unserem Lande durch den weit entwickelten Parteienstaat unitarisch und nicht föderalistisch. Solange das Wahlrecht unitarisch ist, wird es eine starke Tendenz zum sozialen Ausgleich, zur Angleichung der Lebensverhältnisse also, geben. Das gilt europa-, ja weltweit. Ich meine, im Gegensatz zu Herrn Ress, daß es in den Primärtexten der Europäischen Gemeinschaft ein Sozialprinzip gibt. In den Erwägungen der EEA ist die Rede von „Freiheit, Gleichheit und sozialer Gerechtigkeit“. Damit ist die alte französische Formulierung „Freiheit, Gleichheit, Brüderlichkeit“ aufgegriffen. Dieses fundamentale Bekenntnis rechtfertigt, ja gebietet Sozialpolitik. Die Instrumente sind damit freilich noch nicht geregelt, insbesondere nicht der Finanzausgleich. Auch das einheitliche Wahlrecht besteht in der Gemeinschaft noch nicht. In dem Moment, in dem wir ein egalitäres Wahlrecht in der Europäischen Gemeinschaft praktizieren und nicht die Völker ihre Abgeordneten entsenden, sondern das europäische Volk ein Parlament wählt, wird derselbe Druck auf die Angleichung der Lebensverhältnisse entstehen wie in Deutschland. Finanzverfassungsrechtliche Überlegungen werden dann nur sekundäre Bedeutung haben.

Eine Bemerkung zu Sonderproblemen: Der Bundesbankgewinn steht nach $\$ 27$ Nr. 4 BBankG dem Bund zu. Es geht um erkleckliche Beträge in der Größenordnung von 20 Milliarden DM. Auch das ist 
ein finanzverfassungsrechtliches Problem. Die Länder wären gut beraten, wenn sie ihre Beteiligung an diesen Gewinnen einmal einfordern wollten. Dankeschön.

\section{Vorsitzender: Danke. Herr Hendler.}

Hendler: Herr Vorsitzender, verehrte Anwesende. Zunächst möchte ich die Bemerkungen von Herrn Vogel zur Themenwahl des Vorstandes unterstützen. Ich bin ebenfalls der Meinung, daß der Vorstand kaum einen günstigeren Zeitpunkt finden konnte, um das heutige Thema auf die Tagesordnung zu setzen. Denn in den Ländern, namentlich in den Finanzministerien, besteht erhebliche Unruhe darüber, was im Jahr 1995 auf sie zukommen könnte. Die Referenten haben zu Recht die Regelung des Finanzausgleichs in den Vordergrund ihrer Betrachtungen gestellt. Die öffentliche Diskussion zur Reform der Finanzverfassung weist aber neben der Finanzausgleichsfrage noch einen weiteren Schwerpunkt auf. Er betrifft die Steuergesetzgebungskompetenz der Länder. Dieser Gesichtspunkt ist zwar in den Referaten nicht völlig unerwähnt geblieben, aber - wie ich meine - etwas vernachlässigt worden. Das Thema ist in den bisherigen Diskussionsbeiträgen mit teilweise unterschiedlicher Akzentuierung bereits angesprochen worden. Ich möchte es noch etwas vertiefen.

Die Eigengestaltungsmöglichkeiten der Länder auf der Einnahmenseite ihres Haushalts sind außerordentlich gering. Sie betreffen im wesentlichen die Kreditaufnahme. Demgegenüber besitzen die Länder hinsichtlich ihrer Haupteinnahmequelle, nämlich der Steuern, nur minimale Regelungskompetenzen. Es kommt hinzu, daß in einem gegliederten Staatswesen - bei gleichbleibenden rechtlichen Grundstrukturen - eine Unitarisierungs- und Dezentralisierungstendenz zu beobachten ist. In der Finanzwissenschaft wird dieses Phänomen schon seit Jahrzehnten mit der Formel von der „Anziehungskraft des größeren Haushalts" umschrieben. Die Länder haben daher gegenwärtig ein erhöhtes Interesse daran, daß ihre Steuergesetzgebungskompetenzen gestärkt werden. Hierzu sind auch bereits einige Vorschläge unterbreitet worden. Der weitestgehende Vorschlag kommt von der Konferenz der Präsidentinnen und Präsidenten der deutschen Länderparlamente. Er sieht eine grundlegende Neuordnung der Kompetenzverteilung im Bereich der Steuergesetzgebung vor. Es mag zwar zweifelhaft sein, ob es sinnvoll ist, neben der Neuregelung des Finanzausgleichs auch noch ein zweites Großprojekt bei der Reform der Finanzverfassung in Angriff zu nehmen. Doch besteht ja immerhin die Alternative, sich auf punktuelle Verbesserungen zu beschränken, 
zumal es auch insoweit nicht an Vorschlägen fehlt. Ein Vorschlag ist in unserer Diskussion bereits des öfteren angesprochen worden. Er betrifft die Einführung von Zuschlags- oder Hebesatzrechten der Länder bei der Einkommensteuer. Zu Recht wird gewöhnlich eingewandt, daß ein solches Zuschlags- oder Hebesatzsystem die Standortnachteile der neuen Länder verschärfen könnte. Doch besteht auch hier die Möglichkeit, für eine Übergangszeit eine Kompensation zugunsten der neuen Bundesländer zu schaffen.

Ein weiterer Vorschlag betrifft das Steuererfindungsrecht der Länder. Nach derzeit herrschender Lehre besteht ein solches Steuererfindungsrecht nicht. Nach anderer Auffassung - und ich weiß von Herrn Selmer, $\mathrm{da} ß$ er diese Auffassung vertritt - ist bereits de constitutione lata ein Steuererfindungsrecht der Länder anzuerkennen. Es liegt meines Erachtens nahe, dieses Steuererfindungsrecht der Länder in der Verfassung abzusichern. Für diejenigen, die es bereits nach geltendem Verfassungsrecht anerkennen, handelt es sich insoweit lediglich um eine Klarstellung. Ferner wird diskutiert, ob ein Teil der Landessteuern und ein Teil der Gemeindesteuern in die ausschließliche Gesetzgebungskompetenz der Länder überführt werden sollte. Es geht hier in erster Linie um die Kraftfahrzeugsteuer, die Vermögensteuer, die Grunderwerbsteuer sowie die Grundsteuer. Der letzte Vorschlag, mit dem ich die Vorschlagsliste abschließen möchte, betrifft die Verschärfung des Art. 72 Abs. 2 GG bei der Inanspruchnahme der konkurrierenden Gesetzgebungskompetenz durch den Bund im Bereich des Steuerrechts.

Die dargelegten Vorschläge kann ich hier aus Zeitgründen nicht vertiefen. Aber ich bin der Auffassung, daß hinreichender Anlaß besteht, schon jetzt - und nicht erst in 10 Jahren - intensiv darüber nachzudenken, wie die Steuergesetzgebungskompetenz der Länder im Grundgesetz gestärkt werden kann.

Vorsitzender: Ich danke Ihnen, leider habe ich, auch wenn ich ein Zeiterfindungsrecht hätte, keine Möglichkeit, Zeit zu erfinden, deshalb bitte ich Herrn Birk, die versprochenen zwei Minuten genau einzuhalten.

Bayer: Darf ich einen Satz, Herr Vorsitzender?

\section{Vorsitzender: Einen Satz!}

Bayer: Ich würde doch als Steuererfinder meinen Vorredner ganz gerne fragen, worauf er die These stützt, nach herrschender Lehre gebe es kein Steuererfindungsrecht. 


\section{Vorsitzender: Herr Birk.}

Birk: Die Finanzverfassung und insbesondere die Regelungen über den Finanzausgleich sind durch zwei Prinzipien geprägt, die in einem Spannungsverhältnis stehen. Einmal das Prinzip der Einheitlichkeit der Lebensverhältnisse, das, wenn ich recht sehe, ein mehr zentralistisches Prinzip ist und auf der anderen Seite das Prinzip der Finanzautonomie der Länder, welches geprägt ist durch den Wettbewerb der Länder und das nach meinem Verständnis ein föderalistisches Prinzip ist. Die beiden Referenten haben mit unterschiedlicher Ausprägung ein Fragezeichen hinter das Prinzip der Einheitlichkeit der Lebensverhältnisse gesetzt, mehr noch Herr Selmer, ich möchte mich dem anschließen und nur etwas zu dem Prinzip der Finanzautonomie sagen. Ich habe Bedenken gegen ein Steuererfindungsrecht, gegen eine Steuerautonomie der Länder, gegen eine Verlagerung der Gesetzgebungskompetenzen auf die Länder. Ich muß mich hier kurz fassen und kann mich dem anschließen, was Paul Kirchhof hierzu gesagt hat. Ich möchte nur ergänzen: Wir haben eine Diskussion auf der EG-Ebene, die hier weitgehend ausgeklammert worden ist, die in die Richtung läuft: Verlagerung von Steuergesetzgebungskompetenzen an die EG. Wenn wir nun drei Stufen haben, nämlich EG, Bundesstaat und Länderebene, dann führt dies zu einer völligen Rechtszersplitterung auf dem Bereich des Steuerrechts. Ich meine, daß das nicht sinnvoll sein kann.

Ich möchte abschließen mit einer Grundsatzfrage an die Referenten, die der eigentliche Grund für meine Wortmeldung war: Haben Sie sich Gedanken gemacht über die Möglichkeit, den Länderfinanzausgleich, und zwar den sekundären Länderfinanzausgleich, also die Umverteilung der Finanzmassen unter den Ländern, völlig zu streichen und statt dessen die Länder auszustatten entsprechend dem Finanzaufkommen auf ihrem Gebiet? Eine Korrektur könnte dann erfolgen durch den vertikalen Finanzausgleich des Bundes an die Länder, bei denen noch Bedarf besteht. Das würde die Finanzautonomie enorm stärken und es würde, und das ist ein letzter Blick auf die EG-Ebene, in etwa so laufen, wie man sich es vielleicht später bei der Europäischen Union vorstellt: Die Mitgliedstaaten werden wohl niemals untereinander einen Finanzausgleich stattfinden lassen, vielmehr werden diejenigen Staaten, die "Bedarf“ haben, über den Zentralstaat nur diesen "Zusatzbedarf" gedeckt bekommen. Ich nenne hier nur die Stichworte, die zur Zeit in der Diskussion sind: Regionalfond, Konversionsfond, man könnte noch weiter denken. Vielleicht wäre das auch eine Lösung auf der gegenwärtigen bundesstaatlichen Ebene. 
Vorsitzender: Ich danke. Jetzt kommen wir zu Punkt 2. Das Wort hat Herr Stern.

Stern: Herr Vorsitzender, meine Damen und Herren. Ich freue mich sehr, daß der zweite Teil des Titels unserer Verhandlungen „das vereinigte Deutschland“ jetzt auch wirklich zur Geltung kommt. Es haben ja viele schon zu den Problemen der Vereinigung gesprochen; Sie gestatten mir, daß ich dann auch ein paar grundsätzliche Dinge zur Sprache bringe.

In der Tat hat die Finanzverfassung durch die Wiederherstellung der deutschen Einheit eine neue Qualität und eine neue Dimension angenommen. Es ist die Schuldenproblematik schon genannt worden; wir sollten aber auch erwähnen, das kam noch nicht zur Sprache, daß erhebliche Steuereinnahmen durch die Wiedervereinigung vor allem beim Bund, aber auch bei den alten Ländern entstanden sind. Diese Einnahmen hat man meistens kommentarlos eingesteckt; man hat daraus nicht immer das gemacht für die neuen Länder, was nötig gewesen wäre.

Im Zusammenhang mit der Schuldenproblematik haben Sie, Herr Kirchbof, den Art. 115 Abs. 2 GG erwähnt und dort den Begriff der Sondervermögen, der parafisci. Mittels dieses Art. 115 Abs. 2 GG ist es möglich, über die Grenzen des Art. 115 Abs. 1 GG hinwegzukommen. Daß der Begriff „Sondervermögen“ ganz sicher nicht für das gedacht war, wozu er im Rahmen der Vereinigung angewendet worden ist, also Fonds Deutsche Einheit, Kreditabwicklungsfonds und Kreditaufnahme der Treuhandanstalt, das ist sicher richtig. Ich glaube, Sie haben die Zahl 250 Milliarden in diesem Zusammenhang als neben dem Haushalt herlaufende Schulden erwähnt. Heute früh kam in den Nachrichten, es hätten sich bei der Treuhand noch weitere 20 Milliarden Schulden ergeben; so beträgt dieses Schuldenpotential insgesamt 270 Milliarden.

In der Tat ist dann auch die 1,5-Billionen-Zahl Gesamtschulden, die im Raum ist, vielleicht sogar etwas mehr, doch eine Realität, mit der wir rechnen müssen. Insofern sind unsere Diskussionen heute über die Finanzverfassung von ganz anderer Dimension und Qualität wie 1955. Damals gab es den Juliusturm, heute würde ich sagen, gibt es den Schuldenturm, und wir haben zu überlegen, wie wir diesen Schuldenturm, Herr Bayer hat es schon gesagt, in der Zukunft abbauen, so daß die Belastungen für die Zukunft nicht zu groß werden und Gefahren für das Leben zukünftiger Generationen entstehen.

Der Einigungsvertrag hat in Art. 7 wesentliche Teile der Finanzverfassung suspendiert. Das kam auch den alten Ländern zugute, aber 
gemeint war es in erster Linie für die neuen Länder. Allerdings ist dieser Art. 7 des Einigungsvertrages befristet bis zum 31.12.1994. Nicht erwähnt worden ist, daß wir ja noch eine zweite Bestimmung haben, den Art. 143 Abs. 2 des Grundgesetzes, der eingefügt worden ist durch den Einigungsvertrag; dort sind die Abweichungen von Abschnitt X des Grundgesetzes bis zum 31.12.1995 möglich. Wir müssen jetzt die Frage aufwerfen, und das Stichwort ist ja bei Herrn Selmer gefallen, ich beziehe mich auf die Leitsätze 25 und 27, wie die enormen strukturellen Unterschiede im finanziellen Bereich, aber auch im gesamtwirtschaftlichen, verwaltungsmäßigen, das gehört ja alles zusammen, zwischen den neuen Ländern und dem alten Bundesgebiet beseitigt werden können.

Was ist zu tun, um nach dem 1.1.1995 die Dinge in den Griff zu bekommen? Es war bei beiden Referenten die Rede davon, mit einer Übergangsverfassung zu arbeiten, wobei Herr Selmer eine zehnjährige Frist, Herr Kirchbof wohl eine fünfjährige, wenn ich es richtig im Gedächtnis habe, genannt hat; dann erst soll es zur grundsätzlichen Finanzverfassungsreform kommen. Ich könnte mir vorstellen, daß wir vielleicht einen anderen Weg gehen, weil das nicht so ganz einfach ist, was Sie vorgeschlagen haben, und ohne grundsätzliche Verfassungsreform nicht zu erledigen ist. Wenn wir einmal überlegen, ob man den Art. 7 des Einigungsvertrages nicht zeitweilig verlängert. Man hat nämlich schon nach Art. 7 des letzten Absatzes des Einigungsvertrages die Möglichkeit, auf besondere Gegebenheiten vertragsweise oder gesetzlich einzugehen; denn der Einigungsvertrag steht ja einem einfachen Bundesgesetz gleich. Möglicherweise wird man auch den Art. 143 Abs. 2 GG in seiner zeitlichen Form verlängern müssen. Ich meine, das wäre ein Vorschlag, den man diskutieren sollte und der manches dem einfachen Gesetzgeber ermöglicht.

Herr Selmer hat weiter vorgeschlagen, wir lösen die Probleme mit einem Art. 120 b Grundgesetz im Anschluß an Kriegsfolgen und Lastenausgleich und ähnlichem. Dazu würde ich von ihm gern die Grundsätze hören, die man in den Art. 120 b GG hineinpacken soll. Denn mir scheint richtig, was Herr Kirchbof sagt, wir dürfen, so haben Sie es, glaube ich, wörtlich gesagt, das Grundgesetz nicht überfrachten, auch nicht in finanzverfassungsrechtlicher Hinsicht. Der Abschnitt X gehört zu den umstrittensten, meistgeänderten des Grundgesetzes überhaupt, und, wenn wir die Vorschriften anschauen, auch zu den längsten Abschnitten des Grundgesetzes. Also mein Problem: Muß nicht in vielerlei Hinsicht vielleicht doch der einfache Gesetzgeber etwas machen können, um nicht alles in 
die Verfassungsebene zu schieben, scheint mir ein sehr grundsätzliches zu sein.

Nun ein paar Worte zur „Einheitlichkeit der Lebensverhältnisse“. Ich unterstütze Herrn Selmer, Herr Badura hat es auch noch einmal deutlich gemacht, das ist kein zwingendes Verfassungsgebot, sondern mehr, wie Sie gesagt haben, eine staatspolitische, verfassungspolitische, regionalpolitische Richtlinie, eine Staatszielbestimmung. Der Art. 72 GG, Herr Badura hat ihn erwähnt, wollte ja eigentlich eine Bremse sein zugunsten der Länderkompetenzen und nicht eine Dynamik entfesseln; aber in der Entwicklung hat sich die Einheitlichkeit der Lebensverhältnisse so ausgewirkt, daß sie gegenüber der Bevölkerung einfach so zwingend geworden ist, daß auf seiner Linie gehandelt wurde zusammen mit dem Sozialstaat, der von einem Diskussionsredner ebenfalls angesprochen worden ist.

Stärkere Steuerautonomie der Länder ist genannt worden, ebenso Steuererfindungsrecht und Hebesatzrecht der Länder. Das sind alles gute Vorschläge und sicher im Sinne des Föderalismus, aber da hängen viele grundsätzliche offene Fragen daran, und ich habe Zweifel, ob sich das realisieren läßt.

Ähnliches glaube ich auch, Herr Kisker hat es angesprochen, im Hinblick auf die Neugliederungsproblematik. Die Geschichte der Neugliederung der Bundesrepublik Deutschland ist eine Geschichte in dem Sinne, daß die Neugliederung nicht vollzogen worden ist, sieht man von Baden-Württemberg ab und sieht man vielleicht, das sehe ich als einzige Chance, von Berlin und Brandenburg ab, alles andere wird sich wohl nicht realisieren lassen. Die Kosten der Kleinheit, die natürlich bei bestimmten Ländern entstehen, und das Bundesverfassungsgericht, Herr Paul Kirchbof hat ja die extreme Haushaltsnotlage als einen Ansatzpunkt für Entscheidungen genannt, sind bei Bremen und dem Saarland ganz offensichtlich.

Zum Problem Gemeinschaftsaufgaben: Ich erinnere daran, daß die Enquête-Kommission Verfassungsreform schon den Versuch gemacht hat, sie abzuschaffen. Ich glaube, auch das geht nicht. Die kleineren Länder sind dagegen; das sind nicht wenige; denn wir müssen jetzt differenzieren zwischen finanzstarken, finanzschwachen und ärmsten Ländern. Das heißt im Interesse der finanzschwachen und der ärmsten Länder werden wir diese Gemeinschaftsaufgaben benötigen, daran ist nichts zu ändern.

Letzter Punkt: Zustimmung zu Leitsatz 17 von Herrn Kirchbof, Reform der Bundesergänzungszuweisungen. Ich teile ihre Begründungen und brauche dazu nichts Zusätzliches zu sagen. Wie kommen wir aus dem Gesamtdilemma heraus? 1969 ist es geglückt, eine 
grundsätzliche Reform der Finanzverfassung durchzuführen, aber da hat vorher die Tröger-Kommission gewirkt, vielleicht brauchen wir nun erneut eine solche Kommission. Vielen Dank.

Vorsitzender: Danke, Herr Stern. Herr Kisker.

Kisker: Im Anschluß an den Beitrag von Herrn Stern darf ich darauf hinweisen, daß das Bundesverfassungsgericht in seiner Entscheidung zum Finanzausgleich vom 27.5.1992 ausführt, daß bei einer Neugestaltung des Finanzausgleichs auch an die Möglichkeit einer Neugliederung zu denken ist. Das Thema Neugliederung ist also gewiß nicht „vom Tisch“.

Stern: Sie nehmen mir das vorweg. Ich will ja nicht sagen, daß man die Neugliederung deshalb nicht durchführen sollte, sondern nur: Die Neugliederung ist ein so schwieriges Unterfangen, daß ich behaupte, sie ist nicht realisierbar.

\section{Vorsitzender: Danke. Herr Schneider.}

H.-P. Schneider: Herr Vorsitzender, meine Damen und Herren. Vieles ist schon gesagt worden, ich beschränke mich auf einige kurze ergänzende Bemerkungen. Zunächst stimme ich beiden Referenten mit ihrem Vorschlag zu, zwischen der Normallage und einer Übergangsregelung zu unterscheiden, wobei man sich allerdings klar darüber werden muß, daß diese Übergangsregelung wahrscheinlich nicht nur 5 oder 10 Jahre, sondern vermutlich eine ganze Generation Bestand haben muß, wenn man insbesondere an die Schulden der DDR denkt, an die ja verschiedentlich schon erinnert worden ist. Das ist das eine. Man muß ferner bei dieser Trennung zwischen Normallage und Übergangsregelung berücksichtigen, daß hier Wechselwirkungen bestehen. Die alten Länder sind nicht bereit, irgendwelche Übergangsregelungen zu akzeptieren, wenn dadurch ihr Verhältnis untereinander und die Disparitäten, die jetzt schon zwischen den alten Ländern vorhanden sind, verstärkt würden. Das heißt: Es sollte dafür gesorgt werden, daß bei den Übergangsregelungen nicht Rückwirkungen auf das Verhältnis der Finanzkraft der alten Länder untereinander entstehen, die die ganze Sache nicht mehr konsensfähig machen. Wenn die alten Länder im Geleitzug in diese Übergangsphase hineingehen, müssen sie da auch die Chance haben, so wieder herauszukommen wie sie jetzt hineingegangen sind. Will man zum Beispiel die Probleme durch eine Vertikalisierung des Finanzausgleichs lösen, 
etwa indem man allen Ländern einen höheren Anteil an der Umsatzsteuer verschafft, so muß man bedenken, daß diese Umverteilung zunächst erst mal zugunsten der finanzstarken alten Bundesländer wirkt.

Der zweite Punkt: Ich halte es für problematisch, einen Weg zu beschreiten, bei dem die Bundesergänzungszuweisungen das Allheilmittel bilden sollen. Wir müssen meines Erachtens am Fehlbetragsmaßstab strikt festhalten und darauf achten, daß hier nicht alle möglichen Sonderbedarfe Eingang finden in diese Form der zusätzlichen, ergänzenden Finanzierung durch den Bund. Das gilt insbesondere im Hinblick auf die neuen Länder deshalb, weil es sich ja hier um Mittel zur Deckung des allgemeinen Finanzbedarfs handelt, bei denen ich fürchte, daß sie in den Personalhaushalten versickern werden und daß schon von daher die Finanzierung der Einheit ein „Faß ohne Boden" wird. Deshalb meine ich, wir sollten hier eher auf die Finanzhilfen nach Art. 104 a Abs. 4 GG verweisen und auf die Gemeinschaftsaufgabe „Förderung der regionalen Wirtschaftsstruktur". Das sind die geeigneten Instrumente, um strukturelle Ungleichgewichte zu beseitigen und Kompensation zu erreichen, nicht die Bundesergänzungszuweisung.

Letzte Bemerkung: Was die Altschulden der DDR angeht, so möchte ich hier für die Vorlage eines "nationalen Gesamtbudgets" plädieren. Es ist ja so, daß die gesamte Frage der Reform der Finanzverfassung wesentlich davon abhängt, ob und inwieweit es gelingt, auch die Schulden gleichmäßig zu verteilen. Dabei geht es nicht nur um die Schulden der Treuhand; da ist der Kreditabwicklungsfonds, da sind die Schulden der kommunalen Wohnungswirtschaft in den neuen Ländern, da ist nicht zuletzt der Fonds Deutsche Einheit, der ja auch kreditfinanziert wird. Ich glaube, wenn wir diese Schuldenproblematik nicht einbeziehen und uns um ein nationales Gesamtbudget bemühen, das auch Regelungen dazu enthält, wie diese Schulden getilgt werden sollen und wer die Zinslast für die Schulden in Zukunft übernimmt (ich denke dabei an 30 Jahre oder vielleicht noch an eine längere Zeit), dann wird das ganze scheitern, dann werden wir in eine erste wirkliche Verfassungskrise geraten, bei der man noch nicht weiß, ob die Idee des "sozialen Bundesstaates“ dann die Ressourcen an föderaler Solidarität mobilisieren wird, die wir brauchen, um das Problem zu lösen. Ich darf nur daran erinnern, daß die Thesen von Bundesfinanzminister Waigel schon zwei Tage später auf strikte Ablehnung durch das Bundesland Bayern gestoßen sind.

Vorsitzender: Ich danke. Herr Heun. 
Heun: Ich möchte ganz kurz zu drei Punkten sprechen.

Erstens: Die Funktion des Finanzausgleichs. Nach der Theorie der Finanzwissenschaftler hat der Finanzausgleich, das ist bisher noch nicht ausdrücklich thematisiert worden, drei Funktionen, nämlich die Stabilisierungsfunktion, die Distributionsfunktion und die Allokationsfunktion. In der Sache tauchen diese Probleme auf, bei Ihnen Herr Selmer, insbesondere unter dem Stichwort der Einheitlichkeit der Lebensverhältnisse, und der Allokationsgesichtspunkt unter dem Stichwort allgemeine Stärkung der Autonomie der Länder. Das Interessante ist nun, daß ganz offensichtlich die Juristen einen ganz entscheidenden Wert vor allem auf die Distributionsfunktion legen, während die Ökonomen, und hier gibt es einen deutlichen Dissens und deswegen auch ganz unterschiedliche Reformvorschläge, in erster Linie die allokationspolitischen Gesichtspunkte hervorheben, die vor allem auf einen stärkeren Wettbewerb hinauslaufen, insbesondere um die Effizienz der Mittelverwendung zu steigern. Dieser Dissens zwischen Ökonomen und Juristen kommt auch durchaus zum Ausdruck in dem Punkt der Einheitlichkeit der Lebensverhältnisse in der Betonung der Distributionsfunktion, während die Ökonomen im Gegenteil darauf abstellen, daß die Autonomie unbedingt gestärkt werden soll. Hier bin ich äußerst skeptisch, es haben sich ja einige Juristen, insbesondere auch Herr Starck, dem angeschlossen, ich bin hier äußerst skeptisch, weil die Angleichung der Lebensverhältnisse in den neuen Bundesländern im Moment ein ganz wesentlicher politischer Gesichtspunkt ist, und ich glaube kaum, daß wir an der Angleichung der Lebensverhältnisse in einem ganz erheblichen Maße vorbeikommen.

Wenn das so ist, dann ist, und das ist jetzt der zweite Punkt, ein Zentralisierungsschub ganz unvermeidlich. Ein Zentralisierungsschub deswegen, weil man zwar sagen kann, wie Sie Herr Selmer, daß die Herstellung der Einheitlichkeit der Lebensverhältnisse nicht von der Verfassung her eine Sache des Bundes sein muß, sie aber ökonomisch und politisch es gar nicht anders sein kann, weil, wie sich auch praktisch herausgestellt hat, in den ganzen verschiedenen Verhandlungen seit 1948 um den Finanzausgleich die reichen Länder im Prinzip nicht bereit sind, im wesentlichen abzugeben an die ärmeren Länder, wenn sie nicht mehr oder weniger durch den Bund dazu gezwungen werden. Insofern habe ich stärkste Bedenken gegen eine Stärkung der Autonomie der Länder in den nächsten, ich würde sagen, eher zwei Jahrzehnten als einem Jahrzehnt.

Ein dritter Punkt, der mir noch wichtig erscheint, ist folgender: Es kommt nicht so sehr darauf an, ob wir den vertikalen oder den 
horizontalen Ausgleich stärken. In der Sache kommt es nämlich darauf an, zwischen dem vertikalen und dem horizontalen Finanzausgleich eine Einheit herzustellen. Das kann man schon daran sehen, daß hier ja verschiedentlich vorgeschlagen worden ist, den horizontalen Ausgleich durch eine stärkere Betonung der Bundesergänzungszuweisungen oder auch anderer Zuweisungen nach Art. 91 a und Art. 104 a GG zu entlasten. Hier muß man sich nur bewußt machen, daß, wenn man eine solche Änderung des Inhalts der Bundesergänzungszuweisungen vornimmt, die ja bisher im wesentlichen nur ein Spitzenausgleich waren, daß man dann grundsätzlich das Institut der Bundesergänzungszuweisungen qualitativ entscheidend verändert. In der Sache muß man vor Augen haben, daß der Ausgleichsbedarf von 30 Milliarden, der befürchtet worden ist, natürlich nicht dadurch verschwindet, daß wir ihn in den vertikalen Ausgleich hineinpacken, denn im Ergebnis muß dann der Bund jedenfalls die Mittel dazu bekommen, diese über den vertikalen Finanzausgleich erzielbaren horizontalen Ausgleichseffekte durch eine stärkere Beteiligung etwa an dem Umsatzsteueranteil, finanzieren zu können. Insofern ist meines Erachtens die Frage, ob wir die anstehenden Probleme stärker über den horizontalen oder über den vertikalen Finanzausgleich bewältigen, für die Angleichung der Lebensverhältnisse im Grunde genommen gleichgültig. Danke.

Vorsitzender: Danke, Herr Heun. Herr Kilian.

Kilian: Eigentlich wollte ich aus der Sicht des Neu-Ossi einige Bemerkungen machen. Ich möchte insbesondere Herrn Heun beipflichten, was die Vorgehensweise der alten Bundesländer anbetrifft. Ihre Abkoppelung im Finanzausgleich von den neuen Bundesländern halte ich für einen schweren politischen Fehler, hier wurde das bündische Prinzip ohne Not aufgegeben. Dieses Prinzip sollte vor allem auch für Notzeiten gelten: man darf zwar nicht die erste Strophe der Nationalhymne zitieren, wo es heißt „in Schutz und Trutz zusammenhält", hier stimmt sie aber! Wir werden eine Stärkung des unitarischen Trends bekommen, was ich nicht für gut halte. Der Bund zieht zu viel an sich, die neuen Länder werden so zu Reichslanden. Ich bin zum Beispiel Sachsen-Anhaltinischer Beamter und werde aber vollkommen vom Bund alimentiert, bin also eine Art Zwitterwesen. Das klingt zwar alles nach einem Duodezfürstentümchen, hat aber dennoch seinen tiefen Sinn für die Identitätsstiftung der neuen Bundesbürger: Es ist außerordentlich schwierig, im Osten diese fünf neuen Bundesländer zueinander zu führen. Im Unterricht hat man es 
ohnehin sehr schwer, den Studenten den Föderalismus anschaulich zu machen: Wenn mir das Bundesland Sachsen-Anhalt weggenommen wird, bleibt überhaupt nichts mehr an Staatsgefühl übrig. Das heißt, wir sind gezwungen, den Leuten eine Identität zu geben; allein die Schilder an der Autobahn "Willkommen in Thüringen" und „Auf Wiedersehen in Sachsen-Anhalt" sind ein kleines Indiz dafür. Ich möchte daher weiter bemerken, daß ich die Koppelung von Finanzkraft und der Berechtigung, ein Land zu sein, für gefährlich halte. Länderneugliederung und Finanzierung dürfen nichts miteinander zu tun haben.

Ich habe vier Fragen, die ich noch stellen möchte:

1. Was ist der Aufbaubonus der neuen Länder, wie wäre er zu bewerten? Aus welchen Kriterien besteht die Geschichtslast, die sie aufzuholen haben, etwa die Kriegsfolgelasten, und wie lange könnte der Bonus maximal gewährt werden?

2. Was ist mit dem Begriff der Grundversorgung gemeint? Wie ich mal gehört habe, ist dies eigentlich ein rundfunkrechtlicher Begriff, was ist also unter Grundversorgung als Staatsmindestaufgabe zu verstehen?

3. Was ist von der Abschöpfung von Vereinigungsgewinnen zugunsten der neuen Bundesländer zu halten, Stichwort etwa: Neuauflage des Lastenausgleichsfonds? Und schließlich

4. eine allgemeine Frage: Wie sind die Chancen einer Staatsaufgabenreduzierung durch Teil- oder Vollprivatisierung? Ich habe vorgestern in Österreich gelesen, daß der österreichische Finanzminister die vom Staat gehaltenen Aktien der Casino Austria AG zu verkaufen gedenkt. Dankeschön.

Vorsitzender: Ich danke. Wir kommen zu Punkt 3, Herr Bothe.

Bothe: Ein paar Bemerkungen zum Umweltschutz in der Finanzverfassung. Herr Kirchbof hat sich gegen eine Ökologisierung des Steuersystems ausgesprochen. Seine Kritik hat er etwas karikierend formuliert, mit einem Hinweis auf den Beamten, den Steuerbeamten wohlgemerkt, der mit dem Lackmuspapier herumlaufe. Ich glaube dies führt die Diskussion in eine völlig falsche Sicht. Wir diskutieren die ganze Zeit über wirtschaftspolitische und sozialpolitische Folgen der Finanzverfassung. Wenn man darüber redet, dann muß eben auch die Frage erlaubt sein, welche ökologischen Konsequenzen eigentlich Finanzverfassung hat. Es ist doch ganz einfach einleuchtend, daß Vorschriften über Abschreibungen sich auf die Lebensdauer von Wirtschaftsgütern auswirken, daß Bewertungsregeln für die Vermö- 
genssteuer Nutzungsmöglichkeiten bestimmen. All dieses sind ökologische Konsequenzen von Steuern, die ganz einfach bedacht werden müssen, und darum wünsche ich mir für jedes Steuergesetz eine Umweltverträglichkeitsprüfung.

Die andere Seite dieser Sache ist der Einbau von ökologisch wirksamen ökonomischen Steuerungsinstrumenten in die Finanzverfassung. Man will die Sonderabgaben in dem Abschnitt über die Finanzverfassung sozusagen an die Leine legen. Es kann nicht sein, daß ein wesentliches Element des umweltpolitischen Instrumentariums finanzverfassungsrechtlich unmöglich gemacht wird. Aber: Genau so wie das Steuersystem die Ökologie berücksichtigen muß, muß natürlich ökologische Steuerung die wirtschaftspolitischen Konsequenzen, die sie anrichtet, mit bedenken. Die EG versucht gegenwärtig, diesem Rechnung zu tragen, indem sie für die neuen $\mathrm{CO}_{2}$-Abgaben die finanzpolitische Neutralität fordert, das heißt, die Belastung muß irgendwo wieder ausgeglichen werden. Ich halte dieses für eine Illusion. Das läßt sich nicht rechnen. Natürlich müssen bei solchen umweltpolitischen Steuerungselementen diese wirtschaftlichen Seiten mit bedacht werden. Allerdings muß man auch berücksichtigen, daß die Länder in diesem Zusammenhang gezwungen sind, teilweise aus der Not eine Untugend zu machen. Wenn und soweit das Erfinden von Steuern schwierig ist, sage ich jetzt mal, um hier nicht in diese Kontroverse einzugreifen, so stehen die Länder doch immer wieder vor der Notwendigkeit, neue Aufgaben zu erfüllen, ich nenne nur als Stichwort „Altlastensanierung“. Wenn sie dafür keine neuen Steuern erfinden dürfen oder können, dann geht das nur über Sonderabgaben, jedenfalls kann einem dazu nicht viel anderes einfallen.

\section{Vorsitzender: Danke. Herr Pieroth.}

Pieroth: Ich möchte einen Einwand von Herrn Meyer aufgreifen und kurz etwas näher begründen. Ich wende mich also gegen einen Teil der These 12 von Herrn Kirchbof, wonach die Finanzverfassung das Geldwesen zur Sicherung von Fachkompetenz in Unabhängigkeit einem ministerialfreien Institut anvertraut. Nach Wortlaut und Kontext muß das als eine Aussage zum geltenden Verfassungsrecht verstanden werden. Mir geht es demgegenüber um ein Ernstnehmen des Verfassungstextes. Ich rufe in Erinnerung, Art. 88 GG lautet: „Der Bund errichtet eine Währungs- und Notenbank als Bundesbank." Nun kann man daraus zwei Folgerungen ziehen: 1. Die Bundesbank ist ein Gegenstand der obligatorischen Bundesverwaltung. 2. Es besteht eine Pflicht des Bundes zur Errichtung und - wird man in 
teleologischer Auslegung ergänzen - Unterhaltung dieser Einrichtung. Herr Stern hat das die institutionelle Garantie genannt. Damit hört aber auch das, was man aus diesem Wortlaut herausholen kann, auf. Eine Unabhängigkeit und Autonomie, wie sie von Herrn Kirchbof postuliert wird, ist im geltenden Verfassungsrecht nicht enthalten. Einerseits ist eine gesetzliche Regelung, die der Bundesbank diese Unabhängigkeit und Autonomie gibt, nicht verfassungswidrig; andererseits ist eine Unabhängigkeit aber auch nicht verfassungsgeboten. Ein Gesetz kann also in den Grenzen der dargestellten institutionellen Garantie, die aber nur sehr grobe Festlegungen enthält, die Unabhängigkeit einschränken. Im Moment wird allerdings wieder deutlich, wie stark ein allgemeiner Konsens besteht über die Sinnhaftigkeit dieser Unabhängigkeit. Vielleicht führt die gegenwärtige Verfassungsdiskussion dazu, die Festlegungen zu treffen, über die als ein wesentlicher Stützpfeiler unserer Verfassungsordnung - auch mit Blick auf die weitere europäische Einigung möglicherweise - weitgehend Konsens besteht.

\section{Vorsitzender: Danke! Herr Mußgnug.}

Mußgnug: Ich möchte zwei Punkte ansprechen.

1. Die Finanzverfassung soll die verfassungsrechtliche und politische Eigenständigkeit der Länder sichern. Aber das tut die Finanzverfassung nur leidlich, wenn sie den Ländern lediglich den Anteil am bundesweiten Steueraufkommen garantiert, den sie benötigen, um die ihnen vom Bund vorgegebenen Aufgaben erfüllen zu können. Denn dann fehlt den Ländern die Manövriermasse, die sie brauchen um neben dem Vollzug des Bundesrechts in breiterem Umfang auch eigene politische Initiativen entfalten zu können. Die Art. 104 a und 106 Abs. 4 GG verpflichten den Bund zwar zu zusätzlichen Mittelzuweisungen an die Länder, wenn er ihnen im Übermaß neue Aufgaben aufbürdet. Aber das Grundgesetz läßt offen, ob zu der angemessenen Finanzausstattung der Länder nicht doch auch ein ausreichendes Quantum an frei disponiblen Einnahmen gehört, über die die Länder unabhängig von bundesrechtlichen Vorgaben verfügen können. M.E. gebietet es das föderalistische Prinzip zwingend, diese „Manövriermasse" nachdrücklicher in die Finanzausstattung der Länder miteinzubeziehen, als dies bislang geschieht. Den Ländern droht sonst die Gefahr, vom Bund fortwährend zur Erhöhung des Personal- und Sachmittelaufwands genötigt zu werden, den der Vollzug der Bundesgesetze verlangt, und darüber jeden Spielraum für landeseigene Kulturpolitik zu verlieren. Das würde das föderalistische Prinzip emp- 
findlich stören. Ich glaube, davor kann nicht genügend gewarnt werden.

2. Herr Kirchbof hat für eine strenge verfassungsrechtliche Begrenzung der Sonderabgaben plädiert. Was die Sonderabgaben des Bundes angeht, so halte auch ich das für eine berechtigte Forderung. Aber auf der Ebene der Länder sehen die Dinge anders aus. Denn den Ländern bleibt kaum eine andere Wahl, als neue Sonderabgaben einzuführen, wenn sie ihre Einnahmen vermehren wollen. Ihr Steuererfindungsrecht, um das wir uns vorhin gestritten haben, trägt nämlich nicht allzu weit. Es gibt nur wenig Quellen, aus denen die Länder neue Steuereinnahmen schöpfen könnten. Das meiste, was dafür in Betracht kommt, führt zu Verbrauchssteuern, also zu Bundessteuern. Für neue Verkehrssteuern, die die Länder für sich vereinnahmen dürften, bleibt wenig Spielraum übrig. Er wird zusätzlich dadurch eingeengt, daß die Erhebung der Verkehrssteuern kompliziertere verwaltungstechnische Probleme bereitet als die Beitreibung der einfacher zu handhabenden Verbrauchssteuern. Darum nützt den Ländern ihr Steuererfindungsrecht nicht besonders viel. Es erlaubt ihnen kaum mehr, als die Erfindung neuer örtlicher Verbrauchs- und Aufwandsteuern, die sie gemäß Art.106 Abs. 6 Satz 1 GG ihren Gemeinden überlassen müssen. Möchten sich die Länder gleichwohl neue Einkommensquellen erschließen, so bleibt ihnen daher nur übrig, neue Sonderabgaben zu erfinden. Gelingt es ihnen, diese Abgaben mit einem hinreichend konkretisierten politischen Programm zu verbinden und sicherzustellen, daß sie ausschließlich zu dessen Finanzierung verwendet werden, so brauchen sie bei diesem Unterfangen das Bundesverfassungsgericht auch nicht zu fürchten.

Drum meine ich, wir sollten den Ländern das SonderabgabenErfindungsrecht als bescheidenen Ersatz für ihr im Grunde wertloses Steuererfindungsrecht gönnen. Verglichen mit den von Herrn Kirchhof zu Recht kritisierten zweckgebundenen Steuern, sind die Sonderabgaben ohnehin das kleinere Übel. Es sind zwar auch sie zweckgebunden. Aber beiden Sonderabgaben hat die $Z$ weckbindung ihren guten Sinn; sie ist auch besser unter Kontrolle zu halten als die Zweckbindung der Steuern, die in aller Regel nur zur politischen Beruhigung der Steuerzahler eingesetzt wird und jederzeit durch das Haushaltsgesetz gelockert oder gar gänzlich beiseite geschoben werden kann.

Vorsitzender: Ich danke. Herr Murswiek.

Murswiek: Umweltabgaben, so haben Sie gesagt Herr Kirchhof, gefährdeten die Steuersystematik. Wenn das richtig ist, dann ist die 
Steuersystematik falsch. Ein ökologischer Umbau der Steuerordnung, so ihre These, sei nicht möglich. Das mag stimmen, wenn man darunter versteht, daß sämtliche Steuern durch Ökosteuern ersetzt werden. Was wir aber ökologisch brauchen, ist nicht der Umbau der gesamten Steuerordnung, aber ist doch eine weitgehende Modifizierung und Ergänzung des Abgabensystems. Und was in diesem Sinne ökologisch notwendig ist, das ist auch möglich. Wenn es heute Finanzwissenschaftler gibt, die das Gegenteil behaupten, dann liegt das wohl daran, daß sie noch nicht kreativ genug waren. Was aber ist heute ökologisch nötig? Um sich das klarzumachen, muß man sich unsere heutige Situation vergegenwärtigen. Sie ist dadurch charakterisiert, daß die Folgen und Kosten umweltbelastenden Verhaltens zum großen Teil von der Allgemeinheit getragen werden. Diese Kosten sind immens, sie betragen viele Milliarden jährlich, das ist kein Pappenstiel. Der Sache nach bedeutet dies: Umweltbelastende Produktion und umweltbelastender Konsum werden von der Allgemeinheit in Höhe dieser Kosten subventioniert. Diese Subventionen lassen sich nicht rechtfertigen. Sie müssen neutralisiert werden, indem die Kosten dem Verursacher angelastet werden. Es geht um die Internalisierung der externen Kosten. Und sofern diese Aufgabe nur durch Abgaben bewältigt werden kann, muß sie eben durch Abgaben bewältigt werden. Dies ist nicht nur, unter Lenkungsaspekten, eine ökologische Notwendigkeit, es ist auch ein fundamentales Gerechtigkeitspostulat. Es widerspricht allen Aspekten sozialer Gerechtigkeit, daß Leistungen der Allgemeinheit zugunsten derjenigen erbracht werden, die die Umwelt belasten und schädigen, und daß der Umweltverschmutzer um so mehr an Subventionen erhält, je mehr er die Umwelt schädigt. Diese Ungerechtigkeit muß beseitigt werden. Und das darf nicht daran scheitern, daß ein herkömmlicher Steuerbeamter nicht mit Lackmuspapier umzugehen versteht.

Vorsitzender: Ich danke. Herr Pernice.

Pernice: Ich möchte ein paar Punkte ansprechen, die im Rahmen der Überlegungen zur Reform der Finanzverfassung vielleicht aus der Sicht Europas eine Rolle spielen könnten. Und zwar beziehen sich die drei Punkte auf alle drei Punkte ihrer Gliederung heute und ich möchte mit dem beginnen, was jetzt zur Diskussion steht, nämlich mit Punkt 3: Sonderprobleme, Umweltabgaben. Nur eine Frage: Was sind die Implikationen des Europäischen Gemeinschaftsrechts heute für die Struktur der Finanzverfassung? Sie lassen sich erörtern am Beispiel dessen, was die Kommission kürzlich vorgeschlagen hat, nämlich der 
bereits genannten $\mathrm{CO}_{2}$-Abgabe. Ich glaube nicht, daß es unbedingt notwendig ist, Umweltabgaben als solche vom Tisch zu wischen, solange die sich eingliedern lassen in das geltende Finanzsystem. Die Umweltabgabe, wie sie vorgeschlagen ist, ist eine Steuer auf den Verbrauch von bestimmten Energieträgern, etwa Rohöl in einer recht erheblichen Höhe ansteigend bis zum Jahr 2000 auf 10 \$ pro Barrel; das ist ungefähr ein Drittel des jetzigen Preises, was dann aufgeschlagen wird. Also Frage an Sie, Herr Kirchhof, läßt sich eine solche Umweltabgabe als Verbrauchssteuer nicht integrieren in das jetzige System?

Zum zweiten Punkt: Deutsche Wiedervereinigung. Sie alle wissen, $\mathrm{daß}$ zur Wiedervereinigung es notwendig war, für eine Reihe von Vorschriften der Europäischen Gemeinschaft Übergangsregelungen zu schaffen, vor allem im Umweltrecht. Wenn man daran denkt, daß die Umweltvorschriften der EG bis 1993 oder allerspätestens, im Fall der Trinkwasserrichtlinie, bis 1996 in den neuen Bundesländern umgesetzt sein müssen, wenn also die Grenzwerte, die durch EGRichtlinien gesetzt werden, im Jahre 1996 flächendeckend eingehalten werden müssen, dann verursacht das natürlich ungeheure Kosten. Und die Frage ist, wie ist das in der Finanzverfassung geregelt, oder wie kann das Problem gelöst werden, daß diese Kosten gerade bei den armen, neuen Bundesländern anfallen, obwohl sie extern verursacht wurden, gibt es einen Finanzausgleich oder wie wird die Finanzierung dieser Aufgaben geleistet?

Dieser Punkt führt mich zum Punkt 1 der Gliederung: Grundsätze. Sie werden sich erinnern an Art.130 r EWG-Vertrag, der nicht nur vom Subsidiaritätsprinzip spricht, sondern auch davon, daß die Ausführung und die Finanzierung der Umweltpolitik Sache der Mitgliedstaaten ist. Das heißt: die Europäische Gemeinschaft entscheidet nach Art.130s EWG-Vertrag zur Zeit noch einstimmig, bald vielleicht mehrheitlich über neue Aufgaben, deren Durchführung den Mitgliedstaaten obliegt, unabhängig davon, ob der Bund oder die Länder speziell innerstaatlich zuständig sind. Nun entscheidet also die EG nehmen wir die Abfallrichtlinien -, daß bestimmte Müllbeseitigungsmethoden verwendet werden: auch das verursacht hohe Kosten. Niemand fragt danach, ob denn die Länder oder die Gemeinden, die jetzt für die Durchführung dieser speziellen Dinge zuständig sind, dafür auch die Finanzmittel zur Verfügung haben. Gibt es Überlegungen zur Struktur der neuen Finanzverfassung, diese Implikationen des Europäischen Gemeinschaftsrechts heute mit einzubeziehen? Vielen Dank. 
Vorsitzender: Ich danke Herrn Pernice, damit haben alle Redner sprechen können. Wir kommen zu den Schlußworten. Herr Haller.

H. Haller: Ich habe nur zu einer Intervention zu antworten. Herr Mantl hat darauf hingewiesen, daß Änderungen unseres Systems nur bei Anstößen von außen erfolgen. Ja, nach 70 Jahren erzwingen die Länder eine Mitwirkung, weil sie anders ihren Landesbürgern bei einer Abstimmung zum EG-Beitritt ein Ja nicht empfehlen würden, wenn sie nicht vorher ihre Position als Länder finanzverfassungsrechtlich abgesichert bekommen haben. Der Bund muß sich hier beugen, ein kluger Schachzug. Zum Hinweis, daß die finanzverfassungsrechtliche Stellung der Gemeinde fehlt, ja, ich habe in $15 \mathrm{Minu}-$ ten das Wort "Gemeinde“ zwar mehr als sechsmal verwendet, werde es aber noch als Ansatzpunkt für opulente Fußnoten nutzen, um das Erarbeiten eines pastosen Ölgemäldes des kompletten Finanzverfassungsrechts möglich zu machen. Ich danke für ihre Zustimmung, Kollege Mantl.

Schlagwort Verfassungsgerichtshof. Ich glaube auch, daß wir bei der Judikatur des Verfassungsgerichtshofs übereinstimmen. Ein Hinweis, daß die Einigung zu einem riesigen Gesetzeswerk, wie das Finanzausgleichsgesetz es ist, die Verfassungsmäßigkeit in einem starken Maße indiziert, ich glaube, das ist ein Zurückweichen vor einer sach- und inhaltsbezogenen Begründungspflicht, die auch ein Höchstgericht treffen sollte. Dankeschön.

Vorsitzender: Ich danke Ihnen, Herr Haller, Herr Jaag hat verzichtet. Herr Kircbhof.

F. Kirchhof: Die Ausführungen zur Geltungskraft der Finanzverfassung sollten keine realpolitische Analyse der Verfassungswirklichkeit erbringen, sondern nur die Frage beantworten, ob die normative Wirkung der Finanzverfassung wegen ihres ökonmischen Gegenstandes Unterschiede zu anderen Verfassungsnormen aufweist. Hier ist in der Tat kein Unterschied festzustellen; inwieweit die Vorschriften der Finanzverfassung tatsächlich beachtet werden, steht freilich auf einem ganz anderen Blatt.

Die Argumente und Erwägungen zu Art. 88 GG, insbesondere zur Frage, ob die Vorschrift eine unabhängige Bundesbank fordert oder zuläßt, sind in der Literatur erschöpfend ausgetauscht worden, so daß ich darauf nicht mehr im einzelnen eingehen will. Ich neige zur Ansicht, daß der Bundesbank ein Bereich unabhängiger Tätigkeit zustehen kann. Auch die Verfassungswirklichkeit hat dies bisher 
bewiesen; wenn unsere Tagung zwei Wochen früher stattgefunden hätte, wäre allerdings der Hinweis auf die Verfassungsrealität deutlich kraftvoller gewesen.

Art. 3 GG hat als Grundsatz der Belastungsgleichheit prägende Kraft für das deutsche Abgabensystem. Kein anderes Grundrecht hat - vor allem im Bereich der Sonderlasten - eine ähnliche Wirkung entfalten können. Es ist erstaunlich, wie blaß die Grundrechte bei der Entwicklung des staatlichen Einnahmesystems bisher geblieben sind, obwohl wir den Grundrechten ansonsten mit Recht eine hervorgehobene Stellung im staatlichen Eingriffsrecht zuschreiben. Zur Konturierung und Mäßigung des staatlichen Abgabensystems ist Art. 14 GG außer einer formelhaften Erwähnung überhaupt noch nicht genutzt worden. Die Grundrechte der Art. 2, 6 und 12 GG werden zwar zunehmend einbezogen. Letztlich war es aber nur der Gleichheitsgrundsatz, der System in die Abgabenentwicklung gebracht hat. Die Rechtsformen der Abgaben und damit auch ihre Rechtsfolgen orientieren sich fast ausschließlich am Belastungsgrund und damit am Gleichheitssatz. Das hat den Typus der Steuer mitgeprägt und von den Sonderlasten abgegrenzt. Deshalb halte ich an der Aussage fest, daß Art. 3 GG typprägende Kraft im Finanzwesen entwickelt hat. Das zweite Unterscheidungskriterium für Abgaben war die staatsorganisationsrechtliche Vorgabe, daß die Steuer alleiniges Mittel zur Finanzierung allgemeiner Staatsaufgaben sein müsse.

Daß dem Grundsatz der Belastungsgleichheit und der verfassungsrechtlichen Steuerdefinition in ihrer Funktion der Abgrenzung zu den Sonderlasten in der Verfassungswirklichkeit noch mehr Aufmerksamkeit geschenkt werden sollte, wäre auch mein Anliegen. Die Erkenntnis, daß sich im tatsächlichen Bereich beide verfassungsrechtlichen Vorgaben nicht genügend durchgesetzt haben, war Grund für meine Vorschläge, bestimmte Abgabearten, vor allem Sonder- und Umweltabgaben, im Text einer novellierten Verfassung deutlicher zu konturieren.

Auf welcher Stufe der vertikalen Distribution der Staatsfinanzen Finanzausgleichselemente oder Sonderbedarfe berücksichtigt werden sollten, bleibt zum großen Teil der Einschätzung nach verfassungspolitischen Erwägungen oder Praktikabilitätsmaßstäben überlassen. Von besonderer Bedeutung für eine Novellierung der Finanzverfassung scheint mir aber die grundsätzliche Erkenntnis zu sein, daß das vierstufige Gesamtsystem des vertikalen Finanzausgleichs letztlich dem Ziel dient, Ausgaben, Aufgaben und Finanzmittel zur Deckung zu bringen. Hier könnte der Verfassungsgeber das bisherige Eigenleben der vier Stufen, Zielrichtungen, Berechnungsweisen u. ä. zum Nutzen des Gesamtsystems zurückdrängen. In dieser einheitlichen 
Zielsetzung liegt auch mein Vorschlag begründet, den einheitlichen Verteilungskampf um die Finanzen in einem einzigen Verfahren durchzuführen und mit einem einzigen Finanztransfergesetz zu beenden statt sich nach drei einheitlich durchgeführten Verteilungsschritten plötzlich auf der vierten Stufe in Einzeldotationen, Mischfinanzierung und Gemeinschaftsaufgaben zu verlieren. Sicherlich kann man besondere Interessenlagen nicht über einen Kamm scheren; ich halte es aber für vorteilhaft, bei einer Novellierung der Finanzverfassung den vertikalen Finanzausgleich wieder auf seinen gemeinsamen Nenner zu bringen, in einem Verfahren zu betreiben und mit einem Gesetz abzuschließen, wie wir es vom Staatshaushalt gewohnt sind. Das bringt Klarheit in die vertikalen Finanzbeziehungen; vor allem agieren nach Abschluß des Verteilungsverfahrens für ein Jahr alle Beteiligten wieder selbständig.

Damit bin ich schon bei der Frage, wie man die Autonomie der Länder fördern kann. Finanzielle Eigenständigkeit ohne Beeinflussung durch dritte Geldgeber würde der Autonomie am ehesten förderlich sein. Diese Eigenständigkeit würde man am besten sichern, indem man den Ländern stabile Zuweisungen gibt, die schon im voraus berechenbar und damit planbar sind. Transfers am Maßstab besonderer Bedarfssituationen und für Einzelfälle unterlaufen die Autonomie. Deshalb plädiere ich dafür, den Ländern eher eigene steuerliche Ertragsquellen zuzuweisen und die bundesstaatsgefährdenden Einzeldotationen zurückzudrängen, weil mit deren Hilfe der Bund die Länder am goldenen Zügel führt.

Mit dem Stichwort der finanziellen Autonomie der Länder taucht zur Zeit regelmäßig der Hinweis auf, den Ländern mehr Kompetenzen auf dem Gebiet der Steuergesetzgebung einzuräumen. Das gäbe ihnen zweifellos größere Eigenständigkeit. Ich habe allerdings Bedenken, ob diese rechtliche Eigenständigkeit in der Praxis wirklich zu mehr Autonomie führen würde. Ich darf das am Beispiel der vorgeschlagenen Länderzuschlagsrechte zur Einkommen- und Körperschaftsteuer erläutern. Man erhofft sich von solchen Zuschlagsrechten einen Wettbewerb zwischen den Ländern um Steuerschuldner, der auch steuersenkend wirken könnte. Die Praxis dürfte wohl anders verlaufen: letzten Endes wird nämlich der Wohn- oder Firmensitz oder der Ort der Betriebsstätte darüber entscheiden, welches Land Steuererträge erhält. Die Entscheidung über die Plazierung von Wohnung oder Produktionsort sind aber derartig grundlegend und langfristig, daß sie kaum eine Wettbewerbsbewegung hervorrufen werden. Wenn man z. B. an die Lohnsteuer des Arbeitnehmers denkt, müßte er seine Entscheidung über Arbeitsplatz, Wohnsitz u. ä. allein von steu- 
erlichen Gegebenheiten abhängig machen statt von Wirtschaftslage, Arbeitsmarkt oder sonstigen lokalen oder regionalen Gebundenheiten. Es ist aber wahrscheinlicher, daß ein Arbeitnehmer die Steuerbelastung als unveränderlich hinnehmen wird und die anderen Gegebenheiten zur Entscheidungsgrundlage machen wird. Selbst wenn er auf die unterschiedliche Steuerbelastung reagieren wollte, würden sich Verlagerungen des Arbeits- und Lebensmittelpunktes über Jahre hinziehen. Der Erfolg des länderautonomen Wettbewerbs würde also erst - wie von den Finanzwissenschaftlern auch freimütig eingeräumt wird - in einem Zeitraum, der etwa zehn Jahre umfaßt, eintreffen. Das würde ein sehr schwerfälliger Wettbewerb. Zu bedenken ist auch, daß das Parlament, das die Steuergesetze erläßt, in meist vierjährigen Legislaturperioden plant und in der politischen Wirklichkeit weniger an einem erst Jahre später zutage tretenden Wettbewerbseffekt interessiert ist. Deshalb habe ich Zweifel, ob die Zuweisung von Hebesatzoder Zuschlagsrechten zu diesen Steuern die Autonomie der Länder fördern würde; ich hege eher die Befürchtung, daß ein solches System die Länder zur Ausreizung des Hebesatz- oder Zuschlagspielraums veranlassen würde und Autonomie und Wettbewerb dabei auf der Strecke bleiben.

Den Hinweis von Herrn Stern, daß die deutsche Vereinigung die staatlichen Einnahmen kräftig vermehrt habe, kann ich nur nachdrücklich unterstreichen; die Politik hat diesen finanziellen Seiteneffekt bisher zu Unrecht heruntergespielt oder verschwiegen. Zum Thema Treuhand und Verschuldung: Mir bereitet nicht nur die Höhe der von der Treuhand aufgenommenen Kredite Sorgen. Ebenso bedenklich ist die Art mancher übernommener Verpflichtungen. Die Aufnahme von Krediten oder die Übernahme von Gewährleistungen sollte nach der Finanzverfassung grundsätzlich der Höhe nach bestimmt oder bestimmbar sein. Die Treuhand geht aber zunehmend dazu über, für nicht bezifferte, auch für künftige Schulden anderer Unternehmen Garantien zu übernehmen, sich im Umfang noch nicht absehbare Verpflichtungen für Altlasten aufzubürden, ja sogar Garantien für das künftige ökonomische Gedeihen eines in private Hände gegebenen Unternehmens abzugeben. Mit diesem Verfahren nimmt sie zukünftige Schulden auf sich, die nicht nur von großem Umfang sein können, sondern zur Zeit noch nicht einmal beziffert werden könnten. Ich glaube, daß hier - wenn es auch vielleicht etwas dramatisch klingt - eine finanzielle Zeitbombe tickt.

Unter der Fragestellung „Umweltschutz und Umweltschutzabgaben" will ich mich nicht grundsätzlich gegen Umweltabgaben aussprechen, sondern nur zum maßvollen Einbau von Umweltgesichts- 
punkten in unser Abgabensystem mahnen. Umweltabgaben bringen ein fremdes Element in ein staatliches Finanzierungssystem und können dieses in seiner staatsnotwendigen Funktion der Staatsalimentation gefährden. Vor allem ein in der Regel am Grundsatz der Leistungsfähigkeit orientiertes Steuersystem wird bei einer Überfrachtung mit ökologischen Zielen Schaden leiden. Hier werden Systembrüche unvermeidlich, wenn man nicht behutsam vorgeht. Wer z.B. die Einkommen- oder Körperschaftsteuer zur Umweltlenkung einsetzt, läuft Gefahr, daß sein Instrumentarium dort versagt, wo diese Finanzlasten gemeinnützige oder staatliche Betriebe von der Abgabenlast ausnehmen, obwohl solche Betriebe in gleicher Weise wie andere die Umwelt benutzen oder gefährden. Deshalb kann man z. B. umweltlenkende Elemente in Steuergesetze nur einfügen, wenn sie im konkreten Tatbestand keinen Widerspruch mit dem Leistungsfähigkeitsprinzip verursachen. Das ist sicher nur ein Beispiel. Es kann aber zeigen, welche Probleme die unbedachte Übernahme ökologischer Zwecke in ein staatliches Finanzierungssystem heraufbeschwören wird.

\section{Vorsitzender: Danke Herr Kirchhof, Herr Selmer.}

Selmer: Meine Damen und Herren, ich darf mich nolens volens und vielleicht auch im Interesse der Ehefrauen der Anwesenden auf einige wenige Bemerkungen beschränken, um einen zeitlich angemessenen Ausklang zu ermöglichen. Herr Birk, Sie haben gefragt, warum eigentlich ein horizontaler Finanzausgleich; kann er nicht entfallen? Es versteht sich von selbst, daß ich mich dieser Frage bei der Vorbereitung des Berichts auch noch einmal unterzogen habe. Dabei habe ich vor allem feststellen müssen, daß alle, seit den fünfziger Jahren immer wieder unternommenen Versuche, unter (völligem oder doch weitgehendem) Verzicht auf einen horizontalen Finanzausgleich ein substantiell bedarfsorientiertes Ertragsverteilungssystem zu etablieren, schon im Ansatz mißglückt sind. Auch die Kommission Finanzverfassungsreform hat seinerzeit letzten Endes resigniert und einem spezifisch bedarfsbezogenen Finanzausgleich eine Absage erteilt. Ungeachtet aller Bemühungen hat sich insbesondere immer wieder herausgestellt, daß es keine verläßlichen Kriterien gibt, um den unterschiedlichen Bedarf der einzelnen Länder allseits überzeugungskräftig verbindlich festzustellen. Deshalb muß man heute sagen: So klappt das nicht. Im übrigen ist, so meine ich, der horizontale Finanzausgleich als solcher auch ein wertvolles Instrument, das Gefühl bündischer Solidarität wach und lebendig $\mathrm{zu}$ halten und immer wieder in Erinnerung 
zu rufen, daß wir in einem Bundesstaat leben, dessen Mitglieder füreinander einzustehen und sich erforderlichenfalls gegenseitig Hilfe zu leisten haben. Auch diesen Gesichtspunkt darf man vielleicht nicht ganz außer Betracht lassen.

Herr Stern, in der Tat, es muß nicht alles verfassungsrechtlich geregelt werden. Das ist völlig richtig; auch ich teile diese Auffassung. Allerdings, die Finanztransfers, die die neuen Bundesländer in den nächsten Jahren benötigen, insbesondere die von Seiten des Bundes, müssen zum Teil verfassungsrechtlich besonders abgesegnet werden. Es kann nicht angehen, daß - wie es sich im Augenblick darstellt von den neuen Ländern kurzerhand 50 Milliarden „Nachschlag“ gefordert werden, die einfach bezahlt und finanzverfassungsrechtlich dann im nachhinein irgendwo einsortiert werden, passe es nun oder nicht. Wir brauchen - jedenfalls auch - verfassungsrechtlich neuartige Kanäle für diese riesigen Finanztransfers, die sich dem herkömmlichen Instrumentarium des Finanzausgleichs ersichtlich entziehen. Sicher, es gibt die Bundesergänzungszuweisungen, es gibt den Art. 104 a IV GG, es gibt die regionalpolitische Förderung des Art. 91 a I Nr. 2 GG, alles richtig. Aber: Alle gebotenen Hilfen für den Osten über dieses Regelwerk zu bewerkstelligen, scheint mir seine Instrumente zu überfordern. Denken Sie nur an die Ende 1993 voraussichtlich zu bilanzierenden 400 Milliarden DM DDR-Altschulden - des Kreditabwicklungsfonds und der Treuhandanstalt - oder an die Erblasten aus dem Umwelt- und Infrastrukturbereich. Kann man die hier letztlich fälligen Leistungen des Bundes und der Westländer tatsächlich sämtlich noch über Zahlungen im Bereich der Bundesergänzungszuweisungen und Mischfinanzierungen bzw. des horizontalen Finanzausgleichs abwickeln? Also ich meine schon, hier besteht ein Bedürfnis, außerhalb der engeren Finanzverfassung gewisse Erblastfragen besonders zu regeln. Auf Einzelfragen kann ich hier leider nicht mehr eingehen.

Was die weitere Fortentwicklung der Finanzverfassung als solcher anbetrifft, so sollten wir zu verhindern suchen, daß die Regelung der Finanzverfassung $\mathrm{zu}$ einem mehr oder weniger rein technischen Thema wird. Auf der Tagung 1955 war ja ganz richtig von der „Finanzverfassung im Rahmen der Staatsverfassung" die Rede. Hierin kam treffend auch die Notwendigkeit zum Ausdruck, die Finanzverfassung nicht isoliert, sondern vor dem allgemeinen bundesstaatlichen Hintergrund zu sehen, mit dem sie ersichtlich unmittelbar verknüpft ist. Grund, hieran zu erinnern, bieten auch die vor wenigen Wochen erschienenen Thesen des Bundes zur Neuordnung der Bund-LänderFinanzbeziehungen. Sie erscheinen mir, gemessen an der genannten 
Einsicht, ausgesprochen kurzatmig. Gewiß, es gibt - zumal nach der Entscheidung des BVerfG vom Mai dieses Jahres - eine Reihe von Einzelfragen, die schnell geregelt werden müssen. Auch kann man manchen Empfehlungen der Thesen für die Übergangszeit sicher zustimmen. Aber man vermißt schließlich doch einen grundsätzlichen Blick in die zukünftige Gestaltung unseres Bundesstaates, wie sie letzten Endes auch das Bild der Finanzverfassung entscheidend mitbestimmen wird. Es wird nunmehr Aufgabe der Verfassungskommission sein, hier die entscheidenden Weichenstellungen ins Auge zu fassen.

Ein letztes Wort: Ich glaube, erst in der nächsten Zeit wird allen Beteiligten deutlich werden, was uns allen an Opferbereitschaft noch abverlangt werden wird. Weite Teile der Öffentlichkeit machen sich noch keine rechte Vorstellung davon, was in den nächsten Jahren auf uns zukommt. Wernhard Möschel, der Tübinger Wirtschaftswissenschaftler, hat in einem Aufsatz in der Juristenzeitung (JZ 1992, 489) in diesem Zusammenhang nicht ganz zu Unrecht vor allem von einem unfaßbaren Egoismus der westlichen Bundesländer und Gemeinden gesprochen, die so agierten, als ob nichts gewesen wäre. In der Tat: Es ist teilweise beschämend, wie in manchen Ländern und Kommunen alle Anstrengungen unternommen werden, um sich im künftigen Finanzausgleich als arm ausweisen zu können. Sie können das an vielen Baustellen und Planungsvorhaben geradezu ablesen. Aber selbst bei größerer Sparsamkeit von Bund, Ländern und Gemeinden: Auch der Bürger wird in den nächsten Jahren erheblich zur Kasse gebeten werden müssen. Das Ziel einer Integration der neuen Länder wird ohne zusätzliche Sonderopfer der Bürger nicht zu erreichen sein. Das gilt grundsätzlich auch für die Bürger der neuen Länder, die etwa bei einer Ergänzungsabgabe auf die Einkommen- und Körperschaftsteuer - von jedem finanziellen Beitrag für den Prozeß der inneren Vereinigung a priori auszuschließen kein Anlaß besteht. Ich danken Ihnen.

Vorsitzender: Danke Herr Selmer für dieses staatsmännische Schlußwort, ich bedanke mich auch bei Herrn F. Kirchhof, dem Referenten, bedanke mich vor allem für die sehr hohe Diskussion und die hervorragenen Voten der Diskussionsredner heute Nachmittag, entschuldige mich für die autoritäre Verwaltung des knappen Gutes Zeit und hoffe auf Ihr Verständnis. Die Sitzung ist geschlossen. 